


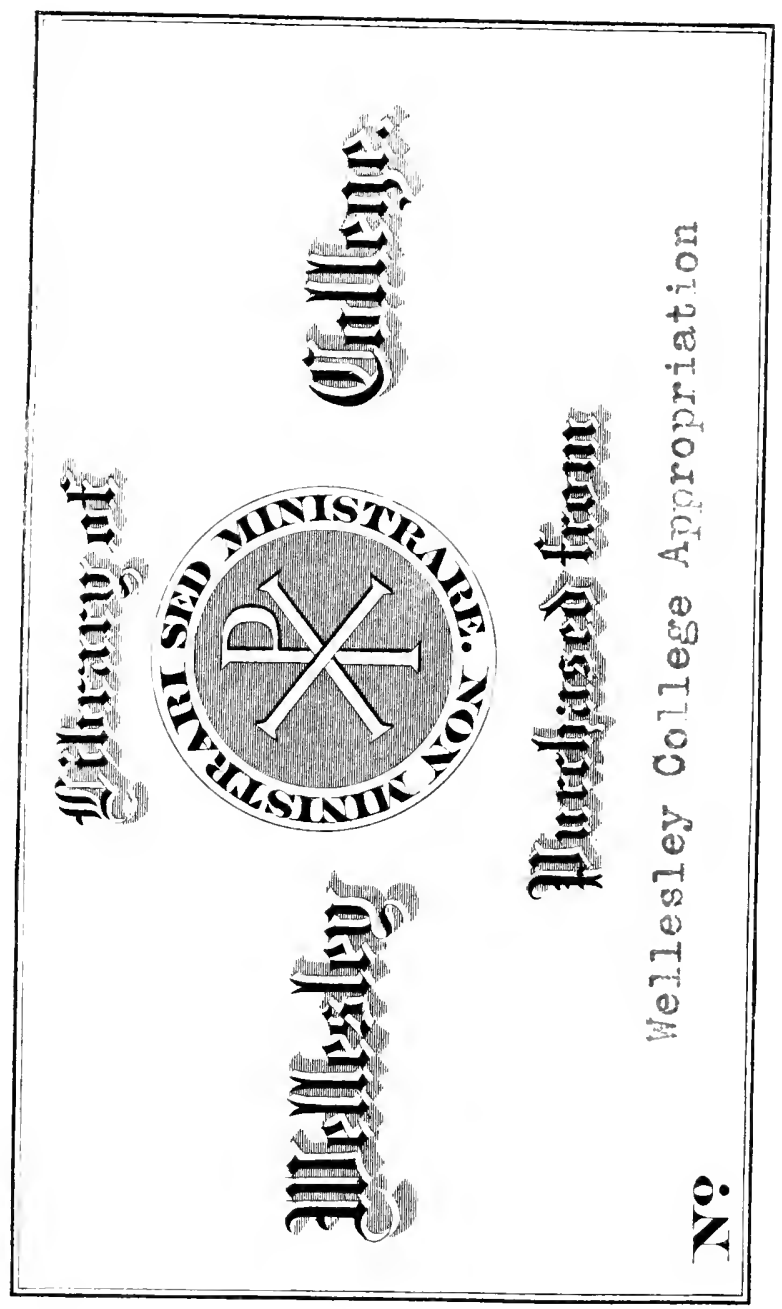








\section{HISTORY OF MATHEVATICS}

AN AUTHORIZED TRANSLATION OF

DR. KARL FINK'S GESCHICHTE DER ELEMENTAR-MATHEMATIK

BY

WOOSTER WOODRUFF BEMAN

PROFESSOR OF MATHEMATICS IN THE UNIVERSITY OF MICHIGAN

AND

DAVID EUGENE SMITH

PRINCIPAL OF THE STATE NORMAL SCHOOL AT BROCKPORT, N. Y.

\section{CHICAGO}

THE OPEN COURT PUBLISHING COMPANY

LONDON AGENTS

Kegan Paul, Trench, Trübner \& Co., Ltd.

I 900 


\author{
53299 \\ TRANSLATION COPYRIGHTED \\ BY \\ The Open Court Publishing Co. \\ I900.
}




\section{'TRANSLATORS' PREFACE.}

THE translators feel that no apology is necessary for any reasonable effort to encourage the study of the history of mathematics. The clearer view of the science thus afforded the teacher, the inspiration to improve his methods of presenting it, the increased interest in the class-work, the tendency of the subject to combat stagnation of curricula,-these are a few of the reasons for approving the present renaissance of the study.

This phase of scientific history which Montucla brought into such repute-it must be confessed rather by his literary style than by his exactness-and which writers like De Morgan in England, Chasles in France, Quetelet in Belgium, Hankel and Baltzer in Germany, and Boncompagni in Italy encouraged as the century wore on, is seeing a great revival in our day. This new movement is headed by such scholars as Günther, Eneström, Loria, Paul Tannery, and Zeuthen, but especially by Moritz Cantor, whose Vorlesungen über Geschichte der Mathematik must long remain the world's standard.

In any movement of this kind compendia are always necessary for those who lack either the time or the linguistic power to read the leading treatises. Several such works have recently appeared in various languages. But the most systematic attempt in this direction is the work here translated. The writers of most handbooks of this kind feel called upon to collect a store of anecdotes, to incorporate tales of no historic value, and to minimize the real history of the science. Fink, on the other hand, omits biography entirely, referring the reader to a brief table in the appendix or to the encyclopedias. He systematically considers the growth of 
arithmetic, algebra, geometry, and trigonometry, carrying the historic development, as should be done, somewhat beyond the limits of the ordinary course.

At the best, the work of the translator is a rather thankless task. It is a target for critics of style and for critics of matter. For the style of the German work the translators will hardly be held responsible. It is not a fluent one, leaning too much to the scientific side to make it always easy reading. Were the work less scientific, it would lend itself more readily to a better English form, but the translators have preferred to err on the side of a rather strict adherence to the original.

As to the matter, it has seemed unwise to make any considerable changes. The attempt has been made to correct a number of unquestionable errors, occasional references have been added, and the biographical notes have been rewritten. It has not seemed advisable, however, to insert a large number of bibliographical notes. Readers who are interested in the subject will naturally place upon their shelves the works of De Morgan, Allman, Gow, Ball, Heath, and other English writers, and, as far as may be, works in other languages. The leading German authorities are mentioned in the footnotes, and the French language offers little at present beyond the works of Chasles and Paul Tannery.

The translators desire to express their obligations to Professor Markley for valuable assistance in the translation.

Inasmuch as the original title of the work, Geschichte der Elementar-Mathematik, is misleading, at least to English readers, the work going considerably beyond the limits of the elements, it has been thought best to use as the English title, A Brief His tory of Mathematics.

W. W. Beman, Ann Arbor, Mich

D. E. Sмітн, Brockport, N. Y.

March, I900. 


\section{PREFACE.}

IF the history of a science possesses value for every one whom

calling or inclination brings into closer relations to it,-if the knowledge of this history is imperative for all who have influence in the further development of scientific principles or the methods of employing them to advantage, then acquaintance with the rise and growth of a branch of science is especially important to the man who wishes to teach the elements of this science or to penetrate as a student into its higher realms.

The following history of elementary mathematics is intended to give students of mathematics an historical survey of the elementary parts of this science and to furnish the teacher of the elements opportunity, with little expenditure of time, to review connectedly points for the most part long familiar to him and to utilise them in his teaching in suitable comments. The enlivening influence of historical remarks upon this elementary instruction has never been disputed. Indeed there are text-books for the elements of mathematics (among the more recent those of Baltzer and Schubert) which devote considerable space to the history of the science in the way of special notes. It is certainly desirable that instead of scattered historical references there should be offered a connected presentation of the history of elementary mathematics, not one intended for the use of scholars, not as an equivalent for the great works upon the history of mathematics, but only as a first picture, with fundamental tones clearly sustained, of the principal results of the investigation of mathematical history.

In this book the attempt has been made to differentiate the histories of the separate branches of mathematical science. There 
are considered in order number-systems and number-symbols, arithmetic, algebra, geometry and trigonometry, allowing, as far as possible, within the narrow confines of a single branch of the elements, a rapid and sure orientation. Against such a procedure the objection may be raised that in this way the general survey of the culture history of a certain epoch will suffer. On the other hand, in a history of elementary mathematics, especially one confined within such modest bounds, an exhaustive description of whole periods with all their correlations of past and future cannot well be presented.

It is not the purpose of this work to set forth the interesting historical development of mechanics and astronomy. Although it cannot be denied that by this separation of related branches there is wanting a certain definitiveness to the work, yet the hope may be expressed that this lack will not be felt too keenly. The elementary parts of mathematics have only few points of contact with these branches, and our endeavor is to present in brief compass only that which is most essential.

Further, in the interest of a presentation as condensed as pos sible, the biographical notices which often lend great attraction to a more extended treatment of a subject must be relegated to the appendix and there treated but briefly.

The work had its inception in certain suggestions which the author received at the semi-monthly meetings of a mathematical club in Tübingen, founded and conducted by Prof. Dr. A. Brill, for which suitable thanks ought here to be expressed. Acknowledgment is especially due to the president of the club whose interpretations have been decisive for certain parts of the present work. These meetings furnished the author the desired opportunity, through the lectures connected with the most diverse branches of the science and through the discussions which often followed, with references to recent literature, to penetrate into those circles of thought which to-day dominate the higher branches of mathematics. The writer was thus led to complete his studies 
by going into the recent history of the science. The results of such investigations are here presented with perhaps greater fullness than seems necessary for the main purpose of the book or justified by its title. But in default of such a digest, a first experiment may lay claim to a friendly judgment, in spite of the continually increasing subdivisions of the science; nor will such an attempt be thought inappropriate, inasmuch as it does not seem possible to draw a sharp line of demarcation between the elementary and higher mathematics. For on the one hand certain problems of elementary mathematics have from time to time furnished the occasion for the development of higher branches, and on the other from the acquisitions of these new branches a clear light has fallen upon the elementary parts. Accordingly it may be gratifying to many a student and teacher to find here at least that which is fundamental.

The exceedingly rich literature, especially in German, at the disposal of the author is referred to in the footnotes. He has made free use of the excellent Jahrbuch über die Fortschritte der Mathematik, which with clear and systematic arrangement enumerates and discusses the most recent mathematical literature.

K. FINK.

TÜBINGEN, June, 18g•. 



\section{CONTENTS.}

Translators' Preface . . . . . . . . . . . . . . iii

Author's Preface. . . . . . . . . . . . . . . . v

General Survey . . . . . . . . . . . . . . . . I

I. NUMBER-SYSTEMS AND NUMBER-SYMBOLS. 6

II. ARITHMETIC.

A. General Survey . . . . . . . . . . . . . . . I8

B. First Period. The Arithmetic of the Oldest Nations to the Time of the Arabs.

I. The Arithmetic of Whole Numbers . . . . . . 24

2. The Arithmetic of Fractions . . . . . . . . . 3I

3. Applied Arithmetic . . . . . . . . . . . . 34

C. Second Period. From the Eighth to the Fourteenth Century.

I. The Arithmetic of Whole Numbers . . . . . . 36

2. The Arithmetic of Fractions . . . . . . . . 40

3. Applied Arithmetic . . . . . . . . . . . . 4 I

D. Third Period. From the Fifteenth to the Nineteenth Century.

I. The Arithmetic of Whole Numbers . . . . . . 4 I

2. The Arithmetic of Fractions . . . . . . . 49

3. Applied Arithmetic . . . . . . . . . . . $5 \mathrm{I}$

III. ALGEBRA.

A. General Survey . . . . . . . . . . . . . . 6I

B. First Pericd. From the Earliest Times to the Arabs.

I. General Arithmetic . . . . . . . . . . . . 63

Egyptian Symbolism 63. Greek Arithmetic 64; Symbolism

65; Theory of Numbers 66 ; Series 67; the Irrational 68; Neg- 
ative Numbers 7o; Archimedes's Notation for Large Numbers 7r. Roman Arithmetic 7r. Hindu Arithmetic 7I; Symbolism 72; Negative Numbers 72; Involution and Evolution 73; Permutations and Combinations 74; Series 74. Chinese Arithmetic 74. Arab Arithmetic 74 ; "Algorism" 75; Radical Signs 76; Theory of Numbers 76 ; Series 76 .

2. Algebra

The Egyptians 77. The Greeks; Form of the Equation 77; Equations of the First Degree 78 ; Equations of the Second Degree (Application of Areas) 79; Equations of the Third Degree $8 \mathbf{r}$; Indeterminate Equations (Cattle Problem of Archimedes; Methods of Solution of Diophantus) 83. Hindu Algebra 84. Chinese Algebra 87. Arab Algebra 88.

C. Second Period. To the Middle of the Seventeenth Century.

I. General Arithmetic .

Symbolism of the Italians and the German Cossists 95; Irrational and Negative Numbers 99; Imaginary Quantities Ior; Powers I02; Series ro3; Stifel's Duplication of the Cube I04; Magic Squares ro5.

2. Algebra .

Representation of Equations 107; Equations of the First and Second Degrees ro8; Complete Solution of Equations of the Third and Fourth Degrees by the Italians III; Work of the German Cossists II3; Beginnings of a General Theory of Algebraic Equations 115 .

D. Third Period. From the Middle of the Seventeenth Century to the Present Time.

Symbolism I17; Pascal's Arithmetic Triangle I18; Irrational Numbers I19; Complex Numbers I23; Grassmann's Ausdehnungslehre 127; Quaternions I29; Calculus of Logic 13I; Continued Fractions 131; Theory of Numbers 133; Tables of Primes 141; Symmetric Functions 142; Elimination 143; Theory of Invariants and Covariants 145; Theory of Probabilities 148; Method of Least Squares 149; Theory of Combinations 150; Infinite Series (Convergence and Divergence) I5I; Solution of Algebraic Equations 155; the Cyclotomic Equation 160 ; Investigations of Abel and Galois 163 ; Theory of Substiturions 164 ; the Equation of the Fifth Degree 165; Approximation of Real Roots 166; Determinants 167 ; Differential and Integral Calculus r68; Differential Equations 174 ; Calculus of Variations 178; Elliptic Functions 180; Abelian Functions I86; More Rigorous Tendency of Analysis 189. 
IV. GEOMETRY.

A. General Survey . . . . . . . . . . . . I90

B. First Period. Egyptians and Babylonians . . . . . 192

C. Second Period. The Greeks . . . . . . . . . . 193

The Geometry of Thales and Pythagoras r94; Application of the Quadratrix to the Quadrature of the Circle and the Trisection of an Angle 196; the Elements of Euclid r98; Archimedes and his Successors 199; the Theory of Conic Sections 202; the Duplication of the Cube, the Trisection of an Angle and the Quadrature of the Circle 209; Plane, Solid, and Linear Loci 209; Surfaces of the Second Order 212; the Stereographic Projection of Hipparchus 2 r3.

D. Third Period. Romans, Hindus, Chinese, Arabs . . . $2 I_{4}$

E. Fourth Period. From Gerbert to Descartes. . . . . 218

Gerbert and Leonardo 218; Widmann and Stifel 220; Vieta and Kepler 222; Solution of Problems with but One Opening of the Compasses 225; Methods of Projection 226.

F. Fifth Period. From Descartes to the Present . . . .

Descartes's Analytic Geometry 230; Cavalieri's Method of Indivisibles 234; Pascal's Geometric Works 237; Newton's Investigations 239; Cramer's Paradox 240; Pascal's Limaģon and other Curves 24I; Analytic Geometry of Three Dimensions 242; Minor Investigations 243; Introduction of Projective Geometry 246; Möbius's Barycentrischer Calcül 250; Bellavitis's Equipollences 250; Plücker's Investigations 25I; Steiner's Developments 256; Malfatti's Problem 256; Von Staudt's Geometrie der Lage 258; Descriptive Geometry 259; Form-theory and Deficiency of an Algebraic Curve 26r; Gauche Curves 263; Enumerative Geometry 264; Conformal Representation 266; Differential Geometry (Theory of Curvature of Surfaces) 267; Non-Euclidean Geometry 270; PseudoSpheres 273; Geometry of $n$ Dimensions 275; Geometria and Analysis Situs 275; Contact-transformations 276; Geometric Theory of Probability 276; Geometric Models 277 ; the Mathematics of To-day 279 .

\section{TRIGONOMETRY.}

A. General Survey.

B. First Period. From the Most Ancient Times to the Arabs

The Egyptians 282. The Greeks 282. The Hindus 284 The Arabs 285. 
C. Second Period. From the Middle Ages to the Middle of the Seventeenth Century . . . . . . . . . 287

Vieta and Regiomontanus 287; Trigonometric Tables 289; Logarithms 290.

1). Third Period. From the Middle of the Seventeenth Century to the Present . . . . . . . . . . . . 294

Biographical Notes . . . . . . . . . . . 297

Index . . . . . . . . . . . . . . 323 


\section{GENERAL SURVEY.}

THE beginnings of the development of mathemat-

1 ical truths date back to the earliest civilizations of which any literary remains have come down to us, namely the Egyptian and the Babylonian. On the one hand, brought about by the demands of practical life, on the other springing from the real scientific spirit of separate groups of men, especially of the priestly caste, arithmetic and geometric notions came into being. Rarely, however, was this knowledge transmitted through writing, so that of the Babylonian civilization we possess only a few traces. From the ancient Egyptian, however, we have at least one manual, that of Ahmes, which in all probability appeared nearly two thousand years before Christ.

The real development of mathematical knowledge, obviously stimulated by Egyptian and Babylonian influences, begins in Greece. This development shows itself predominantly in the realm of geometry, and enters upon its first classic period, a period of no great duration, during the era of Euclid, Archimedes, Eratosthenes, and Apollonius. Subsequently it inclines more toward the arithmetic side; but it soon becomes so completely engulfed by the heavy waves 
of stormy periods that only after long centuries and in a foreign soil, out of Greek works which had escaped the general destruction, could a seed, new and full of promise, take root.

One would naturally expect to find the Romans entering with eagerness upon the rich intellectual inheritance which came to them from the conquered Greeks, and to find their sons, who so willingly resorted to Hellenic masters, showing an enthusiasm for Greek mathematics. Of this, however, we have scarcely any evidence. The Romans understood very well the practical value to the statesman of Greek geometry and surveying-a thing which shows itself also in the later Greek schools-but no real mathematical advance is to be found anywhere in Roman history. Indeed, the Romans often had so mistaken an idea of Greek learning that not infrequently they handed it down to later generations in a form entirely distorted.

More important for the further development of mathematics are the relations of the Greel teachings to the investigations of the Hindus and the Arabs. The Hindus distinguished themselves by a pronounced talent for numerical calculation. What especially distinguishes them is their susceptibility to the influence of Western science, the Babylonian and especially the Greek, so that they incorporated into their own system what they received from outside sources and then worked out independent results. 
The Arabs, however, in general do not show this same independence of apprehension and of judgment. Their chief merit, none the less a real one however, lies in the untiring industry which they showed in translating into their own language the literary treasures of the Hindus, Persians and Greeks. The courts of the Mohammedan princes from the ninth to the thirteenth centuries were the seats of a remarkable scientific activity, and to this circumstance alone do we owe it that after a period of long and dense darkress Western Europe was in a comparatively short time opened up to the mathematical sciences.

The learning of the cloisters in the earlier part of the Middle Ages was not by nature adapted to enter seriously into matters mathematical or to search for trustworthy sources of such knowledge. It was the Italian merchants whose practical turn and easy adaptability first found, in their commercial relations with Mohammedan West Africa and Southern Spain, abundant use for the common calculations of arithmetic. Nor was it long after that there developed among them a real spirit of discovery, and the first great triumph of the newly revived science was the solution of the cubic equation by Tartaglia. It should be said, however, that the later cloister cult labored zealously to extend the Western Arab learning by means of translations into the Latin.

In the fifteenth century, in the persons of Peurbach and Regiomontanus, Germany first took position 
in the great rivalry for the advancement of mathematics. From that time until the middle of the seventeenth century the German mathematicians were chiefly calculators, that is teachers in the reckoning schools (Rechenschulen). Others, however, were algebraists, and the fact is deserving of emphasis that there were intellects striving to reach still loftier heights. Among them Kepler stands forth pre-eminent, but with him are associated Stifel, Rudolff, and Bürgi. Certain is it that at this time and on German soil elementary arithmetic and common algebra, vitally influenced by the Italian school, attained a standing very conducive to subsequent progress.

The modern period in the history of mathematics begins about the middle of the seventeenth century. Descartes projects the foundation theory of the analytic geometry. Leibnitz and Newton appear as the discoverers of the differential calculus. The time has now come when geometry, a science only rarely, and even then but imperfectly, appreciated after its banishment from Greece, enters along with analysis upon a period of prosperous advance, and takes full advantage of this latter sister science in attaining its results. Thus there were periods in which geometry was able through its brilliant discoveries to cast analysis, temporarily at least, into the shade.

The unprecedented activity of the great Gauss divides the modern period into two parts: before Gauss-the establishment of the methods of the dif- 
ferential and integral calculus and of analytic geometry as well as more restricted preparations for later advance; with Gauss and after him-the magnificent development of modern mathematics with its special regions of grandeur and depth previously undreamed of. The mathematicians of the nineteenth century are devoting themselves to the theory of numbers, modern algebra, the theory of functions and projective geometry, and in obedience to the impulse of human knowledge are endeavoring to carry their light into remote realms which till now have remained in darkness. 


\section{NUMBER-SYSTEMS AND NUMBER- SYMBOLS.}

$A^{\mathrm{N}}$ inexhaustible profusion of external influences expression in the formation of speech and writing in numbers and number-symbols. It is true that a counting of a certain kind is found among peoples of a low grade of civilization and even among the lower animals. "Even ducks can count their young."* But where the nature and the condition of the objects have been of no consequence in the formation of the number itself, there human counting has first begun.

The oldest counting was even in its origin a process of reckoning, an adjoining, possibly also in special elementary cases a multiplication, performed upon the objects counted or upon other objects easily employed, such as pebbles, shells, fingers. Hence arose number-names. The most common of these undoubtedly belong to the primitive domain of language; with the advancing development of language their aggregate was gradually enlarged, the legitimate combina-

* Hankel, Zur Geschichte der Mathematik im Altertum und Mittelalter, I874, p. 7. Hereafter referred to as Hankel. Tylor's Primitive Culture also has a valuable chapter upon counting. 
tion of single terms permitting and favoring the creation of new numbers. Hence arose number-systems.

The explanation of the fact that 10 is almost everywhere found as the base of the system of counting is seen in the common use of the fingers in elementary calculations. In all ancient civilizations finger-reckoning was known and even to-day it is carried on to a remarkable extent among many savage peoples. Certain South African races use three persons for numbers which run above 100 , the first counting the units on his fingers, the second the tens, and the third the hundreds. They always begin with the little finger of the left hand and count to the little finger of the right. The first counts continuously, the others raising a finger every time a ten or a hundred is reached.*

Some languages contain words belonging fundamentally to the scale of 5 or 20 without these systems having been completely elaborated; only in certain places do they burst the bounds of the decimal system. In other cases, answering to special needs, 12 and 60 appear as bases. The New Zealanders have a scale of 11 , their language possessing words for the first few powers of 11 , and consequently 12 is represented as 11 and 1,13 as 11 and 2,22 as two 11 's, and so on. $\dagger$

* Cantor, M., Vorlesungen über Geschichte der Mathematik. Vol. I, I8so; and ed., 1894 , p. 6. Hereafter referred to as Cantor. Conant, L. L., The Number Concept, N. Y. I 896 . Gow, J., History of Greek Geometry, Cambridge, $188_{4}$, Chap. I.

+Cantor, I., p. xо. 
In the verbal formation of a number-system addition and multiplication stand out prominently as definitive operations for the composition of numbers ; very rarely does subtraction come into use and still more rarely division. For example, 18 is called in Latin

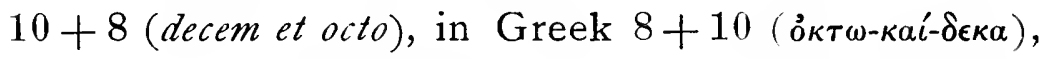
in French 108 (dix-huit), in German 810 (acht-zehn), in Latin also $20-2$ (duo-de-viginti), in Lower Breton $3 \cdot 6$ (tri-omc'h), in Welsh 2.9 (dew-naw), in Aztec $15+3$ (caxtulli-om-ey), while 50 is called in the Basque half-hundred, in Danish two-and-a-half times twenty.* In spite of the greatest diversity of forms, the written representation of numbers, when not confined to the mere rudiments, shows a general law according to which the higher order precedes the lower in the direction of the writing. $t$ Thus in a four-figure number the thousands are written by the Phœnicians at the right, by the Chinese above, the former writing from right to left, the latter from above downward. A striking exception to this law is seen in the sub tractive principle of the Romans in IV, IX, XL, etc., where the smaller number is written before the larger.

Among the Egyptians we have numbers running from right to left in the hieratic writing, with varying direction in the hieroglyphics. In the latter the numbers were either written out in words or represented by symbols for each unit, repeated as often as neces- 
sary. In one of the tombs near the pyramids of Gizeh have been found hieroglyphic numerals in which 1 is represented by a vertical line, 10 by a kind of horse. shoe, 100 by a short spiral, 10000 by a pointing finger, 100000 by a frog, 1000000 by a man in the attitude of astonishment. In the hieratic symbols the figure for the unit of higher order stands to the right of the one of lower order in accordance with the law of sequence already mentioned. The repetition of symbols for a unit of any particular order does not obtain, because there are special characters for all nine units, all the tens, all the hundreds, and all the thousands.* We give below a few characteristic specimens of the hieratic symbols :

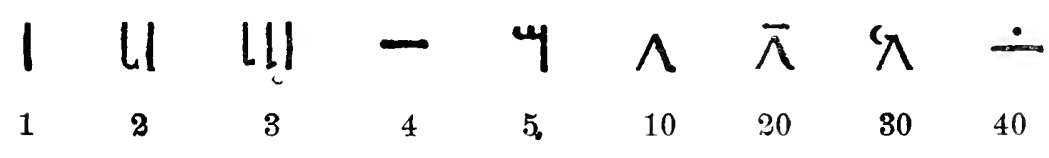

The Babylonian cuneiform inscriptions $\dagger$ proceed from left to right, which must be looked upon as exceptional in a Semitic language. In accordance with the law of sequence the units of higher order stand on the left of those of lower order. The symbols used in writing are chiefly the horizontal wedge $>$, the vertical wedge $\mathbf{Y}$, and the combination of the two at an angle $\boldsymbol{\psi}$. The symbols were written beside one another, or, for ease of reading and to save space, over one another. The symbols for $1,4,10,100,14,400$, respectively, are as follows: 


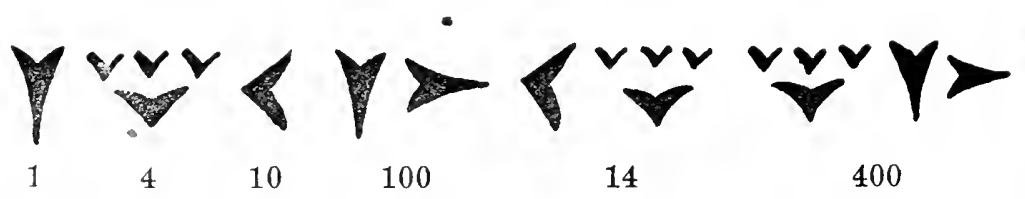

For numbers exceeding 100 there was also, besides the mere juxtaposition, a multiplicative principle; the symbol representing the number of hundreds was placed at the left of the symbol for hundreds as in the case of 400 already shown. The Babylonians probably had no symbol for zero.* The sexagesimal system (i. e., with the base 60 ), which played such a part in the writings of the Babylonian scholars (astronomers and mathematicians), will be mentioned later.

The Phonicians, whose twenty-two letters were derived from the hieratic characters of the Egyptians, either wrote the numbers out in words or used special numerical symbols-for the units vertical marks, for the tens horizontal. Som what later the Syrians used the twenty-two letters of their alphabet to represent the numbers $1,2, \ldots 9,10,20, \ldots 90,100, \ldots 400$; 500 was $400+100$, etc. The thousands were repre sented by the symbols for units with a subscript comma at the right.t. The Hebrew notation follows the same plan.

The oldest Greek numerals (aside from the written words) were, in general, the initial letters of the fundamental numbers. I for $1, \Pi$ for 5 ( $\boldsymbol{\pi} \dot{\boldsymbol{c}} \boldsymbol{\nu} \boldsymbol{\tau} \boldsymbol{\epsilon}), \Delta$ for 10 ( ¿́є́кa), $\S$ and these were repeated as often as necessary.

\footnotetext{
* Cantor, I., p. 84 † Cantor, 1, p. riz.

‡ Cantor. I., pp. II3-1 $I_{4}$.
}

\$Cantor, I., p. IIo. 
These numerals are described by the Byzantine grammarian Herodianus (A. D. 200) and hence are spoken of as Herodianic numbers. Shortly after 500 B. C. two new systems appeared. One used the 24 letters of the Ionic alphabet in their natural order for the numbers from 1 to 24 . The other arranged these letters apparently at random but actually in an order fixed arbitrarily; thus, $a=1, \beta=2, \ldots, \iota=10, \kappa=$ $20, \ldots, \rho=100, \sigma=200$, etc. Here too there is no special symbol for the zero.

The Roman numerals* were probably inherited from the Etruscans. The noteworthy peculiarities are the lack of the zero, the subtractive principle whereby the value of a symbol was diminished by placing before it one of lower order $(\mathrm{IV}=4, \mathrm{IX}=9$, $\mathrm{XL}=40, \mathrm{XC}=90$ ), even in cases where the language itself did not signify such a subtraction; and finally the multiplicative effect of a bar over the numerals $(\overline{\mathrm{XXX}}=30000, \overline{\mathrm{C}}=100000)$. Also for certain fractions there were special symbols and names. According to Mommsen the Roman number-symbols I, V, $X$ represent the finger, the hand, and the double hand. Zangemeister proceeds from the standpoint that decem is related to decussare which means a perpendicular or oblique crossing, and argues that every straight or curved line drawn across the symbol of a number in the decimal system multiplies that number by ten. In fact, there are on monuments

*Cantor, I., p. 486. 
representations of 1,10 , and 1000 , as well as of $\mathbf{5}$ and 500 , to prove his assertion.*

Of especial interest in elementary arithmetic is the number-system of the Hindus, because it is to these Aryans that we undoubtedly owe the valuable positionsystem now in use. Their oldest symbols for 1 to 9 were merely abridged number-words, and the use of letters as figures is said to have been prevalent from the second century A. D. $\dagger$ The zero is of later origin; its introduction is not proven with certainty till after $400 \mathrm{~A}$. D. The writing of numbers was carried on, chiefly according to the position-system, in various ways. One plan, which Aryabhatta records, represented the numbers from 1 to 25 by the twenty-five consonants of the Sanskrit alphabet, and the succeeding tens $(30,40 \ldots 100)$ by the semi-vowels and sibilants. A series of vowels and diphthongs formed multipliers consisting of powers of ten, ga meaning 3 , si $300, g u 30000, g a u 3 \cdot 10^{16}$. + In this there is no application of the position-system, although it appears in two other methods of writing numbers in use among the arithmeticians of Southern India. Both of these plans are distinguished by the fact that

* Sitzungsberichte der Berliner Akademie vom I0. November 1887 . Wordsworth, in his Fragments and Specimens of Early Latin, 1874, derives C for centum, $\mathrm{M}$ for mille, and $\mathrm{L}$ for quinquaginta from three letters of the Chalcidian alphabet, corresponding to $\theta, \phi$, and $\chi$. He says: "The origin of this notation is, I believe, quite uncertain, or rather purely arbitrary, though, of course, we observe that the initials of mille and centum determined the final shape taken by the signs, which at first were very different in form."

+See Encyclopadia Britannica, under "Numerals "

†Cantor, I., p. 566 . 
the same number can be made up in various ways. Rules of calculation were clothed in simple verse easy to hold in mind and to recall. For the Hindu mathematicians this was all the more important since they sought to avoid written calculation as far as possible. One method of representation consisted in allowing the alphabet, in groups of 9 symbols, to denote the numbers from 1 to 9 repeatedly, while certain vowels represented the zeros. If in the English alphabet according to this method we were to denote the numbers from 1 to 9 by the consonants $b, c, \ldots z$ so that after two countings one finally has $z=2$, and were to denote zero by every vowel or combination of vowels, the number 60502 might be indicated by siren or heron, and might be introduced by some other words in the text. A second method employed type-words and combined them according to the law of position. Thus abdhi (one of the 4 seas) $=4$, surya (the sun with its 12 houses) $=12$, agvin (the two sons of the sun) $=2$. The combination abdhisuryacvinas denoted the number 2124.*

Peculiar to the Sanskrit number-language are special words for the multiplication of very large numbers. Arbuda signifies 100 millions, padma 10000 millions; from these are derived maharbuda $=1000$ millions, mahapadma $=100000$ millions. Speciallyformed words for large numbers run up to $10^{17}$ and even further. This extraordinary extension of the 
decimal system in Sanskrit resembles a number-game, a mania to grasp the infinitely great. Of this endeavor to bring the infinite into the realm of number-perception and representation, traces are found also among the Babylonians and Greeks. This appearance may find its explanation in mystic-religious conceptions or philosophic speculations.

The ancient Chinese number-symbols are confined to a comparatively few fundamental elements arranged in a perfectly developed decimal system. Here the combination takes place sometimes by multiplication, sometimes by addition. Thus $\operatorname{san}=3$, che $=10$;

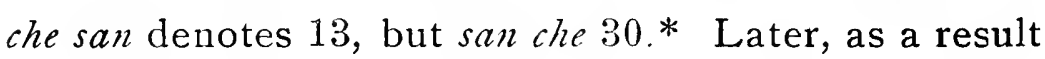
of foreign influence, there arose two new kinds of notation whose figures show some resemblance to the ancient Chinese symbols. Numbers formed from them were not written from above downward but after the Hindu fashion from left to right beginning with the highest order. The one kind comprising the merchants' figures is never printed but is found only in writings of a business character. Ordinarily the ordinal and cardinal numbers are arranged in two lines one above another, with zeros when necessary, in the form of small circles. In this notation

$$
\begin{aligned}
& \|=2, X=1, \perp=6,+=10, \hbar=10000, O=0 \\
& \| X \\
& \text { and hence } \hbar \circ \circ+\perp=20046 .
\end{aligned}
$$


Among the Arabs, those skilful transmitters of Oriental and Greek arithmetic to the nations of the West, the custom of writing out number-words continued till the beginning of the eleventh century. Yet at a comparatively early period they had already formed abbreviations of the number-words, the Divani figures. In the eighth century the Arabs became acquainted with the Hindu number-system and its figures, including zero. From these figures there arose among the Western Arabs, who in their whole literature presented a decided contrast to their Eastern relatives, the Gubar numerals (dust-numerals) as variants. These Gubar numerals, almost entirely forgotten to-day among the Arabs themselves, are the ancestors of our modern numerals, * which are immediately derived from the apices of the early Middle Ages. These primitive Western forms used in the abacus-calculations are found in the West European MSS. of the eleventh and twelfth centuries and owe much of their prominence to Gerbert, afterwards Pope Sylvester II. (consecrated 999 A. D.).

The arithmetic of the Western nations, cultivated to a considerable extent in the cloister-schools from the ninth century on, employed besides the abacus the Roman numerals, and consequently made no use of a symbol for zero. In Germany up to the year 1500 the Roman symbols were called German numerals in distinction from the symbols-then seldom employed-

*Hankel, p. 255. 
of Arab-Hindu origin, which included a zero (Arabic as-sifr, Sanskrit sunya, the void). The latter were called ciphers (Ziffern). From the fifteenth century on these Arab-Hindu numerals appear more frequently in Germany on monuments and in churches, but at that time they had not become common property.* The oldest monument with Arabic figures (in Katharein near Troppau) is said to date from 1007. Monuments of this kind are found in Pforzheim (1371), and in Ulm (1388). A frequent and free use of the zero in the thirteenth century is shown in tables for the calculation of the tides at London and of the duration of moonlight. $\dagger$ In the year 1471 there appeared in Cologne a work of Petrarch with page-numbers in Hindu figures at the top. In 1482 the first German aritkmetic with similar page-numbering was published in Bamberg. Besides the ordinary forms of numerals everywhere used to-day, which appeared exclusively in an arithmetic of 1489 , the following forms for 4,5 , $\checkmark$ were used in Germany at the time of the struggle between the Roman and Hindu notations:

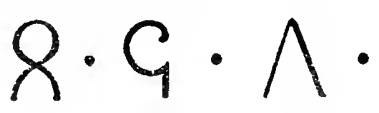

The derivation of the modern numerals is illustrated by the examples below which are taken in succession from the Sanskrit, the apices, the Eastern Arab; the

* Unger, Die Methodik der praktischen Arithmetik, I888, p. 70. Hereafter referred to as Unger.

+Günther, Geschichte des mathematischen Unterrichts im deutschen Mittelaltur bis zum Jah 1525, 1887, p. I75. Hereafter referred to as Günther. 
Western Arab Gubar numerals, the numerals of the eleventh, thirteenth, and sixteenth centuries.*

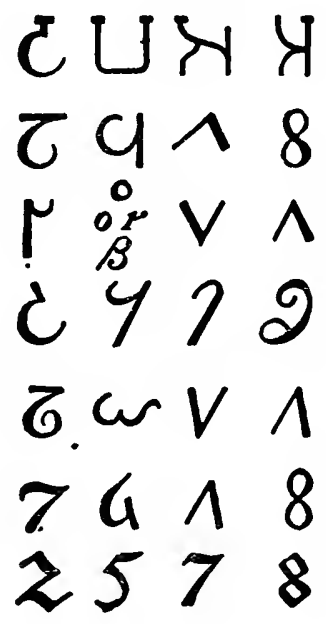

In the sixteenth century the Hindu position-arithmetic and its notation first found complete introduction among all the civilized peoples of the West. By this means was fulfilled one of the indispensable conditions for the development of common arithmetic in the schools and in the service of trade and commerce.

*Cantor, table appended to Vol. I, and Hankel, p. 325. 


\section{ARITHMETIC.}

\section{A. GENERAL SURVEY.}

THE simplest number-words and elementary count . 1 ing have always been the common property of the people. Quite otherwise is it, however, with the different methods of calculation which are derived from simple counting, and with their application to complicated problems. As the centuries passed, that part of ordinary arithmetic which to-day every child knows, descended from the closed circle of particular castes or smaller communities to the common people, so as to form an important part of general culture. Among the ancients the education of the youth had to do almost wholly with bodily exercises. Only a riper age sought a higher cultivation through intercourse with priests and philosophers, and this consisted in part in the common knowledge of to-day: people learned to read, to write, to cipher.

At the beginning of the first period in the historic development of common arithmetic stand the Egyptians. To them the Greek writers ascribe the invention of surveying, of astronomy, and of arithmetic. To their literature belongs also the most ancient book on 
arithmetic, that of Ahmes, which teaches operations with whole numbers and fractions. The Babylonians employed a sexagesimal system in their position-arithmetic, which latter must also have served the purposes of a religious number-symbolism. The common arithmetic of the Greeks, particularly in most ancient times, was moderate in extent until by the activity of the scholars of philosophy there was developed a real mathematical science of predominantly geometric character. In spite of this, skill in calculation was not esteemed lightly. Of this we have evidence when Plato demands for his ideal state that the youth should be instructed in reading, writing, and arithmetic.

The arithmetic of the Romans had a purely practical turn; to it belonged a mass of quite complicated problems arising from controversies regarding questions of inheritance, of private property and of reimbursement of interest. The Romans used duodecimal fractions. Concerning the most ancient arithmetic of the Hindus only conjectures can be made; on the contrary, the Hindu elementary arithmetic after the introduction of the position-system is known with tolerable accuracy from the works of native authors. The Hindu mathematicians laid the foundations for the ordinary arithmetic processes of to-day. The influence of their learning is perceptible in the Chinese arithmetic which likewise depends on the decimal system; in still greater measure, however, among the 
Arabs who besides the Hindu numeral-reckoning also employed a calculation by columns.

The time from the eighth to the beginning of the fifteenth century forms the second period. This is a noteworthy period of transition, an epoch of the transplanting of old methods into new and fruitful soil, but also one of combat between the well-tried Hindu methods and the clumsy and detailed arithmetic operations handed down from the Middle Ages. At first only in cloisters and cloister-schools could any arithmetic knowledge be found, and that derived from Roman sources. But finally there came new suggestions from the Arabs, so that from the eleventh to the thirteenth centuries there was opposed to the group of abacists, with their singular complementary methods, a school of algorists as partisans of the Hindu arithmetic.

Not until the fifteenth century, the period of investigation of the original Greek writings, of the rapid development of astronomy, of the rise of the arts and of commercial relations, does the third period in the history of arithmetic begin. As early as the thirteenth century besides the cathedral and cloister-schools which provided for their own religious and ecclesiastical wants, there were, properly speaking, schools for arithmetic. Their foundation is to be ascribed to the needs of the brisk trade of German towns with Italian merchants who were likewise skilled computers. In the fifteenth and sixteenth centuries 
school affairs were essentially advanced by the humanistic tendency and by the reformation. Latin schools, writing schools, German schools (in Germany) for boys and even for girls, were established. In the Latin schools only the upper classes received instruction in arithmetic, in a weekly exercise : they studied the four fundamental rules, the theory of fractions, and at most the rule of three, which may not seem so very little when we consider that frequently in the universities of that time arithmetic was not carried much further. In the writing schools and German boys' schools the pupils learned something of calculation, numeration, and notation, especially the difference between the German numerals (in Roman writing) and the ciphers (after the Hindu fashion). In the girls' schools, which were intended only for the higher classes of people, no arithmetic was taught. Considerable attainments in computation could be secured only in the schools for arithmetic. The most celebrated of these institutions was located at Nuremberg. In the commercial towns there were accountants' guilds which provided for the extension of arithmetic knowledge. But real mathematicians and astronomers also labored together in developing the methods of arithmetic. In spite of this assistance from men of prominence, no theory of arithmetic instruction had been established even as late as in the sixteenth century. What had been done before had to be copied. In the books on arithmetic 
were found only rules and examples, almost never proofs or deductions.

The seventeenth century brought no essential change in these conditions. Schools existed as before where they had not been swallowed up by the horrors of the Thirty-Years' War. The arithmeticians wrote their books on arithmetic, perhaps contrived calculating machines to make the work easier for their pupils, or composed arithmetic conversations and poems. A specimen of this is given in the following extracts from Tobias Beutel's Arithmetica, the seventh edition of which appeared in $1693 .^{*}$

"Numerieren lehrt im Rechen

Zahlen schreiben und aussprechen."

"In Summen bringen heisst addieren

Dies muss das Wörtlein Und vollführen."

"Wie eine Hand an uns die andre wäschet rein

Kann eine Species der andern Probe seyn."

"We are taught in numeration

Number writing and expression," etc., etc.

Commercial arithmetic was improved by the cultiva tion of the study of exchange and discount, and the abbreviated method of multiplication. The form of instruction remained the same, i. e., the pupil reckoned according to rules without any attempt being made to explain their nature.

The eighteenth century brought as its first and

*Unger, p. I24. 
most important innovation the statutory regulation of school matters by special school laws, and the establishment of normal schools (the first in 1732 at Stettin in connection with the orphan asylum). As reorganizers of the higher schools appeared the pietists and philanthropinists. The former established Realschulen (the oldest founded 1738 in Halle) and higher Bürgerschulen; the latter in their Schulen der Aufklärung sought by an improvement of methods to educate cultured mien of the world. The arithmetic exercisebooks of this period contain a simplification of division (the downwards or under-itself division) as well as a more fruitful application of the chain rule and decimal fractions. By their side also appear manuals of method whose number is rapidly increasing in the nineteenth century. In these, elementary teaching receives especial attention. According to Pestalozzi (1803) the foundation of calculation is sense-perception, according to Grube (1842), the comprehensive treatment of each number before taking up the next, according to Tanck and Knilling (1884), counting. In Pestalozzi's method "the decimal structure of our number-system, which includes so many advantages in the way of calculation, is not touched upon at all, addition, subtraction, and division do not appear as separate processes, the accompanying explanations smother the principal matter in the propositions, that is the arithmetic truth."* Grube has simply drawn 
from Pestalozzi's principles the most extreme conclusions. His sequence "is in many respects faulty; his processes unsuitable." * The historical development of arithmetic speaks in favor of the counting-principle : the first reckoning in every age has been an observing and counting.

\section{B. FIRS'T PERIOD.}

THE ARITHMETIC OF THE OLDEST NATIONS TO THE TIME OF THE ARABS.

\section{r. The Arithmetic of Whole Numbers.}

If we leave out of account finger-reckoning, which cannot be shown with absolute certainty, then according to a statement of Herodotus the ancient Egyptian computation consisted of an operating with pebbles on a reckoning-board whose lines were at right angles to the computer. Possibly the Babylonians also used a similar device. In the ordinary arithmetic of the latter, as among the Egyptians, the decimal system prevails, but by its side we also find, especially in dealing with fractions, a sexagesimal system. This arose without doubt in the working out of the astronomical observations of the Babylonian priests. $†$ The length of the year of 360 days furnished the occasion for the division of the circle into 360 equal parts, one of which was to represent the apparent daily path of the sun upon the celestial sphere. If in addition the construc- 
tion of the regular hexagon was known, then it was natural to take every 60 of these parts again as units. The number 60 was called soss. Numbers of the sexagesimal system were again multiplied in accordance with the rules of the decimal system : thus a ner $=600$, a sar $=3600$. The sexagesimal system established by the Babylonian priests also entered into their religious speculations, where each of their divinities was designated by one of the numbers from 1 to 60 corresponding to his rank. Perhaps the Babylonians also divided their days into 60 equal parts as has been shown for the Veda calendars of the ancient Hindus.

The Greek elementary mathematics, at any rate as early as the time of Aristophanes (420 B. C.), * used finger-reckoning and reckoning-boards for ordinary computation. An explanation of the finger-reckoning is given by Nicholas Rhabda $†$ of Smyrna (in the fourteenth century). Moving from the little finger of the left hand to the little finger of the right, three fingers were used to represent units, the next two, tens, the next two, hundreds, and the last three, thousands. On the reckoning board, the $a b a x$ ( $\beta a \xi$, dust board), whose columns were at right angles to the user, the operations were carried on with pebbles which had a different place-value in different lines. Multiplication was performed by beginning with the highest order in each factor and forming the sum of the partial pro-

* Cantor, I., pp. 120, 479. +Gow, History of Greek Mathematics, p. 24. 
ducts. Thus the calculation was effected (in modern form) as follows:

$$
\begin{aligned}
& 126 \cdot 237=(100+20+6)(200+30+7) \\
& =20000+3000+700 \\
& +4000+600+140 \\
& +1200+180+42 \\
& =29862
\end{aligned}
$$

According to Pliny, the finger-reckoning of the Romans goes back to King Numa;* the latter had made a statue of Janus whose fingers represented the number of the days of a year (355). Consistently with this Boethius calls the numbers from 1 to 9 fingernumbers, $10,20,30, \ldots$ joint-numbers, $11,12, \ldots$ $19,21,22, \ldots 29, \ldots$ composite numbers. In ele

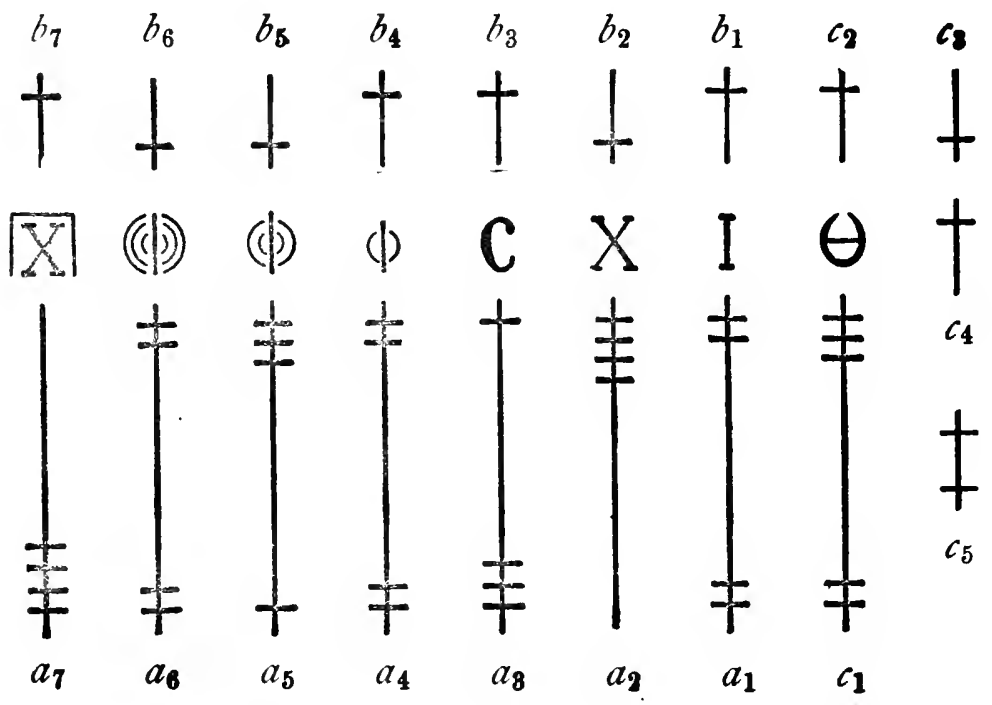

mentary tetching the Romans used the abacus, a board usually covered with dust on which one could *Cantor, I., p. 49 r. 
trace figures, draw columns, and work with pebbles. Or if the abacus was to be used for computing only, it was made of metal and provided with grooves (the vertical lines in the schematic drawing on the preceding page) in which arbitrary marks (the crosslines) could be shifted.

The columns $a_{1} \ldots a_{7}, b_{1} \ldots b_{7}$ form a system from 1 to 1000000 ; upon a column $a$ are found four marks, upon a column $b$ only one mark. Each of the four marks represents a unit, but the upper single mark five units of the order under consideration. Further a mark upon $c_{1}=\frac{1}{12}$, upon $c_{2}=\frac{6}{12}$, upon $c_{3}$ $=\frac{1}{24}$, upon $c_{4}=\frac{1}{48}$, upon $c_{5}=\frac{1}{7^{2}}$ (relative to the $\mathrm{di}$ vision of the $a$ 's). The abacus of the figure represents the number $782192+\frac{3}{12}+\frac{1}{24}+\frac{1}{72}=782192 \frac{1}{3} \frac{1}{6}$. This abacus served for the reckoning of results of simple problems. Along with this the multiplication-table was also employed. For larger multiplications there . were special tables. Such a one is mentioned by Victorius (about 450 A. D.).* From Boethius, who calls the abacus marks apices, we learn something about multiplication and division. Of these operations the former probably, the latter certainly, was performed by the use of complements. In Boethius the term differentia is applied to the complement of the divisor to the next complete ten or hundred. Thus for the divisors $7,84,213$ the differentiæ are $3,6,87 \dagger$ respectively. The essential characteristics of this comple- 
mentary division are seen from the following example put in modern form :

$$
\begin{aligned}
\frac{257}{14}=\frac{257}{20-6}= & 10+\frac{60+57}{20-6}=10+\frac{117}{20-6} \\
\frac{117}{20-6} & =5+\frac{30+17}{20-6}=5+\frac{47}{20-6} \\
\frac{47}{20-6} & =2+\frac{12+7}{20-6}=2+\frac{19}{20-6} \\
\frac{19}{14} & =1+\frac{5}{14} \\
\frac{257}{14}= & 18+\frac{5}{14} .
\end{aligned}
$$

The swanpan of the Chinese somewhat resembles the abacus of the Romans. This calculating machine consists of a frame ordinarily with ten wires inserted. A cross wire separates each of the ten wires into two unequal parts; on each smaller part two and on each larger five balls are strung. The Chinese arithmetics give no rules for addition and subtraction, but do for multiplication, which, as with the Greeks, begins with the highest order, and fordivision, which appears in the form of a repeated subtraction.

The calculation of the Hindus, after the introduction of the arithmetic of position, possessed a series of suitable rules for performing the fundamental operations. In the case of a smaller figure in the minuend subtraction is performed by borrowing and by addition (as in the so-called Austrian subtraction).*

* The Austrian subtraction corresponds in part to the usual method of "making change." 
In multiplication, for which several processes are available, the product is obtained in some cases by separating the multipliers into factors and subsequently adding the partial products. In other cases a schematic process is introduced whose peculiarities are shown in the example $315 \cdot 37=11655$.

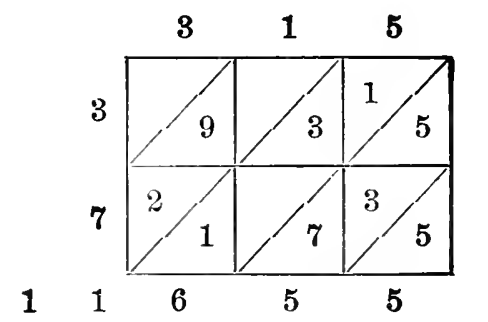

The result of the multiplication is obtained by the addition of the figures found within the rectangle in the direction of the oblique lines. With regard to division we have only a few notices. Probably, however, complementary methods were not used.

The earliest writer giving us information on the arithmetic of the Arabs is Al Khowarazmi. The borrowing from Hindu arithmetic stands out very clearly. Six operations were taught. Addition and subtraction begin with the units of highest order, therefore on the left; halving begins on the right, doubling again on the left. Multiplication is effected by the process which the Hindus called Tatstha (it remains standing).* The partial products, beginning with the highest order in the multiplicand, are written above the corresponding figures of the latter and each figure

*Cantor, I., p. 674, 57 I. 
of the product to which other units from a later partial product are added (in sand or dust), rubbed out and corrected, so that at the end of the computation the result stands above the multiplicand. In division, which is never performed in the complementary fashion, the divisor stands below the dividend and advances toward the right as the calculation goes on. Quotient and remainder appear above the divisor in $\frac{461}{16}=28 \frac{1}{1} \frac{3}{6}$, somewhat as follows: *

\section{3}

14

28

461

16

16

Al Nasawit also computes after the same fashion as Al Khowarazni. Their methods characterise the elementary arithmetic of the Eastern Arabs.

In essentially the same manner, but with more or less deviation in the actual work, the Western Arabs computed. Besides the Hindu figure-computation Ibn al Banna teaches a sort of reckoning by columns. Proceeding from right to left, the columns are combined in groups of three; such a group is called $t a$ karrur; the number of all the columns necessary to record a number is the mukarrar. Thus for the number 3819922 the takarm or number of complete groups is 2, the mukarrar $=7$. Al Kalsadi wrote a

$$
\text { * Cantor, 1., p. 674. † †antor, I., p. 7I6. ‡. Cantor, I., p. } 757 .
$$


work Raising of the Veil of the Science of Gubar.* The original meaning of Gubar (dust) has here passed over into that of the written calculation with figures. Especially characteristic is it that in addition, subtraction (=tarh, tarah $a=$ to throw away) and multiplication the results are written above the numbers operated upon, as in the following examples:

$\begin{array}{rr}193+45=238 & \text { and } 238-193=\mathbf{4 5} \\ \text { is written, } & \text { is written, } \\ \frac{238}{\mathbf{1 9 3}} ; & \frac{\mathbf{4 5}}{\mathbf{2 3 8}} \\ \mathbf{4 5} & \mathbf{1 9 3} \\ \mathbf{1} & 1\end{array}$

Several rules for multiplication are found in $\mathrm{Al} \mathrm{Kal}$. sadi, among them one with an advancing multiplier In division the result stands below.

$\begin{array}{rr}\text { FIRST EXAMPLE. } & \text { Second Example. } \\ 7 \cdot 143=1001 & \frac{1001}{7}=143 \\ \text { is written, } \frac{1001}{21} & \text { is written } 32 \\ 28 & 1001 \\ \frac{7}{143} & \mathbf{7 7 7} \\ 777 & 143\end{array}$

2. Calculation With Fractions.

In his arithmetic Ahmes gives a large number of examples which show how the Egyptians dealt with fractions. They made exclusive use of unit-fractions,

* Cantor, I., p. 762 . 
i. e., fractions with numerator 1 . For this numerator, therefore, a special symbol is found, in the hieroglyphic writing $\odot$, in the hieratic a point, so that in the latter a unit fraction is represented by its denominator with a point placed above it. Besides these there are found for $\frac{1}{2}$ and $\frac{2}{3}$ the hieroglyphs $\square$ and II; ${ }^{*}$ in the hieratic writing there are likewise special symbols corresponding to the fractions $\frac{1}{2}, \frac{2}{3}, \frac{1}{3}$, and $\frac{1}{4}$. The first problem which Ahmes solves is this, to separate a fraction into unit fractions. E. g., he finds $\frac{2}{9}=\frac{1}{6}+\frac{1}{18}, \quad \frac{2}{95}=\frac{1}{60}+\frac{1}{880}+\frac{1}{570}$. This separation, really an indeterminate problem, is not solved by Ahmes in general form, but only for special cases.

The fractions of the Babylonians being entirely in the sexagesimal system, had at the outset a common denominator, and could be dealt with like whole numbers. In the written form only the numerator was given with a special sign attached. The Greeks wrote a fraction so that the numerator came first with a single stroke at the right and above, followed in the same line by the denominator with two strokes, written twice, thus $\iota \zeta^{\prime} \kappa a^{\prime \prime} k a^{\prime \prime}=\frac{17}{2}$. In unit fractions the numerator was omitted and the denominator written only once: $\boldsymbol{\delta}^{\prime \prime}=\frac{1}{4}$. The unit fractions to be added follow immediately one after another. $\dagger \zeta^{\prime \prime} \kappa \eta^{\prime \prime} \rho \iota \beta^{\prime \prime} \sigma \kappa \delta^{\prime \prime}$ $=\frac{1}{7}+\frac{1}{28}+\frac{1}{112}+\frac{1}{2 \frac{1}{2}}=\frac{43}{224}$. In arithmetic proper, extensive use was made of unit-fractions, later also of

* For carefully drawn symbols see Cantor, I. p. 45.

† Cantor, I., p. IIs. 
sexagesimal fractions (in the computation of angles). Of the use of a bar between the terms of a fraction there is nowhere any mention. Indeed, where such use appears to occur, it marks only the result of an addition, but not a division.*

The fractional calculations of the Romans furnish an example of the use of the duodecimal system. The fractions (minutia) $\frac{1}{12}, \frac{2}{12}, \ldots \frac{21}{12}$ had special names and symbols. The exclusive use of these duodecimal fractionst wies due to the fact that the as, a mass of copper weighing one pound. Was divided into twelve uncia. The urcia had four sicilici and twenty-four scripuli. $1=a s, \frac{1}{2}=$ simis. $\frac{1}{3}=$ triens, $\frac{1}{2}=$ quairans, etc. Besides the twelfths special names were given to the iractions $\frac{1}{2 \frac{1}{4}} \cdot \frac{1}{\frac{1}{3}} \cdot \frac{1}{\frac{1}{2}}, \frac{1}{14 \frac{1}{4}} \cdot \frac{1}{2}$. The addition and subtraction of such fractions was com. paratively simple, but their multiplication very detailed. The greatest disadvantage of this system consisted in the fact that all divisions which dic not fit into this duodecimal system could be represented by minutiæ either with extreme diffculty or only approxi. mately.

In the computations of the Hindus both unit fractions and derived fractions likewise appear. The denominator stands under the numerator but is not separated from it by a bar. The Hindu astronomers preferred to calculate with sexasesimal iractions. In the computations of the Arabs Al hhowarazmi gives 
special words for half, third, ... ninth (expressible fractions).* All fractions with denominators non-divisible by $2,3, \ldots 9$, are called mute fractions; they were expressed by a circumlocution, e. g., $\frac{2}{17}$ as 2 parts of 17 parts. Al Nasawi writes mixed numbers in three lines, one under another, at the top the whole number, below this the numerator, below this the denominator. For astronomical calculations fractions of the sexagesimal system were used exclusively.

\section{Applied Arithmetic.}

The practical arithmetic of the ancients included besides the common cases of daily life, astronomical and geometrical problems. The latter will be passed over here because they are mentioned elsewhere. In Ahmes problems in partnership are developed and also the sums of some of the simplest series determined. Theon of Alexandria showed how to obtain. approximately the square root of a number of angle degrees by the use of sexagesimal fractions and the gnomon. The Romans were concerned principally with problems of interest and inheritance. The Hindus had already developed the method of false position (Regula falsi) and the rule of three, and made a study of problems of alligation, cistern-filling, and series, which were still further developed by the Arabs. Along with the practical arithmetic appear frequent 
traces of observations on the theory of numbers. The Egyptians knew the test of divisibility of a number by 2. The Pythagoreans distinguished numbers as odd and even, amicable, perfect, redundant and defective.* Of two amicable numbers each was equal to the sum of the aliquot parts of the other ( 220 gives $1+2+4$ $+5+10+11+20+22+44+55+110=284$ and 284 gives $1+2+4+71+142=220$ ). A perfect number was equal to the sum of its aliquot parts $(6=1+$ $2+3$ ). If the sum of the aliquot parts was greater or less than the number itself, then the latter was called redundant or defective respectively $(8>1+2+4 ; 12$ $<1+2+3+4+6$ ). Besides this, Euclid starting from his geometric standpoint commenced some fundamental investigations on divisibility, the greatest common measure and the least common multiple. The Hindus were familiar with casting out the nines and with continued fractions, and from them this knowledge went over to the Arabs. However insignificant may be these beginnings in their ancient form, they contain the germ of that vast development in the theory of numbers which the nineteenth century has brought about.

* Cantor, I., p. 156. 


\section{STCOND PERIOD.}

FROM THE EIGHTH TO THE FOURTEENTH CENTURY.

\section{The Arithmetic of Whole Numbers.}

In the cloister schools, the episcopal schools, and the private schools of the Merovingian and Carlovingian period it was the monks almost exclusively who gave instruction. The cloister schools proper were of only slight importance in the advancement of mathematical knowledge: on the contrary, the episcopal and private schools, the latter based on Italian methods, seem to have brought very beneficial results. The first to foreshadow something of the mathematical knowledge of the monks is Isidorus of Seville. This cloister scholar confined himself to making conjectures regarding the derivation of the Roman numerals, and says nothing at all about the method of computation of his contemporaries. The Venerable Bede likewise published only some extended observations on finger-reckoning. He shows how to represent numbers by the aid of the fingers, proceeding from left to right, and thereby assumes a certain acquaintance with finger-reckoning, mentioning as his predecessors Macrobius and Isidorus.* This calculus digitalis, appearing in both the East and the West in

*Cantor, I., p. 778. 
exactly the same fashion, played an important part in fixing the dates of church feasts by the priests of that time; at least computus digitalis and computus ecclesiasticus were frequently used in the same sense.*

With regard to the fundamental operations proper Bede does not express himself. Alcuin makes much of number-mysticism and reckons in a very cumbrous manner with the Roman numerals. $\nmid$ Gerbert was the first to give in his Regula de abaco computi actual rules, in which he depended upon the arithmetic part of Boethius's work. What he teaches is a pure abacusreckoning, which was widely spread by reason of his reputation. Gerbert's abacus, of which we have an accurate description by his pupil Bernelinus, was a table which for the drawing of geometric figures was sprinkled with blue sand, but for calculation was divided into thirty columns of which three were reserved for fractional computations. The remaining twentyseven columns were separated from right to left into groups of three. At the head of each group stood likewise from right to left S (singularis), D (decem), C (centum). The number-symbols used, the so-called apices, are symbols for 1 to 9 , but without zero. In calculating with this abacus the intermediate operations could be rubbed out, so that finally only the result remained; or the operation was made with counters. The fundamental operations were performed principally by the use of complements, and in this respect 
division is especially characteristic. The formation of the quotient $1 \frac{99}{6}=33 \frac{1}{6}$ will explain this complementary division.

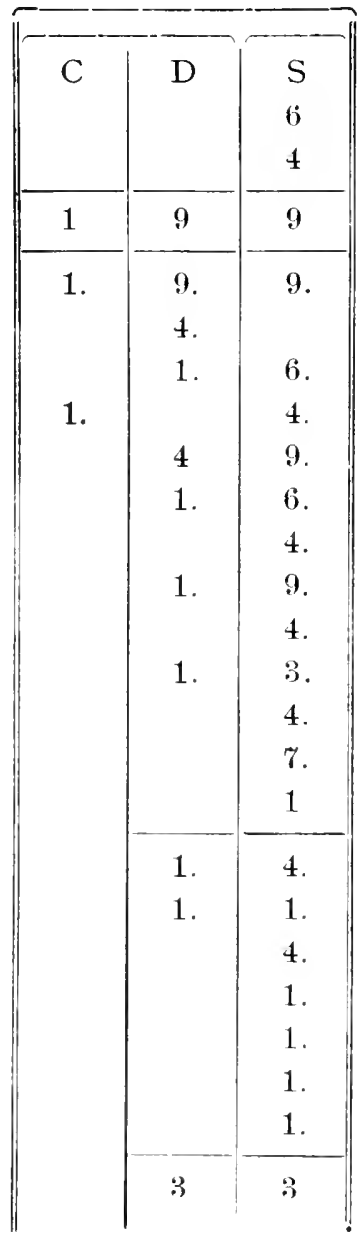

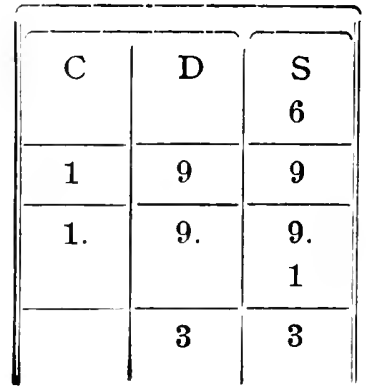

In the example given the complete performance of the complementary division stands on the left; the figures to be rubbed out as the calculation goes on are indicated by a period on the right. On the right is found the abacus-division without the formation of the difference in the divisor, below it the explanation of the complementary division in modern notation. 
In the tenth and eleventh centuries there appeared a large number of authors belonging chiefly to the clergy who wrote on abacus-reckoning with apices but without the zero and without the Hindu-Arab methods. In the latter the apices were connected with the abacus itself or with the representation of numbers of one figure, while in the running text the Roman numeral symbols stood for numbers of several figures. The contrast between the apices-plan and the Roman is so striking that Oddo, for example, writes: "If one takes 5 times 7 , or 7 times 5 , he gets $\mathrm{XXXV"} \mathrm{(the} \mathbf{5}$ and 7 written in apices).*

At the time of the abacus-reckoning there arose the peculiar custom of representing by special signs certain numbers which do not appear in the Roman system of symbols, and this use continued far into the Middle Ages. Thus, for example, in the townbooks of Greifswald 250 is continually represented by $C C C^{\nu} \dagger$

The abacists with their remarkable methods of division completely dominated Western reckoning up to the beginning of the twelfth century. But then a complete revolution was effected. The abacus, the heir of the computus, i. e., the old Roman method of calculation and number-writing, was destined to give way to the algorism with its sensible use of zero and its simpler processes of reckoning, but not without a further struggle. $\$$ People became pupils of the Western Arabs. Among the names of those who extended

\footnotetext{
* Cantor, I., p. 846 .
}

† Günther, p. 175 .

$\ddagger$ Günther, p. I07. 
Arab methods of calculation stands forth especially pre-eminent that of Gerhard of Cremona, because he translated into Latin a series of writings of Greek and Arab authors. * Then was formed the school of algorists who in contrast to the abacists possessed no complementary division but did possess the Hindu place-system with zero. The most lasting material for the extension of Hindu methods was furnished by Fibonacci in his Liber abaci. This book "has been the mine from which arithmeticians and algebraists have drawn their wisdom; on this account it has become in general the foundation of modern science." $\dagger$ Among other things it contains the four rules for whole numbers and fractions in detailed form. It is worthy of especial notice that besides ordinary subtraction with borrowing he teaches subtraction by increasing the next figure of the subtrahend by one, and that therefore Fibonacci is to be regarded as the creator of this elegant method.

\section{Arithmetic of Fractions.}

Here, also, after Roman duodecimal fractions had been exclusively cultivated by the abacists Beda, Gerbert and Bernelinus, Fibonacci laid a new foundation in his exercises preliminary to division. He showed how to separate a fraction into unit fractions. Especially advantageous in dealing with small numbers 
is his method of determining the common denominator: the greatest denominator is multiplied by each following denominator and the greatest common measure of each pair of factors rejected. (Example: the least common multiple of $24,18,15,9,8,5$ is $24 \cdot 3 \cdot 5$ $=360$.)

\section{Applied Arithmetic.}

The arithmetic of the abacists had for its main purpose the determination of the date of Easter. Besides this are found, apparently written by Alcuin, Problems for Quickening the Mind which suggest Roman models. In this department also Leonardo Fibonacci furnishes the most prominent rule (the regula falsi), but his problems belong more to the domain of algebra than to that of lower arithmetic.

Investigations in the theory of numbers could hardly be expected from the school of abacists. On the other hand, the algorist Leonardo was familiar with casting out the nines, for which he furnished an independent proof.

\section{THIRD PERIOD.}

FROM THE FIFTEENTH TO THE NINETEENTH CENTURY.

I. The Arithmetic of Whole Numbers.

While on the whole the fourteenth century had only reproductions to show, a new period of brisk ac- 
tivity begins with the fifteenth century, marked by Peurbach and Regiomontanus in Germany, and by Luca Pacioli in Italy. As far as the individual processes are concerned, in addition the sum sometimes stands above the addends, sometimes below; subtraction recognizes "carrying" and "borrowing"; in multiplication various methods prevail; in division no settled method is yet developed. The algorism of Peurbach names the following arithmetic operations: Numeratio, additio, subtractio, mediatio, duplatio, multiplicatio, divisio, progressio (arithmetic and geometric series), besides the extraction of roots which before the invention of decimal fractions was performed by the aid of sexagesimal fractions. His upwards-division still used the arrangement of the advancing divisor; it was performed in the manner following (on the left the explanation of the process, on the right Peurbach's division, where figures to be erased in the course of the reckoning are indicated by a period to the right and below): The oral statement would be somewhat like this : 36 in 84 twice, $2 \cdot 3=6,8-6=2$, written above $8 ; 2 \cdot 6=12,24-12=12$, write above, strike out 2 , etc. The proof of the accuracy of the result is obtained as in the other operations by casting out the nines. This method of upwards-division which is not difficult in oral presentation is still found in arithmetics which appeared shortly before the beginning of the nineteenth century. 


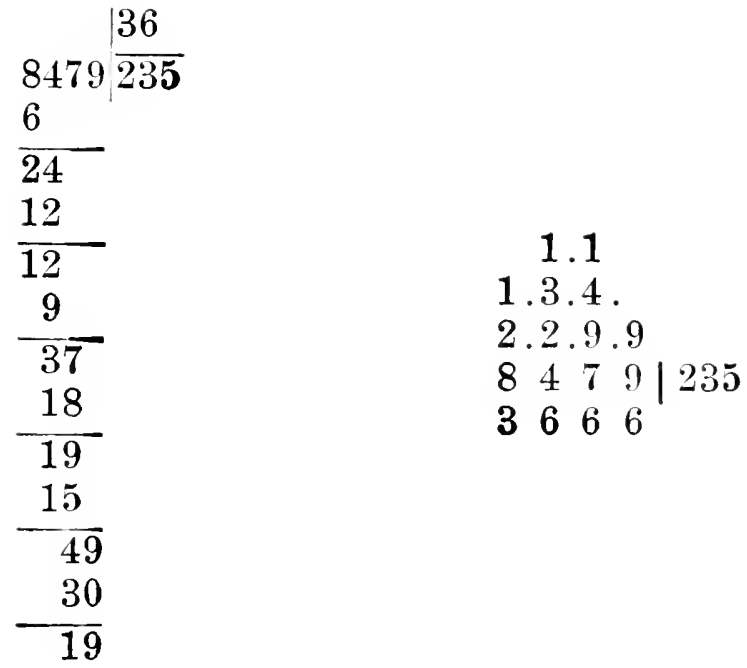

In the sixteenth century work in arithmetic had entered the Latin schools to a considerable extent; but to the great mass of children of the common people neither school men nor statesmen gave any thought before 1525. The first regulation of any value in this line is the Bavarian Schuelordnungk de anno 1548 which introduced arithmetic as a required study into the vil. lage schools. Aside from an occasional use of fingerreckoning, this computation was either a computation upon lines with counters or a figure-computation. In both cases the work began with practice in numeration in figures. To perform an operation with counters a series of horizontal parallels was drawn upon a suitable base. Reckoned from below upward each counter upon the $1 \mathrm{st}, 2 \mathrm{~d}, 3 \mathrm{~d}, \ldots$ line represented the value $1,10,100, \ldots$, but between the lines they represented $5,50,500, \ldots$ The following figure shows the rep. 
resentation of $41096 \frac{1}{2}$. In subtraction the minuend, in multiplication the multiplicand was put upon the lines. Division was treated as repeated subtractions. This line-reckoning was completely lost in the seven-

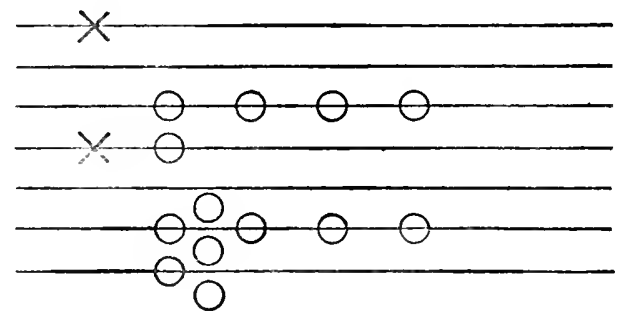

teenth century when it gave place to real written arithmetic or figure-reckoning by which it had been accompanied in the better schools almost from the first.

In the ordinary business and trade of the Middle Ages use was also made of the widely-extended scorereckoning. At the beginning of the fifteenth century this method was quite usual in Frankfort on the Main, and in England it held its own even into the nineteenth century. Whenever goods were bought of a merchant on credit the amount was represented by notches cut upon a stick which was split in two lengthwise so that of the two parts which matched, the debtor kept one and the creditor one so that both were secured against fraud.*

In the cipher-reckoning the computers of the sixteenth century generally distinguished more than 4 operations; some counted 9 , i. e., the 8 named by

* Cantor, M. Mathem. Beitr. zum Kulturleben der Völker. Halle, 1863. 
Peurbach and besides, as a ninth operation, evolution, the extraction of the square root by the formula $(a+b)^{2}$ $=a^{2}+2 a b+b^{2}$, and the extraction of the cube root by the formula $(a+b)^{3}=a^{3}+(a+b) 3 a b+b^{3}$. Definitions appeared, but these were only repeated circumlocutions. Thus Grammateus says: "Multiplication shows how to multiply one number by the other. Subtraction explains how to subtract one number from the other so that the remainder shall be seen."*

Addition was performed just as is done to-day. In subtraction for the case of a larger figure in the subtrahend, it was the custom in Germany to complete this figure to 10 , to add this complement to the minuend figure, but at the same time to increase the figure of next higher order in the subtrahend by 1 (Fibonacci's counting-on method). In more comprehensive books, borrowing for this case was also taught. Multiplication, which presupposed practice in the multiplication table, was performed in a variety of ways. Most frequently it was effected as to-day with a descent in steps by movement toward the left. Luca Pacioli describes eight different kinds of multiplication, among them those above mentioned, with two old Hindu methods, one represented on p. 29, the other cross-multiplication or the lightning method. In the latter method there were grouped all the products involving units, all those involving tens, all those involving hundreds. The multiplication

*Unger, p. 72. 


$$
\begin{aligned}
243 \cdot 139= & 9 \cdot 3+10(9 \cdot 4+3 \cdot 3)+100(9 \cdot 2+3 \cdot 4+1 \cdot 3) \\
& +1000(2 \cdot 3+1 \cdot 4)+10000 \cdot 2 \cdot 1
\end{aligned}
$$

was represented as follows:

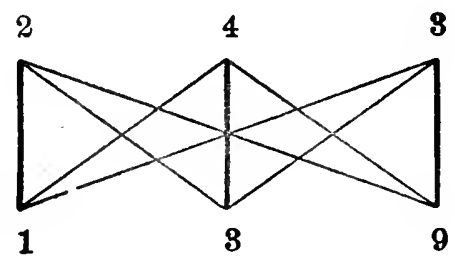

In German books are found, besides these, two noteworthy methods of multiplication, of which one begins on the left (as with the Greeks), the partial products being written in succession in the proper place, as shown by the following example $243 \cdot 839$ :

839

$\frac{243}{166867}$

3129

232

$$
\begin{aligned}
839 \cdot 243 & =2 \cdot 8 \cdot 10^{4}+2 \cdot 3 \cdot 10^{3}+2 \cdot 9 \cdot 10^{2} \\
& +4 \cdot 8 \cdot 10^{3}+4 \cdot 3 \cdot 10^{2}+4 \cdot 9 \cdot 10 \\
& +3 \cdot 8 \cdot 10^{2}+3 \cdot 3 \cdot 10+3 \cdot 9
\end{aligned}
$$

14

2

203877

In division the upwards-division prevailed; it was used extensively, although Luca Pacioli in 1494 taught the downwards-division in modern form.

After the completion of the computation, in conformity to historical tradition, a proof was demanded. At first this was secured by casting out the nines. On account of the untrustworthiness of this method, which Pacioli perfectly realised, the performance of 
the inverse operation was recommended. In course of time the use of a proof was entirely given up.

Signs of operation properly so called were not yet in use; in the eighteenth century they passed from algebra into elementary arithmetic. Widmann, however, in his arithmetic has the signs + and which had probably been in use some time among the merchants, since they appear also in a Vienna MS. of the fifteenth century.* At a later time Wolf has the sign $\div$ for minus. In numeration the first use of the word "million" in print is due to Pacioli (Summa de Arithmetica, I494). Among the Italians the word "million" is said originally to have represented a concrete mass, viz., ten tons of gold. Strangely enough, the words "byllion, tryllion, quadrillion, quyllion, sixlion, septyllion, ottyllion, nonyllion," as well as "'million,' are found as early as $\mathbf{1 4 8 4}$ in Chuquet, while the word "miliars" (equal to 1000 millions) is to be traced back to Jean Trenchant of Lyons (1588). $\dagger$

The seventeenth century was especially inventive in instrumental appliances for the mechanical performance of the fundamental processes of arithmetic. Napier's rods sought to make the learning of the multiplication-table superfluous. These rods were quadrangular prisms whish bore on each side the small multiplication-table for one of the numbers $1,2, \ldots 9$.

* Gerhardt, Geschichte der Mathematik in Deutschland, 1877. Hereafter referred to as Gerhardt.

t Müller. Historisch-etymologische Studien über mathematische Terminologie. Hereafter referred to as Müller. 
For extracting square and cube roots rods were used with the squares and cubes of one-figure numbers inscribed upon them. Real calculating machines which gave results by the simple turning of a handle, but on that account must have proved elaborate and expensive, were devised by Pascal, Leibnitz, and Matthäus Hahn ( I778).

A simplification of another kind was effected by calculating-tables. These were tables for solving problems, accompanied also by very extended multiplication-tables, such as those of Herwart von Hohenburg, from which the product of any two numbers from 1 to 999 could be read immediately.

For the methods of computation of the eighteenth century the arithmetic writings of the two Sturms, and of Wolf and Kästner, are of importance. In the interest of commercial arithmetic the endeavor was made to abbreviate multiplication and division by various expedients. Nothing essentially new was gained, however, unless it be the so-called mental arithmetic or oral reckoning which in the later decades of this period appears as an independent branch.

The nineteenth century has brought as a novelty in elementary arithmetic only the introduction of the so-called Austrian subtraction (by counting on) and division, methods for which Fibonacci had paved the way. The difference $323-187=136$ is computed by saying, 7 and 6,9 and 3,2 and 1 ; and $43083: 185$ is arranged as in the first of the following examples : 


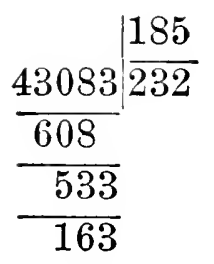

\begin{tabular}{l|r|r|r}
$\frac{1}{1}$ & $\frac{1679}{621}$ & $\frac{2737}{1058}$ & $\frac{1}{1}$ \\
\hline$\frac{2}{2}$ & $\frac{184}{46}$ & $\frac{437}{46}$ & $\frac{2}{2}$ \\
\hline- & $\frac{69}{23}$ & $\frac{1}{2}$ & -
\end{tabular}

With sufficient practice this process certainly secured a considerable saving of time, especially in the case of the determination of the greatest common divisor of two or more numbers as shown by the second of the above examples

$$
\frac{1679}{2737} \stackrel{23}{=} \frac{73}{119} .
$$

\section{Arithmetic of Fractions.}

At the beginning of this period reckoning with fractions was regarded as very difficult. The pupil was first taught how to read fractions: "It is to be noticed that every fraction has two figures with a line between. The upper is called the numerator, the lower the denominator. The expression of fractions is then: name first the upper figure, then the lower, with the little word part as $\frac{2}{3}$ part" (Grammateus, 1518).* Then came rules for the reduction of fractions to a common denominator, for reduction to lowest terms, for multiplication and division; in the last the fractions were first made to have a common denominator. Still more is found in Tartaglia who knew how to find the least common denominator; in Stifel who performed 
division by a fraction by the use of its reciprocal, and in the works of other writers.

The way for the introduction of decimal fractions was prepared by the systems of sexagesimal and duodecimal fractions, since by their employment operations with fractions can readily be performed by the corresponding operations with whole numbers. A notation such as has become usual in decimal fractions was already known to Rudolff,* who, in the division of integers by powers of 10 , cuts off the requisite number of places with a comma. The complete knowledge of decimal fractions originated with Simon Stevin who extended the position-system below unity to any extent desired. Tenths, hundredths, thousandths, ... were called primes, sekondes, terzes . . ; 4.628 is written $4_{(0)} 6_{(1)} 2_{(2)} 8_{(3)}$. Joost Bürgi, in his tables of sines, perhaps independently of Stevin, used decimal fractions in the form 0.32 and 3.2. The introduction of the comma as a decimal point is to be assigned to Kepler. $\dagger$ In practical arithmetic, aside from logarithmic computations, decimal fractions were used only in computing interest and in reduction-tables. They were brought into ordinary arithmetic at the beginning of the nineteenth century in connection with the introduction of systems of decimal standards.

* Gerhardt.

†The first use of the decimal point is found in the trigonometric tables of Pitiscus, I6I2. Cantor, 11., p. 555. 


\section{Applied Arithmetic.}

During the transition period of the Middle Ages applied arithmetic had absorbed much from the Latin treatises in a superficial and incomplete manner; the fifteenth and sixteenth centuries show evidences of progress in this direction also. Even the Bamberger Arithmetic of 1483 bears an exclusively practical stamp and aims only at facility of computation in mercantile affairs. That method of solution which in the books on arithmetic everywhere occupied the first place was the "regeldetri" (regula de tri, rule of three), known also as the "merchant's rule," or "golden rule."* The statement of the rule of three was purely mechanical; so little thought was bestowed upon the accompanying proportion that even master accountants were content to write $4 \mathrm{fl} 12 \mathrm{fb} 20 \mathrm{fl}$ ? instead of $4 \mathrm{fl}: 20 \mathrm{fl}=12 \mathrm{tb}: x \mathrm{tb} . \dagger$ There can indeed be found examples of the rule of three with indirect ratios, but with no explanations of any kind whatever. Problems involving the compound rule of three (regula de quinque, etc.) were solved merely by successive applications of the simple rule of three. In Tartaglia and Widmann we find equation of payments treated according to the method still in use to-day. Otherwise, Widmann's Arithmetic of 1489 shows great obscurity and lack of scope in rules and nomenclature, so that not infrequently the same matter appears un-

\footnotetext{
* Cantor, II., p. 205 : Unger, p. 86. † Cantor, II., p. 368; Unger, p. 87.
} 
der different names. He introduces "Regula Residui, Reciprocationis, Excessus, Divisionis, Quadrata, Inventionis, Fusti, Transversa, Ligar, Equalitatis, Legis, Augmenti, Augmenti et Decrementi, Sententiarum, Suppositionis, Collectionis, Cubica, Lucri, Pagamenti, Alligationis, Falsi," so that in later years Stifel did not hesitate to declare these things simply laughable.* Problems of proportional parts and alligation were solved by the use of as many proportions as corresponded to the number of groups to be separated. For the computation of compound interest Tartaglia gave four methods, among them computation by steps from year to year, or computation with the aid of the formula $b=a q^{n}$, although he does not give this formula. Computing of exchange was taught in its most simple form. It is said that bills of exchange were first used by the Jews who migrated into Lombardy after being driven from France in the seventh century. The Ghibellines who fled from Lombardy introduced exchange into Amsterdam, and from this city its use spread. $\dagger$ In 1445 letters of exchange were brought to Nuremberg.

The chain rule (Kettensatz), essentially an Indian method which is described by Brahmagupta, was developed during the sixteenth century, but did not come into common use until two centuries later. The methods of notation differed. Pacioli and Tartaglia

* Treutlein, Die deutsche Coss, Schlömilch's Zitschrift, Bd. 24, Hl. A. + Unger, p. 90. 
wrote all numbers in a horizontal line and multiplied terms of even and of odd order into separate products. Stifel proceeded in the same manner, only he placed all terms vertically beneath one another. In the work of Rudolff, who also saw the advantage of cancellation, we find the modern method of representing the chain rule, but the answer comes at the end.*

About this time a new method of reckoning was introduced from Italy into Germany by the merchants, which came to occupy an important place in the sixteenth century, and still more so in the seventeenth. This Welsh (i. e., foreign) practice, as it soon came to be called, found its application in the development of the product of two terms of a proportion, especially when these were unlike quantities. The multiplier, together with the fraction belonging to it, was separated into its addends, to be derived successively one from another in the simplest possible manner. How well Stifel understood the real significance and applicability of the Welsh practice, the following statement shows: $\dagger$ "The Welsh practice is nothing more than a clever and entertaining discovery in the rule of three. But let him who is not acquainted with the Welsh practice rely upon the simple rule of three, and he will arrive at the same result which another obtains through the Welsh practice." At this time, too, we find tables of prices and tables of interest in use, their introduction being also ascribable to the Italians. 
In the sixteenth century we also come upon examples for the regula virginum and the regula falsi in writings intended for elementary instruction in arithmetic, writings into which, ordinarily, was introduced all the learning of the author. The significance of these rules, however, does not lie in the realm of elementary arithmetic, but in that of equations. In the same way, a few arithmetic writings contained directions for the construction of magic squares, and most of them also contained, as a side-issue, certain arithmetic puzzles and humorous questions (Rudolff calls them Schimpfrechnung). The latter are often mere disguises of algebraic equations (the problem of the hound and the hares, of the keg with three taps, of obtaining a number which has been changed by certain operations, etc.).

The seventeenth century brought essential innovations only in the province of commercial computation. While the sixteenth century was in possession of correct methods in all computations of interest when the amount at the end of a given time was sought, there were usually grave blunders when the principal was to be obtained, that is, in computing the discount on a given sum. The discount in 100 was computed somewhat in this manner:* 100 dollars gives after two years 10 dollars in interest; if one is to pay the 100 dollars immediately, deduct 10 dollars." No less a man than Leibnitz pointed out that the discount * Unger, p. I32. 
must be reckoned upon 100. Among the majority of arithmeticians his method met with the misunderstanding that if the discount at $5 \%$ for one year is $\frac{1}{21}$, the discount for two years must be $\frac{2}{21}$. It was not until the eighteenth century, after long and sharp controversy, that mathematicians and jurists united upon the correct formula.

In the computation of exchange the Dutch were essentially in advance of other peoples. They possessed special treatises in this line of commercial arithmetic and through them they were well acquainted with the fundamental principles of the arbitration of exchange. In the way of commercial arithmetic many expedients were discovered in the eighteenth century to aid in the performance of the fundamental operations and in solving concrete problems. Calculation of exchange and arbitration of exchange were firmly established and thoroughly discussed by Clausberg. Especial consideration was given to what was called the Reesic rule, which was looked upon as differing from the well-known chain-rule. Rees's book, which was written in Dutch, was translated into French in 1737 , and from this language into German in 1739. In the construction of his series Rees began with the required term; in the computation the elimination of fractions and cancellation came first, and then followed the remaining operations, multiplication and division.

Computation of capital and interest was extended, 
through the establishment of insurance associations, to a so-called political arithmetic, in which calculation of contingencies and annuities held an important place.

The first traces of conditions for the evolution of a political arithmetic* date back to the Roman prefect Ulpian, who about the opening of the third century A.D. projected a mortality table for Roman subjects. $\dagger$ But there are no traces among the Romans of life insurance institutions proper. It is not until the Middle Ages that a few traces appear in the legal regulations of endowments and guild finances. From the fourteenth century there existed travel and accident insurance companies which bound themselves, in consideration of the payment of a certain sum, to ransom the insured from captivity among the Turks or Moors.

Among the guilds of the Middle Ages the idea of association for mutual assistance in fires, loss of cattle and similar losses had already assumed definite shape. To a still more marked degree was this the case among the guilds of artisans which arose after the Reformation-guilds which established regular sick and burial funds.

We must consider tontines as the forerunner of annuity insurance. In the middle of the seventeenth century an Italian physician, Lorenzo Tonti, induced a number of persons in Paris to contribute sums of

* Karup, Theoretisches Handbuch der Lebensversicherung. I871.

†Cantor, I., p. 522 . 
money the interest of which should be divided annually among the surviving members. The French government regarded this procedure as an easy method of obtaining money and established from 1689 to 1759 ten state tontines which, however, were all given up in 1770 , as it had been proved that this kind of state loan was not lucrative.

In the meantime two steps had been taken which, by using the results of mathematical science, provided a secure foundation for the business of insurance. Pascal and Fermat had outlined the calculation of contingencies, and the Dutch statesman De Witt had made use of their methods to lay down in a separate treatise the principles of annuity insurance based upon the birth and death lists of several cities of Holland. On the other hand, Sir William Petty, in 1662, in a work on political arithmetic* contributed the first valuable investigations concerning general mortality-a work which induced John Graunt to construct mortality tables. Mortality tables were also published by Kaspar Neumann, a Breslau clergyman, in 1692, and these attracted such attention that the Royal Society of London commissioned the astronomer Halley to verify these tables. With the aid of Neumann's material Halley constructed the first complete tables of mortality for the various ages. Although these tables did not obtain the recognition they merited until half a century later, they furnished the foundation for all

* Recently republished in inexpensive form in Cassell's National Library. 
later works of this kind, and hence Halley is justly called the inventor of mortality tables.

The first modern life-insurance institutions were products of English enterprise. In the years 1698 and 1699 there arose two unimportant companies whose field of operations remained limited. In the year 1705 , however, there appeared in London the "Amicable" which continued its corporate existence until 1866. The "Royal Exchange" and "London Assurance Corporation," two older associations for fire and marine insurance, included life insurance in their business in 1721, and are still in existence. There was soon felt among the managers of such institutions the imperative need for reliable mortality tables, a fact which resulted in Halley's work being rescued from oblivion by Thomas Simpson, and in James Dodson's projecting the first table of premiums, on a rising scale, after Halley's method. The oldest company which used as a basis these scientific innovations was the "Society for Equitable Assurances on Lives and Survivorships," founded in 1765 .

While at the beginning of the nineteenth century eight life insurance companies were already carrying on their beneficent work in England, there was at the same time not a single institution of this kind upon the Continent, in spite of the progress which had been made in the science of insurance by Leibnitz, the Bernoullis, Euler and others. In France there appeared in 1819 “La compagnie d' assurances générales sur la 
vie." In Bremen the founding of a life insurance company was frustrated by the disturbances of the war in 1806. It was not until 1828 that the two oldest German companies were formed, the one in Lübeck, the other in Gotha under the management of Ernst Wilhelm Arnoldi, the "Father of German Insurance."

The nineteenth century has substantially enriched the literature of mortality tables, in such tables as those compiled by the Englishmen Arthur Morgan (in the eighteenth century) and Farr, by the Belgian Quetelet, and by the Germans, Brune, Heym, Fischer, Wittstein, and Scheffler. A recent acquisition in this field is the table of deaths compiled in accordance with the vote of the international statistical congress at Budapest in 1876, which gives the mortality of the population of the German Empire for the ten years 1871-1881. Further development and advancement of the science of insurance is provided for by the "Institute of Actuaries" founded in London in 1849an academic school with examinations in all branches of the subject. There has also been in Berlin since 1868 a "College of the Science of Insurance," but it offers no opportunity for study and no examinations.

The following compilations furnish a survey of the conditions of insurance in the year 1890 and of its development in Germany.* There were in Germany:

* Karup, Theorctisches Handbuch der Lebenswersicherung, I87I. Johnson, Universal Cyclopadia, under "Life-Insurance." 
AT THE BEGINNING OF THE YEAR
NUMBER OF LIFE INS. co's.

12

20

32

49

\section{NUMBER OF PERSONS INSURED}

46,980

90,128

305,433
FOR THE SUM IN ROUND NUMBERS (MILLION MARKS)

170

300

900

There were in 1890 :

IN

Germany ............... 49

Great Britain and Ireland..... 75

France.................. 17

Rest of Europe............ 58

United States of America...... 48
AMOUNT OF INSURANCE IN FORCE

4250 million marks 900 " pounds 3250 " francs 3200 " francs 4000 " dollars

All that the eighteenth century developed or discovered has been further advanced in the nineteenth. The center of gravity of practical calculation lies in commercial arithmetic. This is also finding expression in an exceedingly rich literature which has been extended in an exhaustive manner in all its details, but which contains nothing essentially new except the methods of calculating interest in accounts current. 


\section{ALGEBRA.}

\section{A. GENERAL SURVEY.}

THE beginnings of general mathematical science 1 are the first important outcome of special studies of number and magnitude; they can be traced back to the earliest times, and their circle has only gradually been expanded and completed. The first period reaches up to and includes the learning of the Arabs; its contributions culminate in the complete solution of the quadratic equation of one unknown quantity, and in the trial method, chiefly by means of geometry, of solving equations of the third and fourth degrees.

The second period includes the beginning of the development of the mathematical sciences among the peoples of the West from the eighth century to the middle of the seventeenth. The time of Gerbert forms the beginning and the time of Kepler the end of this period. Calculations with abstract quantities receive a material simplification in form through the use of abbreviated expressions for the development of formulæ; the most important achievement lies in the purely algebraic solution of equations of the third and fourth degrees by means of radicals. 
The third period begins with Leibnitz and Newton and extends from the middle of the seventeenth century to the present time. In the first and larger part of this period a new light was diffused over fields which up to that time had been only partially explored, by the discovery of the methods of higher analysis. At the end of this first epoch there appeared certain mathematicians who devoted themselves to the study of combinations but failed to reach the lofty points of view of a Leibnitz. Euler and Lagrange, thereupon, assumed the leadership in the field of pure analysis. Euler led the way with more than seven hundred dissertations treating all branches of mathematics. The name of the great Gauss, who drew from the works of Newton and Euler the first nourishment for his creative genius, adorns the beginning of the second epoch of the third period. Through the publication of more than fifty large memoirs and number of smaller ones, not alone on mathematical subjects but also on physics and astronomy, he set in motion a multitude of impulses in the most varied directions. At this time, too, there opened new fields in which men like Abel, Jacobi, Cauchy, Dirichlet, Riemann, Weierstrass and others have made a series of most beautiful discoveries. 


\section{B. FIRST PERIOD.}

FROM THE EARLIEST TIMES TO THE ARABS.

\section{General Arithmetic.}

However meagre the information which describes the evolution of mathematical knowledge among the earliest peoples, still we find isolated attempts among the Egyptians to express the fundamental processes by means of signs. In the earliest mathematical papyrus* we find as the sign of addition a pair of walking legs travelling in the direction toward which the birds pictured are looking. The sign for subtraction consists of three parallel horizontal arrows. The sign for equality is ". Computations are also to be found which show that the Egyptians were able to solve simple problems in the field of arithmetic and geometric progressions. The last remark is true also of the Babylonians. They assumed that during the first five of the fifteen days between new moon and full moon, the gain in the lighted portion of its disc (which was divided into 240 parts) could be represented by a geo metric progression, during the ten following days by an arithmetic progression. Of the 240 parts there were visible on the first, second, third... fifteenth day

\footnotetext{
* Cantor, I., p. 37.
} 


$$
\begin{array}{rrrrr}
5 & 10 & 20 & 40 & 1.20 \\
1.36 & 1.52 & 2.08 & 2.24 & 2.40 \\
2.56 & 3.12 & 3.28 & 3.44 & 4 .
\end{array}
$$

The system of notation is sexagesimal, so that we are to take $3.28=3 \times 60+28=208$. $*$ Besides this there have been found on ancient Babylonian monuments the first sixty squares and the first thirty-two cubes in the sexagesimal system of notation.

The spoils of Greek treasures are far richer. Even the name of the entire science $\dot{\eta} \mu a \theta \eta \mu a \tau \iota \kappa \dot{\eta}$ comes from the Greek language. In the time of Plato the word $\mu a \theta \eta_{\mu a \tau a}$ included all that was considered worthy of scientific instruction. It was not until the time of the Peripatetics, when the art of computation (logistic) and arithmetic, plane and solid geometry, astronomy and music were enumerated in the list of mathematical sciences, that the word received its special significance. Especially with Heron of Alexandria logistic appears as elementary arithmetic, while arithmetic so called is a science involving the theory of numbers.

Greek arithmetic and algebra appeared almost always under the guise of geometry, although the purely arithmetic and algebraic method of thinking was not altogether lacking, especially in later times. Aristotle $f$ is familiar with the representation of quantities by letters of the alphabet, even when those quantities do not represent line-segments; he says in 
one place: "If $\mathbf{A}$ is the moving force, $\mathbf{B}$ that which is moved, $\Gamma$ the distance, and $\Delta$ the time, etc." By the time of Pappus there had already been developed a kind of reckoning with capital letters, since he was able to distinguish as many general quantities as there were such letters in the alphabet. (The small letters $\alpha, \beta, \gamma$, stood for the numbers $1,2,3, \ldots)$ Aristotle has a special word for "continuous" and a definition for continuous quantities. Diophantus went farther than any of the other Greek writers. With him there already appear expressions for known and unknown quantities. Hippocrates calls the square of a number

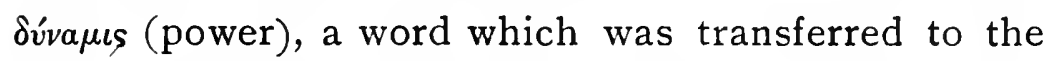
Latin as potentia and obtained later its special mathematical significance. Diophantus gives particular names to all powers of unknown quantities up to the sixth, and introduces them in abbreviated forms, so that $x^{2}, x^{3}, x^{4}, x^{5}, x^{6}$, appear as $\delta^{\hat{\nu}}, \kappa^{\hat{\nu}}, \delta \delta^{\hat{\nu}}, \delta \kappa^{\hat{\nu}}, \kappa \kappa^{\hat{\nu}}$. The sign for known numbers is $\mu^{\hat{o}}$. In subtraction Diophantus makes use of the sign $\uparrow$ (an inverted and abridged $\psi$ ); $\iota$, an abbreviation for $\iota$ oo as the sign of equality. A term of an expression is called eioos; this word went into Latin as species and was used in forming the title arithmetica speciosa=algebra.* The formulæ are usually given in words and are represented geometrically, as long as they have to do only with expressions of the second dimension. The first ten propositions in the second book of Euclid,

*Cantor, I., p. 442. 
for example, are enunciations in words and geometric figures, and correspond among others to the expressions $a(b+c+d \ldots)=a b+a c+a d+\ldots \ldots,(a+b)^{2}$ $=a^{2}+2 a b+b^{2}=(a+b) a+(a+b) b$.

Geometry was with the Greeks also a means for investigations in the theory of numbers. This is seen, for instance, in the remarks concerning gnomon-numbers. Among the Pythagoreans a square out of which a corner was cut in the shape of a square was called a gnomon. Euclid also used this expression for the figure $A B C D E F$ which is obtained from the parallelogram $A B C B^{\prime}$ by cutting out the parallelogram $D B^{\prime} F E$. The gnomon-number of the Pythagoreans is $2 n+1$; for when $A B C B^{\prime}$ is a square, the square upon $D E=n$

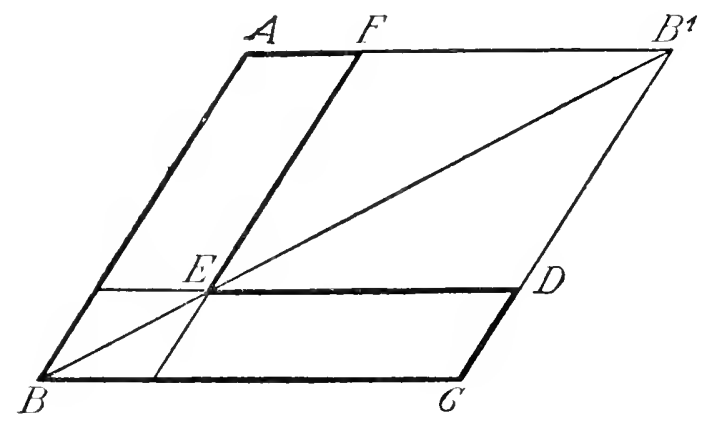

can be made equal to the square on $B C=n+1$ by adding the square $B E=1 \times 1$ and the rectangles $A E$ $=C E=1 \times n$, since we have $n^{2}+2 n+1=(n+1)^{2}$. Expressions like plane and solid numbers used for the contents of spatial magnitudes of two and three dimensions also serve to indicate the constant tend- 
ency to objectify mathematical thought by means of geometry.

All that was known concerning numbers up to the third century B. C., Euclid comprehended in a general survey. In his Elements he speaks of magnitudes, without, however, explaining this concept, and he understands by this term, besides lines, angles, surfaces and solids, the natural numbers. ${ }^{*}$ The difference between even and odd, between prime and composite numbers, the method for finding the least common multiple and the greatest common divisor, the construction of rational right angled triangles according to Plato and the Pythagoreans-all these are familiar to him. A method (the "sieve") for sorting out prime numbers originated with Eratosthenes. It consists in writing down all the odd numbers from 3 on, and then striking out all multiples of $3,5,7 \ldots$ Diophantus stated that numbers of the form $a^{2}+2 a b$ $+b^{2}$ represent a square and also that numbers of the form $\left(a^{2}+b^{2}\right)\left(c^{2}+d^{2}\right)$ can represent a sum of two squares in two ways; for $(a c+b d)^{2}+(a d-b c)^{2}=$ $(a c-b d)^{2}+(a d+b c)^{2}=\left(a^{2}+b^{2}\right)\left(c^{2}+d^{2}\right)$.

The knowledge of the Greeks in the field of elementary series was quite comprehensive. The Pythagoreans began with the series of even and odd numbers. The sum of the natural numbers gives the triangular number, the sum of the odd numbers the square, the sum of the even numbers gives the hetero-

*Treutlein. 
mecic (oblong) number of the form $n(n+1)$. Square numbers they also recognised as the sum of two successive triangular numbers. The Neo-Pythagoreans and the Neo-Platonists made a study not only of polygonal but also of pyramidal numbers. Euclid treated geometrical progressions in his Elements. He obtained the sum of the series $1+2+4+8 \ldots$ and noticed that when the sum of this series is a prime number, a "perfect number" results from multiplying it by the last term of the series $(1+2+4=7$; $7 \times 4=28 ; 28=1+2+4+7+14$; cf. p. 35 ). Infinite convergent series appear frequently in the works of Archimedes in the form of geometric series whose ratios are proper fractions; for example, in calculating the area of the segment of a parabola, where the value of the series $1+\frac{1}{4}+\frac{1}{16}+\ldots$ is found to be $\frac{4}{3}$. $\mathrm{He}$ also performs a number of calculations for obtaining the sum of an infinite series for the purpose of estimating areas and volumes. His methods are a substitute for the modern methods of integration, which are used in cases of this kind, so that expressions like

$$
\int_{0}^{c} x d x=\frac{1}{2} c^{2}, \quad \int_{0}^{c} x^{2} d x=\frac{1}{3} c^{3}
$$

and other similar expressions are in their import and essence quite familiar to him.*

The introduction of the irrational is to be traced back to Pythagoras, since he recognised that the hy-

* Zeuthen, Die Lehre won den Kegelschnitten im Altertum. Deutsch von v. Fischer-Benzon. I886. 
potenuse of a right-angled isosceles triangle is incommensurable with its sides. The Pythagorean Theodorus of Cyrene proved the irrationality of the square roots of $3,5,7, \ldots 17$.*

Archytas classified numbers in general as rational and irrational. Euclid devoted to irrational quantities a particularly exhaustive investigation in his Elements, a work which belongs to the domain of Arithmetic as much as to that of Geometry. Three books among the thirteen, the seventh, eighth and ninth, are of purely arithmetic contents, and in the tenth book there appears a carefully wrought-out theory of "Incommensurable Quantities," that is, of irrational quantities, as well as a consideration of geometric ratios. At the end of this book Euclid shows in a very ingenious manner that the side of a square and its diagonal are incommensurable; the demonstration culminates in the assertion that in the case of a rational relationship between these two quantities a number must have at the same time the properties of an even and an odd number. $t$ In his measurement of the circle Archimedes calculated quite a number of approximate values for square roots; for example,

$$
\frac{1351}{780}>\sqrt{3}>\frac{265}{153} \text {. }
$$

Nothing definite, however, is known concerning the

* Cantor, 1., p. 170.

$\dagger$ Montucla, I., p. 208. Montucla says that he knew an architect who lived in the firm conviction that the square root of 2 could be represented as a ratio of finite integers, and who assured him that by this method he had already reached the rooth decimal. 
method he used. Heron also was acquainted with such approximate values $\left(\frac{7}{5}\right.$ instead of $\sqrt{2}, \frac{2}{1} \frac{6}{5}$ instead of $\sqrt{3}) ; *$ and although he did not shrink from the labor of obtaining approximate values for square roots, in the majority of cases he contented himself with the well-known approximation $\sqrt{a^{2} \pm b}=a \pm \frac{b}{2 a}$, e. g., $\sqrt{63}=\sqrt{8^{2}-1}=8-\frac{1}{16}$. In case greater exactness was necessary, Heron $\dagger$ used the formula $\sqrt{a^{2}+b}=a+\frac{1}{x}+\frac{1}{y}+\frac{1}{z}+\ldots$ Incidentally he used the identity $\sqrt{a^{2} b}=a \sqrt{b}$ and asserted, for example, that $\sqrt{108}=\sqrt{6^{2} \cdot 3}=6 \sqrt{3}=6 \cdot \frac{26}{15}=10+\frac{1}{3}+\frac{1}{15}$. Moreover, we find in Heron's Stereometrica the first example of the square root of a negative number, namely $\sqrt{81-144}$, which, however, without further consideration, is put down by the computer as 8 less $\frac{1}{16}$, which shows that negative quantities were unknown among the Greeks. It is true that Diophantus employed differences, but only those in which the minuend was greater than the subtrahend. Through Theon we are made acquainted with another method of extracting the square root; it corresponds with the method in use at present, with the exception that the Babylonian sexagesimal fractions are used, as was customary until the introduction of decimal fractions.

Furthermore, we find in Aristotle traces of the theory of combinations, and in Archimedes an attempt at the representation of a quantity which in- 
creases beyond all limits, first in his extension of the number-system, and then in his work entitled $\psi \alpha \mu$ $\mu i r \eta s$ (Latin arenarius, the sand-reckoner). Archimedes arranges the first eight orders of the decimal system together in an octad; $10^{8}$ octads constitute a period, and then these periods are arranged again according to the same law. In the sand-reckoning, Archimedes solves the problem of estimating the number of grains of sand that can be contained in a sphere which includes the whole universe. He assumes that 10,000 grains of sand take up the space of a poppy-seed, and he finds the sum of all the grains to be 10000000 units of the eighth period of his system, or $10^{63}$. It is possible that Archimedes in these observations intended to create a counterpart to the domain of infinitesimal quantities which appeared in his summations of series, a counterpart not accessible to the ordinary arithmetic.

In the fragments with which we are acquainted from the writings of Roman surveyors (agrimensores) there are but few arithmetic portions, these having to do with polygonal and pyramidal numbers. $\mathrm{Ob}$ viously they are of Greek origin, and the faulty style in parts proves that there was among the Romans no adequate comprehension of matters of this kind.

The writings of the Hindu mathematicians are exceedingly rich in matters of arithmetic. Their symbolism was quite highly developed at an early date.*

*Cantor, I., p. $55^{8}$. 
Aryabhatta calls the unknown quantity gulika ("little ball"), later yavattavat, or abbreviated ya ("as much as"). The known quantity is called rupaka or ru ("coin"). If one quantity is to be added to another, it is placed after it without any particular sign. The same method is followed in subtraction, only in this case a dot is placed over the coefficient of the subtrahend so that positive (dhana, assets) and negative quantities (kshaya, liabilities) can be distinguished. The powers of a quantity also receive special designations. The second power is varga or va, the third ghana or gha, the fourth va va, the fifth va gha ghata, the sixth va gha, the seventh va va gha ghata (ghata signifies addition). The irrational square root is called karana or $k a$. In the Çulvasutras, which are classed among the religious books of the Hindus, but which in addition contain certain arithmetic and geometric deductions, the word karana appears in conjunction with numerals; dvikarani $=\sqrt{2}$, trikarani $=\sqrt{3}$, daçakarani $=\sqrt{10}$. If several unknown quantities are to be distinguished, the first is called $y^{\prime} a$; the others are named after the colors: kalaka or ka (black), nilaka or $n i$ (blue), pitaka or pi (yellow); for example, by ya kabha is meant the quantity $x \cdot y$, since bhavita or bha indicates multiplication. There is also a word for "equal"; but as a rule it is not used, since the mere placing of a number under another denotes their equality.

In the extension of the domain of numbers to include negative quantities the Hindus were certainly 
successful. They used them in their calculations, and obtained them as roots of equations, but never regarded them as proper solutions. Bhaskara was even aware that a square root can be both positive and negative, and also that $\sqrt{-a}$ does not exist for the ordinary number-system. He says: "The square of a positive as well as of a negative number is positive, and the square root of a positive number is double, positive, and negative. There can be no square root of a negative number, for this is no square."*

The fundamental operations of the Hindus, of which there were six, included raising to powers and extracting roots. In the extraction of square and cube roots Aryabhatta used the formulæ for $(a+b)^{2}$ and $(a+b)^{3}$, and he was aware of the advantage of separating the number into periods of two and three figures each, respectively. Aryabhatta called the square root varga mula, and the cube root ghana mula (mula, root, used also of plants). Transformations of expressions involving square roots were also known. Bhaskara applied the formula

$$
\sqrt{a+\sqrt{b}}=\sqrt{\frac{1}{2}\left(a+\sqrt{a^{2}-b}\right)}+\sqrt{\frac{1}{2}\left(a-\sqrt{a^{2}-b}\right)},
$$

and was also able to reduce fractions with square roots in the denominator to forms having a rational denominator. In some cases the approximation methods for square root closely resemble those of the Greeks. 
Problems in transpositions, of which only a few traces are found among the Greeks, occupy considerable attention among the Indians. Bhaskara made use of formulæ for permutations and combinations* with and without repetitions, and he was acquainted with quite a number of propositions involving the theory of numbers, which have reference to quadratic and cubic remainders as well as to rational rightangled triangles. But it is noticeable that we discover among the Indians nothing concerning perfect, amicable, defective, or redundant numbers. The knowledge of figurate numbers, which certain of the Greek schools cultivated with especial zeal, is likewise wanting. On the contrary, we find in Aryabhatta, Brahmagupta and Bhaskara summations of arithmetic series, as well as of the series $1^{2}+2^{2}+3^{2}+\ldots, 1^{3}$ $+2^{3}+3^{3}+\ldots$. The geometric series also appears in the works of Bhaskara. As regards calculation with zero, Bhaskara was aware that $\frac{a}{0}=\infty$.

The Chinese also show in their literature some traces of arithmetic investigations; for example, the binomial coefficients for the first eight powers are given by Chu shi kih in the year 1303 as an "old method." There is more to be found among the Arabs. Here we come at the outset upon the name of Al Khowarazmi, whose Algebra, which was probably translated into Latin by Ethelhard of Bath, opens 
with the words* "Al Khowarazmi has spoken." In the Latin translation this name appears as Algoritmi, and to-day appears as algorism or algorithm, a word completely separated from all remembrance of Al Khowarazmi, and much used for any method of computation commonly employed and proceeding according to definite rules. In the beginning of the sixteenth century there appears in a published mathematical work a "philosophus nomine Algorithmus," a sufficient proof that the author knew the real meaning of the word algorism. But after this, all knowledge of the fact seems to disappear, and it was not until our own century that it was rediscovered by Reinaud and Boncompagni. $\dagger$

Al Khowarazmi increased his knowledge by studying the Greek and Indian models. A known quantity he calls a number, the unknown quantity jidr (root) and its square mal (power). In Al Karkhi we find the expression $k a b$ (cube) for the third power, and there are formed from these expressions mal mal $=x^{4}$, mal $k a b=x^{5}$, kab $k a b=x^{6}$, mal mal $k a b=x^{7}$, etc. He also treats simple expressions with square roots, but without arriving at the results of the Hindus. There is a passage in Omar Khayyam from which it is to be inferred that the extraction of roots was always performed by the help of the formula for $(a+b)^{n}$. Al Kalsadi $\ddagger$ contributed something new by the introduc-

* Cantor, 1., p. 67I.

$\dagger$ Jahrbuch über die Fortschritte der Mathematik, 1887, p. 23.

$\ddagger$ Cantor, I., p. 765 . 
tion of a radical sign. Instead of placing the word jidr before the number of which the square root was to be extracted, as was the custom, Al Kalsadi makes use only of the initial letter $\rightarrow$ of this word and places it over the number, as,

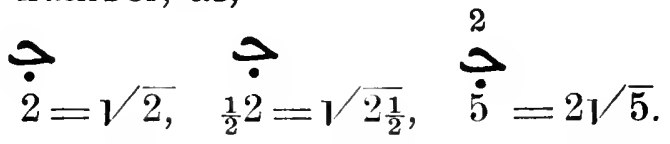

Among the Eastern Arabs the mathematicians who investigated the theory of numbers occupied themselves particularly with the attempt to discover rational right-angled triangles and with the problem of finding a square which, if increased or diminished by a given number, still gives a square. An anonymous writer, for example, gave a portion of the theory of quadratic remainders, and Al Khojandi also demonstrated the proposition that upon the hypothesis of rational numbers the sum of two cubes cannot be another third power. There was also some knowledge of cubic remainders, as is seen in the application by Avicenna of the proof by excess of nines in the formation of powers. This mathematician gives propositions which can be briefly represented in the form*

$$
\begin{aligned}
& (9 n \pm 1)^{2} \equiv 1(\bmod 9),(9 n \pm 2)^{2} \equiv 4(\bmod 9), \\
& (9 n+1)^{3} \equiv(9 n+4)^{3} \equiv(9 n+7)^{3} \equiv 1(\bmod 9), \text { etc. }
\end{aligned}
$$

Ibn al Banna has deductions of a similar kind which form the basis of a proof by eights and sevens. $\dagger$

In the domain of series the Arabs were acquainted 
at least with arithmetic and geometric progressions and also with the series of squares and cubes. In this field Greek influence is unmistakable.

\section{Algebra.}

The work of Ahmes shows that the Egyptians were possessed of equations of the first degree, and used in their solution methods systematically chosen. The unknown $x$ is called hau (heap); an equation* appears in the following form: heap, its $\frac{2}{3}$, its $\frac{1}{2}$, its $\frac{1}{7}$, its whole, gives 37 , that is $\frac{2}{3} x+\frac{1}{2} x+\frac{1}{7} x+x=37$.

The ancient Greeks were acquainted with the solution of equations only in geometrical form. Nowhere, save in proportions, do we find developed examples of equations of the first degree which would show unmistakably that the root of a linear equation with one unknown was ever determined by the intersection of two straight lines; but in the cases of equations of the second and third degrees there is an abundance of material. In the matter of notation Diophantus makes the greatest advance. He calls the coefficients of the unknown quantity $\pi \lambda \hat{\eta} \theta_{\text {os. If }}$ there are several unknowns to be distinguished, he makes use of the ordinal numbers : $\delta \pi \rho \hat{\omega} \tau$ os a $\rho \iota \theta \mu$ ós, $\delta$ $\delta \epsilon u ́ \tau \epsilon \rho o s, \delta$ $\tau \rho$ íros. An equation $\dagger$ appears in his works in the abbreviated form:

* Matthiessen, Grundzüge der antiken und modernen Algcbra der litteralen Gleichungen, 1878, p. 269. Hereafter referred to as Matthiessen.

$\uparrow$ Matthiessen, p. 269. 


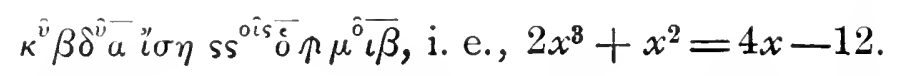

Diophantus classifies equations not according to the degree, but according to the number of essentially distinct terms. For this purpose he gives definite rules as to how equations can be brought to their simplest form, that is, the form in which both members of the equation have only positive terms. Practical problems which lead to equations of the first degree can be found in the works of Archimedes and Heron; the latter gives some of the so-called "fountain problems," which remind one of certain passages in the work of Ahmes. Equations of the second degree were mostly in the form of proportions, and this method of operation in the domain of a geometric algebra was well known to the Greeks. They undoubtedly understood how to represent by geometric figures equations of the form

$$
\frac{a^{\prime}}{a^{\prime \prime}} x=b, \frac{a^{\prime}}{a^{\prime \prime}} x+\frac{b^{\prime}}{b^{\prime \prime}} y+\ldots=m,
$$

where all quantities are linear. Every calculation of means in two equal ratios, i. e., in a proportion, was really nothing more than the solution of an equation. The Pythagorean school was acquainted with the arithmetic, the geometric and the harmonic means of two quantities; that is, they were able to solve geometrically the equations

$$
x=\frac{a+b}{2}, \quad x^{2}=a b, \quad x=\frac{2 a b}{a+b} .
$$

According to Nicomachus, Philolaus called the cube 
with its six surfaces, its eight corners, and its twelve edges, the geometric harmony, because it presented equal measurements in all directions; from this fact, it is said, the terms "harmonic mean" and "harmonic proportion" were derived, the relationship being:

$$
\frac{12-8}{8-6}=\frac{12}{6} \text {, whence } 8=\frac{2 \cdot 6 \cdot 12}{6+12} \text {, i. e., } x=\frac{2 a b}{a+b} \text {. }
$$

The number of distinct proportions was later increased to ten, although nothing essentially new was gained thereby. Euclid gives thorough analyses of proportions, that is, of the geometric solution of equations of the first degree and of incomplete quadratics; these, however, are not given as his own work, but as the result of the labors of Eudoxus.

The solution of the equation of the second degree by the geometric method of applying areas, largely employed by the ancients, especially by Euclid, deserves particular attention.

In order to solve the equation

$$
x^{2}+a x=b^{2}
$$

by Euclid's method, the problem must first be put in the following form:

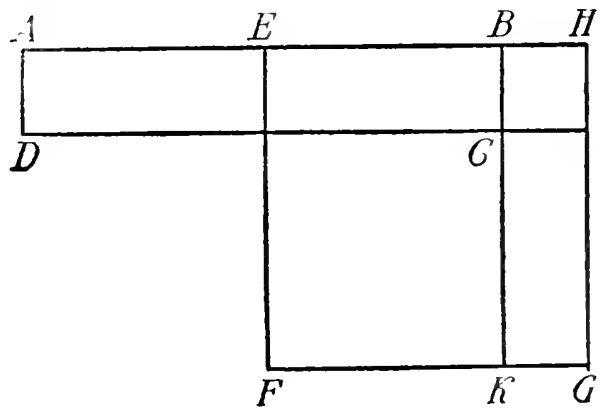


"To the segment $A B=a$ apply the rectangle $D H$ of known area $=b^{2}$, in such a way that $C H$ shall be a square." The figure shows that for $C K=\frac{a}{2}, F H=$ $x^{2}+2 x \cdot \frac{a}{2}+\left(\frac{a}{2}\right)^{2}=b^{2}+\left(\frac{a}{2}\right)^{2}$; but by the Pythagorean proposition, $b^{2}+\left(\frac{a}{2}\right)^{2}=c^{2}$, whence $E H=c=\frac{a}{2}+x$, from which we have $x=c-\frac{a}{2}$. The solution obtained by applying areas, in which case the square root is always regarded as positive, is accordingly nothing more than a constructive representation of the value

$$
x=-\frac{a}{2}+\sqrt{b^{2}+\left(\frac{a}{2}\right)^{2}}=c-\frac{a}{2} .
$$

In the same manner Euclid solves all equations of the form

$$
x^{2} \pm a x \pm b^{2}=0,
$$

and he remarks in passing that where $\sqrt{b^{2}-\left(\frac{a}{2}\right)^{2}}$, according to our notation, appears, the condition for a possible solution is $b>\frac{a}{2}$. Negative quantities are nowhere considered; but there is ground for inferring that in the case of two positive solutions the Greeks regarded both and that they also applied their method of solution to quadratic equations with numerical coefficients. * By applying their knowledge of proportion, they were able to solve not only equations of the form $x^{2} \pm a x \pm b=0$, but also of the more general form

$$
a x^{2} \pm a x \pm b^{2}=0,
$$

for $a$ as the ratio of two line-segments. Apollonius

*Zeuthen, Die Lehre von den Kegelschnitten im Altertum. Deutsch von v. Fischer-Benzon. I 886. 
accomplished this with the aid of a conic, having the equation

$$
y^{2}=p x \mp \frac{p}{a} x^{2} .
$$

The Greeks were accordingly able to solve every general equation of the second degree having two essentially different coefficients, which might also contain numerical quantities, and to represent their positive roots geometrically.

The three principal forms of equations of the second degree first to be freed from geometric statement and completely solved, are

$$
x^{2}+p x=q, x^{2}=p x+q, p x=x^{2}+q .
$$

The solution consisted in applying an area, the problem being to apply to a given line a rectangle in such a manner that it would either contain a given area or be greater or less than this given area by a constant. For these three conditions there arose the technical expressions $\pi \alpha \rho \alpha \beta o \lambda \eta^{\prime}, \dot{v} \pi \epsilon \rho \beta o \lambda \eta^{\prime}, \stackrel{\bullet}{\epsilon} \lambda \lambda \epsilon \iota \psi \iota s$, which after Archimedes came to refer to conics.*

In later times, with Heron and Diophantus, the solution of equations of the second degree was partly freed from the geometric representation, and passed into the form of an arithmetic computation proper (while disregarding the second sign in the square root).

The equation of the third degree, owing to its dependence on geometric problems, played an im-

* Tannery in Bordeaux Mém., IV. 
portant part among the Greeks. The problem of the duplication (and also the multiplication) of the cube attained especial celebrity. This problem demands nothing more than the solution of the continued proportion $a: x=x: y=y: 2 a$, that is, of the equation $x^{3}=2 a^{3}$ (in general $x^{3}=\frac{m}{n} a^{3}$ ). This problem is very old and was considered an especially important one by the leading Greek mathematicians. Of this we have evidence in a passage of Euripides in which he makes King Minos say concerning the tomb of Glaucus which is to be rebuilt*: "The enclosure is too small for a royal tomb: double it, but fail not in the cubical form." The numerous solutions of the equation $x^{3}=2 a^{3}$ obtained by Hippocrates, Plato, Menæchmus, Archytas and others, followed the geometric form, and in time the horizon was so considerably extended in this direction that Archimedes in the study of sections of a sphere solved equations of the form

$$
x^{3}-a x^{2}+b^{2} c=0
$$

by the intersection of two lines of the second degree, and in doing so also investigated the conditions to be fulfilled in order that there should be no root or two or three roots between 0 and $a$. Since the method of reduction by means of which Archimedes obtains the equation $x^{3}-a x^{2}+b^{2} c=0$ can be applied with considerable ease to all forms of equations of the third degree, the merit of having set forth these equations 
in a comprehensive manner and of having solved one of their principal groups by geometric methods belongs without question to the Greeks.*

We find the first trace of indeterminate equations in the cattle problem (Problema bovinum) of Archimedes.

This problem, which was published in the year 1773 by Lessing, from a codex in the library at Wolfenbüttel, as the first of four unprinted fragments of Greek anthology, is given in twentytwo distichs. In all probability it originated directly with Archimedes who desired to show by means of this example how, proceeding from simple numerical quantities, one could easily arrive at very large numbers by the interweaving of conditions. The problem runs something as follows: $\dagger$

The sun had a herd of bulls and cows of different colors. Of Bulls the white $(W)$ were in number $\left(\frac{1}{2}+\frac{1}{3}\right)$ of the black $(X)$ and the yellow $\left(Y^{\prime}\right)$; the black $(X)$ were $\left(\frac{1}{4}+\frac{1}{5}\right)$ of the dappled $(Z)$ and the yellow $(Y)$; the dappled $(Z)$ were $\left(\frac{1}{6}+\frac{1}{7}\right)$ of the white $(\mathrm{W})$ and the yellow $(Y)$. (2) Of Cows which had the same colors $(w, x, y, z), \quad w=\left(\frac{1}{3}+\frac{1}{4}\right)(X+x), \quad x=\left(\frac{1}{4}+\frac{1}{5}\right)(Z+z), \quad z=\left(\frac{1}{5}+\frac{1}{6}\right)$ $(Y+y), y=\left(\frac{1}{6}+\frac{1}{7}\right)(W+z w) . \quad W V+X$ is to be a square; $Y+Z$ a triangular number.

The problem presents nine equations with ten unknowns:

$$
\begin{array}{cc}
W=\left(\begin{array}{l}
1 \\
2
\end{array}+\frac{1}{3}\right) X+Y & X=\left(\frac{1}{4}+\frac{1}{6}\right) Z+Y \\
Z=\left(\frac{1}{6}+\frac{1}{7}\right) W+Y & w=\left(\frac{1}{3}+\frac{1}{4}\right)(X+x) \\
x=\left(\begin{array}{l}
1 \\
4
\end{array}+\frac{1}{5}\right)(Z+z) & z=\left(\frac{1}{5}+\frac{1}{6}\right)(Y+y) \\
y=\left(\begin{array}{c}
1 \\
6
\end{array}+\frac{1}{7}\right)(W+w) & W+X=n^{2} \\
Y+Z=\frac{m^{2}+m}{2} .
\end{array}
$$

* Zeuthen, Die Lehre von den Kegelschnitten im Altertum. Deutsch von v. Fischer-Benzon I8s6.

† Krumbiegel und Amthor, Das Problema bovinum des Archimcdes. Schlömilch's Zeitschrift, Bd. 25, Hl. A.; Gow, p. 99. 
According to Amthor the solution is obtained by Pell's equation $t^{2}-2 \cdot 3 \cdot 7 \cdot 11 \cdot 29 \cdot 353 u^{2}=1$, assuming the condition $u \equiv 0(\bmod$. $2 \cdot 465 \tau)$, in which process there arises a continued fraction with a period of ninety-one convergents. If we omit the last two conditions, we get as the total number of cattle 5916837175686 , a number which is nevertheless much smaller than that involved in the sand-reckoning of Archimedes.

But the name of Diophantus is most closely connected with systems of equations of this kind. $\mathrm{He}$ endeavors to satisfy his indeterminate equations not by means of whole numbers, but merely by means of rational numbers (always excluding negative quantities) of the form $\frac{p}{q}$ where $p$ and $q$ must be positive integers. It appears that Diophantus did not proceed in this field according to general methods, but rather by ingeniously following out special cases. At least those of his solutions of indeterminate equations of the first and second degrees with which we are acquainted permit of no other inference. Diophantus seems to have been not a little influenced by earlier works, such as those of Heron and Hypsicles. It may therefore be assumed that even before the Christian era there existed an indeterminate analysis upon which Diophantus could build.*

The Hindu algebra reminds $u$ s in many respects of Diophantus and Heron. As in the case of Diophantus, the negative roots of an equation are not admitted as solutions, but they are consciously set

* P. Tannery, in Mémoires de Bordcaux, 1880. This view of Tannery's is controverted by Heath, T. L., Diophantos of Alexandria, 1885, p. I35. 
aside, which marks an advance upon Diophantus. The transformation of equations, the combination of terms containing the same powers of the unknown, is also performed as in the works of Diophantus. The following is the representation of an equation according to Bhaskara :*,

\begin{tabular}{cc|cc|cc} 
va ra $^{2}$ & va & 1 & ru & 30 \\
\hline va $v a$ & 0 & va & 0 & ru & 8
\end{tabular} , i. e.,

$2 x^{2}-x+30=0 x^{2}+0 x+8$, or $2 x^{2}-x+30=8$.

Equations of the first degree appear not only with one, but also with several unknowns. The Hindu method of treating equations of the second degree shows material advance. In the first place, $a x^{2}+b x$ $=c$ is considered the only typet instead of the three Greek forms $a x^{2}+b x=c, b x+c=a x^{2}, a x^{2}+c=b x$. From this is easily derived $4 a^{2} x^{2}+4 a b x=4 a c$, and then $(2 a x+b)^{2}=4 a c+b^{2}$, whence it follows that

$$
x=\frac{-b+\sqrt{4 a c+b^{2}}}{2 a} .
$$

Bhaskara goes still further. He considers both signs of the square root and also knows when it cannot be extracted. The two values of the root are, however, admitted by him as solutions only when both are positive,-evidently because his quadratic equations appear exclusively in connection with practical problems of geometric form. Bhaskara also solves equations of the third and fourth degrees in cases where these 
equations can be reduced to equations of the second degree by means of advantageous transformations and the introduction of auxiliary quantities.

The indeterminate analysis of the Hindus is especially prominent. Here in contrast to Diophantus only solutions in positive integers are admitted. Indeterminate equations of the first degree with two or more unknowns had already been solved by Aryabhatta, and after him by Bhaskara, by a method in which the Euclidean algorism for finding the greatest common divisor is used; so that the method of solution corresponds at least in its fundamentals with the method of continued fractions. Indeterminate equations of the second degree, for example those of the form $x y=a x+b y+c$, are solved by arbitrarily assigning a value to $y$ and then obtaining $x$, or geometrically by the application of areas, or by a cyclic method.* This cyclic method does not necessarily lead to the desired end, but may nevertheless, by a skilful selection of auxiliary quantities, give integral values. It consists in solving in the first place, instead of the equation $a x^{2}+b=c y^{2}$, the equation $a x^{2}+1=y^{2}$. This is done by the aid of the empirically assumed equation $a A^{2}+B=C^{2}$, from which other equations of the same form, $a A_{n}^{2}+B_{n}=C_{n}^{2}$, can be deduced by the solution of indeterminate equations of the first degree. By means of skilful combinations 
the equations $a A_{n}^{2}+B_{n}=C_{n}^{2}$ furnish a solution of $a x^{2}+1=y^{2} \cdot *$

The algebra of the Chinese, at least in the earliest period, has this in common with the Greek, that equations of the second degree are solved geometrically. In later times there appears to have been developed a method of approximation for determining the roots of higher algebraic equations. For the solution of indeterminate equations of the first degree the Chinese developed an independent method. It bears the name of the "great expansion" and its discovery is ascribed to Sun tse, who lived in the third century A. D. This method can best be briefly characterised by the following example: Required a number $x$ which when divided by $7,11,15$ gives respectively the remainders $2,5,7$. Let $k_{1}, k_{2}, k_{3}$, be found so that

$$
\begin{gathered}
\frac{11 \cdot 15 \cdot k_{1}}{7}=q_{1}+\frac{1}{7}, \quad \frac{15 \cdot 7 \cdot k_{2}}{11}=q_{2}+\frac{1}{11}, \\
\frac{7 \cdot 11 \cdot k_{3}}{15}=q_{3}+\frac{1}{15} ;
\end{gathered}
$$

we have, for example, $k_{1}=2, k_{2}=2, k_{8}=8$, and obtain the further results

$$
\begin{aligned}
11 \cdot 15 \cdot 2 & =330, & & 330 \cdot 2=660, \\
15 \cdot 7 \cdot 2 & =210, & 210 \cdot 5 & =1050, \\
7 \cdot 11 \cdot 8 & =616, & 616 \cdot 7 & =4312,
\end{aligned}
$$

$660+1050+4312=6022 ; \quad \frac{6022}{7 \cdot 11 \cdot 15}=5+\frac{247}{7 \cdot 11 \cdot 15} ;$ $x=247$ is then a solution of the given equation. $\dagger$

*Cantor, I., p. 593. +L. Matthiessen in Schlömilch's Zeitschrift, XXVI. 
In the writing of their equations the Chinese make as little use as the Hindus of a sign of equality. The positive coefficients were written in red, the negative in black. As a rule täe is placed beside the absolute term of the equation and yuen beside the coefficient of the first power; the rest can be inferred from the example $14 x^{3}-27 x=17$, * where $r$ and $b$ indicate the color of the coefficient:

\begin{tabular}{|c|c|c|c|}
\hline${ }_{r} 14$ & ${ }_{r} 14$ & or & ${ }_{r} 14$ \\
\hline$r_{r} 00$ & ${ }_{r} 00$ & & ${ }_{r} 00$ \\
\hline${ }_{b} 27 y u e n$ & ${ }_{b}^{27}$ & & ${ }_{b} 27 y u e n$ \\
\hline .17 t $\ddot{a} e$ & ${ }_{r} 17 \mathrm{t} \ddot{a} e$ & & ${ }_{r} 17$. \\
\hline
\end{tabular}

The Arabs were pupils of both the Hindus and the Greeks. They made use of the methods of their Greek and Hindu predecessors and developed them, especially in the direction of methods of calculation. Here we find the origin of the word algebra in the writings of Al Khowarazmi who, in the title of his work, speaks of "al-jabr wa'l muqabalail," i. e., the science of redintegration and equation. This expression denotes two of the principal operations used by the Arabs in the arrangement of equations. When from the equation $x^{3}+r=x^{2}+p x+r$ the new equation $x^{3}=x^{2}+p x$ is formed, this is called al muqabalah; the transformation which gives from the equation $p x-q=x^{2}$ the equation $p x=x^{2}+q$, a transformation which was considered of great importance by the 
ancients, was called al-jabr, and this name was extended to the science which deals in general with equations.

The earlier Arabs wrote out their equations in words, as for example, Al Khowarazmi* (in the Latin translation):

Census et quinque radices equantur viginti quatuor

$$
x^{2}+5 x=24 ;
$$

and Omar Khayyam,

Cubus, latera et numerus aequales sunt quadratis

$$
x^{3}+b x+c=a x^{2} .
$$

In later times there arose among the Arabs quite an extended symbolism. This notation made the most marked progress among the Western Arabs. The unknown $x$ was called jidr, its square mal; from the initials of these words they obtained the abbreviations $x=\dot{\dot{m}}, x^{2}=v$. Quantities which follow directly one after another are added, but a special sign is used to denote subtraction. "Equals" is denoted by the final letter of adala (equality), namely, by means of a final lam. In Al Kalsadi $\uparrow 3 x^{2}=12 x+63$ and $\frac{1}{2} x^{2}+x=7 \frac{1}{2}$ are represented by

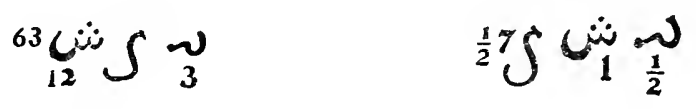

and the proportion $7: 12=84: x$ is given the form ?.. $.84 \cdot \cdot .12 \cdot \cdot 7$. 
Diophantus had already classified equations, not according to their degree, but according to the number of their terms. This principle of classification we find completely developed among the Arabs. According to this principle Al Khowarazmi* forms the following six groups for equations of the first and second degrees :

$x^{2}=a x$ ("a square is equal to roots"),

$x^{2}=a$ ("a square is equal to a constant"),

$a x=b, \quad x^{2}+a x=b, \quad x^{2}+a=b x, \quad a x+b=x^{2}$, ("roots and a constant are equal to a square").

The Arabs knew how to solve equations of the first degree by four different methods, only one of which has particular interest, and that because in modern algebra it has been developed as a method of approximation for equations of higher degree. This method of solution, Hindu in its origin, is found in particular in Ibn al Banna and Al Kalsadi and is there called the method of the scales. It went over into the Latin translations as the regula falsorum and regula falsi. To illustrate, let the equation $a x+b=0$ be givent and let $z_{1}$ and $z_{2}$ be any numerical quantities; then if we place $a z_{1}+b=y_{1}, a z_{2}+b=y_{2}$,

$$
x=\frac{z_{2} y_{1}-z_{1} y_{2}}{y_{1}-y_{2}},
$$

as can readily be seen. Ibn al Banna makes use of the following graphic plan for the calculation of the value of $x$ : 


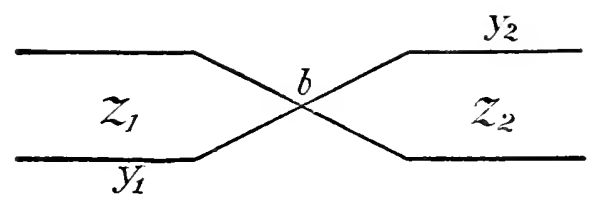

The geometric representation, which with $y$ as a negative quantity somewhat resembles a pair of scales, would be as follows, letting $O B_{1}=z_{1}, O B_{2}=z_{2}, B_{1} C_{1}$ $=y_{1}, B_{2} C_{2}=y_{2}, O A=x$ :

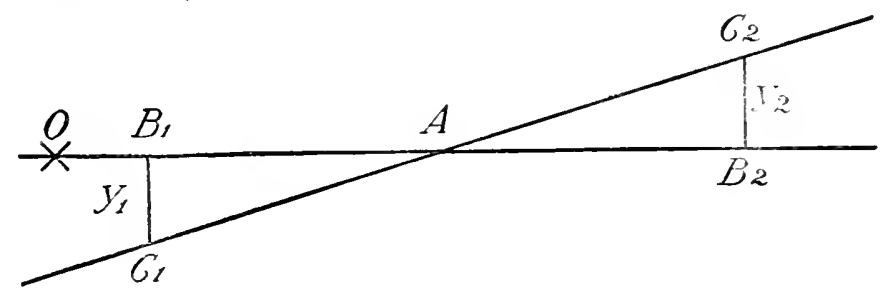

From this there results directly

$$
\frac{x-z_{1}}{x-\frac{z_{2}}{z_{2}}}=\frac{y_{1}}{y_{2}}
$$

that is, that the errors in the substitutions bear to each other the same ratio as the errors in the results, the method apparently being discovered through geometric considerations.

In the case of equations of the second degree $\mathrm{Al}$ Khowarazmi gives in the first place a purely mechanical solution (negative roots being recognised but not admitted), and then a proof by means of a geometric figure. He also undertakes an investigation of the number of solutions. In the case of

$$
x^{2}+c=b x \text {, from which } x=\frac{b}{2} \pm \sqrt{\left(\frac{b}{2}\right)^{2}-c}
$$

Al Khowarazmi obtains two solutions, one or none according as 


$$
\left(\frac{b}{2}\right)^{2}>c, \quad\left(\frac{b}{2}\right)^{2}=c, \quad\left(\frac{b}{2}\right)^{2}<c .
$$

He gives the geometric proof for the correctness of the solution of an equation like $x^{2}+2 x=15$, where he takes $x=3$, in two forms, either by means of a perfectly symmetric figure, or by the gnomon. In the first case, for $A B=x, B C=\frac{1}{2}, B D=1$, we have
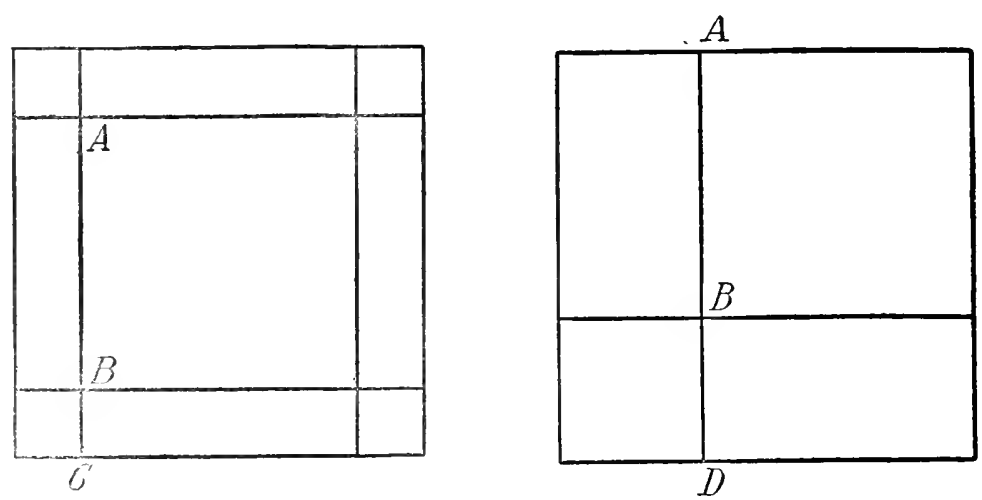

$x^{2}+4 \cdot \frac{1}{2} \cdot x+4 \cdot\left(\frac{1}{2}\right)^{2}=15+1,(x+1)^{2}=16 ;$ in the second we have $x^{2}+2 \cdot 1 \cdot x+1^{2}=15+1$. In the treatment of equations of the form $a x^{2 n} \pm b x^{n} \pm c=0$, the theory of quadratic equations receives still further development at the hands of Al Kalsadi.

Equations of higher degree than the second, in the form in which they presented themselves to the Arabs in the geometric or stereometric problems of the Greek type, were not solved by them arithmetically, but only by geometric methods with the aid of conics. Here Omar Khayyam* proceeded most systematically. He solved the following equations of the third degree geometrically: 
$r=x^{3}, \quad x^{3} \pm p x^{2}=q x, \quad x^{3}+r=q x, \quad x^{3} \pm p x^{2} \pm q x=r$, $q x=x^{3}, \quad x^{3}+q x=p x^{2}, x^{3} \pm p x^{2}=r, x^{3} \pm p x^{2}+r=q x$, $p x^{2}=x^{3}, x^{3} \pm q x=r, \quad x^{3}+r=p x^{2}, x^{3} \pm p x^{2}=q x+r$. The following is the method of expression which he employs in these cases:

"A cube and square are equal to roots;"

"a cube is equal to roots, squares and one number," when the equations

$$
x^{3}+p x^{2}=q x, \quad x^{3}=p x^{2}+q x+r
$$

are to be expressed. Omar calls all binomial forms simple equations; trinomial and quadrinomial forms he calls composite equations. He was unable to solve the latter, even by geometric methods, in case they reached the fourth degree.

The indeterminate analysis of the Arabs must be traced back to Diophantus. In the solution of indeterminate equations of the first and second degree Al Karkhi gives integral and fractional numbers, like Diophantus, and excludes only irrational quantities. The Arabs were familiar with a number of propositions in regard to Pythagorean triangles without having investigated this field in a thoroughly systematic manner.

\section{THE SECOND PERIOD.}

TO THE MIDDLE OF THE SEVENTEENTH CENTURY.

As long as the cultivation of the sciences among the Western peoples was almost entirely confined to 
the monasteries, during a period lasting from the eighth century to the twelfth, no evidence appeared of any progress in the general theory of numbers. As in the learned Roman world after the end of the fifth century, so now men recognised seven liberal arts, - the trivium, embracing grammar, rhetoric and dialectics, and the quadrivium, embracing arithmetic, geometry, music and astronomy.* But through Arab influence, operating in part directly and in part through writings, there followed in Italy and later also in France and Germany a golden age of mathematical activity whose influence is prominent in all the literature of that time. Thus Dante, in the fourth canto of the Divina Commedia mentions among the personages

"... who slow their eyes around

Majestically moved, and in their port

Bore eminent authority,"

a Euclid, a Ptolemy, a Hippocrates and an Avicenna.

There also arose, as a further development of certain famous cloister, cathedral and chapter schools, and in rare instances, independent of them, the first universities, at Paris, Oxford, Bologna, and Cambridge, which in the course of the twelfth century associated the separate faculties, and from the beginning of the thirteenth century became famous as Studia generalia. $\dagger$ Before long universities were also es-

\footnotetext{
* Müller, Historisch-etymologische Studien über mathematische Terminologie, 1887.

t Suter, Die Mathematik auf den Unizersitäten des Mittelalters, I88;.
} 
tablished in Germany (Prague, 1348; Vienna, 1365 ; Heidelberg, 1386 ; Cologne, 1388 ; Erfurt, 1392 ; Leipzig, 1409 ; Rostock, 1419 ; Greifswalde, 1456 ; Basel, 1459 ; Ingolstadt, 1472 ; Tübingen and Mainz, 1477), in which for a long while mathematical instruction constituted merely an appendage to philosophical research. We must look upon Johann von Gmunden as the first professor in a German university to devote himself exclusively to the department of mathematics. From the year 1420 he lectured in Vienna upon mathematical branches only, and no longer upon all departments of philosophy, a practice which was then universal.

\section{General Arithmetic.}

Even Fibonacci made use of words to express mathematical rules, or represented them by means of line-segments. On the other hand, we find that Luca Pacioli, who was far inferior to his predecessor in arithmetic inventiveness, used the abbreviations.p., .m., $R$. for plus, minus, and radix (root). As early as 1484, ten years before Pacioli, Nicolas Chuquet had written a work, in all probability based upon the researches of Oresme, in which there appear not only the signs $\bar{p}$ and $\tilde{m}$ (for plus and minus), but also expressions like

$$
\mathrm{R}^{4} .10, \mathrm{R}^{2} .17 \text { for } \sqrt[4]{10}, \sqrt{17} \text {. }
$$

He also used the Cartesian exponent-notation, and 
the expressions equipolence, equipolent, for equivalence and equivalent. $*$

Distinctively symbolic arithmetic was developed upon German soil. In German general arithmetic and algebra, in the Deutsche Coss, the symbols + and - for plus and minus are characteristic. $\dagger$ They were in common use while the Italian school was still writing $\bar{p}$ and $\tilde{m}$. The earliest known appearance of these signs is in a manuscript (Regula Cose vel Algebre) of the Vienna library, dating from the middle of the fifteenth century. In the beginning of the seventeenth century Reymers and Faulhaber used the sign $\div$, \& and Peter Roth the sign $\because$ as minus signs.

Among the Italians of the thirteenth and fourteenth centuries, in imitation of the Arabs, the course of an arithmetic operation was expressed entirely in words. Nevertheless, abbreviations were gradually introduced and Luca Pacioli was acquainted with such abbreviations to express the first twenty-nine powers of the unknown quantity. In his treatise the absolute term and $x, x^{2}, x^{3}, x^{4}, x^{5}, x^{6}, \ldots$ are always respectively represented by numero or $n^{\circ}, \cos a$ or co, censo or ce, cubo or cu, censo de censo or ce.ce, primo relato or p. ${ }^{\circ}{ }^{\circ}$, censo de cuba or ce.cu...

The Germans made use of symbols of their own

* A. Marre in Boncompagni's Bulletino, XIIl. Jahrbuch ïber die Fortschritte der Math., I88I, p. 8.

†Treutlein, "Die deutsche Coss," Schlömilch's Zeitschrift, Bd. 24, H1. A. Hereafter referred to as Treutlein.

$¥$ The sign $\div$ is first used as a sign of division in Rahn's Teutsche Algebra Zürich, 1659 . 
invention. Rudolff and Riese represented the absolute term and the powers of the unknown quantity in the following manner: Dragma, abbreviated in writing, $\phi$; radix (or coss, i. e., root of the equation) is expressed by a sign resembling an $r$ with a little flourish; zensus by $z$; cubus by $c$ with a long flourish on top in the shape of an $l$ (in the following pages this will be represented merely by $c$ ); zensus de zensu (zensdezens) by $\hat{\jmath} \hat{\jmath}$, sursolidum by $\beta$ or $\tilde{k}$; zensikubus by $z c$; bissursolidum by $\mathfrak{b i} \tilde{i}$ or $\mathfrak{B}_{\mathfrak{B}}$; zensus zensui de zensu (zenszensdezens) by 333 ; cubus de cubo by cc.

There are two opinions concerning the origin of the $x$ of mathematicians. According to the one, it was originally an $r$ (radix) written with a flourish which gradually came to resemble an $x$, while the original meaning was forgotten, so that half a century after Stifel it was read by all mathematicians as $x{ }^{*}$ The other explanation depends upon the fact that it is customary in Spain to represent an Arabic $s$ by a Latin $x$ where whole words and sentences are in question;

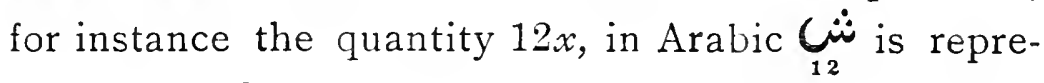
sented by $12 x a i$, more correctly by 12 sai. According to this view, the $x$ of the mathematicians would be an abbreviation of the Arabic sai $=x a i$, an expression for the unknown quantity.

By the older cossists $\uparrow$ these abbreviations are introduced without any explanation; Stifel, however,

\footnotetext{
*Treutleiu. G. Wertheim in Schlömilch's Zeitschrift, Bd. ${ }_{t+}, \mathrm{Hl}$. A.
}

+ Treutlein. 
considers it necessary to give his readers suitable explanations. The word "root," used for the first power of an unknown quantity he explains by means of the geometric progression, "because all successive members of the series develop from the first as from a root"; he puts for $x^{0}, x^{1}, x^{2}, x^{3}, x^{4}, \ldots$ the signs 1 , $1 x, 1_{\mathfrak{z}}, 1 c, 1_{\mathfrak{\jmath} \mathfrak{\jmath}}, \ldots$ and calls these "cossic numbers," which can be continued to infinity, while to each is assigned a definite order-number, that is, an exponent. In the German edition of Rudolff's Coss, Stifel at first writes the "cossic series" to the seventeenth power in the manner already indicated, but also later as follows :

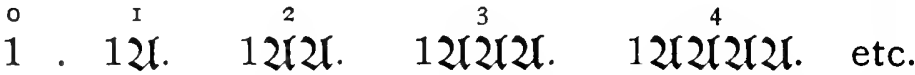

$\mathrm{He}$ also makes use of the letters $\mathcal{B}$ and $\mathcal{C}$ in writing this expression. The nearest approach to our present notation is to be found in Bürgi and Reymers, where with the aid of "exponents" or "characteristics" the polynomial $8 x^{6}+12 x^{5}-9 x^{4}+10 x^{3}+3 x^{2}+7 x-4$ is represented in the following manner:

$$
\stackrel{\mathrm{vI}}{8}+12 \stackrel{\mathrm{v}}{\mathrm{IV}}+1{ }^{\mathrm{II}}+\stackrel{\mathrm{II}}{3}+\frac{\mathrm{I}}{\mathbf{7}}-\stackrel{\circ}{4}
$$

In Scheubel we find for $x, x^{2}, x^{3}, x^{4}, x^{5} \ldots, p r i$, sec., ter., quar., quin., and in Ramus $l, q, c, b q, s$ as abbreviations for latus, quadratus, cubus, biquadratus, solidus.

The product $\left(7 x^{2}-3 x+2\right)(5 x-3)=35 x^{3}-36 x^{2}$ $+19 x-6$ is represented in its development by Gram. mateus, Stifel, and Ramus in the following manner: 
GRAMMATEUS :

7x. $-3 p r i+2 N$

by 5 pri. $-3 N$

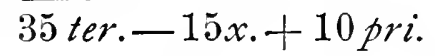

$-21 x+9$ pri. $-6 N$

$\overline{35 \text { ter. }-36 x .+19 \text { pri. }-6 N}$
STIFEL :

$$
\begin{array}{r}
7 z-3 x+2 \\
\frac{5 x-3}{35 c-15 z+10 x} \\
-21 z+9 x-6 \\
\hline 35 c-36 z+19 x-6
\end{array}
$$

RAMUS :

$$
\begin{array}{r}
7 q-3 l+2 \\
5 l-3 \\
\hline 35 c-15 q+10 l \\
-21 q+9 l-6 \\
\hline 35 c-36 q+19 l-6 .
\end{array}
$$

As early as the fifteenth century the German Coss made use of a special symbol to indicate the extraction of the root. At first .4 was used for $\sqrt{4}$; this period placed before the number was soon extended by means of a stroke appended to it. Riese and Rudolff write merely $\sqrt{4}$ for $\sqrt{4}$. Stifel takes the first step towards a more general comprehension of radical quantities in his Arithmetica integra, where the second, third, fourth, fifth, roots of six are represented by $\sqrt{3^{6}, V^{\prime} 6}, \sqrt{3} 3^{6}, \sqrt{\mathfrak{k}^{6}}$, while elsewhere the symbols

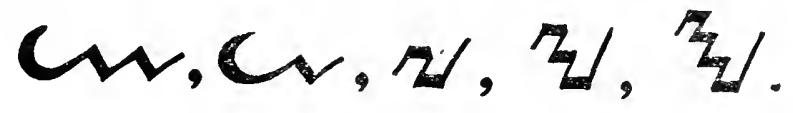

are used as radical signs. These symbols, of which the first two occur in Rudolff and the other three in a work of Stifel, indicate respectively the third, fourth, second, third, and fourth roots of the numbers which they precede. 
Rudolff gives a few rules for operations with radical quantities, but without demonstrations. Like Fibonacci he calls an irrational number a numerus surdus. Such expressions as the following are introduced:

$$
\begin{aligned}
& \sqrt{a} \pm \sqrt{b}=\sqrt{a+b \pm \sqrt{4 a b}} \\
& \sqrt{a^{2} c+1} \bar{b}^{2} c=\sqrt{(a+b)^{2} \cdot c,} \\
& \overline{\sqrt{a} \pm \sqrt{b}}=\frac{x(\sqrt{a}+\sqrt{b})}{a-b} .
\end{aligned}
$$

Stifel enters upon the subject of irrational numbers with especial zeal and even refers to the speculations of Euclid, but preserves in all his developments a well-grounded independence. Stifel distinguishes two classes of irrational numbers: principal and subordinate (Houpt-und Nebenarten). In the first class are included (1) simple irrational numbers of the form $\sqrt[n]{a},(2)$ binomial irrationals with the positive sign, as

$$
\sqrt{3} 3^{10}+\sqrt{33^{6}}, 4+\sqrt{ } 3^{6}, \sqrt{ } 3^{12}+\sqrt{ } / 12,
$$

(3) square roots of such binomial irrationals as

$$
\begin{gathered}
\sqrt{3} \cdot \sqrt{3^{6}+\sqrt{ } 3^{8}}=\sqrt{\sqrt{\overline{6}}+\sqrt{\overline{8}}} ; \\
\sqrt{3} \cdot 5+\sqrt{3^{5}}=\sqrt{5+\sqrt{5}},
\end{gathered}
$$

(4) binomial irrationals with the negative sign, as $\sqrt{3} 3^{10}-\sqrt{3} 3^{6}$, and $(5)$ square roots of such binomial irrationals, as

$$
\sqrt{3} \cdot \sqrt{ } 3^{6}-\sqrt{3^{8}}=\sqrt{\sqrt{6}-\sqrt{\overline{8}}}
$$

The subordinate class of irrational quantities, according to Stifel, includes expressions like 


$$
\begin{aligned}
& \sqrt{ }^{\prime} 3^{2}+\sqrt{ } 3^{3}+\sqrt{ } 3^{5}, \sqrt{ } 3^{2}+\sqrt{ } / 3^{4}+\sqrt{ } / c 3,
\end{aligned}
$$

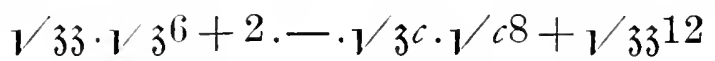

$$
\begin{aligned}
& =\sqrt[4]{\sqrt{6}+2}-\sqrt[6]{\sqrt[3]{8}+\sqrt[4]{12}}
\end{aligned}
$$

Fibonacci evidently obtained his knowledge of negative quantities from the Arabs, and like them he does not admit negative quantities as the roots of an equation. Pacioli enunciates the rule, minus times minus gives aiways plus, but he makes use of it only for the expansion of expressions of the form $(p-q)$ $(r-s)$. Cardan proceeds in the same way; he recognises negative roots of an equation, but he calls them aestimationes falsae or fictae, * and attaches to them no independent significance. Stifel calls negative quantities numeri absurdi. Harriot is the first to consider negative quantities in themselves, allowing them to form one side of an equation. Calculations involving negative quantities consequently do not begin until the seventeenth century. It is the same with irrational numbers; Stifel is the first to include them among numbers proper.

Imaginary quantities are scarcely mentioned. Cardan incidentally proves that

$$
(5+\sqrt{-15}) \cdot(5-\sqrt{-\overline{15}})=40 .
$$

Bombelli goes considerably farther. Although not entering into the nature of imaginary quantities, of which he calls $+\sqrt{-1}$ piu di meno, and $-\sqrt{-1}$ meno di meno, he gives rules for the treatment of ex- 
pressions of the form $a+b \sqrt{-1}$, as they occur in the solution of the cubic equation.

The Italian school early made considerable advancement in calculations involving powers. Nicole Oresme* had long since instituted calculations with fractional exponents. In his notation

$$
\frac{1}{2} \cdot 1^{\not \frac{2}{3}}=\left(1 \frac{2}{3}\right)^{\frac{1}{2}}, \frac{1}{4} \cdot 2^{\dagger} \frac{1}{2}=\left(2 \frac{1}{2}\right)^{\frac{1}{4}}
$$

it appears that he was familiar with the formulæ

$$
a^{\frac{m}{n}}=\left(\alpha^{m}\right)^{\frac{1}{n}}, a^{\frac{1}{m}} \cdot \beta^{\frac{1}{n}}=\left(\alpha^{n} \cdot \beta^{m}\right)^{\frac{1}{m n}}, a^{\frac{1}{m}}: \beta^{\frac{1}{n}}=\left(\frac{\alpha^{n}}{\beta^{m}}\right)^{\frac{1}{m n}} \text {. }
$$

In the transformation of roots Cardan made the first important advance by writing

$$
\sqrt[3]{a+\sqrt{\bar{b}}}=p+\sqrt{\bar{q}}, \quad \sqrt[3]{a-\sqrt{\bar{b}}}=p-\sqrt{\bar{q}}
$$

and therefore $\sqrt[3]{a^{2}-b}=p^{2}-q=c, a^{2}-b=c^{3}$. Bombelli $\dagger$ enlarged upon this observation and wrote $\sqrt[3]{a+\sqrt{-b}}=p+\sqrt{-q}, \quad \sqrt[3]{a-\sqrt{-b}}=p-\sqrt{-q}$, from which follows $\sqrt[3]{a^{2}+b}=p^{2}+q$. With reference to the equation $x^{3}=15 x+4$ he discovered that

$$
\begin{aligned}
x & =\sqrt[3]{2+\sqrt{-121}}+\sqrt[3]{2-\sqrt{-121}} \\
& =2+\sqrt{-1}+2-\sqrt{-1}=4 .
\end{aligned}
$$

For in this case

$$
\begin{gathered}
p^{2}+q=5, \quad(p+\sqrt{=q})^{3}=2+\sqrt{-121}, \\
(p-\sqrt{-q})^{3}=2-\sqrt{-121},
\end{gathered}
$$

become through addition $p^{3}-3 p q=2$, and with $q=$ $5-p^{2}, 4 p^{3}-15 p=2$, and consequently (by trial) $p=2$ and $q=1$. 
The extraction of square and cube roots according to the Arab, or rather the Indian, method, was set forth by Grammateus. In the process of extracting the square root, for the purpose of dividing the number into periods, points are placed over the first, third, fifth, etc., figures, counting from right to left. Stifel* developed the extracting of roots to a considerable extent; it is undoubtedly for this purpose that he worked out a table of binomial coefficients as far as $(a+b)^{\mathbf{1 7}}$, in which, for example, the line for $(a+b)^{4}$ reads :

$$
\begin{array}{lllllll}
133 & \cdot & 4 & 6 & 4 & 1
\end{array} \text {. }
$$

The theory of series in this period made no advance upon the knowledge of the Arabs. Peurbach found the sum of the arithmetic and the geometric progressions. Stifel examined the series of natural numbers, of even and of odd numbers and deduced from them certain power series. In regard to these series he was familiar, through Cardan, with the theorem that $1+2+2^{2}+2^{3}+\ldots+2^{n-1}=2^{n}-1$. With Stifel geometric progressions appear in an application which is not found in Euclid's treatment of means. $\dagger$ As is well known, $n$ geometric means are inserted between the two quantities $a$ and $b$ by means of the equations

$$
\frac{a}{x_{1}}=\frac{x_{1}}{x_{2}}=\frac{x_{2}}{x_{3}}=\ldots=\frac{x_{n-1}}{x_{n}}=\frac{x_{n}}{b}=q
$$


where $q=n+1 / \frac{a}{b}$. Stifel inserts five geometric means between the numbers 6 and 18 in the following manner :

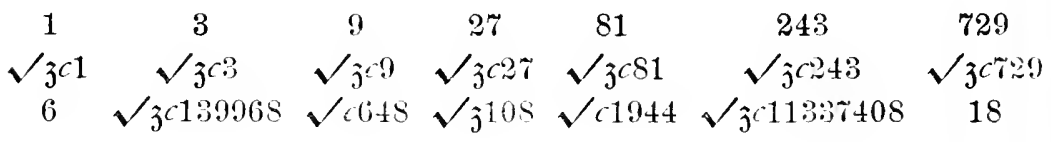
in which the last line is obtained from the preceding by multiplying by 6 . Stifel makes use of this solution for the purpose of duplicating the cube. He selects 6 for the edge of the given cube; three geometric means are to be inserted between 6 and 12 , and as $q=7^{3 / \frac{1}{2}}$, the edge of the required cube will be $x=6 \sqrt[3]{2}=$ $1 \overline{c 432}$. This length is constructed geometrically by Stifel in the following manner:

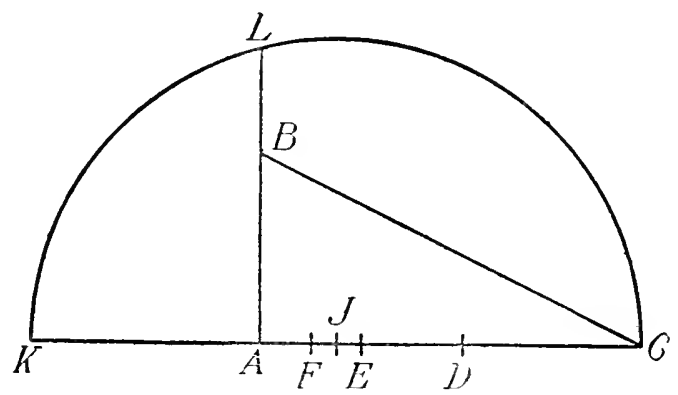

In the right angled triangle $A C B$, with the hypotenuse $B C$, let $A B=6, A C=12$; make $A D=D C, A E=$ $E D, A F=F E, F J=J E, J K=J C=J L$. Then $A K^{\circ}$ is the first, $A L$ the second geometric mean between 6 and 12. This construction, which Stifel regards as entirely correct, is only an approximation, since $A K=7.5$ instead of $6 \gamma^{3} \overline{2}=7.56, A L=3 \sqrt{10}=9.457$ instead of $61^{3 / 4}=9.524$. 
Simple facts involving the theory of numbers were also known to Stifel, such as theorems relating to perfect and diametral numbers and to magic squares.

A diametral number is the product of two numbers the sum of whose squares is a rational square, the square of the diameter, e. g., $65^{2}=25^{2}+60^{2}=39^{2}+$ $52^{2}$, and hence $25.60=1500$ and $39.52=2028$ are diametral numbers of equal diameter.

\begin{tabular}{|c|c|c|c|c|}
\hline 11 & 24 & 7 & 20 & 3 \\
\hline 4 & 12 & 25 & 8 & 16 \\
\hline 17 & 5 & 13 & 21 & 9 \\
\hline 10 & 18 & 1 & 14 & 22 \\
\hline 23 & 6 & 19 & 2 & 15 \\
\hline
\end{tabular}

Magic squares are figures resembling a chess board, in which the terms of an arithmetic progression are so arranged that their sum, whether taken diagonally or by rows or columns, is always the same. A magic square containing an odd number of cells, which is easier to construct than one containing an even number, can be obtained in the following manner: Place 1 in the cell beneath the central one, and the other numbers, in their natural order, in the empty cells in a diagonal direction. Upon coming to a cell 
already occupied, pass vertically downwards over two cells. * Possibly magic squares were known to the Hindus; but of this there is no certain evidence. $\nmid$ Manuel Moschopulus $\ddagger$ (probably in the fourteenth century) touched upon the subject of magic squares. He gave definite rules for the construction of these figures, which long after found a wider diffusion through Lahire and Mollweide. During the Middle Ages magic squares formed a part of the wide-spread numbermysticism. Stifel was the first to investigate them in a scientific way, although Adam Riese had already introduced the subject into Germany, but neither he nor Riese was able to give a simple rule for their construction. We may nevertheless assume that towards the end of the sixteenth century such rules were known to a few German mathematicians, $\S$ as for instance, to the Rechenmeister of Nuremberg, Peter Roth. In the year 1612 Bachet published in his Problemes plaisants a general rule for squares containing an odd number of cells, but acknowledged that he had not succeeded in finding a solution for squares containing an even number. Frénicle was the first to make a real advance beyond Bachet. He gave rules (1693) for both classes of squares, and even discovered squares that maintain their characteristics after striking off th

\footnotetext{
* Unger, p. Iog.

$\dagger$ Montucla, Histoire des Mathématiques, 1799-1802.

$\ddagger$ Cantor, I., p. 480 .

§Giesing, Leben und Schriften Leonardo's da Pisa, 1886.

$\|$ This work is now accessible in a new edition published in $188_{4}$, Paris. Gauthier-Villars.
} 
outer rows and columns. In 1816 Mollweide collected the scattered rules into a book, De quadratis magicis, which is distinguished by its simplicity and scientific form. More modern works are due to Hugel (Ansbach, 1859), to Pessl (Amberg, 1872), who also considers a magic cylinder, and to Thompson (Quarterly Journal of Mathematics, Vol. X.), by whose rules the magic square with the side $p n$ is deduced from the square with the side $n . *$

\section{Algebra.}

Towards the end of the Middle Ages the Ars major, Arte maggiore, Algebra or the Coss is opposed to the ordinary arithmetic (Ars minor). The Italians called the theory of equations either simply Algebra, like the Arabs, or Ars magna, Ars rei et census (very common after the time of Leonardo and fully settled in Regiomontanus), La regola della cosa (cosa = res, thing), Ars cossica or Regula cosae. The German algebraists of the fifteenth and sixteenth centuries called it Coss, Regula Coss, Algebra, or, like the Greeks, Logistic. Vieta used the term Arithmetica speciosa, and Reymers Arithmetica analytica, giving the section treating of equations the special title von der Aequation. The method of representing equations gradually took on the modern form. Equality was generally, even by the cossists, expressed by words; it was not until the middle of the seventeenth century that a special sym-

* Günther, “Ueber magische Quadrate," Grunert's Arch., Bd. 57. 
bol came into common use. The following are examples of the different methods of representing equations :*

Cardan :

Cubus $\bar{p} 6$ rebus aequalis $20, \quad x^{3}+6 x=20 ;$ Vieta :

$$
1 C-8 Q+16 N \text { aequ. } 40, x^{3}-8 x^{2}+16 x=40 ;
$$

Regiomontanus :

16 census et 2000 aequ. 680 rebus, $16 x^{2}+2000=$ $680 x$;

Reymers :

$$
\begin{aligned}
& \begin{array}{lllllll}
\text { XXVIII XII } & \mathrm{X} & \text { VI } & \text { III } & \mathbf{I} & \mathrm{O}
\end{array} \\
& 1 \text { gr } 65532+18 \div 30 \div 18+12 \div 8 \text {; } \\
& x^{28}=65532 x^{12}+18 x^{10}-30 x^{6}-18 x^{3}+12 x-8 ;
\end{aligned}
$$

Descartes:

$$
\begin{aligned}
& z^{2}-\infty a z-b b \\
& z^{2}=a z-b^{2} \\
& y^{4}-8 y^{3}-1 y y+8 y^{*} x_{0} 0, \quad y^{4}-8 y^{3}-y^{2}+8 y=0 \text {; } \\
& x^{6} * * * *-b x \text { so } 0, x^{6}-b x=0 \text {; } \\
& x^{5 * * * * *-b} \text { so } 0, x^{5}-b \quad=0 \text {; }
\end{aligned}
$$

Hudde :

$$
x^{3} \text { so qx.r, } \quad x^{3}=q x+r .
$$

In Euler's time the last transformation in the development of the modern form had already been accom. plished.

Equations of the first degree offer no occasion for remark. We may nevertheless call attention to the peculiar form of the proportion which is found in Grammateus and Apian. $\dagger$ The former writes : "Wie

* Matthiessen, Grundzüge der antiken und modernen Algebra, 2 ed., 1896, p. 270 , etc.

† Gerhardt, Geschichte der Mathematik in Deutschland, 1877. 
sich hadt $a$ zum $b$, also hat sich $c$ zum $d$, "and the latter places

$$
4-12-9-0 \text { for } \frac{4}{12}=\frac{9}{x} \text {. }
$$

Leonardo of Pisa solved equations of the second degree in identically the same way as the Arabs.* Cardan recognized two roots of a quadratic equation, even when one of them was negative; but he did not regard such a root as forming an actual solution. Rudolff recognized only positive roots, and Stifel stated explicitly that, with the exception of the case of quadratic equations with two positive roots, no equation can have more than one root. In general, the solution was affected in the manner laid down by Grammateus $\nmid$ in the example $12 x+2 t=2 \frac{10}{4} x^{2}$ : "Proceed thus: divide $24 N$ by $2 \frac{10}{49}$ sec., which gives $10 \frac{8}{9} a$ $\left(10 \frac{8}{9}=a\right)$. Also divide 12 pri. by $2 \frac{10}{49}$ sec., which gives the result $5 \frac{4}{9} b\left(5 \frac{4}{9}=b\right)$. Square the half of $b$, which gives $\frac{2+01}{32} 4$, to which add $a=10 \frac{8}{4}$, giving $\frac{5929}{324}$, of which the square root is $\frac{77}{18}$. Add this to $\frac{1}{2}$ of $b$, or $\frac{46}{1}$, and 7 is the number represented by 1 pri. Proof : $12 \times 7 N=84 N ;$ add $24 N,=108 N$. $2 \frac{1}{4} \frac{0}{9}$ sec. multiplied by 49 must also give $108 N$."

This "German Coss" was certainly cultivated by Hans Berneclier in Leipzig and by Hans Conrad in Eisleben $\$$ (about I525), yet no memoranda by either of these mathematicians have been found. The University of Vienna encouraged Grammateus to publish,

* Cantor, II., p. 3 I. $\quad$ Gerhardt. $\quad$ Cantor, 1I. p. 387. 
in the year 1523, the first German treatise on Algebra under the title, "Eyn new kunstlich behend vnd gewiss Rechenbüchlin | vff alle Kauffmannschafft. Nach Gemeynen Regeln de tre. Welschen practic. Regeln falsi. Etlichen Regeln Cosse.. Buchhalten.. Visier Ruthen zu machen." Adam Riese, who bad published his Arithmetic in 1518, completed in 1524 the manuscript of the Coss; but it remained in manuscript and was not found until 1855 in Marienberg. The Coss published by Christoff Rudolff in 1525 in Strassburg met with universal favor. This work, which is provided with many examples, all completely solved, is described in the following words :

"Behend vnd Hübsch Rechnung durch die kunstreichen regeln Algebre | so gemeinicklich die Coss genennt werden. Darinnen alles so treulich an Tag geben / das auch allein ausz vleissigem Lesen on allen mündtliche vnterricht mag begriffen werden. Hindangesetzt die meinung aller dere / so bisher vil vngegründten regeln angehangen. Einem jeden liebhaber diser kunst lustig vnd ergetzlich Zusamen bracht durch Christoffen Rudolff von Jawer."*

The principal work of the German Coss is Michael Stifel's Arithmetica integra, published in Nuremberg in 1544. In this book, besides the more common operations of arithmetic, not only are irrational quantities treated at length, but there are also to be found appli-

* A translation would read somewhat as follows: "Rapid and neat computation by means of the ingenious rules of algebra, commonly designated the Coss. Wherein are faithfully elucidated all things in such wise that they may be comprehended from diligent reading alone, without any oral instruction whatsoever. In disregard of the opinions of all those who hitherto have adhered to numerous unfounded rules. Happily and divertingly collected for lovers of this art, by Christoff Rudolff, of Jauer." 
cations of algebra to geometry. Stifel also published in 1553 Die Cosz Christoffs Rudolffs mit schönen Exempeln der Cosz Gebessert ond sehr gemehrt, with copious appendices of his own, giving compendia of the Coss. With pardonable self-appreciation Stifel asserts, "It is my purpose in such matters (as far as I am able) from complexity to produce simplicity. Therefore from many rules of the Coss I have formed a single rule and from the many methods for roots have also established one uniform method for the innumerable cases."

Stifel's writings were laid under great contribution by later writers on mathematics in widely distant lands, usually with no mention of his name. This was done in the second half of the sixteenth century by the Germans Christoph Clavius and Scheubel, by the Frenchmen Ramus, Peletier, and Salignac, by the Dutchman Menher, and by the Spaniard Nuñez. It can, therefore, be said that by the end of the sixteenth century or the beginning of the seventeenth the spirit of the German Coss dominated the Algebra of all the European lands, with the single exception of Italy.

The history of the purely arithmetical solution of equations of the third and fourth degrees which was successfully worked out upon Italian soil demands marked attention. Fibonacci (Leonardo of Pisa)* made the first advance in this direction in connection

*Cantor, II., p. 43 
with the equation $x^{3}+2 x^{2}+10 x=20$. Although he succeeded in solving this only approximately, it furnished him with the opportunity of proving that the value of $x$ cannot be represented by square roots alone, even when the latter are chosen in compound form, like

$$
\sqrt{\sqrt{m} \pm \sqrt{n}}
$$

The first complete solution of the equation $x^{3}+m x=n$ is due to Scipione del Ferro, but it is lost.* The second discoverer is not Cardan, but Tartaglia. On the twelfth of February, 1535, he gave the formula for the solution of the equation $x^{3}+m x=n$, which has since become so famous under the name of his rival. By 1541 Tartaglia was able to solve any equation whatsoever of the third degree. In 1539 Cardan enticed his opponent Tartaglia to his house in Milan and importuned him until the latter finally confided his method under the pledge of secrecy. Cardan broke his word, publishing Tartaglia's solution in 1545 in his Ars magna, although not without some mention of the name of the discoverer. Cardan also had the satisfaction of giving to his contemporaries, in his Ars magna, the solution of the biquadratic equation which his pupil Ferrari had succeeded in obtaining. Bombelli is to be credited with representing the roots of the equation of the third degree in the simplest form, in the so-called irreducible case, by means of a transformation of the irrational quantities. Of the German

* Hankel, p. 360 . 
mathematicians, Rudolff also solved a few equations of the third degree, but without explaining the method which he followed. Stifel by this time was able to give a brief account of the "cubicoss," that is, the theory of equations of the third degree as given in Cardan's work. The first complete exposition of the Tartaglian solution of equations of the third degree comes from the pen of Faulhaber (1604).

The older cossists* had arranged equations of the first, second, third, and fourth degrees (in so far as they allow of a solution by means of square roots alone) in a table containing twenty-four different forms. The peculiar form of these rules, that is, of the equations with their solutions, can be seen in the following examples taken from Riese:

"The first rule is when the root [of the equation] is equal to a number, or dragma so called. Divide by the number of roots; the result of this division must answer the question." (I. e., if $a x=b$, then $x=\frac{b}{a}$.)

"The sixteenth rule is when squares equal cubes and fourth powers. Divide through by the number of fourth powers [the coefficient of $x^{4}$ ], then take half the number of cubes and multiply this by itself, add this product to the number of squares, extract the square root, and from the result take half the number of cubes. Then you have the answer." 
Taking this step by step we have,

$$
\begin{aligned}
& a x^{4}+b x^{3}=c x^{2}, \quad x^{4}+\frac{b}{a} x^{3}=\frac{c}{a} x^{2}, \text { or } \\
& x^{4}+a x^{3}=\beta x^{2}, \quad x=\sqrt{\left(\frac{a}{2}\right)^{2}+\beta-\frac{\alpha}{2} .}
\end{aligned}
$$

The twenty-four forms of the older cossists are reduced by Riese to "acht equationes" (eight equations, as his combination of German and Latin means), but as to the fact that the square root is two-valued he is not at all clear. Stifel was the first to let a single equation stand for these eight, and he expressly asserts that a quadratic can have only two roots; this he asserts, however, only for the equation $x^{2}=a x-b$. In order to reduce the equations above mentioned to one of Riese's eight forms, Rudolff availed himself of "four precautions (Cautelen)," from which it is clearly seen what labor it cost to develop the coss step by step. For example, here is his

"First precaution. When in equating two numbers, in the one is found a quantity, and in the other is found one of the same name, then (considering the signs + and - ) must one of these quantities be added to or subtracted from the other, one at a time, care being had to make up for the defect in the equated numbers by subtracting the + and adding the -." (I. e., from $5 x^{2}-3 x+4=2 x^{2}+5 x$, we derive $3 x^{2}+$ $4=8 x$.)

The first examples of this period, of equations with more than one unknown quantity, are met with 
in Rudolff, * who treats them only incidentally. Here also Stifel went decidedly beyond his predecessors. Besides the first unknown, $1 x$, he introduced $1 A, 1 B$, $1 C$, . . as secundae radices or additional unknowns and indicated the new notation made necessary in the performance of the fundamental operations, as $8 x \mathrm{~A}$ $(=8 x y), 1 A z\left(=y^{2}\right)$, and several others.

Cardan, over whose name a shadow has been cast by his selfishness in his intercourse with Tartaglia, is still deserving of credit, particularly for his approximate solution of equations of higher degrees by means of the regula falsi which he calls regula aurea. Vieta went farther in this direction and evolved a method of approximating the solution of algebraic equations of any degree whatsoever, the method improved by Newton and commonly ascribed to him. Reymers and Bürgi also contributed to these methods of approximation, using the regula falsi. We can therefore say that by the beginning of the seventeenth century there were practical methods at hand for calculating the positive real roots of algebraic equations to any desired degree of exactness.

The real theory of algebraic equations is especially due to Vieta. He understood (admitting only positive roots) the relation of the coefficients of equations of the second and third degree to their roots, and also made the surprising discovery that a certain equation of the forty-fifth degree, which had arisen in trig- 
onometric work, possessed twenty-three roots (in this enumeration he neglected the negative sine). In German writings there are also found isolated statements concerning the analytic theory of equations; for example, Bürgi recognized the connection of a change of sign with a root of the equation. However unimportant these first approaches to modern theories may appear, they prepared the way for ideas which became dominant in later times.

\section{THIRD PERIOD.}

FROM THE MIDDLE OF THE SEVENTEENTH CENTURY TO THE PRESENT TIME.

The founding of academies and of royal societies characterizes the opening of this period, and is the external sign of an increasing activity in the field of mathematical sciences. The oldest learned society, the Accademia dei Lincei, was organized upon the suggestion of a Roman gentleman, the Duke of Cesi, as early as 1603, and numbered, among other famous members, Galileo. The Royal Society of London was founded in 1660, the Paris Academy in 1666, and the Academy of Berlin in 1700.*

With the progressive development of pure mathematics the contrast between arithmetic, which has to do with discrete quantities, and algebra, which relates rather to continuous quantities, grew more and more

*Cantor, III., pp. 7, 29. 
marked. Investigations in algebra as well as in the theory of numbers attained in the course of time great proportions.

The mighty impulse which Vieta's investigations had given influenced particularly the works of Harriot. Building upon Vieta's discoveries, he gave in his Artis analyticae praxis, published posthumously in the year 1631, a theory of equations, in which the system of notation was also materially improved. The signs $>$ and < for "greater than" and "less than" originated with Harriot, and he always wrote $x^{2}$ for $x x$ and $x^{3}$ for $x x x$, etc. The sign $\times$ for "times" is found almost simultaneously in both Harriot and Oughtred, though due to the latter; Descartes used a period to indicate multiplication, while Leibnitz in 1686 indicated multiplication by $\frown$ and division by $\smile$, although already in the writings of the Arabs the quotient of $a$ divided by $b$ had appeared in the forms $a-b, a / b$, or $\frac{a}{b}$. The form $a: b$ is used for the first time by Clairaut in a work which was published posthumously in the year 1760. Wallis made use in 1655 of the sign $\infty$ to indicate infinity. Descartes made extensive use of the the form $a^{n}$ (for positive integral exponents). Wallis explained the expressions $x^{-n}$ and $x^{\frac{1}{n}}$ as indicating the same thing as $1: x^{n}$ and $\sqrt[n]{x}$ respectively; but Leibnitz and Newton were the first to recognize the great importance of, and to suggest, a consistent system of notation. 
The powers of a binomial engaged the attention of Pascal in his correspondence with Fermat in 1654,* which contains the "arithmetic triangle," although, in its essential nature at least, it had been suggested by Stifel more than a hundred years before. This arithmetic triangle is a table of binomial coefficients arranged in the following form:

$\begin{array}{rrrrrrrr}1 & 1 & 1 & 1 & 1 & 1 & . & . \\ 1 & 2 & 3 & 4 & 5 & 6 & . & . \\ 1 & .3 & 6 & 10 & 15 & 21 & . & . \\ 1 & 4 & 10 & 20 & 35 & 56 & . & . \\ 1 & 5 & 15 & 35 & 70 & 126 & . & . \\ 1 & 6 & 21 & 56 & 126 & 252 & . & . \\ . & . & . & . & . & . & . & . \\ . & . & . & . & . & . & . & .\end{array}$

so that the $n$th diagonal, extending upwards from left to right contains the coefficients of the expansion of $(a+b)^{n}$. Pascal used this table for developing figurate numbers and the combinations of a given number of elements. Newton generalized the binomial formula in 1669, Vandermonde gave an elementary proof in 1764, and Euler in 1770 in his Anleitung zur Algebra gave a proof for any desired exponent.

A series of interesting investigations, for the most part belonging to the second half of the nineteenth century, relates to the nature of number and the extension of the number-concept. While among the ancients a "number" meant one of the series of natural 
numbers only, in the course of time the fundamental operations of arithmetic have been extended from whole to fractional, from positive to negative, from rational and real to irrational and imaginary numbers.

For the addition of natural, or integral absolute, numbers, which by Newton and Cauchy are often termed merely " numbers," the associative and commutative laws hold true, that is,

$$
a+b+c=a+(b+c), a+b+c=a+c+b .
$$

Their multiplication obeys the associative, commutative, and distributive laws, so that

$$
a b c=(a b) c ; a b=b a ;(a+b) c=a c+b c .
$$

To these direct operations correspond, as inverses, subtraction and division. The application of these operations to all natural numbers necessitates the introduction of the zero and of negative and fractional numbers, thus forming the great domain of rational numbers, within which these operations are always valid, if we except the one case of division by zero.

This extension of the number-system showed itself in the sixteenth century in the introduction of negative quantities. Vieta distinguished affirmative (positive) and negative quantities. But Descartes was the first to venture, in his geometry, to use the same letter for both positive and negative quantities.

The irrational had been incorporated by Euclid into the mathematical system upon a geometric basis, this plan being followed for many centuries. Indeed 
it was not until the most modern times* that a purely arithmetic theory of irrational numbers was produced through the researches of Weierstrass, Dedekind, G. Cantor, and Heine.

Weierstrass proceeds from the concept of the whole number. A numerical quantity consists of a series of objects of the same kind; a number is therefore nothing more than the "combined representation of one and one and one, etc." tion and division we arrive at negative and fractional numbers. Among the latter there are certain numbers which, if referred to one particular system, for example to our decimal system, consist of an infinite number of elements, but by transformation can be made equal to others arising from the combination of a finite number of elements (e. g., $0.1333 \ldots=\frac{2}{15}$ ). These numbers are capable of still another interpretation. But it can be proved that every number formed from an infinite number of elements of a known species, and which contains a known finite number of those elements, possesses a very definite meaning, whether it is capable of actual expression or not. When a number of this kind can only be represented by the infinite number of its elements, and in no other way, it is an irrational number.

Dedekind $\$$ arranges all positive and negative, in-

* Stolz, lorlesungen ïber allgemeine Arithmetik, 1885-1886.

+ Kossak, Die Eleminte der Arithmetik, 1872.

$¥$ Rösler, Die neueren Definitionsformen der irrationalen Zahlen, 1886 .

$\$$ Dedekind, stitigheit und irrationale Zahlen, I872. 
tegral and fractional numbers, according to their magnitude, in a system or in a body of numbers (Zahlen körper), $R$. A given number, $a$, divides this system into the two classes, $A_{1}$ and $A_{2}$, each containing infinitely many numbers, so that every number in $A_{1}$ is less than every number in $A_{2}$. Then $a$ is either the greatest number in $A_{1}$ or the least in $A_{2}$. These rational numbers can be put into a one-to-one correspondence with the points of a straight line. It is then evident that this straight line contains an infinite number of other points than those which correspond to rational numbers, that is, the system of rational numbers does not possess the same continuity as the straight line, a continuity possible only by the introduction of new numbers. According to Dedekind the essence of continuity is contained in the following axiom : "If all the points of a straight line are divided into two classes such that every point of the first class lies to the left of every point of the second, then there exists one point and only one which effects this division of all points into two classes, this separation of the straight line into two parts." With this assumption it becomes possible to create irrational numbers. A rational number, $a$, produces a Schnitt or section $\left(A_{1} \mid A_{2}\right)$, with respect to $A_{1}$ and $A_{2}$, with the characteristic property that there is in $A_{1}$ a greatest, or in $A_{2}$ a least number, $a$. To every one of the infinitely many points of the straight line which are not covered by rational numbers, or in which the straight line is 
not cut by a rational number, there corresponds one and only one section $\left(A_{1} \mid A_{2}\right)$, and each one of these sections defines one and only one irrational number $a$.

In consequence of these distinctions " the system $R$ constitutes an organized domain of all real numbers of one dimension; by this no more is meant to be said than that the following laws govern :*

I. If $a>\beta$, and $\beta>\gamma$, then $a$ is also $>\gamma$; that is, the number $\beta$ lies between the numbers $\alpha, \gamma$.

II. If $a, \gamma$ are two distinct numbers, then there are infinitely many distinct numbers $\beta$ which lie between $a$ and $\gamma$.

III. If $a$ is a definite number, then all numbers of the system $R$ fall into two classes, $A_{1}$ and $A_{2}$, each of which contains infinitely many distinct numbers; the first class $A_{1}$ contains all numbers $a_{1}$ which are $\left\langle a\right.$; the second class $A_{2}$ contains all numbers $a_{2}$ which are $>a$; the number $a$ itself can be assigned indifferently to either the first or the second class and it is then respectively either the greatest number of the first class, or the least of the second. In every case, the separation of the system $R$ into the two classes $A_{1}$ and $A_{2}$ is such that every number of the first class $A_{1}$ is less than every number of the second class $A_{2}$, and we affirm that this separation is effected by the number $a$.

IV. If the system $R$ of all real numbers is separated into two classes, $A_{1}, A_{2}$, such that every number $\alpha_{1}$, of the class $A_{1}$ is less than every number $a_{2}$ of the class $A_{2}$, then there exists one and only one number $a$ by which this separation is effected (the domain $R$ possesses the property of continuity)."

According to the assertion of $\mathrm{J}$. Tanneryt the fundamenta; ideas of Dedekind's theory had already appeared in J. Bertrand's text-books of arithmetic and algebra, a statement denied by Dedt kind. $f$

* Dedekind, Stetigkeit und irrationale Zahlen, 1872.

+Stolz, Vorlesungen über allgemeine Arithmetik, 1885-1886.

¥Dedekind, Was sind und was sollen die Zahlen? 1888. 
G. Cantor and Heine* introduce irrational numbers through the concept of a fundamental series. Such a series consists of infinitely many rational numbers, $a_{1}, a_{2}, a_{3}, \ldots . a_{n+r}, \ldots$, and it possesses the property that for an assumed positive number $\epsilon$, however small, there is an index $n$, so that for $n \geqq n_{1}$ the absolute value of the difference between the term $a_{n}$ and any following term is smaller than $\epsilon$ (condition of the convergency of the series of the $a^{\prime}$ s). Any two fundamental series can be compared with each other to determine whether they are equal or which is the ¿reater or the less; they thus acquire the definiteness of a number in the ordinary sense. A number defined by a fundamental series is called a "series number." A series number is either identical with a rational number, or not identical; in the latter case it defines an irrational number. The domain of series numbers consists of the totality of all rational and irrational numbers, that is to say, of all real numbers, and of these only. In this case the domain of real numbers can be associated with a straight line, as G. Cantor has shown.

The extension of the number-domain by the addition of imaginary quantities is closely connected with the solution of equations, especially those of the third degree. The Italian algebraists of the sixteenth century called them "impossible numbers." As proper solutions of an equation, imaginary quantities first

* Rösler, Die neueren Definitionsformen der irrationalen Zahlen, i 886. 
appear in the writings of Albert Girard* (1629). The expressions "real" and "imaginary" as characteristic terms for the difference in nature of the roots of an equation are due to Descartes. $\dagger$ De Moivre and Lambert introduced imaginary quantities into trigonometry, the former by means of his famous proposition concerning the power $(\cos \phi+i \sin \phi)^{n}$, first given in its present form by Euler.

Gauss $\S$ added to his great fame by explaining the nature of imaginary quantities. He brought into general use the sign $i$ for $V-1$ first suggested by Euler; ll he calls $a+b i$ a complex number with the norm $a^{2}+b^{2}$. The term "modulus" for the quantity $\sqrt{a^{2}+b^{2}}$ comes from Argand (1814), the term "reduced form" for $r(\cos \phi+i \sin \phi)$, which equals $a+b i$, is due to Cauchy, and the name "direction coefficient" for the factor $\cos \phi+i \sin \phi$ first appeared in print in an essay of Hankel's (1861), although it was in use somewhat earlier. Gauss, to whom in 1799 it seemed simply advisable to retain complex numbers, $\uparrow$ by his explanations in the advertisement to the second treatise on biquadratic residues gained for them a triumphant introduction into arithmetic operations.

The way for the geometric representation of complex quantities was prepared by the observations of

* Cantor, II., p. 7I8. +Cantor, II., p. 724. $\quad \ddagger$ Cantor, III., p. 684.

SHankel, Die komplexen Zahlen, r867, p. 7r.

\| Beman. "Euler's Use of $i$ to Represent an Imaginary," Bull. Amer. Math. Soc, March, I898, p. 274.

Treutlein. 
various mathematicians of the seventeenth and eighteenth centuries, among them especially Wallis,* who in solving geometric problems algebraically became aware of the fact that when certain assumptions give two real solutions to a problem as points of a straight line, other assumptions give two "impossible" roots as the points of a straight line perpendicular to the first one. The first satisfactory representation of complex quantities in a plane was devised by Caspar Wessel in 1797, without attracting the attention it deserved. A similar treatment, but wholly independent, was given by Argand in 1806. $\nmid$ But his publication was not appreciated even in France. In the year 1813 there appeared in Gergonne's Annales by an artillery officer Français in the city of Metz the outlines of a theory of imaginary quantities the main ideas of which can be traced back to Argand. Although Argand improved his theory by his later work, yet it did not gain recognition until Cauchy entered the lists as its champion. It was, however, Gauss who (1831), by means of his great reputation, made the representation of imaginary quantities in the "Gaussian plane" the common property of all mathematicians. $f$

Gauss and Dirichlet introduced general complex numbers into arithmetic. The primary investigations

* Hankel, Die komplexen Zahlen, r867, p. 81.

† Hankel, Die komplexen Zahlen, r867, p. 82.

$\ddagger$ For a résumé of the history of the geometric representation of the imaginary, see Beman, "A Chapter in the History of Mathematics," Proc. Amer. Assn. Adv. Science, 1897, pp. 33-50 
of Dirichlet in regard to complex numbers, which, together with indications of the proof, are contained in the Berichte der Berliner Akademie for 1841, 1842, and 1846 , received material amplifications through Eisenstein, Kummer, and Dedekind. Gauss, in the development of the real theory of biquadratic residues, introduced complex numbers of the form $a+b i$, and Lejeune Dirichlet introduced into the new theory of complex numbers the notions of prime numbers, congruences, residue-theorems, reciprocity, etc, the propositions, however, showing greater complexity and variety and offering greater difficulties in the way of proof.* Instead of the equation $x^{4}-1=0$, which gives as roots the Gaussian units, $+1,-1,+i,-i$, Eisenstein made use of the equation $x^{8}-1=0$ and considered the complex numbers $a+b \rho$ ( $\rho$ being a complex cube root of unity) the theory resembling that of the Gaussian numbers $a+b i$, but yet possessing certain marked differences. Kummer generalized the theory still further, using the equation $x^{n}-1=0$ as the basis, so that numbers of the form

$$
a=a_{1} A_{1}+a_{2} A_{2}+a_{3} A_{3}+\ldots
$$

arise where the $a$ 's are real integers and the $A$ 's are roots of the equation $x^{n}-1=0$. Kummer also set forth the concept of ideal numbers, that is, of such numbers as are factors of prime numbers and possess the property that there is always a power of these ideal numbers which gives a real number. For example,

\footnotetext{
* Cayley, Address to the British Association, etc., 1883.
} 
there exists for the prime number $p$ no rational factorization so that $p^{3}=A \cdot B$ (where $A$ is different from $p$ and $\left.p^{2}\right)$; but in the theory of numbers formed from the twenty-third roots of unity there are prime numbers $p$ which satisfy the condition named above. In this case $p$ is the product of two ideal numbers, of which the third powers are the real numbers $A$ and $B$, so that $p^{3}=A \cdot B$. In the later development given by Dedekind the units are the roots of any irreducible equation with integral numerical coefficients. In the case of the equation $x^{2}-x+1=0, \frac{1}{2}(1+i \sqrt{3})$, that is to say, the $\rho$ of Eisenstein, is to be regarded as integral.

In tracing out the nature of complex numbers, H. Grassmann, Hamilton, and Scheffler have arrived at peculiar discoveries. Grassmann, who also materially developed the theory of determinants, investigated in his treatise on directional calculus (Ausdehnungslehre) the addition and multiplication of complex numbers. In like manner, Hamilton originated the calculus of quaternions, a method of calculation regarded with especial favor in England and America and justified by its relatively simple applicability to spherics, to the theory of curvature, and to mechanics.

The complete double title* of H. Grassmann's chief work which appeared in the year 1844, as translated, is: "The Science of Extensive Quantities or Directional Calculus (Ausdehnungslehre). A New 
Mathematical Theory, Set Forth and Elucidated by Applications. Part First, Containing the Theory of Lineal Directional Calculus. The Theory of Lineal Directional Calculus, A New Branch of Mathematics, Set Forth and Elucidated by Applications to the Remaining Branches of Mathematics, as well as to Statics, Mechanics, the Theory of Magnetism and Crystallography." The favorable criticisms of this wonderful work by Gauss, who discovered that "the tendencies of the book partly coincided with the paths upon which he had himself been travelling for half a century," by Grunert, and by Möbius who recognised in Grassmann "a congenial spirit with respect to mathematics, though not to philosophy," and who congratulated Grassmann upon his "excellent work," were not able to secure for it a large circle of readers. As late as 1853 Möbius stated that "Bretschneider was the only mathematician in Gotha who had assured him that he had read the Ausdehnungslehre through."

Grassmann received the suggestion for his researches from geometry, where $A, B, C$, being points of a straight line, $A B+B C=A C$. With this he combined the propositions which regard the parallelo gram as the product of two adjacent sides, thus introducing new products for which the ordinary rules of multiplication hold so long as there is no permutation of factors, this latter case requiring the change of

* Grassmann, Die Ausdchnungslehre von 1844 oder die lineale Ausdehnungslehre, ein neuer Zzueig der Mathematik. Zweite Auflage, 1878 . 
signs. More exhaustive researches led Grassmann to regard as the sum of several points their center of gravity, as the product of two points the finite linesegment between them, as the product of three points the area of their triangle, and as the product of four points the volume of their pyramid. Through the study of the Barycentrischer Calcül of Möbius, Grassmann was led still further. The product of two linesegments which form a parallelogram was called the "external product" (the factors can be permuted only by a change of sign), the product of one line-segment and the perpendicular projection of another upon it formed the "internal product" (the factors can here be permuted without change of sign). The introduction of the exponential quantity led to the enlargement of the system, of which Grassmann permitted a brief survey to appear in Grunert's Archiv (1845).*

Hamilton $\dagger$ gave for the first time, in a communication to the Academy of Dublin in 1844 , the values $i, j, k$, so characteristic of his theory. The Lectures on Quaternions appeared in 1853, the Elements of Quaternions in 1866. From a fixed point $O$ let a line $\neq$ be drawn to the point $P$ having the rectangular co-ordinates $x, y, z$. Now if $i, j, k$ represent fixed coefficients (unit distances on the axes), then

* Translated by Beman, Analyst, I88I, pp. 96, II4.

† Unverzagt, Theorie der goniometrischen und longimetrischen Quaternionen, IS-6.

$¥$ Cayley, A., "On Multiple Algebra," in Quarterly Journal of Mathematics, 1887 . 


\section{$V=i x+j y+k z$}

is a vector, and this additively joined to the "pure quantity" or "scalar" $w$ produces the quaternion

$$
Q=w+i x+j y+k z \text {. }
$$

The addition of two quaternions follows from the usual formula

$$
Q+Q^{\prime}=w+w^{\prime}+i\left(x+x^{\prime}\right)+j\left(y+y^{\prime}\right)+k\left(z+z^{\prime}\right)
$$

But in the case of multiplication we must place

$$
\begin{gathered}
i^{2}=j^{2}=k^{2}=-1, i=j k=-k j, j=k i=-i \stackrel{i}{k=i j=-j i,}
\end{gathered}
$$

so that we obtain

$$
\begin{aligned}
Q \cdot Q^{\prime}=w w^{\prime}-x x^{\prime}-y y^{\prime}- & z z^{\prime} \\
& +i\left(w x^{\prime}+x w^{\prime}+y z^{\prime}-z y^{\prime}\right) \\
& +j\left(w y^{\prime}+y w^{\prime}+z x^{\prime}-x z^{\prime}\right) \\
& +k\left(w z^{\prime}+z w^{\prime}+x y^{\prime}-y x^{\prime}\right) .
\end{aligned}
$$

On this same subject Scheffler published in 1846 his first work, Ueber die Verhältnisse der Arithmetik zur Geometrie, in 1852 the Situationscalcul, and in 1880 the Polydimensionalen Grössen. For him* the vector $r$ in three dimensions is represented by

$$
\begin{gathered}
r=a \cdot e^{a \gamma=1} \cdot e^{\beta / \overline{\div}} \text {, or } \\
r=x+y v-1+z 1=1 \cdot \sqrt{\div-1} \text {, or } \\
r=x+y \cdot i+z \cdot i \cdot i_{1} \text { where } i=\sqrt{-1} \text { and } i_{1}=\sqrt{\div-1}
\end{gathered}
$$
are turning factors of an angle of $90^{\circ}$ in the plane of $x y$ and $x z$. In Scheffler's theory the distributive law does not always hold true for multiplication, that is to say, $a(b+c)$ is not always equivalent to $a b+a c$.

Investigations as to the extent of the domain in

* Unverzagt, Ueber die Grundlagen der lichnung mit Quaternionen, 1881. 
which with certain assumptions the laws of the elementary operations of arithmetic are valid have led to the establishment of a calculus of logic.* To this class of investigations there belong, besides Grassmann's Formenlehre (1872), notes by Cayley and Ellis, and in particular the works of Boole, Schröder, and Charles Peirce.

A minor portion of the modern theory of numbers or higher arithmetic, which concerns the theories of congruences and of forms, is made up of continued fractions. The algorism leading to the formation of such fractions, which is also used in calculating the greatest common measure of two numbers, reaches back to the time of Euclid. The combination of the partial quotients in a continued fraction originated with Cataldi, $\uparrow$ who in the year 1613 approximated the value of square roots by this method, but failed to examine closely the properties of the new fractions.

Daniel Schwenter was the first to make any material contribution (1625) towards determining the convergents of continued fractions. He devoted his attention to the reduction of fractions involving large numbers, and determined the rules now in use for calculating the successive convergents. Huygens and Wallis also labored in this field, the latter discovering the general rule, together with a demonstration, which combines the terms of the convergents

* Schröder, Der Operationskreis des Logikcalculs, 1877.

† Cantor, II., p. 695. 


$$
\frac{p_{n}}{q_{n}}, \frac{p_{n-1}}{q_{n-1}}, \frac{p_{n-2}}{q_{n-2}}
$$

in the following manner:

$$
\frac{p_{n}}{q_{n}}=\frac{a_{n} p_{n-1}+b_{n} p_{n-2}}{a_{n} q_{n-1}+b_{n} q_{n-2}}
$$

The theory of continued fractions received its greatest development in the eighteenth century with Euler,* who introduced the name fractio continua (the German term Kettenbruch has been used only since the beginning of the nineteenth century). He devoted his attention chiefly to the reduction of continued fractions to the form of infinite products and series, and doubtless in this way was led to the attempt to give the convergents independent form, that is to discover a general law by means of which it would be possible to calculate any required convergent without first obtaining the preceding ones. Although Euler did not succeed in discovering such a law, he created an algorism of some value. This, however, did not bring him essentially nearer the goal because, in spite of the example of Cramer, he neglected to make use of determinants and thus to identify himself the more closely with the pure theory of combinations. From this latter point of view the problem was attacked by Hindenburg and his pupils Burckhardt and Rothe. Still, those who proceed from the theory of combina. tions alone know continued fractions only from one side; the method of independent presentation allows *Cantor, III., p. 670. 
the calculation of the desired convergent from both sides, forward as well as backward, to the practical value of which Dirichlet has testified.

Only in modern times has the calculus of determinants been employed in this field, together with a combinatory symbol, and the first impulse in this direction dates from the Danish mathematician Ramus (1855). Similar investigations were begun, however, by Heine, Möbius, and S. Günther, leading to the formation of "continued fractional determinants." The irrationality of certain infinite continued fractions* had been investigated before this by Legendre, who, like Gauss, gave the quotient of two power series in the form of a continued fraction. By means of the application of continued fractions it can be shown that the quantities $e^{x}$ (for rational values of $x$ ), $e, \pi$, and $\pi^{2}$ cannot be rational (Lambert, Legendre, Stern). It was not until very recent times that the transcendental nature of $e$ was established by Hermite, and that of $\pi$ by F. Lindemann.

In the theory of numbers strictly speaking, quite difficult problems concerning the properties of numbers were solved by the first exponents of that study, Euclid and Diophantus. Any considerable advance was impossible, however, as long as investigations had to be conducted $\nmid$ without an adequate numerical notation, and almost exclusively with the aid of an algebra

* Treutlein.

+ Legendre, Théorie des nombres, ist ed. I798, 3rd ed. I830. 
just developing under the guise of geometry. Until the time of Vieta and Bachet there is no essential advance to be noted in the theory of numbers. The former solved many problems in this field, and the latter gave in his work Problèmes plaisants et delectables a satisfactory treatment of indeterminate equations of the first degree. Still later the first stones for the foundation of a theory of numbers were laid by Fermat, who had carefully studied Diophantus and into whose works as elaborated by Bachet he incorporated valuable additional propositions. The great mass of propositions which can be traced back to him he gave for the most part without demonstration, as for example the following statement:

"Every prime number of the form $4 n+1$ is the sum of two squares; a prime number of the form $8 n+1$ has at the same time the three forms $y^{2}+z^{2}$, $y^{2}+2 z^{2}, y^{2}-2 z^{2}$; every prime number of the form $8 n+3$ appears as $y^{2}+2 z^{2}$, every one of the form $8 n+7$ appears as $y^{2}-2 z^{2}$." Further, "Any number can be formed by the addition of three cubes, of four squares, of five fifth powers, etc."

Fermat proved that the area of a Pythagorean right-angled triangle, for example a triangle with the sides 3,4 , and 5 , cannot be a square. He was also the first to obtain the solution of the equation $a x^{2}+$ $1=y^{2}$, where $a$ is not a square; at all events, he brought this problem to the attention of English mathematicians, among whom Lord Brouncker dis- 
covered a solution which found its way into the works of Wallis. Many of Fermat's theorems belong to "the finest propositions of higher mathematics,"* and possess the peculiarity that they can easily be discovered by induction, but that their demonstrations are extremely difficult and yield only to the most searching investigation. It is just this which imparts to higher arithmetic that magic charm which made it a favorite with the early geometers, not to speak of its inexhaustible treasure-house in which it far exceeds all other branches of pure mathematics.

After Fermat, Euler was the first again to attempt any serious investigations in the theory of numbers. To him we owe, among other things, the first scientific solution of the chess board problem, which requires that the knight, starting from a certain square, shall in turn occupy all sixty-four squares, and the further proposition that the sum of four squares multiplied into another similar sum also gives the sum of four squares. He also discovered demonstrations of various propositions of Fermat, as well as the general solution of indeterminate equations of the second degree with two unknowns on the hypothesis that a special solution is known, and he treated a large number of other indeterminate equations, for which he discovered numerous ingenious solutions.

Euler (as well as Krafft) also occupied himself 
with amicable numbers. ${ }^{*}$ These numbers, which are mentioned by Iamblichus as being known to the Pythagoreans, and which are mentioned by the Arab Tabit ibn Kurra, suggested to Descartes the discovery of a law of formation, which is given again by Van Schooten. Euler made additions to this law and deduced from it the proposition that two amicable num bers must possess the same number of prime factors. The formation of amicable numbers depends either upon the solution of the equation $x y+a x+b y+c=0$, or upon the factoring of the quadratic form $a x^{2}+b x y$ $+c y^{2}$.

Following Euler, Lagrange was able to publish many interesting results in the theory of numbers. He showed that any number can be represented as the sum of four or less squares, and that a real root of an algebraic equation of any degree can be converted into a continued fraction. $\mathrm{He}$ was also the first to prove that the equation $x^{2}-A y^{2}=1$ is always soluble in integers, and he discovered a general method for the derivation of propositions concerning prime numbers.

Now the development of the theory of numbers bounds forward in two mighty leaps to Legendre and Gauss. The valuable treatise of the former, Essai sur la théorie des nombres, which appeared but a few years before Gauss's Disquisitiones arithmeticae, contains an epitome of all results that had been published up to

\footnotetext{
*Seelhoff, "Befreundete Zahlen," Hoppe Arch., Bd. 70.
} 
that time, besides certain original investigations, the most brilliant being the law of quadratic reciprocity, or, as Gauss called it, the Theorema fundamentale in doctrina de residuis quadratis. This law gives a relationship between two odd and unequal prime numbers and can be enunciated in the following words :

"Let $\left(\frac{m}{n}\right)$ be the remainder which is left after dividing $m^{\frac{n-1}{2}}$ by $n$, and let $\left(\frac{n}{m}\right)$ be the remainder left after dividing $n^{\frac{m-1}{2}}$ by $m$. These remainders are always +1 or -1 . Whatever then the prime numbers $m$ and $n$ may be, we always obtain $\left(\frac{n}{m}\right)=\left(\frac{m}{n}\right)$ in case the numbers are not both of the form $4 x+3$. But if both are of the form $4 x+3$, then we have $\left(\frac{n}{m}\right)=-\left(\frac{m}{n}\right)$."

These two cases are contained in the formula

$$
\left(\frac{n}{m}\right)=(-1)^{\frac{m-1}{2} \cdot \frac{n-1}{2}} \cdot\left(\frac{m}{n}\right) \text {. }
$$

Bachet having exhausted the theory of the indeterminate equation of the first degree with two unknowns, an equation which in Gauss's notation appears in the form $x \equiv a(\bmod b)$, identical with $\frac{x}{b}=y+a$, mathematicians began the study of the congruence $x^{2} \equiv m$ $(\bmod n)$. Fermat was aware of a few special cases of the complete solution; he knew under what conditions $\pm 1,2, \pm 3,5$ are quadratic residues or non-residues of the odd prime number $m .^{*}$ For the cases -1 and

*Baumgart, "Ueber das quadratische Reciprocitätsgesetz," in Schlömilch's Zeitschrift, Bd. 30, Hl. Abt. 
\pm 3 the demonstrations originate with Euler, for \pm 2 and \pm 5 with Lagrange. It was Euler, too, who gave the propositions which embrace the law of quadratic reciprocity in the most general terms, although he did not offer a complete demonstration of it. The famous demonstration of Legendre (in Essai sur la théorie des nombres, 1798) is also, as yet, incomplete. In the year 1796 Gauss submitted, without knowing of Euler's work, the first unquestionable demonstration-a demonstration which possesses at the same time the peculiarity that it embraces the principles which were used later. In the course of time Gauss adduced no less than eight proofs for this important law, of which the sixth (chronologically the last) was simplified almost simultaneously by Cauchy, Jacobi, and Eisenstein. Eisenstein demonstrated in partic ular that the quadratic, the cubic and the biquadratic laws are all derived from a common source. In the year 1861 Kummer worked out with the aid of the theory of forms two demonstrations for the law of quadratic reciprocity, which were capable of generalization for the $n$ th-power residue. $\mathrm{Up}$ to 1890 twenty-five distinct demonstrations of the law of quadratic reciprocity had been published; they make use of induction and reduction, of the partition of the perigon, of the theory of functions, and of the theory of forms. In addition to the eight demonstrations by Gauss which have already been mentioned, there are four by Eisenstein, two by Kummer, and one each 
by Jacobi, Cauchy, Liouville, Lebesgue, Genocchi, Stern, Zeller, Kronecker, Bouniakowsky, Schering, Petersen, Voigt, Busche, and Pepin.

However much is due to the co-operation of mathematicians of different periods, yet to Gauss unquestionably belongs the merit of having contributed in his Disquisitiones arithmeticae of 1801 the most important part of the elementary development of the theory of numbers. Later investigations in this branch have their root in the soil which Gauss prepared. Of such investigations, which were not pursued until after the introduction of the theory of elliptic transcendents, may be mentioned the propositions of Jacobi in regard to the number of decompositions of a number into two, four, six, and eight squares, ${ }^{*}$ as well as the investigations of Dirichlet in regard to the equation

$$
x^{n}+y^{n}=z^{n} \text {. }
$$

His work in the theory of numbers was Dirichlet's favorite pursuit. $\uparrow \mathrm{He}$ was the first to deliver lectures on the theory of numbers in a German university and was able to boast of having made the Disquisitiones arithmeticae of Gauss transparent and intelligible-a task in which a Legendre, according to his own avowal, was unsuccessful.

Dirichlet's earliest treatise, Mémoire sur l'impossibilité de quelques équations indéterminés du cinquième degre (submitted to the French Academy in 1825),

* Dirichlet, "Godächtnisrede auf Jacobi," Crelle's Journal, Bd. 52.

† Kummer, "Gedächtnisrede auf Lejeune-Dirichlet," in Berl. Abh. 1860. 
deals with the proposition, stated by Fermat without demonstration, that "the surn of two powers having the same exponent can never be equal to a power of the same exponent, when these powers are of a degree higher than the second." Euler and Legendre had proved this proposition for the third and fourth powers; Dirichlet discusses the sum of two fifth powers and proves that for integral numbers $x^{5}+y^{5}$ cannot be equal to $a z^{5}$. The importance of this work lies in its intimate relationship to the theory of forms of higher degree. Dirichlet's further contributions in the field of the theory of numbers contain elegant demonstrations of certain propositions of Gauss in regard to biquadratic residues and the law of reciprocity, which were published in 1825 in the Göttingen $G e$ lehrte Anzeigen, as well as with the determination of the class-number of the quadratic form for any given determinant. His "applications of analysis to the theory of numbers are as noteworthy in their way as Descartes's applications of analysis to geometry. They would also, like the analytic geometry, be recognized as a new mathematical discipline if they had been extended not to certain portions only of the theory of number, but to all its problems uniformly.*

The numerous investigations into the properties and laws of numbers had led in the seventeenth century ${ }^{\prime}$ to the study of numbers in regard to their divis-

*Kummer, "Gedächtnisrede auf Lejeune-Dirichlet." Berl. Abh. 1860.

+Seelhoff, "Geschichte der Faktorentafeln," in Hoppe Arch., Bd. 7o. 
ors. For almost two thousand years Eratosthenes's "sieve" remained the only method of determining prime numbers. In the year 1657 Franz van Schooten published a table of prime numbers up to ten thousand. Eleven years later Pell constructed a table of the least prime factors (with the exception of 2 and 5 ) of all numbers up to 100000 . In Germany these tables remained almost unknown, and in the year 1728 Poëtius published independently a table of factors for numbers up to 100000 , an example which was repeatedly imitated. Krïger's table of 1746 includes numbers up to 100000 ; that of Lambert of 1770 , which is the first to show the arrangement used in more modern tables, includes numbers up to 102000 . Of the six tables which were prepared between the years 1770 and 1811 that of Felkel is interesting because of its singular fate; its publication by the Kaiserlich königliches Aerarium in Vienna was completed as far as 408000 ; the remainder of the manuscript was then withheld and the portion already printed was used for manufacturing cartridges for the last Turkish war of the eighteenth century. In the year 1817 there appeared in Paris Burckhardt's Table des diviseurs pour tous les nombres du $I^{e r}, 2^{e}, 3^{e}$ million. Between 1840 and 1850 Crelle communicated to the Berlin Academy tables of factors for the fourth, fifth, and sixth million, which, however, were not published. Dase, who is known for his arithmetic genius, was to make the calculations for the seventh to 
the tenth million, having been designated for that work by Gauss, but he died in 1861 before its completion. Since 1877 the British Association has been having these tables continued by Glaisher with the assistance of two computers. The publication of tables of factors for the fourth million was completed in 1879 .

In the year $1856 \mathrm{~K}$. G. Reuschle published his tables for use in the theory of numbers, having been encouraged to undertake the work by his correspondence with Jacobi. They contain the resolution of numbers of the form $10^{n}-1$ into prime factors, up to $n=242$, and numerous similar results for numbers of the form $a^{n}-1$, and a table of the resolution of prine numbers $p=6 n+1$ in to the forms

$$
p=A^{2}+3 B^{2} \text { and } 4 p=C^{2}+27 M^{2},
$$

as they occur in the treatment of cubic residues and in the partition of the perigon.

Of greatest importance for the advance of the science of algebra as well as that of geometry was the development of the theories of symmetric functions, of elimination, and of invariants of algebraic forms, as they were perfected through the application of projective geometry to the theory of equations.*

The first formulas for calculating symmetric functions (sums of powers) of the roots of an algebraic equation in terms of its coefficients are due to Newton.

* A. Brill, Antrittsrede in Tübingen, 1884. Manuscript. 
Waring also worked in this field (1770) and developed a theorem, which Gauss independently discovered (1816), by means of which any symmetric function may be expressed in terms of the elementary symmetric functions. This is accomplished directly by a method devised by Cayley and Sylvester, through laws due to the former in regard to the weight of sym metric functions. The oldest tables of symmetric functions (extending to the tenth degree) were pub. lished by Meyer-Hirsch in his collection of problems (1809). The calculation of these functions, which was very tedious, was essentially simplified by Cayley and Brioschi.

The resultant of two equations with one unknown, or, what is the same, of two forms with two homogeneous variables, was given by Euler (1748) and by Bézout (1764). To both belongs the merit of having reduced the determination of the resultant to the solution of a system of linear equations.* Bézout introduced the name "resultant" (De Morgan suggested "eliminant") and determined the degree of this function. Lagrange and Poisson also investigated questions of elimination; the former stated the condition for common multiple-roots; the latter furnished a method of forming symmetric functions of the common values of the roots of a sysiem of equations. The further advancement of the theory of elimination was made by Jacobi, Hesse, Sylvester, Cayley, Cauchy, *Salmon, Higher Algebra. 
Brioschi, and Gordan. Jacobi's memoir,* which represented the resultant as a determinant, threw light at the same time on the aggregate of coefficients belonging to the resultant and on the equations in which the resultant and its product by another partially arbitrary function are represented as functions of the two given forms. This notion of Jacobi gave Hesse the impulse to pursue numerous important investigations, especially on the resultant of two equations, which he again developed in 1843 after Sylvester's dialytic method (1840); then in 1844, "on the elimination of the variables from three algebraic equations with two variables"; and shortly after "on the points of inflexion of plane curves." Hesse placed the main value of these investigations, not in the form of the final equation, but in the insight into the composition of the same from known functions. Thus he came upon the functional determinant of three quadratic prime forms, and further upon the determinant of the second partial differential coefficients of the cubic form, and upon its Hessian determinant, whose geometric interpretation furnished the interesting result that in the general case the points of inflexion of a plane curve of the $n$th order are given by its complete intersection with a curve of order $3(n-2)$. This result was previously known for curves of the third order, having been discovered by Plücker. To Hesse is further due the first important example of the re-

* O. H. Noether, Schlömilck's Zeitschrift, Bd. 20. 
moval of factors from resultants, in so far as these factors are foreign to the real problem to be solved. Hesse, always extending the theory of elimination, in 1849 succeeded in producing, free from all superfluous factors, the long-sought equation of the 14th degree upon which the double tangents of a curve of the 4 th order depend.

The method of elimination used by Hesse* in 1843 is the dialytic method published by Sylvester in 1840 ; it gives the resultant of two functions of the $n$th and $n$th orders as a determinant, in which the coefficients of the first enter into $n$ rows, and those of the second into $m$ rows. It was Sylvester also, who in 1851 introduced the name "discriminant" for the function which expresses the condition for the existence of two equal roots of an algebraic equation; up to this time, it was customary, after the example of Gauss, to say "determinant of the function."

The notion of invariance, so important for all branches of mathematics to-day, dates back in its beginnings to Lagranget, who in 1773 remarked that the discriminant of the quadratic form $a x^{2}+$ $2 b x y+c y^{2}$ remains unaltered by the substitution of $x+\lambda y$ for $x$. This unchangeability of the discriminant by linear transformation, for binary and ternary quadratic forms, was completely proved by Gauss (1801); but that the discriminant in general and in every case remains invariant by linear transformation, 
G. Boole (1841) recognized and first demonstrated. In 1845, Cayley, adding to the treatment of Boole, found that there are still other functions which possess invariant properties in linear transformation, showed how to determine such functions and named them "hyperdeterminants." This discovery of Cayley developed rapidly into the important theory of invariants, particularly through the writings of Cayley, Aronhold, Boole, Sylvester, Hermite, and Brioschi, and then through those of Clebsch, Gordan, and others. After the appearance of Cayley's first paper, Aronhold made an important contribution by determining the invariants $S$ and $T$ of a ternary form, and by developing their relation to the discriminant of the same form. From 1851 on, there appeared a series of important articles by Cayley and Sylvester. The latter created in these a large part of the termin ology of to-day, especially the name "invariant" (1851). In the year 1854, Hermite discovered his law of reciprocity, which states that to every covariant or invariant of degree $\rho$ and order $r$ of a form of the $m$ th order, corresponds also a covariant or invariant of degree $m$ and of order $r$ of a form of the $\rho$ th order. Clebsch and Gordan used the abbreviation $b_{x}^{n}$, introduced for binary forms by Aronhold, in their fundamental developments, e. g., in the systematic extension of the process of transvection in forming invariants and covariants, already known to Cayley in his preliminary investigations, in the folding-pro- 
cess of forming elementary covariants, and in the formation of simultaneous invariants and covariants, in particular the combinants. Gordan's theorem on the finiteness of the form-system constitutes the most important recent advance in this theory; this theorem states that there is only a finite number of invariants and covariants of a binary form or of a system of such forms. Gordan has also given a method for the formation of the complete form-system, and has carried out the same for the case of binary forms of the fifth and sixth orders. Hilbert (1890) showed the finiteness of the complete systems for forms of $n$ variables.*

To refer in a word to the great significance of the theory of invariants for other branches of mathematics, let it suffice to mention that the theory of binary forms has been transferred by Clebsch to that of ternary forms (in particular for equations in line co-ordinates); that the form of the third order finds its representation in a space-curve of the third order, while binary forms of the fourth order play a great part in the theory of plane curves of the third order, and assist in the solution of the equation of the fourth degree as well as in the transformation of the elliptic integral of the first class into Hermite's normal form; finally that combinants can be effectively introduced in the transformation of equations of the fifth and sixth degrees. The results of investigations by Clebsch, Weierstrass, Klein, Bianchi, and Burckhardt, have shown the great significance of the theory of invariants for the theory of the hyperelliptic and Abelian functions. This theory has been further used by Christoffel and Lipschitz in the representation of the line-element, by Sylvester, Halphen, and Lie in the case of reciprocants or differential invariants in the theory of dif-

* Meyer, IV. F., "Bericht über den gegenwärtigen Stand der Invariantentheorie." Jahresbericht der deutschen Mathomatiker-Vereinigung. Bd. I. 
ferential equations, and by Beltrami in his differential parameter in the theory of curvature of surfaces. Irrational invariants also have been proposed in various articles by Hilbert.

The theory of probabilities assumed form under the hands of Pascal and Fermat.* In the year 1654, a gambler, the Chevalier de Méré, had addressed two inquiries to Pascal as follows: "In how many throws with dice can one hope to throw a double six," and "In what ratio should the stakes be divided if the game is broken up at a given moment?" These two questions, whose solution was for Pascal very easy, were the occasion of his laying the foundation of a new science which was named by him "Géométrie du hasard." At Pascal's invitation, Fermat also turned his attention to such questions, using the theory of combinations. Huygens soon followed the example of the two French mathematicians, and wrote in $1656 \dagger$ a small treatise on games of chance. The first to apply the new theory to economic sciences was the "grand pensioner" Jean de Witt, the celebrated pupil of Descartes. He made a report in 1671 on the manner of determining the rate of annuities on the basis of a table of mortality. Hudde also published investigations on the same subject. "Calculation of chances" (Rechnung ïber den Zufall) received comprehensive treatment at the hand of Jacob Bernoulli in his Ars conjectandi (1713), printed eight years after the death of the author, a book which remained forgotten 
until Condorcet called attention to it. Since Bernoulli, there has scarcely been a distinguished algebraist who has not found time for some work in the theory of probabilities.

To the method of least squares Legendre gave the name in a paper on this subject which appeared in 1805.* The first publication by Gauss on the same subject appeared in 1809, although he. was in possession of the method as early as 1795. The honor is therefore due to Gauss for the reason that he first set forth the method in its present form and turned it to practical account on a large scale. The apparent inspiration for this investigation was the discovery of the first planetoid Ceres on the first of January, 1801, by Piazzi. Gauss calculated by new methods the orbit of this heavenly body so accurately that the same planetoid could be again found towards the end of the year 1801 near the position given by him. The investigations connected with this calculation appeared in 1809 as Theoria motus corporum coelestium, etc. The work contained the determination of the position of a heavenly body for any given time by means of the known orbit, besides the solution of the difficult problem to find the orbit from three observations. In order to make the orbit thus determined agree as closely as possible with that of a greater number of observations, Gauss applied the process

* Merriman, M., "List of Writings relating to the Method of Least Squares." Trans. Conn. Acad., Vol. IV. 
discovered by him in 1795 . The object of this was "so to combine observations which serve the purpose of determining unknown quantities, that the unavoidable errors of observation affect as little as possible the values of the numbers sought." For this purpose Gauss gave the following rule*: "Attribute to each error a moment depending upon its value, multiply the moment of each possible error by its probability and add the products. The error whose moment is equal to this sum will have to be designated as the mean." As the simplest arbitrary function of the error which shall be the moment of the latter, Gauss chose the square. Laplace published in the year 1812 a detailed proof of the correctness of Gauss's method.

Elementary presentations of the theory of combinations are found in the sixteenth century, e. g., by Cardan, but the first great work is due to Pascal. In this he uses his arithmetic triangle, in order to determine the number of combinations of $m$ elements of the $n$th class. Leibnitz and Jacob Bernoulli produced much new material by their investigations. Towards the end of the eighteenth century, the field was cultivated by a number of German scholars, and there arose under the leadership of Hindenburg the "combinatory school," $\dagger$ whose followers added to the development of the binomial theorem. Superior to them all in systematic proof is Hindenburg, who separated

* Gerhardt, Geschichte der Mathematik in Deutschland, 1877.

+ Gerhardt, Geschichte der Mathematik in Deutschland, 1877. 
polynomials into a first class of the form $a+b+c+$ $d+\ldots$ and into a second, $a+b x+c x^{2}+d x^{8}+\ldots$ He perfected what was already known, and gave the lacking proofs to a number of theorems, thus earning the title of "founder of the theory of combinatory analysis."

The combinatory school, which included Eschenbach, Rothe, and especially Pfaff, in addition to its distinguished founder, produced a varied literature, and commanded respect because of its elegant formal results. But, in its aims, it stood so far outside the domain of the new and fruitful theories cultivated especially by such French mathematicians as Lagrange and Laplace, that it remained without influence in the further development of mathematics, at least at the beginning of the nineteenth century.

In the domain of infinite series, $*$ many cases which reduce for the most part to geometric series, were treated by Euclid, and to a greater degree by Apollonius. The Middle Ages added nothing essential, and it remained for more recent generations to make important contributions to this branch of mathematical knowledge. Saint-Vincent and Mercator developed independently the series for $\log (1+x)$, Gregory those for $\tan ^{-1} x, \sin x, \cos x, \sec x, \operatorname{cosec} x$. In the writings of the latter are also found, in the treatment of infinite series, the expressions "convergent" and "divergent." Leibnitz was led to infinite series, through consideration of finite arithmetic series. $\mathrm{He}$ realized at the same time the necessity of examining

* Reiff, R., Geschichte der unendlichen Reihen, Tübingen, 1889. 
more closely into the convergence and divergence of series. This necessity was also felt by Newton, who used infinite series in a manner similar to that of Apollonius in the solution of algebraic and geometric problems, especially in the determination of areas, and consequently as equivalent to integration.

The new ideas introduced by Leibnitz were further developed by Jacob and John Bernoulli. The former found the sums of series with constant terms, the latter gave a general rule for the development of a function into an infinite series. At this time there were no exact criteria for convergence, except those suggested by Leibnitz for alternating series.

During the years immediately following, essential advances in the formal treatment of infinite series were made. De Moivre wrote on recurrent series and exhausted almost completely their essential properties. Taylor's and Maclaurin's closely related series appeared, Maclaurin developing a rigorous proof of Taylor's theorem, giving numerous applications of it, and stating new formulas of summation. Euler displayed the greatest skill in the handling of infinite series, but troubled himself little about convergence and divergence. He deduced the exponential from the binomial series, and was the first to develop rational functions into series of sines and cosines of integral multiple arguments. ${ }^{*}$ In this manner he defined the coefficients of a trigonometric series by

* Reiff, Geschichte der unendlichen Reihen. I889, pp. 105, 127. 
definite integrals without applying these important formulas to the development of arbitrary functions into trigonometric series. This was first accomplished by Fourier (1822), whose investigations were completed by Riemann and Cauchy. The investigation was brought to a temporary termination by Dirichlet (1829), in so far as by rigid methods he gave it a scientific foundation and introduced general and complex investigations on the convergence of series.* From Laplace date the developments into series of two variables, especially into recurrent series. Legendre furnished a valuable extension of the theory of series by the introduction of spherical functions.

With Gauss begin more exact methods of treatment in this as in nearly all branches of mathematics, the establishment of the simplest criteria of convergence, the investigation of the remainder, and the continuation of series beyond the region of convergence. The introduction to this was the celebrated series of Gauss :

$$
1+\frac{a \cdot \beta}{1 \cdot \gamma} x+\frac{a(\alpha+1) \beta(\beta+1)}{1 \cdot 2 \cdot \gamma(\gamma+1)} x^{2}+\ldots,
$$

which Euler had already handled but whose great value he had not appreciated. $\dagger$ The generally accepted naming of this series as "hypergeometric" is due to J. F. Pfaff, who proposed it for the general series in which the quotient of any term divided by the

*Kummer, "Gedächtnissrede auf Lejeume-Dirichlet." Berliner Abhandlungen, 1860 .

† Re:ff, Geschichte der unendlichen Feihien, I889, p. I6I. 
preceding is a function of the index. Euler, following Wallis, used the same name for the series in which that quotient is an integral linear function of the index.* Gauss, probably influenced by astronomical applications, stated that his series, by assuming certain special values of $\alpha, \beta, \gamma$, could take the place of nearly all the series then known; he also investigated the essential properties of the function represented by this series and gave for series in general an important criterion of convergence. We are indebted to Abel (1826) for important investigations on the continuity of series.

The idea of uniform convergence arose from the study of the behavior of series in the neighborhood of their discontinuities, and was expressed almost simultaneously by Stokes and Seidel (1847-1848). The latter calls a series uniformly convergent when it represents a discontinuous function of a quantity $x$, the separate terms of which are continuous, but in the vicinity of the discontinuities is of such a nature that values of $x$ exist for which the series converges as slowly as desired. $\dagger$

On account of the lack of immediate appreciation of Gauss's memoir of 1812, the period of the discovery of effective criteria of convergence and divergence may be said to begin with Cauchy (1821). His meth-

* Riemann, Werke, p. 78 .

† Reiff, Geschichte de'r unendlichen Reihen, I889, p. 207.

$\ddagger$ Pringsheim, "Allgemeine Theorie der Divergenz und Konvergenz von Reihen mit positiven Gliedern," Math. Annalen, XXXV. 
ods of investigation, as well as the theorems on infinite series with positive terms published between 1832 and 1851 by Raabe, Duhamel, De Morgan, Bertrand, Bonnet, and Paucker, set forth special criteria, for they compare generally the $n$th term with particular functions of the form $a^{n}, n^{k}, n(\log n)^{k}$ and others. Criteria of essentially more general nature were first discovered by Kummer (1835), and were generalized by Dini (1867). Dini's researches remained for a time, at least in Germany, completely unknown. Six years later Paul du Bois-Reymond, starting with the same fundamental ideas as Dini, discovered anew the chief results of the Italian mathematician, worked them out more thoroughly and enlarged them essentially to a system of convergence and divergence criteria of the first and second kind, according as the general term of the series $a_{n}$ or the quotient $a_{n+1}: a_{n} \mathrm{i}_{\text {i }}$ the basis of investigation. Du Bois-Reymond's results were completed and in part verified somewhat later by A. Pringsheim.

After the solution of the algebraic equations of the third and fourth degrees was accomplished, work on the structure of the system of algebraic equations in general could be undertaken. Tartaglia, Cardan, and Ferrari laid the keystone of the bridge which led from the solution of equations of the second degree to the complete solution of equations of the third and fourth degrees. But centuries elapsed before an Abel threw a flood of light upon the solution of higher equations. 
Vieta had found a means of solving equations allied to evolution, and this was further developed by Harriot and Oughtred, but without making the process less tiresome.* Harriot's name is connected with another theorem which contains the law of formation of the coefficients of an algebraic equation from its roots, although the theorem was first stated in full by Descartes (1683) and proved general by Gauss.

Since there was lacking a sure method of determining the roots of equations of higher degree, the attempt was made to include these roots within as narrow limits as possible. De Beaune and Van Schooten tried to do this, but the first usable methods date from Maclaurin (Algcbra, published posthumously in 1748) and Newton (1722) who fixed the real roots of an algebraic equation between given limits. In order to effect the general solution of an algebraic equation, the effort was made either to represent the given equation as the product of several equations of lower degree, a method further developed by Hudde, or to reduce, through extraction of the square root, an equation of even degree to one whose degree is half that of the given equation; this method was used by Newton, but he accomplished little in this direction.

Leibnitz had exerted himself as strenuously as Newton to make advances in the theory of algebraic equations. In one of his letters he states that he has

\footnotetext{
* Montucla, Histoire des Mathenatiques, 1799-1802.
} 
been engaged for a long time in attempting to find the irrational roots of an equation of any degree, by eliminating the intermediate terms and reducing it to the form $x^{n}=A$, and that he was persuaded that in this manner the complete solution of the general equation of the $n$th degree could be effected. This method of transformation of the general equation dates back to Tschirnhausen and is found as "Nova methodus etc." in the Leipziger Acta eruditorum of the year 1683. In the equation

$$
x^{n}+A x^{n-1}+B x^{n-2}+\ldots+M x+N=0
$$

Tschirnhausen places

$$
y=\alpha+\beta x+\gamma x^{2}+\ldots+\mu x^{n-1} ;
$$

the elimination of $x$ from these two equations gives likewise an equation of the $n$th degree in $y$, in which the undetermined coefficients $\alpha, \beta, \gamma, \ldots$ can so be taken as to give the equation in $y$ certain special characteristics, for example, to make some of the terms vanish. From the values of $y$, the values of $x$ are determined. By this method the solution of equations of the $3 \mathrm{rd}$ and 4 th degrees is made to depend respectively upon those of the $2 \mathrm{nd}$ and 3 rd degrees; but the application of this method to the equation of the 5 th degree, leads to one of the 24 th degree, upon whose solution the complete solution of the equation of the 5 th degree depends.

Afterwards, also, toward the end of the seventeenth and the beginning of the eighteenth century, De Lagny, 
Rolle, Laloubère, and Leseur made futile attempts to advance with rigorous proofs beyond the equation of the fourth degree. Euler* took the problem in hand in 1749. He attempted first to resolve by means of undetermined coefficients the equation of degree $2 n$ into two equations each of degree $n$, but the results obtained by him were not more satisfactory than those of his predecessors, in that an equation of the eighth degree by this treatment led to an equation of the 70th degree. These investigations were not valueless, however, since through them Euler discovered the proof of the theorem that every rational integral algebraic function of even degree can be resolved into real factors of the second degree.

In a work of the date 1762 Euler attacked the solution of the equation of the $n$th degree directly. Judging from equations of the 2 nd and 3 rd degrees, he surmised that a root of the general equation of the $n$th degree might be composed of $(n-1)$ radicals of the $n$th degree with subordinate square roots. He formed expressions of this sort and sought through comparison of coefficients to accomplish his purpose. This method presented no difficulty up to the fourth degree, but in the case of the fifth degree Euler was compelled to limit himself to particular cases. For example, he obtained from

$$
x^{5}-40 x^{3}-72 x^{2}+50 x+98=0
$$

the following value:

* Cantor, III., p. 582. 


$$
\begin{aligned}
x & =\sqrt[5]{-31+31 / \overline{-7}}+\sqrt[5]{-31-31-7} \\
& +\sqrt[5]{-18+10 \sqrt{-7}}+\sqrt[5]{-18-10 \sqrt{-7}} .
\end{aligned}
$$

Analogous to this attempt of Euler is that of Waring (1779). In order to solve the equation $f(x)=0$ of degree $n$, he places

$$
x=a \sqrt[n]{p}+b \sqrt[n]{p^{2}}+c \sqrt[n]{p^{3}}+\ldots+q \sqrt[n]{p^{n-1}} .
$$

After clearing of radicals, he gets an equation of the $n$th degree, $F(x)=0$, and by equating coefficients finds the necessary equations for determining $a, b, c$, ... $q$ and $p$, but is unable to complete the solution. Bézout also proposed a method. He eliminated $y^{\prime}$ from the equations $y^{n}-1=0, a y^{n-1}+b y^{n-2}+\ldots$ $+x=0$, and obtained an equation of the $n$th degree, $f(x)=0$, and then equated coefficients. Bézout was no more able to solve the general equation of the 5 th degree than Waring, but the problem gave him the impulse to perfect methods of elimination.

Tschirnhausen had begun, with his transformation, to study the roots of the general equation as functions of the coefficients. The same result can be reached by another method not different in principle, namely the formation of resolvents. In this way, Lagrange, Malfatti and Vandermonde independently reached results which were published in the year 1771 . Lagrange's work, rich in matter, gave an analysis of all the then known methods of solving equations, and explained the difficulties which present themselves in 
passing beyond the fourth degree. Besides this he gave methods for determining the limits of the roots and the number of imaginary roots, as well as methods of approximation.

Thus all expedients for solving the general equation, made prior to the beginning of the nineteenth century yielded poor results, and especially with reference to Lagrange's work Montucla* says "all this is well calculated to cool the ardor of those who are inclined to tread this new way. Must one entirely despair of the solution of this problem?"

Since the general problem proved insoluble, attempts were made with special cases, and many elegant results were obtained in this way. De Moivre brought the solution of the equation

$$
n y+\frac{n^{2}-1}{2 \cdot 3} n y^{8}+\frac{\left(n^{2}-1\right) \cdot\left(n^{2}-9\right)}{2 \cdot 3 \cdot 4 \cdot 5} n y^{5}+\ldots=a,
$$

for odd integral values of $n$, into the form

$$
y=\frac{1}{2} \sqrt[n]{a+\sqrt{a^{2}+1}}-\frac{1}{2} \sqrt[n]{-a-\sqrt{a^{2}+1}} .
$$

Euler investigated symmetric equations and Bézout deduced the relation between the coefficients of an equation of the $n$th degree which must exist in order that the same may be transformed into $y^{n}+a=0$.

Gauss made an especially significant step in advance in the solution of the cyclotomic equation $x^{n}-1$ $=0$, where $n$ is a prime number. Equations of this sort are closely related to the division of the circum-

* Histoire des Sciences Mathematiques, I799-1802. 
ference into $n$ equal parts. If $y$ is the side of an inscribed $n$-gon in a circle of radius 1 , and $z$ the diagonal connecting the first and third vertices, then

$$
y=2 \sin \frac{\pi}{n}, \quad z=2 \sin \frac{2 \pi}{n} .
$$

If however

$$
x=\cos \frac{2 \pi}{n}+i \sin \frac{2 \pi}{n}, \quad\left(\cos \frac{2 \pi}{n}+i \sin \frac{2 \pi}{n}\right)^{n}=1,
$$

then the equation $x^{n}-1=0$ is to be considered as the algebraic expression of the problem of the construction of the regular $n$-gon.

The following very general theorem was proved by Gauss.* "If $n$ is a prime number, and if $n-1$ be resolved into prime factors $a, b, c, \ldots$ so that $n-1=$ $a^{a} b^{\beta} c^{\gamma}$. . . , then it is always possible to make the solution of $x^{n}-1=0$ depend upon that of several equations of lower degree, namely upon a equations of degree $a, \beta$ equations of degree $b$, etc." Thus for example, the solution of $x^{73}-1=0$ (the division of the circumference into 73 equal parts) can be effected, since $n-1=72=3^{2} .2^{3}$, by solving three quadratic and two cubic equations. Similarly $x^{17}-1=0$ leads to four equations of the second degree, since $n-1=$ $16=2^{4}$; therefore the regular 17 -gon can be constructed by elementary geometry, a fact which before the time of Gauss no one had anticipated.

Detailed constructions of the regular 17 -gon by elementary geometry were first given by Pauker and

* Legendre, Théorie des Vombres. 
Erchinger.* A noteworthy construction of the same figure is due to von Staudt.

For the case that the prime number $n$ has the form $2^{m}+1$, the solution of the equation $x^{n}-1=0$ depends upon the solution of $m$ quadratic equations of which only $m-1$ are necessary in the construction of the regular $n$-gon. It should be observed that for $m=2^{k}$ ( $k$ a positive integer), the number $2^{m}+1$ may be prime, but, as $\mathrm{R}$. Baltzer $\nmid$ has pointed out, is not necessarily prime. If $m$ is given successively the values

$$
1,2,3,4,5,6.7,8,16.2^{12}, 2^{23},
$$

$n=2^{m}+1$ will take the respective values

$$
3,5,9,17,33,65,129,257,65537,2^{2^{12}}+1,2^{2^{23}}+1,
$$

of which only $3,5,17,257,65537$ are prime. The remaining numbers are composite; in particular, the last two values of $n$ have respectively the factors 114689 and 167772161 . The circle therefore can be divided into 257 or 65537 equal parts by solving respectively 7 or 15 quadratic equations, which is possible by elementary geometric construction.

From the equalities

$$
\begin{aligned}
255 & =2^{8}-1=\left(2^{4}-1\right)\left(2^{4}+1\right)=15 \cdot 17, \quad 256=2^{8}, \\
65535 & =2^{16}-1=\left(2^{8}-1\right)\left(2^{8}+1\right)=255 \cdot 257,65536=2^{16},
\end{aligned}
$$

it is easily seen that, by elementary geometry, that is, by use of only straight edge and compasses, the circle can be divided respectively into $255,256,257 ; 65535,65536,65537$ equal parts. The process cannot be continued without a break, since $n=2^{32}+1$ is not prime.

The possibility of an elementary geometric construction of the regular 65535-gon is evident from the following:

$$
65535=255 \cdot 257=15 \cdot 17 \cdot 257 .
$$

If the circumference of the circle is 1 , then since

* Gauss, Werke, II., p. I 87.

$\dagger$ Netto, Substitutionentheorie, I882; English by Cole, IS92, p. 187. 


$$
\mathrm{I}_{5}-\frac{1}{17}=\frac{2}{2} \frac{2}{5}, \frac{1}{5 \overline{5}}-\frac{1}{2} \overline{5}=\frac{1}{65} \overline{5} \overline{3} \text {, }
$$

it follows that $\overline{6} \overline{5} \frac{1}{\overline{5}} \overline{5}$ of the circumference can be obtained by elementary geometric operations.

After Gauss had given in his earliest scientific work, his doctor's dissertation, the first of his proofs of the important theorem that every algebraic equation has a real or an imaginary root, he made in his great memoir of 1801 on the theory of numbers, the conjecture that it might be impossible to solve general equations of degree higher than the fourth by radicals. Ruffini and Abel gave a rigid proof of this fact, and it is due to these investigations that the fruitless efforts to reach the solution of the general equation by the algebraic method were brought to an end. In their stead the question formulated by Abel came to the front, "What are the equations of given degree which admit of algebraic solution?"

The cyclotomic equations of Gauss form such a group. But Abel made an important generalization by the theorem that an irreducible equation is always soluble by radicals when of two roots one can be rationally expressed in terms of the other, provided at the same time the degree of the equation is prime; if this is not the case, the solution depends upon the solution of equations of lower degree.

A further great group of algebraically soluble equations is therefore comprised in the Abelian equations. But the question as to the necessary and sufficient conditions for the algebraic solubility of an equation 
was first answered by the youthful Galois, the crown of whose investigations is the theorem, "If the degree of an irreducible equation is a prime number, the equation is soluble by radicals alone, provided the roots of this equation can be expressed rationally in terms of any two of them."

Abel's investigations fall between the years 1824 and 1829, those of Galois in the years 1830 and 1831 . Their fundamental significance for all further labors in this direction is an undisputed fact; the question concerning the general type of algebraically soluble equations alone awaits an answer.

Galois, who also earned special honors in the field of modular equations which enter into the theory of elliptic functions, introduced the idea of a group of substitutions.* The importance of this innovation, and its development into a formal theory of substitutions, as Cauchy has first given it in the Exercices d'analy'se, etc., when he speaks of "systems of conjugate substitutions," became manifest through geometric considerations. The first example of this was furnished by Hesse $t$ in his investigation on the nine points of inflexion of a curve of the third degree. The equation of the ninth degree upon which they depend belongs to the class of algebraically soluble equations. In this equation there exists between any two of the roots and a third determined by them an algebraic re-

* Netto, Substitutionentheorie, 1882. English by Cole, 1892.

+ Noether, O. H., Schlömilch's Zeitschrift, Band 20. 
lation expressing the geometric fact that the nine points of inflexion lie by threes on twelve straight lines. To the development of the substitution theory in later times, Kronecker, Klein, Noether, Hermite, Betti, Serret, Poincaré, Jordan, Capelli, and Sylow especially have contributed.

Most of the algebraists of recent times have participated in the attempt to solve the equation of the fifth degree. Before the impossibility of the algebraic solution was known, Jacobi at the age of 16 had made an attempt in this direction; but an essential advance is to be noted from the time when the solution of the equation of the fifth degree was linked with the theory of elliptic functions. * By the help of transformations as given on the one hand by Tschirnhausen and on the other by E. S. Bring (1786), the roots of the equation of the fifth degree can be made to depend upon a single quantity only, and therefore the equation, as shown by Hermite, can be put into the form $t^{5}-t-A$ $=0$. By Riemann's methods, the dependence of the roots of the equation upon the parameter $A$ is illustrated; on the other hand, it is possible by powerseries to calculate these five roots to any degree of approximation. In 185S, Hermite and Kronecker solved the equation of the fifth degree by elliptic functions, but without reference to the algebraic theory of this equation, while Klein gave the simplest possible solu-

* Klein, F., Vergleichende Betrachtuns,i iul,r neucre geonctrische Forschungen, I872. 
tion by transcendental functions by using the theory of the icosahedron.

The solution of general equations of the $n$th degree for $n>4$ by transcendental functions has therefore become possible, and the operations entering into the solution are the following: Solution of equations of lower degree; solution of linear differential equations with known singular points; determination of constants of integration, by calculating the moduli of periodicity of hyperelliptic integrals for which the branch-points of the function to be integrated are known; finally the calculation of theta-functions of several variables for special values of the argument.

The methods leading to the complete solution of an algebraic equation are in many cases tedious; on this account the methods of approximation of real roots are very important, especially where they can be applied to transcendental equations. The most general method of approximation is due to Newton (communicated to Barrow in 1669), but was also reached by Halley and Raphson in another way.* For the solution of equations of the third and fourth degrees, John Bernoulli worked out a valuable method of approximation in his Lectiones calculi integralis. Further methods of approximation are due to Daniel Bernoulli, Taylor, 'Thomas Simpson, Lagrange, Legendre, Horner, and others.

By graphic and mechanical means also, the roots of an equation can be approximated. C. V. Boysł made use of a machine for this purpose, which consisted of a system of levers and fulcrums; Cunynghame $\nmid$ used a cubic parabola with a tangent scale * Montucla. + Nature, XXXIII., p. 166. 
on a straight edge; C. Reuschle* used an hyperbola with an accompanying gelatine-sheet, so that the roots could be read as intersections of an hyperbola with a parabola. Similar methods, suited especially to equations of the third and fourth degrees are due to Bartl, R. Hoppe, and Oekinghausf; Lalanne and Mehmke also deserve mention in this connection.

For the solution of equations, there had been invented in the seventeenth century an algorism which since then has gained a place in all branches of mathematics, the algorism of determinants. $\neq$ The first suggestion of computation with those regularly formed aggregates, which are now called determinants (after Cauchy), was given by Leibnitz in the year 1693 . He used the aggregate

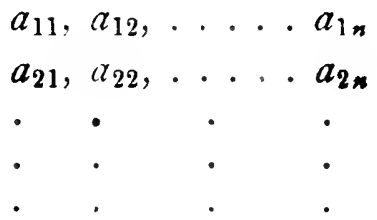

in forming the resultant of $n$ linear equations with $n-1$ unknowns, and that of two algebraic equations with one unknown. Cramer (1750) is considered as a second inventor, because he began to develop a system of computation with determinants. Further theorems are due to Bézout (1764), Vandermonde (1771), Laplace (1772), and Lagrange (1773). Gauss's Disquisitiones arithmeticae (1801) formed an essential ad-

* Böklen, O., Math. Mittheilungen, I886, p. 102.

+ Fortschritte, 1883 ; 1884 .

$\$$ Muir, T., Theory of Determinants in the Historical Order of its Development, Part I, I890; Baltzer. R., Theorie und Anwendungen der Determinanten, I88I. 
vance, and this gave Cauchy the impulse to many new investigations, especially the development of the general law (1812) of the multiplication of two determinants.

Jacobi by his "masterful skill in technique," also rendered conspicuous service in the theory of determinants, having developed a theory of expressions which he designated as "functional determinants." The analogy of these determinants with differential quotients led him to the general "principle of the last multiplier" which plays a part in nearly all problems of integration.* Hesse considered in an especially thorough manner symmetric determinants whose elements are linear functions of the co-ordinates of a geometric figure. He observed their behavior by linear transformation of the variables, and their relations to such determinants as are formed from them by a single bordering. $\dagger$ Later discussions are due to Cayley on skew determinants, and to Nachreiner and S. Günther on relations between determinants and continued fractions.

The appearance of the differential calculus forms one of the most magnificent discoveries of this period. The preparatory ideas for this discovery appear in manifest outline in Cavalieri, $\$$ who in a work Methodus indivisibilium (1635) considers a space-element as

*Dirichlet, "Gedächtnissrede auf Jacobi." Creile's Journal, Band 52.

+ Noether, O. H., Schiömilch's Zeitschrift, Band 20.

$\ddagger$ I.üroth, Rektoratsrede, Freiburg, 1889; Cantor, II., p. 759. 
the sum of an infinite number of simplest space-elements of the next lower dimension, e. g., a solid as the sum of an infinite number of planes. The danger of this conception was fully appreciated by the inventor of the method, but it was improved first by Pascal who considers a surface as composed of an infinite number of infinitely small rectangles, then by Fermat and Roberval ; in all these methods, however, there appeared the drawback that the sum of the resulting series could seldom be determined. Kepler remarked that a function can vary only slightly in the vicinity of a greatest or least value. Fermat, led by this thought, made an attempt to determine the maximum or minimum of a function. Roberval investigated the problem of drawing a tangent to a curve, and solved it by generating the curved line by the composition of two motions, and applied the parallelogram of velocities to the construction of the tangents. Barrow, Newton's teacher, used this preparatory work with reference to Cartesian co-ordinate geometry. He chose the rectangle as the velocity-parallelogram, and at the same time introduced like Fermat infinitely small quantities as increments of the dependent and independent variables, with special symbols. He gave also the rule, that, without affecting the validity of the result of computation, higher powers of infinitely small quantities may be neglected in comparison with the first power. But Barrow was not able to handle fractions and radicals involving infinitely small quantities, 
and was compelled to resort to transformations to remove them. Like his predecessors, he was able to determine in the simpler cases the value of the quotient of two, or the sum of an infinite number of infinitesimals. The general solution of such questions was reached by Leibnitz and Newton, the founders of the differential calculus.

Leibnitz gave for the calculus of infinitesimals, the notion of which had been already introduced, further examples and also rules for more complicated cases. By summation according to the old methods, * he deduced the simplest theorems of the integral calculus, which he, by prefixing a long $S$ as the sign of summation wrote,

$$
\int x=\frac{x^{2}}{2}, \quad \int x^{2}=\frac{x^{8}}{3}, \quad \int(x+y)=\int x+\int y .
$$

From the fact that the sign of summation $\int$ raised the dimension, he drew the conclusion that by difference-forming the dimension must be diminished so that, therefore, as he wrote in a manuscript of Oct. 29,1675 , from $\int l=y a$, follows immediately $l=\frac{y a}{d}$.

Leibnitz tested the power of his new method by geometric problems; he sought, for example, to determine the curve "for which the intercepts on the axis to the feet of the normals vary as the ordinates." In this he let the abscissas $x$ increase in arithmetic ratio and designated the constant difference of the

* Gerhardt, Geschichte der Mathematik in Deutschland, 1877 ; Cantor, III., p. 160 . 
abscissas first by $\frac{x}{d}$ and later by $d x$, without explaining in detail the meaning of this new symbol. In 1676 Leibnitz had developed his new calculus so far as to be able to solve geometric problems which could not be reduced by other methods. Not before 1686, however, did he publish anything about his method, its great importance being then immediately recognized by Jacob Bernoulli.

What Leibnitz failed to explain in the development of his methods, namely what is understood by his infinitely small quantities, was clearly expressed by Newton, and secured for him a theoretical superiority. Of a quotient of two infinitely small quantities Newton speaks as of a limiting value* which the ratio of the vanishing quantities approaches, the smaller they become. Similar considerations hold for the sum of an infinite number of such quantities. For the determination of limiting values, Newton devised an especial algorism, the calculus of fluxions, which is essentially identical with Leibnitz's differential calculus. Newton considered the change in the variable as a flowing; he sought to determine the velocity of the variation of the function when the variable changes with a given velocity. The velocities were called fluxions and were designated by $\dot{x}, \dot{y}, \dot{z}$ (instead of $d x, d y, d z$, as in Leibnitz's writings). The quantities themselves were called fluents, and the calculus of fluxions determines therefore the velocities of given

\footnotetext{
* Lüroth, Rektoratsrede, Freiburg, I88g.
} 
motions, or seeks conversely to find the motions when the law of their velocities is known. Newton's paper on this subject was finished in 1671 under the name of Methodus fuxionum, but was first published in 1736, after his death. Newton is thought by some to have borrowed the idea of fluxions from a work of Napier.*

According to Gauss, Newton deserved much more credit than Leibnitz, although he attributes to the latter great talent, which, however, was too much dissipated. It appears that this judgment, looked at from both sides, is hardly warranted. Leibnitz failed to give sătisfactory explanation of that which led Newton to one of his most important innovations, the idea of limits. On the other hand, Newton is not always entirely clear in the purely analytic proo: Leibnitz, too, deserves very high praise for the introduction of the appropriate symbols $\int$ and $d x$, as well as for stating the rules of operating with them. Today the opinion might safely be expressed that the differential and integral calculus was independently discovered by Newton and by Leibnitz; that Newton is without doubt the first inventor; that Leibnitz, on the other hand, stimulated by the results communicated to him by Newton, but without the knowledge of Newton's methods, invented independently the calculus; and that finally to Leibnitz belongs the priority of publication. " $†$

* Cohen, Das Prinzip der Infinitesimalmethode und seine Geschichte, I889: Cantor, III., p. 163 .

+Lüroth. A very good summary of the discussion is also given in Ball's 
The systematic development of the new calculus made necessary a clearer understanding of the idea of the infinite. Investigations on the infinitely great are of course of only passing interest for the explanation of natural phenomena, ${ }^{*}$ but it is entirely different with the question of the infinitely small. The infinitesimal $\dagger$ appears in the writings of Kepler as well as in those of Cavalieri and Wallis under varying forms, essentially as "infinitely small null-value," that is, as a quantity which is smaller than any given quantity, and which forms the limit of a given finite quantity. Euler's indivisibilia lead systematically in the same direction. Fermat, Roberval, Pascal, and especially Leibnitz and Newton operated with the "unlimitedly small," yet in such a way that frequently an abbreviated method of expression concealed or at least obscured the true sense of the development. In the writings of John Bernoulli, De l'Hospital, and Poisson, the infinitesimal appears as a quantity difterent from zero, but which must become less than an assignable value, i. e., as a "pseudo-infinitesimal" quantity. By the formation of derivatives, which in the main are identical with Newton's fluxions, Lagrange + attempted entirely to avoid the infinitesimal, but his attempts only served the purpose of bringing into

Short History of Mathematics, London, I888. The best summary is that given in Cantor, Vol. III.

* Riemann, Werke, p. 267.

$\dagger$ R. Hoppe, Differentialrechnung, 1865.

${ }_{+}$Lüroth, Rektoratsrede, Freiburg, I889. 
prominence the urgent need for a deeper foundation for the theory of the infinitesimal for which Tacquet and Pascal in the seventeenth century, and Maclaurin and Carnot in the eighteenth had made preparation. We are indebted to Cauchy for this contribution. In his investigations there is clearly established the meaning of propositions which contain the expression "infinitesimal," and a safe foundation for the differential calculus is thereby laid.

The integral calculus was first further extended by Cotes, who showed how to integrate rational algebraic functions. Legendre applied himself to the integration of series, Gauss to the approximate determination of integrals, and Jacobi to the reduction and evaluation of multiple integrals. Dirichlet is especially to be credited with generalizations on definite integrals, his lectures showing his great fondness for this theory.* $\mathrm{He}$ it was who welded the scattered results of his predecessors into a connected whole, and enriched them by a new and original method of integration. The introduction of a discontinuous factor allowed him to replace the given limits of integration by different ones, often by infinite limits, without changing the value of the integral. In the more re. cent investigations the integral has become the means of defining functions or of generating others.

In the realm of differential equations $\dagger$ the works

* Kummer, "Gedächtnissrede auf Lejeune-Dirichlet." Berliner Abh., 1860 † Cantor, IIl., p. 429 ; Schlesinger, L., Handbuch der Theorie der linearen 
worthy of mention date back to Jacob and John Bernoulli and to Riccati. Riccati's merit consists mainly in having introduced Newton's philosophy into Italy. $\mathrm{He}$ also integrated for special cases the differential equation named in his honor-an equation completely solved by Daniel Bernoulli-and discussed the question of the possibility of lowering the order of a given differential equation. The theory first received a detailed scientific treatment at the hands of Lagrange, especially as far as concerns partial differential equations, of which D'Alembert and Euler had handled the equation $\frac{d^{2} u}{d t^{2}}=\frac{d^{2} u}{d x^{2}}$. Laplace also wrote on this differential equation and on the reduction of the solution of linear differential equations to definite integrals.

On German soil, J. F. Pfaff, the friend of Gauss and next to him the most eminent mathematician of that time, presented certain elegant investigations (1814, 1815) on differential equations, * which led Jacobi to introduce the name "Pfaffian problem." Pfaff found in an original way the general integration of partial differential equations of the first degree for any number of variable quantities. Beginning with the theory of ordinary differential equations of the first degree with $n$ variables, for which integrations

Differentialgleichungen, Bd. I., I895,--an excellent historical review; Mansion, P., Theorie der partiellen Differentialgleichungen erster Ordnung, deutsch von Maser, Leipzig, I892, also excellent on history.

*A. Brill, "Das mathematisch-physikalische Seminar in Tübingen." Aus der Festschrift der Universität zum Königs-Jubilüum, 1889. 
were given by Monge (1809) in special simple cases, Pfaff gave their general integration and considered the integration of partial differential equations as a particular case of the general integration. In this the general integration of differential equations of every degree between two variables is assumed as known.* Jacobi $(1827,1836)$ also advanced the theory of differential equations of the first order. The treatment was so to determine unknown functions that an integral which contains these functions and the differential coefficient in a prescribed way reaches a maximum or minimum. The condition therefor is the vanishing of the first variation of the integral, which again finds its expression in differential equations, from which the unknown functions are determined. In order to be able to distinguish whether a real maximum or minimum appears, it is necessary to bring the second variation into a form suitable for investigating its sign. This leads to new differential equations which Lagrange was not able to solve, but of which Jacobi was able to show that their integration can be deduced from the integration of differential equations belonging to the first variation. Jacobi also investigated the special case of a simple integral with one unknown function, his statements being completely proved by Hesse. Clebsch undertook the general investigation of the second variation, and he was successful in showing for the case of multiple integrals that new

-Gauss, Werke, III., p. 232. 
integrals are not necessary for the reduction of the second variation. Clebsch $(1861,1862)$, following the suggestions of Jacobi, also reached the solution of the Pfaffian problem by making it depend upon a system of simultaneous linear partial differential equations, the statement of which is possible without integration. Of other investigations, one of the most important is the theory of the equation

$$
\frac{d^{2} v}{d x^{2}}+\frac{d^{2} v}{d y^{2}}+\frac{d^{2} v}{d^{2}}=0
$$

which Dirichlet encountered in his work on the potential, but which had been known since Laplace (1789). Recent investigations on differential equations, especially on the linear by Fuchs, Klein, and Poincaré, stand in close connection with the theories of functions and groups, as well as with those of equations and series.

"Within a half century the theory of ordinary differential equations has come to be one of the most important branches of analysis, the theory of partial differential equations remaining as one still to be perfected. The difficulties of the general problem of integration are so manifest that all classes of investigators have confined themselves to the properties of the integrals in the neighborhood of certain given points. The new departure took its greatest inspiration from two memoirs by Fuchs (I866, I868), a work elaborated by Thomé and Frobenius. . . .

"Since IS70 Lie's labors have put the entire theory of differential equations on a more satisfactory foundation. He has shown that the integration theories of the older mathematicians, which had been looked upon as isolated, can by the introduction of the concept of continuous groups of transformations be referred to a 
common source, and that ordinary differential equations which admit the same infinitesimal transformations present like difficulties of integration $\mathrm{He}$ has also emphasized the subject of transformations of contact (Berührungs-Transformationen) which underlies so much of the recent theory. . . Recent writers have shown the same tendency noticeable in the works of Monge and Cauchy, the tendency to separate into two schools, the one inclining to use the geometric diagram and represented by Schwarz, Klein, and Goursat, the other adhering to pure analysis, of which Weierstrass, Fuchs, and Frobenius are types."*

A short time after the discovery of the differential and integral calculus, namely in the year 1696, John Bernoulli proposed this problem to the mathematicians of his time: To find the curve described by a body falling from a given point $A$ to another given point $B$ in the shortest time. $\nmid$ The problem came from a case in optics, and requires a function to be found whose integral is a minimum. Huygens had developed the wave-theory of light, and John Bernoulli had found under definite assumptions the differential equation of the path of the ray of light. Of such motion he sought another example, and came upon the cycloid as the brachistochrone, that is, upon the above statement of the problem, for which up to Easter 1697, solutions from the Marquis de l'Hospital, from Tschirnhausen, Newton, Jacob Bernoulli and Leibnitz were received. Only the two latter treated the

* Smith, D. E., "History of Modern Mathematics," in Merriman and Woodward's Higher Mathematics, New York, I896, with authorities cited.

† Reiff, R., "Die Anfänge der Variationsrechnung," Math. Mittheilungen von Böklen, 1887. Cantor, III., p. 225. Woodhouse, A Treatise on Isoperimetrical Problems (Cambridge, $\mathrm{I} 8 \mathrm{ro}$ ). The last named work is rare. 
problem as one of maxima and minima. Jacob Bernoulli's method remained the common one for the treatment of similar cases up to the time of Lagrange, and he is therefore to be regarded as one of the founders of the calculus of variations. At that time* all problems which demanded the statement of a maximum or minimum property of functions were called isoperimetric problems. To the oldest problems of this kind belong especially those in which one curve with a maximum or minimum property was to be found from a class of curves of equal perimeters. That the circle, of all isoperimetric figures, gives the maximum area, is said to have been known to Pythagoras. In the writings of Pappus a series of propositions on figures of equal perimeters are found. Also in the fourteenth century the Italian mathematicians had worked on problems of this kind. But "the calculus of variations may be said to begin with ... John Bernoulli (1696). It immediately occupied the attention of Jacob Bernoulli and the Marquis de l'Hospital, but Euler first elaborated the subject." $\nmid$ Het investigated the isoperimetric problem first in the analytic-geometric manner of Jacob Bernoulli, but after he had worked on the subject eight years, he came in 1744 upon a new and general solution by a purely analytic method (in his celebrated work: Methodus inveniendi

* Anton, Geschichte des isoperimetrischen Froblems, I888.

† Smith, D. E., History of Modern Mathematics, p. 533.

+Cantor, III., pp. 243, 819,830. 
lineas curvas, etc.); this solution shows how those ordinates of the function which are to assume a greatest or least value can be derived from the variation of the curve-ordinate. Lagrange (Essai d'une nouvelle methode, etc., 1760 and 1761) made the last essential step from the pointwise variation of Euler and his predecessors to the simultaneous variation of all ordinates of the required curve by the assumption of variable limits of the integral. His methods, which contained the new feature of introducing $\delta$ for the change of the function, were later taken up in Euler's Integral Calculus. Since then the calculus of variations has been of valuable service in the solution of problems in theory of curvature.

The beginnings of a real theory of functions*, especially that of the elliptic and Abelian functions lead back to Fagnano, Maclaurin, D'Alembert, and Landen. Integrals of irrational algebraic functions were treated, especially those involving square roots of polynomials of the third and fourth degrees; but none of these works hinted at containing the beginnings of a science dominating the whole subject of algebra. The matter assumed more definite form under the hands of Euler, Lagrange, and Legendre. For a long time the only transcendental functions known were the circular func-

* Brill, A., and Noether, M., "Die Entwickelung der Theorie der algebraischen Functionen in älterer und neuercr Zeit, Bericht erstattet der Deutschen Mathematiker-Vereinigung, Jahresbericht, Bd. II., pp. 107-566, Berlin, 1894; Königsberger, L., Zur Geschichte der Theorie der elliptischen Transcendenten in den Jahren $1826-1829$. Leipzig, I879. 
tions $(\sin x, \cos x, \ldots)$, the common logarithm, and, especially for analytic purposes, the hyperbolic logarithm with base $e$, and (contained in this) the exponential function $e^{x}$. But with the opening of the nineteenth century mathematicians began on the one hand thoroughly to study special transcendental functions, as was done by Legendre, Jacobi, and Abel, and on the other hand to develop the general theory of functions of a complex variable, in which field Gauss, Cauchy, Dirichlet, Riemann, Liouville, Fuchs, and Weierstrass obtained valuable results.

The first signs of an interest in elliptic functions* are connected with the determination of the arc of the lemniscate, as this was carried out in the middle of the eighteenth century. In this Fagnano made the discovery that between the limits of two integrals expressing the arc of the curve, one of which has twice the value of the other, there exists an algebraic relation of simple nature. By this means, the arc of the lemniscate, though a transcendent of higher order, can be doubled or bisected by geometric construction like an arc of a circle. $\dagger$ Euler gave the explanation of this remarkable phenomenon. He produced a more general integral than Fagnano (the so-called elliptic integral of the first class) and showed that two such integrals can be combined into a third of the same kind, so that between the limits of these

*Enneper, A., Elliptische Functionen, Theorie und Geschichte, Halle, I89o.

+Dirichlet, "Gedächtnissrede auf Jacobi," Crelle's Journal, Bd. 52. 
integrals there exists a simple algebraic relation, just as the sine of the sum of two arcs can be composed of the same functions of the separate arcs (addition-theorem). The elliptic integral, however, depends not merely upon the limits but upon another quantity belonging to the function, the modulus. While Euler placed only integrals with the same modulus in relation, Landen and Lagrange considered those with different moduli, and showed that it is possible by simple algebraic substitution to change one elliptic integral into another of the same class. The establishment of the addition-theorem will always remain at least as important a service of Euler as his transformation of the theory of circular functions by the introduction of imaginary exponential quantities.

The origin* of the real theory of elliptic functions and the theta-functions falls between 1811 and 1829 . To Legendre are due two systematic works, the Exercices de calcul intégral (1811-1816) and the Théorie des fonctions elliptiques (1825-1828), neither of which was known to Jacobi and Abel. Jacobi published in 1829 the Fundamenta nova theoriae functionum ellipticarum, certain of the results of which had been simultaneously discovered by Abel. Legendre had recognised that a new branch of analysis was involved in those investigations, and he devoted decades of earnest work to its development. Beginning with the integral which depends upon a square root of an expression of 
the fourth degree in $x$, Legendre noticed that such integrals can be reduced to canonical forms. $\Delta \psi=$ $\sqrt{1-k^{2} \sin ^{2} \psi}$ was substituted for the radical, and three essentially different classes of elliptic integrals were distinguished and represented by $F(\psi), E(\psi)$, $\Pi(\psi)$. These classes depend upon the amplitude $\psi$ and the modulus $k$, the last class also upon a parameter $n$.

In spite of the elegant investigations of Legendre on elliptic integrals, their theory still presented sev eral enigmatic phenomena. It was noticed that the degree of the equation conditioning the division of the elliptic integral is not equal to the number of the parts, as in the division of the circle, but to its square. The solution of this and similar problems was reserved for Jacobi and Abel. Of the many productive ideas of these two eminent mathematicians there are especially two which belong to both and have greatly advanced the theory.

In the first place, Abel and Jacobi independently of each other observed that it is not expedient to investigate the elliptic integral of the first class as a function of its limits, but that the method of consideration must be reversed, and the limit introduced as a function of two quantities dependent upon it. Expressed in other words, Abel and Jacobi introduced the direct functions instead of the inverse. Abel called them $\phi, f, F$, and Jacobi named them $\sin a m, \cos a m, \Delta a m$, or, as they are written by Gudermann, $s n, c n, d n$. 
A second ingenious idea, which belongs to Jacobi as well as to Abel, is the introduction of the imaginary into this theory. As Jacobi himself affirmed, it was just this innovation which rendered possible the solution of the enigma of the earlier theory. It turned out that the new functions partake of the nature of the trigonometric and exponential functions. While the former are periodic only for real values of the argument, and the latter only for imaginary values, the elliptic functions have two periods. It can safely be said that Gauss as early as the beginning of the nineteenth century had recognised the principle of the double period, a fact which was first made plain in the writings of Abel.

Beginning with these two fundamental ideas, Jacobi and Abel, each in his own way, made further important contributions to the theory of elliptic functions. Legendre had given a transformation of one elliptic integral into another of the same form, but a second transformation discovered by him was unknown to Jacobi, as the latter after serious difficulties reached the important result that a multiplication in the theory of such functions can be composed of two transformations. Abel applied himself to problems concerning the division and multiplication of elliptic integrals. A thorough study of double periodicity led him to the discovery that the general division of the elliptic integral with a given limit is always algebraically possible as soon as the division of the complete 
integrals is assumed as accomplished. The solution of the problem was applied by Abel to the lemniscate, and in this connection it was proved that the division of the whole lemniscate is altogether analogous to that of the circle, and can be performed algebraically in the same case. Another important discovery of Abel's occurred in his allowing, for elliptic functions of multiple argument, the multiplier to become infinite in formulas deduced from functions with a single argument. From this resulted the remarkable expressions which represent elliptic functions by infinite series or quotients of infinite products.

Jacobi had assumed in his investigations on transformations that the original variable is rationally expressible in terms of the new. Abel, however, entered this field with the more general assumption that between these two quantities an algebraic equation exists, and the result of his labor was that this more general problem can be solved by the help of the special problem completely treated by Jacobi.

Jacobi carried still further many of the investigations of Abel. Abel had given the theory of the general division, but the actual application demanded the formation of certain symmetric functions of the roots which could be obtained only in special cases. Jacobi gave the solution of the problem so that the required functions of the roots could be obtained at once and in a manner simpler than Abel's. When Jacobi had reached this goal, he stood alone on the 
broad expanse of the new science, for Abel a short time before had found an early grave at the age of 27 .

The later efforts of Jacobi culminate in the introduction of the theta-function. Abel had already represented elliptic functions as quotients of infinite products. Jacobi could represent these products as special cases of a single transcendent, a fact which the French mathematicians had come upon in physical researches but had neglected to investigate. Jacobi examined their analytic nature, brought them into connection with the integrals of the second and third class, and noticed especially that integrals of the third class, though dependent upon three elements, can be represented by means of the new transcendent involving only two elements. The execution of this process gave to the whole theory a high degree of comprehensiveness and clearness, allowing the elliptic functions $s n, c n, d n$ to be represented with the new Jacobian transcendents $\Theta_{1}, \Theta_{2}, \Theta_{3}, \Theta_{4}$ as fractions having a common denominator.

What Abel accomplished in the theory of elliptic functions is conspicuous, although it was not his greatest achievement. There is high authority for saying that the achievements of Abel were as great in the algebraic field as in that of elliptic functions. But his most brilliant results were obtained in the theory of the Abelian functions named in his honor, their first development falling in the years 1826-1829. "Abel's Theorem" has been presented by its discov- 
erer in different forms. The paper, Mémoire sur une proprieté générale d'une classe très-étendue de fonctions transcendentes, which after the death of the author received the prize from the French academy, contained the most general expression. In form it is a theorem of the integral calculus, the integrals depending upon an irrational function $y$, which is connected with $x$ by an algebraic equation $F(x, y)=0$. Abel's fundamental theorem states that a sum of such integrals can be expressed by a definite number $p$ of similar integrals where $p$ depends only upon the properties of the equation $F(x, y)=0$. (This $p$ is the deficiency of the curve $F(x, y)=0$; the notion of deficiency, however, dates first from the year 1857.) For the case that

$$
y=\sqrt{A x^{4}+B x^{3}+C x^{2}+D x+E},
$$

Abel's theorem leads to Legendre's proposition on the sum of two elliptic integrals. Here $p=1$. If

$$
y=\sqrt{A x^{6}+B x^{5}+\cdots+P},
$$

where $A$ can also be 0 , then $p$ is 2 , and so on. For $p=3$, or $>3$, the hyperelliptic integrals are only special cases of the Abelian integrals of like class.

After Abel's death (1829) Jacobi carried the theory further in his Considerationes generales de transcendentibus Abelianis (1832), and showed for hyperelliptic integrals of a given class that the direct functions to which Abel's proposition applies are not functions of a single variable, as the elliptic functions $s n, c n, d n$, but are functions of $p$ variables. Separate papers of 
essential significance for the case $p=2$, are due to Rosenhain (1846, published 1851) and Goepel (1847).

Two articles of Riemann, founded upon the writings of Gauss and Cauchy, have become significant in the development of the complete theory of functions. Cauchy had by rigorous methods and by the introduction of the imaginary variable "laid the foundation for an essential improvement and transformation of the whole of analysis." * Riemann built upon this foundation and wrote the Grundlage für eine allgemeine Theorie der Funktionen einer veränderlichen komplexen Grösse in the year 1851, and the Theorie der Abel'schen Funktionen which appeared six years later. For the treatment of the Abelian functions, Riemann used theta-functions with several arguments, the theory of which is based upon the general principle of the theory of functions of a complex variable. He begins with integrals of algebraic functions of the most general form and considers their inverse functions, that is, the Abelian functions of $p$ variables. Then a theta function of $p$ variables is defined as the sum of a $p$-tuply infinite exponential series whose general term depends, in addition to $p$ variables, upon certain $\frac{p(p-1)}{2}$ constants which must be reducible to $3 p-3$ moduli, but the theory has not yet been completed.

Starting from the works of Gauss and Abel as well

* Kummer, "Gedächtnissrede auf Lejeune-Dirichlet," Berliner Abhandlungen, 1860 . 
as the developments of Cauchy on integrations in the imaginary plane, a strong movement appears in which occur the names of Weierstrass, G. Cantor, Heine, Dedekind, P. Du Bois-Reymond, Dini, Scheeffer, Pringshein, Hölder, Pincherle, and others. This tendency aims at freeing from criticism the foundations of arithmetic, especially by a new treatment of irrationals based upon the theory of functions with its considerations of continuity and discontinuity. It likewise considers the bases of the theory of series by investigations on convergence and divergence, and gives to the differential calculus greater preciseness through the introduction of mean-value theorems.

After Riemann valuable contributions to the theory of the theta-functions were made by Weierstrass, Weber, Nöther, H. Stahl, Schottky, and Frobenius. Since Riemann a theory of algebraic functions and point-groups has been detached from the theory of Abelian functions, a theory which was founded through the writings of Brill, Nöther, and Lindemann upon the remainder-theorem and the Riemann-Roch theorem, while recently Weber and Dedekind have allied themselves with the theory of ideal numbers, set forth in the first appendix to Dirichlet. The extremely rich development of the general theory of functions in recent years has borne fruit in different branches of mathematical science, and undoubtedly is to be recognised as having furnished a solid foundation for the work of the future. 


\section{GEOME'TRY.}

A. GENERAL SURVEY.

THE oldest traces of geometry are found among 1 the Egyptians and Babylonians. In this first period geometry was made to serve practical purposes almost exclusively. From the Egyptian and Babylonian priesthood and learned classes geometry was transplanted to Grecian soil. Here begins the second period, a classic era of philosophic conception of geometric notions as the embodiment of a general science of mathematics, connected with the names of Pythagoras, Eratosthenes, Euclid, Apollonius, and Archimedes. The works of the last two indeed, touch upon lines not clearly defined until modern times. Apollonius in his Conic Sections gives the first real example of a geometry of position, while Archimedes for the most part concerns himself with the geometry of measurement.

The golden age of Greek geometry was brief and yet it was not wholly extinct until the memory of the great men of Alexandria was lost in the insignificance of their successors. Then followed more than a thou- 
sand years of a cheerless epoch which at best was restricted to borrowing from the Greeks such geometric knowledge as could be understood. History might pass over these many centuries in silence were it not compelled to give attention to these obscure and unproductive periods in their relation to the past and future. In this third period come first the Romans, Hindus, and Chinese, turning the Greek geometry to use after their own fashion; then the Arabs as skilled intermediaries between the ancient classic and a modern era.

The fourth period comprises the early development of geometry among the nations of the West. By the labors of Arab authors the treasures of a time long past were brought within the walls of monasteries and into the hands of teachers in newly established schools and universities, without as yet forming a subject for general instruction. The most prominent intellects of this period are Vieta and Kepler. In their methods they suggest the fifth period which begins with Descartes. The powerful methods of analysis are now introduced into geometry. Analytic geometry comes into being. The application of its seductive methods received the almost exclusive attention of the mathematicians of the seventeenth and eighteenth centuries. Then in the so-called modern or projective geometry and the geometry of curved surfaces there arose theories which, like analytic geometry, far transcended the geometry of the ancients, especially in 
the way of leading to the almost unlimited generalization of truths already known.

\section{B. FIRST PERIOD.}

EGYP'TIANS AND BABYLONIANS.

In the same book of Ahmes which has disclosed to us the elementary arithmetic of the Egyptians are also found sections on geometry, the determination of areas of simple surfaces, with figures appended. These figures are either rectilinear or circular. Among them are found isosceles triangles, rectangles, isosceles trapezoids and circles.* The area of the rectangle is correctly determined; as the measure of the area of the isosceles triangle with base $a$ and side $b$, however, $\frac{1}{2} a b$ is found, and for the area of the isosceles trapezoid with parallel sides $a^{\prime}$ and $a^{\prime \prime}$ and oblique side $b$, the expression $\frac{1}{2}\left(a^{\prime}+a^{\prime \prime}\right) b$ is given. These approximate formulae are used throughout and are evidently considered perfectly correct. The area of the circle follows, with the exceptionally accurate value $\pi=$ $\left(\frac{16}{9}\right)^{2}=3.1605$.

Among the problems of geometric construction one stands forth preeminent by reason of its practical importance, viz., to lay off a right angle. The solution of this problem, so vital in the construction of temples and palaces, belonged to the profession of 
rope-stretchers or harpedonaptae. They used a rope divided by knots into three segments (perhaps corresponding to the numbers $3,4,5$ ) forming a Pythago. ean triangle.*

Among the Babylonians the construction of figures of religious significance led up to a formal geometry of divination which recognized triangles, quadrilaterals, right angles, circles with the inscribed regular hexagon and the division of the circumference into three hundred and sixty degrees as well as a value $\pi=3$.

Stereometric problems, such as finding the contents of granaries, are found in Ahmes; but not much is to be learned from his statements since no account is given of the shape of the storehouses.

As for projective representations, the Egyptian wall-sculptures show no evidence of any knowledge of perspective. For example a square pond is pictured in the ground-plan but the trees and the waterdrawers standing on the bank are added to the picture in the elevation, as it were from the outside. $t$

\section{SICOND PERIOD.}

THE GREEKS.

In a survey of Greek geometry it will here and there appear as if investigations connected in a very

*Cantor, I.. p. 62.

+Wiener, Lehwuch der darstellenden Geometrie, I884. Hereafter referred to as Wiener. 
simple manner with well-known theorems were not known to the Greeks. At least it seems as if they could not have been established satisfactorily, since they are thrown in among other matters evidently without connection. Doubtless the principal reason for this is that a number of the important writings of the ancient mathematicians are lost. Another no less weighty reason might be that much was handed down simply by oral tradition, and the latter, by reason of the stiff and repulsive way in which most of the Greek demonstrations were worked out, did not always render the truths set forth indisputable.

In Thales are found traces of Egyptian geometry, but one must not expect to discover there all that was known to the Egyptians. Thales mentions the theorems regarding vertical angles, the angles at the base of an isosceles triangle, the determination of a triangle from a side and two adjacent angles, and the angle inscribed in a semi-circle. He knew how to determine the height of an object by comparing its shadow with the shadow of a staff placed at the extremity of the shadow of the object, so that here may be found the beginnings of the theory of similarity. In Thales the proofs of the theorems are either not given at all or are given without the rigor demanded in later times.

In this direction an important advance was made by Pythagoras and his school. To him without question is to be ascribed the theorem known to the Egyptian "rope-stretchers" concerning the right-angled 
triangle, which they knew in the case of the triangle with sides $3,4,5$, without giving a rigorous proof. Euclid's is the earliest of the extant proofs of this theorem. Of other matters, what is to be ascribed to Pythagoras himself, and what to his pupils, it is difficult to decide. The Pythagoreans proved that the sum of the angles of a plane triangle is two right angles. They knew the golden section, and also the regular polygons so far as they make up the boundaries of the five regular bodies. Also regular starpolygons were known, at least the star-pentagon. In the Pythagorean theorems of area the gnomon played an important part. This word originally signified the vertical staff which by its shadow indicated the hours, and later the right angle mechanically represented. Among the Pythagoreans the gnomon is the figure left after a square has been taken from the corner of another square. Later, in Euclid, the gnomon is a parallelogram after similar treatment (see page 66). The Pythagoreans called the perpendicular to a straight line "a line directed according to the gnomon."*

But geometric knowledge extended beyond the school of Pythagoras. Anaxagoras is said to have been the first to try to determine a square of area equal to that of a given circle. It is to be noticed that like most of his successors he believed in the possibility of solving this problem. Enopides showed how to draw a perpendicular from a point to a line and how

*Cantor, I., p. 150. 
to lay off a given angle at a given point of a given line. Hippias of Elis likewise sought the quadrature of the circle, and later he attempted the trisection of an angle, for which he constructed the quadratrix.

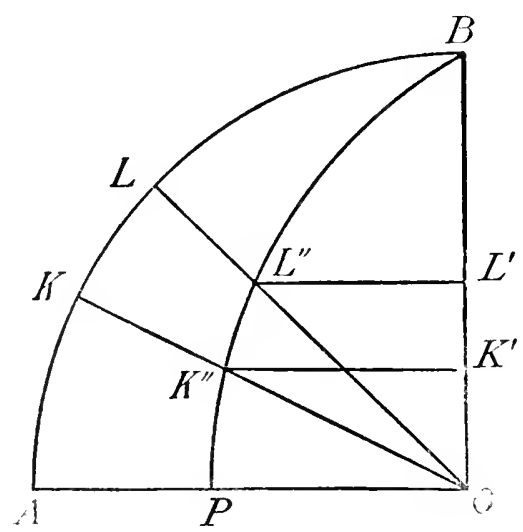

This curve is described as follows: Upon a quadrant of a circumference cut off by two perpendicular radii, $O A$ and $O B$, lie the points $A, \ldots K, L, \ldots B$. The radius $r=O A$ revolves with uniform velocity about $O$ from the position $O A$ to the position $O B$. At the same time a straight line $g$ always parallel to $O A$ moves with uniform velocity from the position $O A$ to that of a tangent to the circle at $B$. If $K^{\prime}$ is the intersection of $g$ with $O B$ at the time when the moving radius falls upon $O K$ then the parallel to $O A$ through $K^{\prime}$ meets the radius $O K$ in a point $K^{\prime \prime}$ belonging to the quadratrix. If $P$ is the intersection of $O A$ with the quadratrix, it follows in part directly and in part from simple considerations, that

$$
\frac{\operatorname{arc} A K^{\prime}}{\operatorname{arc} A L}=\frac{O K^{\prime \prime}}{O L^{\prime}}
$$

a relation which solves any problem of angle sections. Furthermore.

$$
O P=\frac{2 r}{\pi}, \text { or } \frac{O P}{O A}=\frac{O A}{\operatorname{arc} A B}
$$

whence it is obvious that the quadrature of the circle depends upon 
the ratio in which the radius $O A$ is divided by the point $P$ of the quadratrix. If this ratio could be constructed by elementary geometry, the quadrature of the circle would be effected.* It appears that the quadratrix was first invented for the trisection of an angle and that its relation to the quadrature of the circle was discovered later, $\nmid$ as is shown by Dinostratus.

The problem of the quadrature of the circle is also found in Hippocrates. He endeavored to accomplish his purpose by the consideration of crescent-shaped figures bounded by arcs of circles. It is of especial importance to note that Hippocrates wrote an elementary book of mathematics (the first of the kind) in which he represented a point by a single capital letter and a segment by tio, although we are unable to determine who was the first to introduce this symbolism.

Geometry was strengthened on the philosophic side by Plato, who felt the need of establishing definitions and axioms and simplifying the work of the investigator by the introduction of the analytic method.

A systematic representation of the results of all the earlier investigations in the domain of elementary geometry, enriched by the fruits of his own abundant labor, is given by Euclid in the thirteen books of his Elements which deal not only with plane figures but also with figures in space and algebraic investiga-

* The equation of the quadratrix in polar co-ordinates is $r=\frac{2 \phi}{\pi} \cdot \frac{a}{\sin \phi}$, where $a=O A$. Putting $\phi=0, r=r_{0}$, we have $\pi=\frac{2 a}{r_{0}}$.

$\dagger$ Montucla. 
tions. "Whatever has been said in praise of mathematics, of the strength, perspicuity and rigor of its presentation, all is especially true of this work of the great Alexandrian. Definitions, axioms, and conclusions are joined together link by link as into a chain, firm and inflexible, of binding force but also cold and hard, repellent to a productive mind and affording no room for independent activity. A ripened understanding is needed to appreciate the classic beauties of this greatest monument of Greek ingenuity. It is not the arena for the youth eager for enterprise; to captivate him a field of action is better suited where he may hope to discover something new, unexpected."*

The first book of the Elements deals with the theory of triangles and quadrilaterals, the second book with the application of the Pythagorean theorem to a large number of constructions, really of arithmetic nature. The third book introduces circles, the fourth book inscribed and circumscribed polygons. Proportions explained by the aid of line-segments occupy the fifth book, and in the sixth book find their application to the proof of theorems involving the similarity of figures. The seventh, eighth, ninth and tenth books have especially to do with the theory of numbers. These books contain respectively the measurement and division of numbers, the algorism for determining the least common multiple and the greatest common divisor, prime numbers, geometric series,

*A. Brill, Antrittsrede in Tübingen, 1884 . 
and incommensurable (irrational) numbers. Then follows stereometry: in the eleventh book the straight line, the plane, the prism; in the twelfth, the discussion of the prism, pyramid, cone, cylinder, sphere; and in the thirteenth, regular polygons with the regular solids formed from them, the number of which Euclid gives definitely as five. Without detracting in the least from the glory due to Euclid for the composition of this imperishable work, it may be assumed that individual portions grew out of the well grounded preparatory work of others. This is almost certainly true of the fifth book, of which Eudoxus seems to have been the real author.

Not by reason of a great compilation like Euclid, but through a series of valuable single treatises, Archimedes is justly entitled to have a more detailed description of his geometric productions. In his investigations of the sphere and cylinder he assumes that the straight line is the shortest distance between two points. From the Arabic we have a small geometric work of Archimedes consisting of fifteen so-called lemmas, some of which have value in connection with the comparison of figures bounded by straight lines and arcs of circles, the trisection of the angle, and the determination of cross-ratios. Of especial importance is his mensuration of the circle, in which he shows $\pi$ to lie between $3 \frac{1}{7}$ and $3 \frac{1}{7} \frac{0}{1}$. This as well as many other results Archimedes obtains by the method of exhaustions which among the ancients usually took 
the place of the modern integration.* The quantity sought, the area bounded by a curve, for example, may be considered as the limit of the areas of the inscribed and circumscribed polygons the number of whose sides is continually increased by the bisection of the arcs, and it is shown that the difference between two associated polygons, by an indefinite continuance of this process, must become less than an arbitrarily small given magnitude. This difference was thus, as it were, exhausted, and the result obtained by exhaustion.

The field of the constructions of elementary geometry received at the hands of Apollonius an extension in the solution of the problem to construct a circle tangent to three given circles, and in the systematic introduction of the diorismus (determination or limitation). This also appears in more difficult problems in his Conic Sections, from which we see that Apollonius gives not simply the conditions for the possibility of the solution in general, but especially desires to determine the limits of the solutions.

From Zenodorus several theorems regarding isoperimetric figures are still extant; for example, he states that the circle has a greater area than any isoperimetric regular polygon, that among all isoperimetric polygons of the same number of sides the regular has the greatest area, and so on. Hypsicles gives

* Chasles, Apersu historique sur l'origine et le développement des methodes en géométrie, 1875 . Hereafter referred to as Chasles. 
as something new the division of the circumference into three hundred and sixty degrees. From Heron we have a book on geometry (according to Tannery still another, a commentary on Euclid's Elements) which deals in an extended manner with the mensuration of plane figures. Here we find deduced for the area $\Delta$ of the triangle whose sides are $a, b$, and $c$, where $2 s=a+b+c$, the formula

$$
\Delta=\sqrt{s(s-a)(s-b)(s-i)} .
$$

In the measurement of the circle we usually find $\frac{22}{7}$ as an approximation for $\pi$; but still in the Book of Measurements we also find $\pi=3$.

In the period after the commencement of the Christian era the output becomes still more meager. Only occasionally do we find anything noteworthy. Serenus, however, gives a theorem on transversals which expresses the fact that a harmonic pencil is cut by an arbitrary transversal in a harmonic range. In the Almagest occurs the theorem regarding the inscribed quadrilateral, ordinarily known as Ptolemy's Theorem, and a value written in sexagesimal form $\pi=3.8 .30$, i. e.,

$$
\pi=3+\frac{8}{60}+\frac{30}{60 \cdot 60}=3 \frac{17}{120}=3.14166 \ldots *
$$

In a special treatise on geometry Ptolemy shows that he does not regard Euclid's theory of parallels as indisputable. 
To the last supporters of Greek geometry belong Sextus Julius Africanus, who determined the width of a stream by the use of similar right-angled triangles, and Pappus, whose name has become very well known by reason of his Collection. This work consisting originally of eight books, of which the first is wholly lost and the second in great part, presents the substance of the mathematical writings of special repute in the time of the author, and in some places adds corollaries. Since his work was evidently composed with great conscientiousness, it has become one of the most trustworthy sources for the study of the mathematical history of ancient times. The geometric part of the Collection contains among other things discussions of the three different means between two line-segments, isoperimetric figures, and tangency of circles. It also discusses similarity in the case of circles; so far at least as to show that all lines which join the ends of parallel radii of two circles, drawn in the same or in opposite directions, intersect in a fixed point of the line of centers.

The Greeks rendered important service not simply in the field of elementary geometry: they are also the creators of the theory of conic sections. And as in the one the name of Euclid, so in the other the name of Apollonius of Perga has been the signal for controversy. The theory of the curves of second order does not begin with Apollonius any more than does Euclidean geometry begin with Euclid; but what the 
Elements signify for elementary geometry, the eight books of the Conics signify for the theory of lines of the second order. Only the first four books of the Conic Sections of Apollonius are preserved in the Greek text: the next three are known through Arabic translations: the eighth book has never been found and is given up for lost, though its contents have been restored by Halley from references in Pappus. The first book deals with the formation of conics by plane sections of circular cones, with conjugate diameters, and with axes and tangents. The second has especially to do with asymptotes. These Apollonius obtains by laying off on a tangent from the point of contact the half-length of the parallel diameter and joining its extremity to the center of the curve. The third book contains theorems on foci and secants, and the fourth upon the intersection of circles with conics and of conics with one another. With this the elementary treatment of conics by Apollonius closes. The following books contain special investigations in application of the methods developed in the first four books. Thus the fifth book deals with the maximum and minimum lines which can be drawn from a point to the conic, and also with the normals from a given point in the plane of the curve of the second order; the sixth with equal and similar conics; the seventh in a remarkable manner with the parallelograms having conjugate diameters as sides and the theorem upon the sum of the squares of conjugate diameters. The eighth 
book contained, according to Halley, a series of problems connected in the closest manner with lemmas of the seventh book.

The first effort toward the development of the theory of conic sections is ascribed to Hippocrates. ${ }^{*} \mathrm{He}$ reduced the duplication of the cube to the construction of two mean proportionals $x$ and $y$ between two given line-segments $a$ and $b$; thus $\dagger$

$$
\begin{gathered}
\frac{a}{x}=\frac{x}{y}=\frac{y}{b} \text { gives } x^{2}=a y, y^{2}=b x, \text { whence } \\
x^{3}=a^{2} b=\frac{b}{a} \cdot a^{3}=m \cdot a^{3} .
\end{gathered}
$$

Archytas and Eudoxus seem to have found, by plane construction, curves satisfying the above equations but different from straight lines and circles. Menaechmus sought for the new curves, already known by plane constructions, a representation by sections of cones of revolution, and became the discoverer of conic sections in this sense. He employed only sections perpendicular to an element of a right circular cone; thus the parabola was designated as the "section of a right-angled cone" (whose generating angle is $45^{\circ}$ ); the ellipse, the "section of an acute-angled cone"; the hyperbola, the "section of an obtuseangled cone." These names are also used by Archimedes, although he was aware that the three curves can be formed as sections of any circular cone. Apol-

* Zeuthen, Die Lehre von den Kegelschnitten im Altertum. Deutsch von v. Fischer-Benzon, 1886. P. 459. Hereafter referred to as Zeuthen.

+Cantor, I., p. 200. 
lonius first introduced the names "ellipse,' "parabola," "hyperbola." Possibly Menaechmus, but in any case Archimedes, determined conics by a linear equation between areas, of the form $y^{2}=k x x_{1}$. The semi-parameter, with Archimedes and possibly some of his predecessors, was known as "the segment to the axis," i. e., the segment of the axis of the circle from the vertex of the curve to its intersection with the axis of the cone. The designation "parameter" is due to Desargues (1639).*

It has been shown $\nmid$ that Apollonius represented the conics by equations of the form $y^{2}=p x+a x^{2}$, where $x$ and $y$ are regarded as parallel coördinates and every term is represented as an area. From this other linear equations involving areas were derived, and so equations belonging to analytic geometry were obtained by the use of a system of parallel coördinates whose origin could, for geometric reasons, be shifted simultaneously with an interchange of axes. Hence we already find certain fundamental ideas of the analytic geometry which appeared almost two thousand years later.

The study of conic sections was continued upon the cone itself only till the time when a single fundamental plane property rendered it possible to undertake the further investigation in the plane. $\$$ In this way there had become known, up to the time of Archimedes, a number of important theorems on conjugate diameters, and the relations of the lines to these diameters as axes, by the aid of linear equations be-

* Baltzer, R., Analytische Geometrie, I882. 
tween areas. There were also known the so-called Newton's power-theorem, the theorem that the rectangles of the segments of two secants of a conic drawn through an arbitrary point in given direction are in a constant ratio, theorems upon the generation of a conic by aid of its tangents or as the locus related to four straight lines, and the theorem regarding pole and polar. But these theorems were always applied to only one branch of the hyperbola. One of the valuable services of Apollonius was to extend his own theorems, and consequently those already known, to both branches of the hyperbola. His whole method justifies us in regarding him the most prominent representative of the Greek theory of conic sections, and so much the more when we can see from his principal work that the foundations for the theory of projective ranges and pencils had virtually been laid by the ancients in different theorems and applications.

With Apollonius the period of new discoveries in the realm of the theory of conics comes to an end. In later times we find only applications of long known theorems to problems of no great difficulty. Indeed, the solution of problens already played an important part in the oldest times of Greek geometry and furnished the occasion for the exposition not only of conics but also of curves of higher order than the second. In the number of problems, which on account of their classic value have been transmitted from generation to generation and have continually furnished 
occasion for further investigation, three, by reason of their importance, stand forth preëminent : the duplication of the cube, or more generally the multiplication of the cube, the trisection of the angle and the quadrature of the circle. The appearance of these three problems has been of the greatest significance in the development of the whole of mathematics. The first requires the solution of an equation of the third degree; the second (for certain angles at least) leads to an important section of the theory of numbers, i. e., to the cyclotomic equations, and Gauss (see p. I6o) was the first to show that by a finite number of operations with straight edge and compasses we can construct a regular polygon of $n$ sides only when $n-1$ $=2^{2^{p}}$ ( $p$ an arbitrary integer). The third problem reaches over into the province of algebra, for Lindemann $*$ in the year 1882 showed that $\pi$ cannot be the root of an algebraic equation with integral coefficients.

The multiplication of the cube, algebraically the determination of $x$ from the equation

$$
x^{3}=\frac{b}{a} \cdot a^{3}=m \cdot a^{3},
$$

is also called the Delian problem, because the Delians were required to double their cubical altar. $\dagger$ The solution of this problem was specially studied by Plato, Archytas, and Menaechmus; the latter solved it by

* Mathem. Annalen, XX., p. 215. See also Mathem. Annalen, XLIII., and Klein, Famous Problems of Elementary Geometry, 1895, translated by Beman and Smith, Boston, I897.

† Cantor, I., p. 2 Ig. 
the use of conics (hyperbolas and parabolas). Eratosthenes constructed a mechanical apparatus for the same purpose.

Among the solutions of the problem of the trisection of an angle, the method of Archimedes is noteworthy. It furnishes an example of the so-called "insertions" of which the Greeks made use when a solution by straight edge and compasses was impossible. His process was as follows: Required to divide the arc $A B$ of the circle with center $M$ into three equal parts. Draw the diameter $A E$, and through $B$ a secant cutting the circumference in $C$ and the diameter $A E$ in $D$, so that $C D$ equals the radius $r$ of the circle. Then arc $C E=\frac{1}{3} A B$.

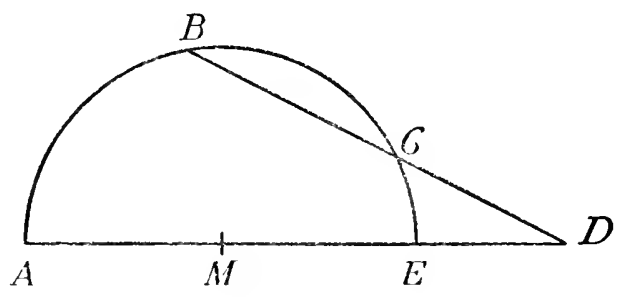

According to the rules of insertion the process consists in laying off upon a ruler a length $r$, causing it to pass through $B$ while one extremity $D$ of the segment $r$ slides along the diameter $A E$. By moving the ruler we get a certain position in which the other extremity of the segment $r$ falls upon the circumference, and thus the point $C$ is determined.

This problem Pappus claims to have solved after the manner of the ancients by the use of conic sec- 
tions. Since in the writings of Apollonius, so largely lost, lines of the second order find an extended application to the solution of problems, the conics were frequently called solid loci in opposition to plane loci, i. e., the straight line and circle. Following these came linear loci, a term including all other curves, of which a large number were investigated.

This designation of the loci is found, for example, in Pappus, who says in his seventh book * that a problem is called plane, solid, or linear, according as its solution requires plane, solid, or linear loci. It is, however, highly probable that the loci received their names from problems, and that therefore the division of problems into plane, solid, and linear preceded the designation of the corresponding loci. First it is to be noticed that we do not hear of "linear problems and loci" till after the terms "plane and solid problems and loci" were in use. Plane problems were those which in the geometric treatment proved to be dependent upon equations of the first or second degree between segments, and hence could be solved by the simple application of areas, the Greek method for the solution of quadratic equations. Problems depending upon the solution of equations of the third degree between segments led to the use of forms of three dimensions, as, e. g., the duplication of the cube, and were termed solid problems; the loci used in their solution (the conics) were solid loci. At a

*Zeuthen, p. 203. 
time when the significance of "plane" and "solid" was forgotten, the term "linear problem" was first applied to those problems whose treatment (by "linear loci") no longer led to equations of the first, second, and third degrees, and which therefore could no longer be represented as linear relations between segments, areas, or volumes.

Of linear loci Hippias applied the quadratrix (to which the name of Dinostratus was later attached through his attempt at the quadrature of the circle)* to the trisection of the angle. Eudoxus was acquainted with the sections of the torus made by planes parallel to the axis of the surface, especially the hippopede or figure-of-eight curve. ${ }^{\prime}$ The spirals of Archimedes attained special celebrity. His exposition of their properties compares favorably with his elegant investigations of the quadrature of the parabola.

Conon had already generated the spiral of Archimedes $\ddagger$ by the motion of a point which recedes with uniform velocity along the radius $O A$ of a circle $k$ from the center $O$, while $O A$ likewise revolves uniformly about $O$. But Archimedes was the first to discover certain of the beautiful properties of this curve; he found that if, after one revolution, the spiral meets the circle $k$ of radius $O A$ in $B$ (where $B O$ is tangent to the spiral at $O$ ), the area bounded by $B O$ and the

* Cantor, I., pp. I84, 233.

† Majer, Proklos über die Petita und Axiomata bei Euklid, 1875.

$\ddagger$ Cantor, I., p. 29 r. 
spiral is one-third of the area of the circle $k$; further that the tangent to the spiral at $B$ cuts off from a perpendicular to $O B$ at $O$ a segment equal to the circumference of the circle $k$.*

The only noteworthy discovery of Nicomedes is the construction of the conchoid which he employed to solve the problem of the two mean proportionals, or, what amounts to the same thing, the multiplication of the cube. The curve is the geometric locus of the point $X$ upon a moving straight line $g$ which constantly passes through a fixed point $P$ and cuts a fixed straight line $h$ in $Y$ so that $X Y$ has a constant length. Nicomedes also investigated the properties of this curve and constructed an apparatus made of rulers for its mechanical description.

The cissoid of Diocles is also of use in the multiplication of the cube. It may be constructed as follows: Through the extremity $A$ of the radius $O A$ of a circle $k$ passes the secant $A C$ which cuts $k$ in $C$ and the radius $O B$ perpendicular to $O A$ in $D ; X$, upon $A C$, is a point of the cissoid when $D X=D C$. $\uparrow \mathrm{Gemi-}$ nus proves that besides the straight line and the circle the common helix invented by Archytas possesses the insertion property.

Along with the geometry of the plane was developed the geometry of space, first as elementary stere-

* Montucla.

t Kilein, F., Famous Problems of Elementary Geometry', translated by Beman and Sinith, Boston, I897, p. 44 . 
ometry and then in theorems dealing with surfaces of the second order. The knowledge of the five regular bodies and the related circumscribed sphere certainly goes back to Pythagoras. According to the statement of Timaeus of Locri,* fire is made up of tetrahedra, air of octahedra, water of icosahedra, earth of cubes, while the dodecahedron forms the boundary of the universe. Of these five cosmic or Platonic bodies Theaetetus seems to have been the first to publish a connected treatment. Eudoxus states that a pyramid (or cone) is $\frac{1}{3}$ of a prism of equal base and altitude. The eleventh, twelfth and thirteenth books of Euclid's Elements offer a summary discussion of the ordinary stereometry. (See p. I99.) Archimedes introduces thirteen semi-regular solids, i. e., solids whose boundaries are regular polygons of two or three different kinds. Besides this he compares the surface and volume of the sphere with the corresponding expressions for the circumscribed cylinder and deduces theorems which he esteems so highly that he expresses the desire to have the sphere and circumscribed cylinder cut upon his tomb-stone. Among later mathematicians Hypsicles and Heron give exercises in the mensuration of regular and irregular solids. Pappus also furnishes certain stereometric investigations of which we specially mention as new only the determination of the volume of a solid of revolution by means of the meridian section and the path of its center of gravity.

* Cantor, I., p. 163. 
He thus shows familiarity with a part of the theorem later known as Guldin's rule.

Of surfaces of the second order the Greeks knew the elementary surfaces of revolution, i. e., the sphere, the right circular cylinder and circular cone. Euclid deals only with cones of revolution, Archimedes on the contrary with circular cones in general. In addition, Archimedes investigates the "right-angled conoids" (paraboloids of revolution), the "obtuse-angled co. noids" (hyperboloids of revolution of one sheet), and "long and flat spheroids" (ellipsoids of revolution about the major and minor axes). He determines the character of plane sections and the volume of segments of such surfaces. Probably Archimedes also knew that these surfaces form the geometric locus of a point whose distances from a fixed point and a given plane are in a constant ratio. According to Proclus, * who is of importance as a commentator upon Euclid, the torus was also known-a surface generated by a circle of radius $r$ revolving about an axis in its plane so that its center describes a circle of radius $e$. The cases $r=e,>e,<e$ were discussed.

With methods of projection, also, the Greeks were not unacquainted. $\dagger$ Anaxagoras and Democritus are said to have known the laws of the vanishing point and of reduction, at least for the simplest cases. Hipparchus projects the celestial sphere from a pole upor

* Majer, Proklos ïber die Petita und Axionata bei Euklid, IS75.

+ Wiener. 
the plane of the equator; he is therefore the inventor of the stereographic projection which has come to be known by the name of Ptolemy.

\section{THIRD PERIOD.}

ROMANS, HINDUS, CHINESE, ARABS.

Among no other people of antiquity did geometry reach so high an eminence as among the Greeks. Their acquisitions in this domain were in part transplanted to foreign soil, yet not so that (with the possible exception of arithmetic calculation) anything essentially new resulted. Frequently what was inherited from the Greeks was not even fully understood, and therefore remained buried in the literature of the foreign nation. From the time of the Renaissance, however, but especially from that of Descartes, an entirely new epoch with more powerful resources investigated the ancient treasures and laid them under contribution.

Among the Romans independent investigation of mathematical truths almost wholly disappeared. What they obtained from the Greeks was made to serve practical ends exclusively. For this purpose parts of Euclid and Heron were translated. To simplify the work of the surveyors or agrimensores, important geometric theorems were collected into a larger work of which fragments are preserved in the Codex Arceri- 
anus. In the work of Vitruvius on architecture (c. - 14) is found the value $\pi=3 \frac{1}{8}$ which, though less accurate than Heron's value $\pi=3 \frac{1}{7}$, was more easily employed in the duodecimal system.* Boethius has left a special treatise on geometry, but the contents are so paltry that it is safe to assume that he made use of an earlier imperfect treatment of Greek geometry.

Although the Hindu geometry is dependent upon the Greek, yet it has its own peculiarities due to the arithmetical modes of thought of the people. Certain parts of the Çulvasutras are geometric. These teach the rope-stretching already known to the Egyptians, i. e., they require the construction of a right angle by means of a rope divided by a knot into segments 15 and 39 respectively, the ends being fastened to a segment $36\left(15^{2}+36^{2}=39^{2}\right)$. They also use the gnomon and deal with the transformation of figures and the application of the Pythagorean theorem to the multiplication of a given square. Instead of the quadrature of the circle appears the circulature of the square, $\dagger$ i. e., the construction of a circle equal to a given square. Here the diameter is put equal to $\frac{4}{5}$ of the diagonal of the square, whence follows $\pi=3 \frac{1}{8}$ (the value used among the Romans). In other cases a process is carried on which yields the value $\pi=3$.

The writings of Aryabhatta contain certain incorrect formulae for the mensuration of the pyramid and 
sphere (for the pyramid $V=\frac{1}{2} B h$ ), but also a number of perfectly accurate geometric theorems. Aryabhatta gives the approximate value $\pi=\frac{62}{20} \frac{832}{000}=3.1416$. Brahmagupta teaches mensurational or Heronic geometry and is familiar with the formula for the area of the triangle,

$$
\Delta=\sqrt{s(s-a)(s-b)(s-c)},
$$

and the formula for the area of the inscribed quadrilateral,

$$
i=\sqrt{(s-a)(s-b)(s-c)(s-d)},
$$

which he applies incorrectly to any quadrilateral. In his work besides $\pi=3$ we also find the value $\pi=\sqrt{10}$, but without any indication as to how it was obtained. Bhaskara likewise devotes himself only to algebraic geometry. For $\pi$ he gives not only the Greek value $\frac{22}{7}$ and that of Aryabhatta $\frac{62}{2} 0 \frac{83}{0} \frac{2}{0}$, but also a value $\pi=\frac{754}{240}=3.14166 \ldots$ Of geometric demonstrations Bhaskara knows nothing. He states the theorem, adds the figure and writes "Behold!"*

In Bhaskara a transfer of geometry from Alexandria to India is undoubtedly demonstrable, and perhaps this influence extended still further eastward to the Chinese. In a Chinese work upon mathematics, composed perhaps several centuries after Christ, the Pythagorean theorem is applied to the triangle with sides $3,4, \mathbf{5}$; rope-stretching is indicated; the ver 
tices of a figure are designated by letters after the Greek fashion; $\pi$ is put equal to 3 , and toward the end of the sixth century to $\frac{22}{7}$.

Greek geometry reached the Arabs in part directly and in part through the Hindus. The esteem, however, in which the classic works of Greek origin were held could not make up for the lack of real productive power, and so the Arabs did not succeed in a single point in carrying theoretic geometry, even in the subject of conic sections, beyond what had been reached in the golden age of Greek geometry. Only a few particulars may be mentioned. In Al Khowarazmi is found a proof of the Pythagorean theorem consisting only of the separation of a square into eight isosceles right-angled triangles. On the whole Al Khowarazmi draws more from Greek than from Hindu sources. The classification of quadrilaterals is that of Euclid; the calculations are made after Heron's fashion. Besides the Greek value $\pi=\frac{22}{7}$ we find the Hindu values $\pi=\frac{62}{2} \frac{28}{00} \frac{2}{0}$ and $\pi=\sqrt{10}$. Abul Wafa wrote a book upon geometric constructions. In this are found combinations of several squares into a single one, as well as the construction of polyhedra after the methods of Pappus. After the Greek fashion the trisection of the angle occupied the attention of Tabit ibn Kurra, Al Kuhi, and Al Sagani. Among later mathematicians the custom of reducing a geometric problem to the solution of an equation is common. It was thus that the Arabs by geometric solu- 
tions attained some excellent results, but results of no theoretic importance.

\section{E. FOURTH PERIOD.}

FROM GERBERT TO DESCARTES.

Among the Western nations we find the first traces of geometry in the works of Gerbert, afterward known as Pope Sylvester II. Gerbert, as it seems, depends upon the Codex Arcerianus, but also mentions Pythagoras and Eratosthenes.* We find scarcely anything here besides field surveying as in Boethius. Something more worthy first appears in Leonardo's (Fibonacci's) Practica geometriae $\dagger$ of 1220 , in which work reference is made to Euclid, Archimedes, Heron, and Ptolemy. The working over of the material handed down from the ancients, in Leonardo's book, is fairly independent. Thus the rectification of the circle shows where this mathematician, without making use of Archimedes, determines from the regular polygon of 96 sides the value $\pi=\frac{1440}{458 \frac{1}{3}}=3.1418$.

Since among the ancients no proper theory of star polygons can be established, it is not to be wondered at that the early Middle Ages have little to show in this direction. Star-polygons had first a mystic sig nificance only; they were used in the black art as the pentacle, and also in architecture and heraldry. Adel- 
ard of Bath went with more detail into the study of star-polygons in his commentary on Euclidean geometry ; the theory of these figures is first begun by Regiomontanus.

The first German mathematical work is the Deut sche Sphära written in Middle High German by Conrad of Megenberg, probably in Vienna in the first half of the fourteenth century. The first popular introduction to geometry appeared anonymously in the fifteenth century, in six leaves of simple rules of construction for geometric drawing. The beginning, containing the construction of $B C$ perpendicular to $A B$ by the aid of the right-angled triangle $A B C$ in which $B E$ bisects the hypotenuse $A C$, runs as follows:* "From geometry some useful bits which are written after this. 1. First to make a right angle quickly. Draw two lines across each other just about as you wish and where the lines cross each other there put an $e$. Then place the compasses with one foot upon the point $e$, and open them out as far as you wish, and make upon each line a point. Let these be the letters $a, b, c$, all at one distance. Then make a line from $a$ to $b$ and from $b$ to $c$. So you have a right angle of which here is an example."

This construction of a right angle, not given in Euclid but first in Proclus, appears about the year 1500 to be in much more extensive use than the method of Euclid by the aid of the angle inscribed in

* Günther, p. 347. 
a semi-circle. By his knowledge of this last construction Adam Riese is said to have humiliated an architect who knew how to draw a right angle only by the method of Proclus.

Very old printed works on geometry in German are $D z$ Puechlen der fialen gerechtikait by Mathias Roriczer (1486) and Albrecht Dürer's Underweysung der messung mit dem zirckel und richtscheyt (Nuremberg, 1525). The former gives in rather unscientific manner rules for a special problem of Gothic architecture; the latter, however, is a far more original work and on that account possesses more interest.*

With the extension of geometric knowledge in Germany Widmann and Stifel were especially concerned. Widmann's geometry, like the elements of Euclid, begins with explanations: "Punctus is a small thing that cannot be divided. Angulus is a corner which is made there by two lines." + Quadrilaterals have Arab names, a striking evidence that the ancient Greek science was brought into the West by Arab in fluence. Nevertheless, by Roman writers (Boethius) Widmann is led into many errors, as, e. g., when he gives the area of the isosceles triangle of side $a$ as $\frac{1}{2} a^{2}$.

In Rudolff's Coss, in the theory of powers, Stifel has occasion to speak of a subject which first receives proper estimation in the modern geometry, viz., the right to admit more than three dimensions. "Since, however, we are in arithmetic where it is permitted to invent many things that otherwise have no form,

* Günther in Schlömilch's Zeitschrift, XX., Hl. 2.

+ Gerhardt. Geschichte der Mathematik in Deutschland, 1877. 
this also is permitted which geometry does not allow, namely to assume solid lines and surfaces and go beyond the cube just as if there were more than three dimensions, which is, of course, against nature... . But we have such good indulgence on account of the charming and wonderful usage of Coss." *

Stifel after the manner of Ptolemy extends the study of regular polygons and after the manner of Euclid the construction of regular solids. He discusses the quadrature of the circle, considering the latter as a polygon of infinitely many sides, and declares the quadrature impossible. According to Albrecht Dürer's Underweysung, etc., the quadrature of the circle is obtained when the diagonal of the square contains ten parts of which the diameter of the circle contains eight, i. e., $\pi=3 \frac{1}{8}$. It is expressly stated, however, that this is only an approximate construction. "We should need to know quadratura circuli, that is the making equal a circle and a square, so that the one should contain as much as the other, but this has not yet been demonstrated mechanically by scholars; but that is merely incidental; therefore so that in practice it may fail only slightly, if at all, they may be made equal as follows. $\dagger$

* Stifel, Die Coss Christoffs Rudolffs, Mit schönen Exempeln der Coss. Durch Michael Stifel Gebessert vnd sehr gemehrt. . . Gegeben zum Habersten | bei Königsberg in Preussen / den letzten tag dess Herbstmonds / im Jar 1552. . . Zu Amsterdam Getruckt bey Wilhem Janson. Im Jar 1615.

+ Dürer, Underweysung der messung mit dem zirckel and richtscheyt in Linien ebnen znd gantzen corporen. Durch Albrecht Dürer zusamen getzogn vnd zu nutz alln kunstlieb habenden mit zu gehörigen figuren in truck gebracht im jar MDXXV. (Consists of vier Büchlein.) 
Upon the mensuration of the circle* there appeared in 1584 a work by Simon van der Eycke in which the value $\pi=\frac{1521}{484}$ was given. By calculating the side of the regular polygon of 192 sides Ludolph van Ceulen found (probably in 1585) that $\pi<3.14205<$ $\frac{1521}{484}$. In his reply Simon v. d. Eycke determined $\pi=3.1446055$, whereupon L. v. Ceulen in 1586 computed $\pi$ between 3.142732 and 3.14103. Ludolph van Ceulen's papers contain a value of $\pi$ to 35 places, and this value of the Ludolphian number was put upon his tombstone (no longer known) in St. Peter's Church in Leyden. Ceulen's investigations led Snellius, Huygens, and others to further studies. By the theory of rapidly converging series it was first made possible to compute $\pi$ to 500 and more decimals. $\dagger$

A revival of geometry accompanied the activity of Vieta and Kepler. With these investigators begins a period in which the mathematical spirit commences to reach out beyond the works of the ancients. $\$$ Vieta completes the analytic method of Plato; in an ingenious way he discusses the geometric construction of roots of equations of the second and third degrees; he also solves in an elementary manner the problem of the circle tangent to three given circles. Still more important results are secured by Kepler. For him geometry furnishes the key to the secrets of the world. With sure step he follows the path of induction and in his geometric investigations freely conforms to Euclid. Kepler established the symbolism of the "golden section," that problem of Eudoxus

* Rudio, F., Das Problem von der Quadratur des Zirkels, Zürich, I89o.

†D. Bierens de Haan in Nieuzw. Arch., I.; Cantor, II., p. 55 I.

$\ddagger$ Chasles. 
stated in the sixth book of Euclid's Elements: "To divide a limited straight line in extreme and mean ratio." * This problem, for which Kepler introduced the designation sectio divina as well as proportio divina, is in his eyes of so great importance that he expresses himself: "Geometry has two great treasures: one is the theorem of Pythagoras, the other the division of a line in extreme and mean ratio. The first we may compare to a mass of gold, the second we may call a precious jewel."

The expression "golden section" is of more modern origin. It occurs in none of the text-books of the eighteenth century and appears to have been formed by a transfer from ordinary arithmetic. In the arithmetic of the sixteenth and seventeenth centuries the rule of three is frequently called the "golden rule." Since the beginning of the nineteenth century this golden rule has given way more and more before the so-called Schlussrechnen (analysis) of the Pestalozzi school. Consequently in place of the "golden rule," which is no longer known to the arithmetics, there appeared in the elementary geometries about the middle of the nineteenth century the "golden section," probably in connection with contemporary endeavors to attribute to this geometric construction the importance of a natural law.

Led on by his astronomical speculations, Kepler made a special study of regular polygons and starpolygons. He considered groups of regular polygons capable of elementary construction, viz., the series of polygons with the number of sides given by $4 \cdot 2^{n}$, $3 \cdot 2^{n}, 5 \cdot 2^{n}, 15 \cdot 2^{n}$ (from $n=0$ on), and remarked that 
a regular heptagon cannot be constructed by the help of the straight line and circle alone. Further there is no doubt that Kepler well understood the Conics of Apollonius and had experience in the solution of problems by the aid of these curves. In his works we first find the term "foci" for those points of conic sections which in earlier usage are known as puncta ex comparatione, puncta ex applicatione facta, umbilici, or "poles";* also the term "eccentricity" for the distance from a focus to the center divided by the semi-major axis, of the curve of the second order, and the name "eccentric anomaly" for the angle $P^{\prime} O A$, where $O A$ is the semi-major axis of an ellipse and $P^{\prime}$ the point in which the ordinate of a point $P$ on the curve intersects the circle upon the major axis. $\dagger$

Also in stereometric investigations, which had been cultivated to a decided extent by Dürer and Stifel, Kepler is preëminent among his contemporaries. In his Harmonice Mundi he deals not simply with the five regular Platonic and thirteen semi-regular Archimedean solids, but also with star-polygons and stardodecahedra of twelve and twenty vertices. Besides this we find the determination of the volumes of solids obtained by the revolution of conics about diameters, tangents, or secants. Similar determinations of volumes were effected by Cavalieri and Guldin. The former employed a happy modification of the method

*C. Taylor, in Cambr. Proc., 1V.

† Baltzer, R., Analytische Geometrie, 1882. 
of exhaustions, the latter used a rule already known to Pappus but not accurately established by him.

To this period belong the oldest known attempts to solve geometric problems with only one opening of the compasses, an endeavor which first found accurate scientific expression in Steiner's Geometrische Construktionen, ausgeführt mittels der geraden Linie und eines festen Kreises (1833). The first traces of such constructions go back to Abul Wafa.* From the Arabs they were transmitted to the Italian school where they appear in the works of Leonardo da Vinci and Cardan. The latter received his impulse from Tartaglia who used processes of this sort in his problem-duel with Cardan and Ferrari. They also occur in the Resolutio omnium Euclidis problematum (Venice, 1553) of Benedictis, a pupil of Cardan, in the Geometria deutsch and in the construction of a regular pentagon by Dürer. In his Underweysung, etc., Dürer gives a geometrically accurate construction of the regular pentagon but also an approximate construction of the same figure to be made with a circle of fixed radius.

This method of constructing a regular pentagon on $A B$ is as follows: About $A$ and $B$ as centers, with radius $A B$, construct circles intersecting in $C$ and $D$. The circle about $D$ as a center with the same radius cuts the circles with centers at $A$ and $B$ in $E$ and $F$ and the common chord $C D$ in $G$. The same circles are cut by $F G$ and $E G$ in $J$ and $H . A J$ and $B H$ are sides of the regular pentagon. (The calculation of this symmetric pentagon shows

*Günther in Schlömilch's Zeitschrift, XX. Cantor, I., p joo. 
$H B A=108^{\circ} 20^{\prime}$, while the corresponding angle of the regular pentagon is $105^{\circ}$.)

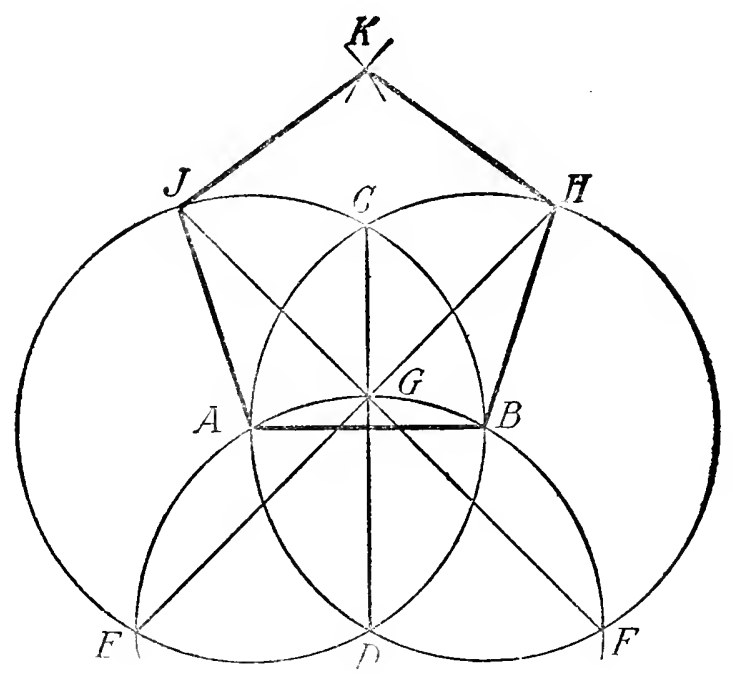

In Dürer and all his successors who write upon rules of geometric construction, we find an approximate construction of the regular heptagon: "The side of the regular heptagon is half that of the equilateral triangle," while from calculation the half sice of the equilateral triangle $=0.998$ of the side of the heptagon. Daniel Schwenter likewise gave constructions with a single opening of the compasses in his Geometria practica nova et aucta (1625). Dürer, as is manifest from his work Underweysung der messung, etc., already cited several times, also rendered decided service in the theory of higher curves. He gave a general conception of the notion of asymptotes and found as new forms of higher curves certain cyclic curves and mussel-shaped lines.

From the fifteenth century on, the methods of projection make a further adrance. Jan van Eyck* in the great altar painting in Ghent makes use of the laws of perspective, e. g., in the application of the 
vanishing point, but without a mathematical grasp of these laws. This is first accomplished by Albrecht Dürer who in his Underweysung der messung mit dem zirckel und richtscheyt makes use of the point of sight and distance-point and shows how to construct the perspective picture from the ground plan and elevation. In Italy perspective was developed by the architect Brunelleschi and the sculptor Donatello. The first work upon this new theory is due to the architect Leo Battista Alberti. In this he explains the perspective image as the intersection of the pyramid of visual rays with the picture-plane. He also mentions an instrument for constructing it, which consists of a frame with a quadratic net-work of threads and a similar net-work of lines upon the drawing surface. He also gives the method of the distance-point as invented by him, by means of which he then pictures the ground divided into quadratic figures.* This process received a further extension at the hands of Piero della Francesca who employed the vanishing points of arbitrary horizontal lines.

In German territory perspective was cultivated with special zeal in Nuremberg where the goldsmith Lencker, some decades after Dürer, extended the latter's methods. The first French study of perspective is due to the artist J. Cousin (1560) who in his Livre de la perspective made use of the point of sight and the distance-point, besides the vanishing points of hori-

*Wiener. 
zontal lines, after the manner of Piero. Guido Ubaldi goes noticeably further when he introduces the vanishing point of series of parallel lines of arbitrary direction. What Ubaldi simply foreshadows, Simon Stevin clearly grasps in its principal features, and in an important theorem he lays the foundation for the development of the theory of collineation.

\section{F. FIFTH PERIOD.}

FROM DESCARTES TO THE PRESENT.

Since the time of Apollonius many centuries had elapsed and yet no one had succeeded in reaching the full height of Greek geometry. This was partly be. cause the sources of information were relatively few, and attainable indirectly and with difficulty, and partly because men, unfamiliar with Greek methods of investigation, looked upon them with devout astonishment. From this condition of partial paralysis, and of helpless endeavor longing for relief, geometry was delivered by Descartes. This was not by a simple addition of related ideas to the old geometry, but merely by the union of algebra with geometry, thus giving rise to analytic geometry.

By way of preparation many mathematicians, first of all Apollonius, had referred the most important elementary curves, namely the conics, to their diameters and tangents and had expressed this relation by equa- 
tions of the first degree between areas, so that certain relations were obtained between line-segments identical with abscissas and ordinates.

In the conics of Apollonius we find expressions which have been translated "ordinatim applicatae" and "abscissae." For the former expression Fermat used "applicate" while others wrote "ordinate." Since the time of Leibnitz (1692) abscissas and ordinates have been called "co-ordinates."*

Even in the fourteenth century we find as an object of study in the universities a kind of co-ordinate geometry, the "latitudines formarum." "Latitudo" $\dagger$ signified the ordinate, "longitudo" the abscissa of a variable point referred to a system of rectangular coordinates, and the different positions of this point formed the "figura." The technical words longitude and latitude had evidently been borrowed from the language of astronomy. In practice of this art Oresme confined himself to the first quadrant in which he dealt with straight lines, circles, and even the parabola, but always so that only a positive value of a coordinate was considered.

Among the predecessors of Descartes we reckon, besides Apollonius, especially, Vieta, Oresme, Cavalieri, Roberval, and Fermat, the last the most distinguished in this field; but nowhere, even by Fermat, had any attempt been made to refer several curves of

* Baltzer, R., Analytische Geometrie, 1882.

+ Günther, p. r8r. 
different orders simultaneously to one system of coordinates, which at most possessed special significance for one of the curves. It is exactly this thing which Descartes systematically accomplished.

The thought with which Descartes made the laws of arithmetic subservient to geometry is set forth by himself in the following manner:*

"All problems of geometry may be reduced to such terms that for their construction we need only to know the length of certain right lines. And just as arithmetic as a whole comprises only four or five operations, viz., addition, subtraction, multiplication, division, and evolution, which may be considered as a kind of division, so in geometry to prepare the lines sought to be known we have only to add other lines to them or subtract others from them; or, having one which I call unity (so as better to refer it to numbers), which can ordinarily be taken at pleasure, having two others to find a fourth which shall be to one of these as the other is to unity, which is the same as multiplication; $\dagger$ or to find a fourth which shall be to one of the two as unity is to the other which is the same as division; $\ddagger$ or finally to find one or two or several mean proportionals between unity and any other line, which is the same as to extract the square, cube, . . . root. $\S$ I shall not hesitate to introduce these terms

\footnotetext{
* Marie, M., Histoire des Sciences Mathématiques et Physiques, 1883-1887.

$\dagger \cdot c: a=b: \mathrm{x}, c=a b$.

$\ddagger c: a=\mathrm{I}: b, c=a: b$.

$\S \mathrm{I}: a=a: b=b: c=c: d=\ldots$ gives $\alpha=\sqrt{ } b=\nabla^{3} \bar{c}=\boldsymbol{V} \bar{d}$. .
} 
of arithmetic into geometry in order to render myself more intelligible. It should be observed that, by $a^{2}$, $b^{3}$, and similar quantities, I understand as usual simple lines, and that I call them square or cube only so as to employ the ordinary terms of algebra." ( $a^{2}$ is the third proportional to unity and $a$, or $1: a=a: a^{2}$, and similarly $b: b^{2}=b^{2}: b^{8}$.)

This method of considering arithmetical expressions was especially influenced by the geometric discoveries of Descartes. As Apollonius had already determined points of a conic section by parallel chords, together with the distances from a tangent belonging to the same system, measured in the direction of the conjugate diameter, so with Descartes every point of a curve is the intersection of two straight lines. Apollonius and all his successors, however, apply such systems of parallel lines only occasionally and that for the sole purpose of presenting some definite property of the conics with especial distinctness. Descartes, on the contrary, separates these systems of parallel lines from the curves, assigns them an independent existence and so obtains for every point on the curve a relation between two segments of given direction, which is nothing else than an equation. The geometric study of the properties of this curve can then be replaced by the discussion of the equation after the methods of algebra. The fundamental elements for the determination of a point of a curve are its co-ordinates, and from long known theorems it was evident 
that a point of the plane can be fixed by two co-ordjnates, a point of space by three.

Descartes's Geometry is not, perhaps, a treatise on analytic geometry, but only a brief sketch which sets forth the foundations of this theory in outline. Of the three books which constitute the whole work only the first two deal with geometry; the third is of algebraic nature and contains the celebrated rule of signs illustrated by a simple example, as well as the solution of equations of the third and fourth degrees with the construction of their roots by the use of conics.

The first impulse to his geometric reflections was due, as Descartes himself says, to a problem which according to Pappus had already occupied the attention of Euclid and Apollonius. It is the problem to find a certain locus related to three, four, or several lines. Denoting the distances, measured in given directions, of a point $P$ from the straight lines $g_{1}, g_{2} \ldots$ $g_{s}$ by $e_{1}, e_{2} \ldots e_{n}$, respectively, we shall have

for three straight lines: $\frac{e_{1} e_{2}}{a e_{3}}=k$, for four straight lines: $\frac{e_{1} e_{2}}{e_{3} e_{4}}=k$, for five straight lines: $\frac{e_{1} e_{2} e_{3}}{a e_{4} e_{5}}=k$,

and so on. The Greeks originated the solution of the first two cases, which furnish conic sections. No example could have shown better the advantage of the 
new method. For the case of three lines Descartes denotes a distance by $y$, the segment of the corresponding line between the foot of this perpendicular and a fixed point by $x$, and shows that every other segment involved in the problem can be easily constructed. Further he states "that if we allow $y$ to grow gradually by infinitesimal increments, $x$ will grow in the same way and thus we may get infinitely many points of the locus in question."

The curves with which Descartes makes us gradually familiar he classifies so that lines of the first and second orders form a first group, those of the third and fourth orders a second, those of the fifth and sixth orders a third, and so on. Newton was the first to call a curve, which is defined by an algebraic equation of the $n$th degree between parallel co-ordinates, a line of the $n$th order, or a curve of the (n-1)th class. The division into algebraic and transcendental curves was introduced by Leibnitz; previously, after the Greek fashion, the former had been called geometric, the latter mechanical lines.*

Among the applications which Descartes makes, the problem of tangents is prominent. This he treats in a peculiar way: Having drawn a normal to a curve at the point $P$, he describes a circle through $P$ with the center at the intersection of this normal with the

* Baltzer, R., Analytische Geometrie, 1882. Up to the time of Descartes all lines except straight lines and conics were called mechanical. He was the first to apply the term geomerric lines to curves of degree higher than the second. 
$X$-axis, and asserts that this circle cuts the curve at $P$ in two consecutive points; i. e., he states the condition that after the elimination of $x$ the equation in $y$ shall have a double root.

A natural consequence of the acceptance of the Cartesian co-ordinate system was the admission of negative roots of algebraic equations. These negative roots had now a real significance; they could be represented, and hence were entitled to the same rights as positive roots.

In the period immediately following Descartes, geometry was enriched by the labors of Cavalieri, Fermat, Roberval, Wallis, Pascal, and Newton, not at first by a simple application of the co-ordinate geometry, but often after the manner of the ancient Greek geometry, though with some of the methods essentially improved. The latter is especially true of Cavalieri, the inventor of the method of indivisibles,* which a little later was displaced by the integral ca'. culus, but may find a place here since it rendered service to geometry exclusively. Cavalieri enjoyed working with the geometry of the ancients. For example, he was the first to give a satisfactory proof of the socalled Guldin's rule already stated by Pappus. His chief endeavor was to find a general process for the determination of areas and volumes as well as centers of gravity, and for this purpose he remodelled the

* In French works Methode des indivisibles, originally in the work Geometria indivisibilibus continuorum nova quadam ratione promota, Bologna, x635. 
method of exhaustions. Inasmuch as Cavalieri's method, of which he was master as early as 1629 , may even to-day replace to advantage ordinary integration in elementary cases, its essential character may be set forth in brief outline.*

If $y=f(x)$ is the equation of a curve in rectangular co-ordinates, and he wishes to determine the area bounded by the axis of $x$, a portion of the curve, and the ordinates corresponding to $x_{0}$ and $x_{1}$, Cavalieri divides the difference $x_{1}-x_{0}$ into $n$ equal parts. Let $h$ represent such a part and let $n$ be taken very large. An element of the surface is then $=h y=h f(x)$, and the whole surface becomes

$$
\sum_{0}^{n-1} h \cdot f\left(x_{0}+n h\right) \text {. }
$$

For $n=\infty$ we evidently get exactly

$$
\int_{x_{0}}^{x_{1}} f(x) d x
$$

But this is not the quantity which Cavalieri seeks to determine. He forms only the ratios of portions of the area sought, to the rectangle with base $x_{1}-x_{0}$ and altitude $y_{1}$, so that the quantity to be determined is the following:

$$
\frac{\sum_{0}^{n-1} h \cdot f\left(x_{0}+n h\right)}{n \cdot h \cdot f\left(x_{1}\right)}=\frac{\sum_{0}^{n-1} f\left(x_{0}+n h\right)}{n f\left(x_{1}\right)} .
$$

Cavalieri applies this formula, which he derives in * Marie. 
complete generality from grounds of analogy, only to the case where $f(x)$ is of the form $A x^{m}(m=2,3,4)$. The extension to further cases was made by Rober val, Wallis, and Pascal.

In the simplest cases the method of indivisibles gives the following results.* For a parallelogram the indivisible quantity or element of surface is a parallel to the base; the number of indivisible quantities is proportional to the altitude; hence we have as the measure of the area of the parallelogram the product of the measures of the base and altitude. The corresponding conclusion holds for the prism. In order to compare the area of a triangle with that of the parallelogram of the same base and altitude, we decompose each into elements by equidistant parallels to the base. The elements of the triangle are then, beginning with the least, 1 , $2,3, \ldots n$; those of the parallelogram, $n, n, \ldots n$. Hence the ratio

$$
\frac{\text { Triangle }}{\text { Parallelogram }}=\frac{1+2+\ldots+n}{n \cdot n}=\frac{\frac{1}{2} n(n+1)}{n^{2}}=\frac{1}{2}\left(1+\frac{1}{n}\right) ;
$$

whence for $n=\infty$ we get the value $\frac{1}{2}$. For the corresponding solids we get likewise

$$
\begin{aligned}
\frac{\text { Pyramid }}{\text { Prism }} & =\frac{1^{2}+2^{2}+\ldots+n^{2}}{n^{3}}=\frac{\frac{1}{6} n(n+1)(2 n+1)}{n^{3}} \\
& =\left.\frac{1}{6}\left(1+\frac{1}{n}\right)\left(2+\frac{1}{n}\right)\right|_{n=\infty}=\frac{1}{3} .
\end{aligned}
$$

After the lapse of a few decades this analyticgeometric method of Cavalieri's was forced into the background by the integral calculus, which could be directly applied in all cases. At first, however, Roberval, known by his method of tangents, trod in the footsteps of Cavalieri. Wallis used the works of Des-

* Marie. 
cartes and Cavalieri simultaneously, and considered especially curves whose equations were of the form $y=x^{m}, m$ integral or fractional, positive or negative. His chief service consists in this, that in his brilliant work he put a proper estimate upon Descartes's discovery and rendered it more accessible. In this work Wallis also defines the conics as curves of the second degree, a thing never before done in this definite manner.

Pascal proved to be a talented disciple of Cavalieri and Desargues. In his work on conics, composed about 1639 but now lost (save for a fragment), * we find Pascal's theorem of the inscribed hexagon or Hexagramma mysticum as he termed it, which Bessel rediscovered in 1820 without being aware of Pascal's earlier work, $\nmid$ also the theorem due to Desargues that if a straight line cuts a conic in $P$ and $Q$, and the sides of an inscribed quadrilateral in $A, B, C, D$, we have the following equation :

$$
\frac{P A \cdot P C}{P B \cdot P D}=\frac{Q A \cdot Q C}{Q C \cdot Q D} \text {. }
$$

Pascal's last work deals with a curve called by him the roulette, by Roberval the trochoid, and generally known later as the cycloid. Bouvelles (1503) already knew the construction of this curve, as did Cardinal von Cusa in the preceding century. Galileo, as is shown by a letter to Torricelli in 1639 , had made (be 
ginning in 1590) an exhaustive study of rolling curves in connection with the construction of bridge arches. The quadrature of the cycloid and the determination of the volume obtained by revolution about its axis had been effected by Roberval, and the construction of the tangent by Descartes. In the year 1658 Pascal was able to determine the length of an arc of a cycloidal segment, the center of gravity of this surface, and the corresponding solid of revolution. Later the cycloid appears in physics as the brachistochrone and tautochrone, since it permits a body sliding upon it to pass from one fixed point to another in the shortest time, while it brings a material point oscillating upon it to its lowest position always in the same time. Jacob and John Bernoulli, among others, gave attention to isoperimetric problems; but only the former secured any results of value, by furnishing a rigid method for their solution which received merely an unimportant simplification from John Bernoulli. (See pages 178-179.)

The decades following Pascal's activity were in largè part devoted to the study of tangent problems and the allied normal problems, but at the same time the general theory of plane curves was constantly developing. Barrow gave a new method of determin ing tangents, and Huygens studied evolutes of curves and indicated the way of determining radii of curva ture. From the consideration of caustics, Tschirn hausen was led to involutes and Maclaurin constructed 
the circle of curvature at any point of an algebraic curve. The most important extension of this theory was made in Newton's Enumeratio linearum tertii ordinis (1706). This treatise establishes the distinction between algebraic and transcendental curves. It then makes an exhaustive study of the equation of a curve of the third order, and thus finds numerous such curves which may be represented as "shadows" of five types, a result which involves an analytic theory of perspective. Newton knew how to construct conics from five tangents. He came upon this discovery in his endeavor to investigate "after the manner of the ancients" without analytic geometry. Further he considered multiple points of a curve at a finite distance and at infinity, and gave rules for investigating the course of a curve in the neighborhood of one of its points ("Newton's parallelogram" or "analytic triangle"), as also for the determination of the order of contact of two curves at one of their common points. (Leibnitz and Jacob Bernoulli had also written upon osculations; Plücker (1831) called the situation where two curves have $k$ consecutive points in common "a $k$-pointic contact"; in the same case Lagrange (1779) had spoken of a "contact of $(k-1)$ th order." $)$

Additional work was done by Newton's disciples, Cotes and Maclaurin, as well as by Waring. Maclaurin made interesting investigations upon corre-

* Baltzer.

† Cayley, A., Address to the British Association, etc., I883. 
sponding points of a curve of the third order, and thus showed that the theory of these curves was much more comprehensive than that of conics. Euler likewise entered upon these investigations in his paper Sur une contradiction apparente dans la théorie des courbes planes (Berlin, 1748), where it is shown that by eight intersections of two curves of the third order the ninth is completely determined. This theorem, which includes Pascal's theorem for conics, introduced point groups, or systems of points of intersection of two curves, into geometry. This theorem of Euler's was noticed in 1750 by Cramer who gave special attention to the singularities of curves in his works upon the intersection of two algebraic curves of higher order; hence the obvious contradiction between the number of points determining a plane curve and the number of independent intersections of two curves of the same order bears the name of "Cramer's paradox." This contradiction was solved by Lamé in 1818 by the principle which bears his name.* Partly in connection with known results of the Greek geometry, and partly independently, the properties of certain algebraic and transcendental curves were investigated. A curve which is formed like the conchoid of Nicomedes, if we replace the straight line by a circle, is called by

* Loria, G., Die hauptsächlichsten Theorien det Geometrie in ihrer frïheren und jetzigen Entwicklung. Deutsch von Sclette, I888. For a more accurate account of Cramer's paradox, in which proper credit is given to Maclaurin's discovery, see Scott, C. A., "On the Intersections of Plane Curves," Bull. Am. Math. Soc., March, 1898. 
Roberval the limaçon of Pascal. The cardioid of the eighteenth century is a special case of this spiral. If, with reference to two fixed points $A, B$, a point $P$ satisfies the condition that a linear function of the distances $P A, P B$ has a constant value, then is the locus of $P$ a Cartesian oval. This curve was found by Descartes in his studies in dioptrics. For $P A \cdot P B=$ constant, we have Cassini's oval, which the astronomer of Louis XIV. wished to regard as the orbit of a planet instead of Kepler's ellipse. In special cases Cassini's oval contains a loop, and this form received from Jacob Bernoulli (1694) the name lemniscate. With the investigation of the logarithmic curve $y=a^{x}$ was connected the study made by Jacob and John Bernoulli, Leibnitz, Huygens, and others, of the curve of equilibrium of an inextensible, flexible thread. This furnished the catenary (catenaria, 1691), the idea of which had already occurred to Galileo.* The group of spirals found by Archimedes was enlarged in the seventeenth and eighteenth centuries by the addition of the hyperbolic, parabolic, and logarithmic spirals, and Cotes's lituus (1722). In 1687 Tschirnhausen defined a quadratrix, differing from that of the Greeks, as the locus of a point $P$, lying at the same time upon $L Q \| B O$ and upon $M P \| O A$ (OAB is a quadrant), where $L$ moves over the quadrant and $M$ over the radius $O B$ uniformly. Whole systems of curves and surfaces were considered. Here belong the investiga- 
tions of involutes and evolutes, envelopes in general, due to Huygens, Tschirnhausen, John Bernoulli, Leibnitz, and others. The consideration of the pencil of rays through a point in the plane, and of the pencil of planes through a straight line in space, was introduced by Desargues, 1639.*

The extension of the Cartesian co-ordinate method to space of three dimensions was effected by the labors of Van Schooten, Parent, and Clairaut. $\dagger$ Parent represented a surface by an equation involving the three co-ordinates of a point in space, and Clairaut perfected this new procedure in a most essential manner by a classic work upon curves of double curvature. Scarcely thirty years later Euler established the analytic theory of the curvature of surfaces, and the classification of surfaces in accordance with theorems analogous to those used in plane geometry. He gives formulae of transformation of space co-ordinates and a discussion of the general equation of surfaces of the second order, with their classification. Instead of Euler's.names: “elliptoid, elliptic-hyperbolic, hyperbolic-hyperbolic, elliptic-parabolic, parabolic-hyperbolic surface," the terms now in use, "ellipsoid, hyperboloid, paraboloid," were naturalized by Biot and Lacroix. $\$$

Certain special investigations are worthy of mention. In 1663 Wallis studied plane sections and effected the cubature, of a conoid with horizontal di-

*Baltzer. $\quad+$ Loria. $\quad$ Baltzer.


recting plane whose generatrix intersects a vertical directing straight line and vertical directing circle (cono-cuneus). To Wren we owe an investigation of the hyperboloid of revolution of two sheets (1669) which he called "cylindroid." The domain of gauche curves, of which the Greeks knew the common helix of Archytas and the spherical spiral corresponding in formation to the plane spiral of Archimedes, found an extension in the line which cuts under a constant angle the meridians of a sphere. Nuñez (1546) had recognized this curve as not plane, and Snellius (1624) had given it the name loxodromia sphaerica. The problem of the shortest line between two points of a surface, leading to gauche curves which the nineteenth century has termed "geodetic lines," was stated by John Bernoulli (1698) and taken in hand by him with good results. In a work of Pitot in 1724 (printed in 1726)* upon the helix, we find for the first time the expression ligne à double courbure, line of double curvature, for a gauche curve. In 1776 and 1780 Meusnier gave theorems upon the tangent planes to ruled surfaces, and upon the curvature of a surface at one of its points, as a preparation for the powerful development of the theory of surfaces soon to begin. $\dagger$

There are still some minor investigations belonging to this period deserving of mention. The algebraic expression for the distance between the centers of the inscribed and circumscribed circles of a triangle 
was determined by William Chapple (about 1746), afterwards by Landen (1755) and Euler (1765).* In 1769 Meister calculated the areas of polygons whose sides, limited by every two consecutive vertices, intersect so that the perimeter contains a certain number of double points and the polygon breaks up into cells with simple or multiple positive or negative areas. Upon the areas of such singular polygons Möbius published later investigations (1827 and 1865).* Saurin considered the tangents of a curve at multiple points and Ceva starting from static theorems studied the transversals of geometric figures. Stewart still further extended the theorems of Ceva, while Cotes determined the harmonic mean between the segments of a secant to a curve of the $n$th order reckoned from a fixed point. Carnot also extended the theory of transversals. Lhuilier solved the problem: In a circle to inscribe a polygon of $n$ sides passing through $n$ fixed points. Brianchon gave the theorem concerning the hexagon circumscribed about a conic dualistically related to Pascal's theorem upon the inscribed hexagon. The application of these two theorems to the surface of the sphere was effected by Hesse and Thieme. In the work of Hesse a Pascal hexagon is formed upon the sphere by six points which lie upon the intersection of the sphere with a cone of the second order having its vertex at the center of the sphere. Thieme selects a right circular cone. The material usually 
taken for the elementary geometry of the schools has among other things received an extension through numerous theorems upon the circle named after $\mathrm{K}$. W. Feuerbach (1822), upon symmedian lines of a triangle, upon the Grebe point and the Brocard figures (discovered in part by Crelle, 1816; again introduced by Brocard, 1875).*

The theory of regular geometric figures received its most important extension at the hands of Gauss, who discovered noteworthy theorems upon the possibility or impossibility of elementary constructions of regular polygons. (See p. 160.) Poinsot elaborated the theory of the regular polyhedra by publishing his views on the five Platonic bodies and especially upon the "Kepler-Poinsot regular solids of higher class," viz., the four star-polyhedra which are formed from the icosahedron and dodecahedron. These studies were continued by Wiener, Hessel, and Hess, with the removal of certain restrictions, so that a whole series of solids, which in an extended sense may be regarded as regular, may be added to those named above. Corresponding studies for four-dimensional space have been undertaken by Scheffler, Rudel, Stringham, Hoppe, and Schlegel. They have determined that in such a space there exist six regular figures of which the simplest has as its boundary five tetrahedra. The boundaries of the remaining five fig-

* Lieber, Ueber die Gegenmittellinie, den Grebe'schen Punkt und den Bro. card'schen Kreis, 1886-1 888 . 
ures require 16 or 600 tetrahedra, 8 hexahedra, 24 octahedra, 120 dodecahedra.* It may be mentioned further that in 1849 the prismatoid was introduced into stereometry by E. F. August, and that Schubert and Stoll so generalised the Apollonian contact problem as to be able to give the construction of the sixteen spheres tangent to four given spheres.

Projective geometry, called less precisely modern geometry or geometry of position, is essentially a creation of the nineteenth century. The analytic geometry of Descartes, in connection with the higher analysis created by Leibnitz and Newton, had registered a series of important discoveries in the domain of the geometry of space, but it had not succeeded in obtaining a satisfactory proof for theorems of pure geometry. Relations of a specific geometric character had, however, been discovered in constructive drawing. Newton's establishment of his five principal types of curves of the third order, of which the sixtyfour remaining types may be regarded as projections, had also given an impulse in the same direction. Still more important were the preliminary works of Carnot, which paved the way for the development of the new theory by Poncelet, Chasles, Steiner, and von Staudt. They it was who discovered "the overflowing spring of deep and elegant theorems which with astonishing facility united into an organic whole, into the graceful edifice of projective geometry, which, especially with

* Serret, Essai d'une nouvelle méthode, etc., I873. 
reference to the theory of curves of the second order, may be regarded as the ideal of a scientific organism."*

Projective geometry found its earliest unfolding on French soil in the Gémétrie descriptive of Monge whose astonishing power of imagination, supported by the methods of descriptive geometry, discovered a host of properties of surfaces and curves applicable to the classification of figures in space. His work created "for geometry the hitherto unknown idea of geometric generality and geometric elegance," $\dagger$ and the importance of his works is fundamental not only for the theory of projectivity but also for the theory of the curvature of surfaces. To the introduction of the imaginary into the considerations of pure geometry Monge likewise gave the first impulse, while his pupil Gaultier extended these investigations by defining the radical axis of two circles as a secant of the same passing through their intersections, whether real or imaginary.

The results of Monge's school thus derived, which were more closely related to pure geometry than to the analytic geometry of Descartes, consisted chiefly in a series of new and interesting theorems upon surfaces of the second order, and thus belonged to the same field that had been entered upon before Monge's time by Wren (1669), Parent and Euler. That Monge

* Brill, A.. Antrittsrede in Tübingen, $188_{4}$.

+ Hankel, Die Elemente der projektivischen Geometrie in synthetischer Behandlung, 1875 . 
did not hold analytic methods in light esteem is shown by his Application de l'algèbre à la géometrie (1805) in which, as Plücker says, "he introduced the equation of the straight line into analytic geometry, thus laying the foundation for the banishment of all constructions from it, and gave it that new form which rendered further extension possible."

While Monge was working by preference in the space of three dimensions, Carnot was making a special study of ratios of magnitudes in figures cut by transversals, and thus, by the introduction of the negative, was laying the foundation for a géométrie de position which, however, is not identical with the Geometrie der Lage of to-day. Not the most important, but the most noteworthy contribution for elementary school geometry is that of Carnot's upon the complete quadrilateral and quadrangle.

Monge and Carnot having removed the obstacles which stood in the way of a natural development of geometry upon its own territory, these new ideas could now be certain of a rapid development in well-prepared soil. Poncelet furnished the seed. His work, Traite des proprietés projectives des figures, which appeared in 1822, investigates those properties of figures which remain unchanged in projection, i. e., their invariant properties. The projection is not made here, as in Monge, by parallel rays in a given direction, but by centrai projection, and so after the manner of perspective. In this way Poncelet came to introduce 
the axis of perspective and center of perspective (according to Chasles, axis and center of homology) in the consideration of plane figures for which Desargues had already established the fundamental theorems. In 1811 Servois had used the expression "pole of a straight line," and in 1813 Gergonne the terms "polar of a point" and "duality," but in 1818 Poncelet developed some observations made by Lahire in 1685 , upon the mutual correspondence of pole and polar in the case of conics, into a method of transforming figures into their reciprocal polars. Gergonne recog. nized in this theory of reciprocal polars a principle whose beginnings were known to Vieta, Lansberg, and Snellius, from spherical geometry. He called it the "principle of duality" (1826). In 1827 Gergonne associated dualistically with the notion of order of a plane curve that of its class. The line is of the $n$th order when a straight line of the plane cuts it in $n$ points, of the $n$th class when from a point in the plane $n$ tangents can be drawn to it.*

While in France Chasles alone interested himself thoroughly in its advancement, this new theory found its richest development in the third decade of the nineteenth century upon German soil, where almost at the same time the three great investigators, Möbius. Plücker, and Steiner entered the field. From this time on the synthetic and more constructive tendency followed by Steiner, von Staudt, and Möbius diverges $†$

* Baltzer. †Brill, A., Antrittsrede in Tïbingen, $188_{4}$. 
from the analytic side of the modern geometry which Plücker, Hesse, Aronhold, and Clebsch had especially developed.

The Barycentrischer Calcül in the year 1827 furnished the first example of homogeneous co-ordinates, and along with them a symmetry in the developed formulae hitherto unknown to analytic geometry. In this calculus Möbius started with the assumption that every point in the plane of a triangle $A B C$ may be regarded as the center of gravity of the triangle. In this case there belong to the points corresponding weights which are exactly the homogeneous co-ordinates of the point $P$ with respect to the vertices of the fundamental triangle $A B C$. By means of this algorism Möbius found by algebraic methods a series of geometric theorems, for example those expressing invariant properties like the theorems on cross-ratios. These theorems, found analytically, Möbius sought to demonstrate geometrically also, and for this purpose he introduced with all its consequences the "law of signs" which expresses that for $A, B, C$, points of a straight line, $A B=-B A, A B+B A=0, A B+B C$ $+C A=0$.

Independently of Möbius, but starting from the same principles, Bellavitis came upon his new geometric method of equipollences.* Two equal and parallel lines drawn in the same direction, $A B$ and $C D$, are called equipollent (in Cayley's notation $A B$ $\equiv C D$ ). By this assumption the whole theory is reduced to the

* Bellavitis, "Saggio di Applicazioni di un Nuovo Metodo di Geometria Analitica (Calcolo delle Equipollenze)," in Ann. Lomb. Veneto, t. 5, 1835. 
consideration of segments proceeding from a fixed point. Further it is assumed that $A B+B C \equiv A C$ (Addition). Finally for the segments $a, b, c, d$, with inclinations $a, \beta, \gamma, \delta$ to a fixed axis, the equation $\alpha \equiv \frac{b c}{d}$ must not only be a relation between lengths but must also show that $a=\beta+\gamma-\delta$ (Proportion). For $d=1$ and $a=0$ this becomes $\alpha \equiv b c$, i. e., the product of the absolute values of the lengths is $\alpha=b c$ and at the same time $a=\beta+\gamma$ (Multiplication). Equipollence is therefore only a special case of the equality of two objects, applied to segments.*

Möbius further introduced the consideration of correspondences of two geometric figures. The oneto-one correspondence, in which to every point of a first figure there corresponds one and only one point of a second figure and to every point of the second one and only one point of the first, Möbius called collineation. He constructed not only a collinear image of the plane but also of ordinary space.

These new and fundamental ideas which Möbius had laid down in the barycentric calculus remained for a long time almost unheeded and hence did not at once enter into the formation of geometric conceptions. The works of Plücker and Steiner found a more favorable soil. The latter "had recognized in immediate geometric perception the sufficient means and the only object of his knowledge. Plücker, on the other hand, $\nmid$ sought his proofs in the identity of the analytic operation and the geometric construc-

* Stolz, O., Vorlesungen über allgemeine Arithmetik, 1885-1886.

f'Clebsch, Versuch einer Darlegung und Würdigung seiner wissenschaftlichen Leistungen von einigen seiner Freunde (Brill, Gordan, Klein, Lüroth, A. Mayer, Nöther, Von der Mühll)," in Math. Ann., Bd. 7. 
tion, and regarded geometric truth only as one of the many conceivable antitypes of analytic relation."

At a later period (1855) Möbius engaged in the study of involutions of higher degree. Such an involution of the $m$ th degree consists of two groups each of $m$ points: $A_{1}, A_{2}, A_{3}, \ldots A_{m} ; B_{1}, B_{2}, B_{3}, \ldots B_{m}$, which form two figures in such a way that to the 1st, $2 \mathrm{~d}, 3 \mathrm{~d}, \ldots . m$ th points of one group, as points of the first figure, there correspond in succession the $2 \mathrm{~d}, 3 \mathrm{~d}$, 4 th ... 1st points of the same group as points of the second figure, with the same determinate relation. Involutions of higher degree had been previously studied by Poncelet (1843). He started from the theorem given by Sturm (1826), that by the conic sections of the surfaces of the second order $u=0, v=0, u+\lambda v$ $=0$, there are determined upon a straight line six points, $A, A^{\prime}, B, B^{\prime}, C, C^{\prime}$ in involution, i. e., so that in the systems $A B C A^{\prime} B^{\prime} C^{\prime}$ and $A^{\prime} B^{\prime} C^{\prime} A B C$ not only $A$ and $A^{\prime}, B$ and $B^{\prime}, C$ and $C^{\prime}$, but also $A^{\prime}$ and $A, B^{\prime}$ and $B, C^{\prime}$ and $C$ are corresponding point-pairs. This mutual correspondence of three point-pairs of a line Desargues had already (in 1639) designated by the term "involution."*

Plücker is the real founder of the modern analytic tendency, and he attained this distinction by "formulating analytically the principle of duality and following out its consequences." $\dagger$ His Analytisch-geometrische Untersuchungen appeared in 1828. By this work 
was created for geometry the method of symbolic notation and of undetermined coefficients, whereby one is freed from the necessity, in the consideration of the mutual relations 'of two figures, of referring to the system of co-ordinates, so that he can deal with the figures themselves. The System der analytischen Geo. metrie of 1835 furnishes, besides the abundant application of the abbreviated notation, a complete classification of plane curves of the third order. In the Theorie der algebraischen Kurven of 1839, in addition to an investigation of plane curves of the fourth order there appeared those analytic relations between the ordinary singularities of plane curves which are generally known as "Plücker's equations."

These Plücker equations which at first are applied only to the four dualistically corresponding singularities (point of inflexion, double point, inflexional tangent, double tangent) were extended by Cayley to curves with higher singularities. By the aid of developments in series he derived four "equivalence numbers" which enable us to determine how many singularities are absorbed into a singular point of ligher order, and how the expression for the deficiency of the curve is modified thereby. Cayley's results were confirmed, extended, and completed as to proofs by the works of Nöther, Zeuthen, Halphen, and Smith. The fundamental question arising from the Cayley method of considering the subject, whether and by what change of parameters a curve with correspond- 
ing elementary singularities can be derived from a curve with higher singularity, for which the Plücker and deficiency equations are the same, has been studied by A. Brill.

Plücker's greatest service consisted in the introduction of the straight line as a space element. The principle of duality had led him to introduce, besides the point in the plane, the straight line, and in space the plane as a determining element. Plücker also used in space the straight line for the systematic generation of geometric figures. His first works in this direction were laid before the Royal Society in London in 1865. They contained theorems on complexes, congruences, and ruled surfaces with some indications of the method of proof. The further development appeared in 1868 as Neue Geometrie des Raumes, gegrïndet auf die Betrachtung der geraden Linie als Raumelement. Plücker had himself made a study of linear complexes but his completion of the theory of complexes of the second degree was interrupted by death. Further extension of the theory of complexes was made by F. Klein.

The results contained in Pliicker's last work have thrown a flood of light upon the difference between plane and solid geometry. The curved line of the plane appears as a simply infinite system either of points or of straight lines; in space the curve may be regarded as a simply infinite system of points, straight lines or planes; but from another point of view this 
curve in space may be replaced by the developable surface of which it is the edge of regression. Special cases of the curve in space and the developable surface are the plane curve and the cone. A further space figure, the general surface, is on the one side a doubly infinite system of points or planes, but on the other, as a special case of a complex, a triply infinite system of straight lines, the tangents to the surface. As a special case we have the skew surface or ruled surface. Besides this the congruence appears as a doubly, the complex as a triply, infinite system of straight lines. The geometry of space involves a number of theories to which plane geometry offers no analogy. Here belong the relations of a space curve to the surfaces which may be passed through it, or of a surface to the gauche curves lying upon it. To the lines of curvature upon a surface there is nothing corresponding in the plane, and in contrast to the consideration of the straight line as the shortest line between two points of a plane, there stand in space two comprehensive and difficult theories, that of the geodetic line upon a given surface and that of the minimal surface with a given boundary. The question of the analytic representation of a gauche curve involves peculiar difficulties, since such a figure can be represented by two equations between the co-ordinates $x, y, z$ only when the curve is the complete intersection of two surfaces. In just this direction tend 
the modern investigations of Nöther, Halphen, and Valentiner.

Four years after the Analytisch-geometrische Untersuchungen of Plücker, in the year 1832, Steiner published his Systematische Entwicklung der Abhängigkeit geometrischer Gestalten. Steiner found the whole theory of conic sections concentrated in the single theorem (with its dualistic analogue) that a curve of the second order is produced as the intersection of two collinear or projective pencils, and hence the theory of curves and surfaces of the second order was essentially completed by him, so that attention could be turned to algebraic curves and surfaces of higher order. Steiner himself followed this course with good results. This is shown by the "Steiner surface," and by a paper which appeared in 1848 in the Berliner Abhandlungen. In this the theory of the polar of a point with respect to a curved line was treated exhaustively and thus a more geometric theory of plane curves developed, which was further extended by the labors of Grassmann, Chasles, Jonquières, and Cremona.*

The names of Steiner and Plücker are also united in connection with a problem which in its simplest form belongs to elementary geometry, but in its generalization passes into higher fields. It is the Malfatti Problem. $\uparrow$ In 1803 Malfatti gave out the following problem: From a right triangular prism to cut out three cylinders which shall have the same altitude as the prism, whose volumes shall be the greatest possible, and consequently the mass remain-

* Loria. † Wittstein, Geschichte des Malfatti'schen Problens, I871. 
ing after their removal shall be a minimum. This problem he reduced to what is now generally known as Malfatti's problem: In a given triangle to inscribe three circles so that each circle shall be tangent to two sides of the triangle and to the other two circles. $\mathrm{He}$ calculates the radii $x_{1}, x_{2}, x_{3}$ of the circles sought in terms of the semi-perimeter $s$ of the triangle, the radius $\rho$ of the inscribed circle, the distances $a_{1}, a_{2}, a_{3} ; b_{1}, b_{2}, b_{3}$ of the vertices of the triangle from the center of the inscribed circle and its points of tangency to the sides, and gets :

$$
\begin{aligned}
& x_{1}=\frac{\rho}{2 b_{1}}\left(s+\alpha_{1}-\rho-\alpha_{2}-\alpha_{3}\right), \\
& x_{2}=\frac{\rho}{2 b_{2}}\left(s+\alpha_{2}-\rho-\alpha_{3}-\alpha_{1}\right), \\
& x_{3}=\frac{\rho}{2 b_{3}}\left(s+\alpha_{3}-\rho-\alpha_{1}-a_{2}\right),
\end{aligned}
$$

without giving the calculation in full; but he adds a simple construction. Steiner also studied this problem. He gave (without proof) a construction, showed that there are thirty-two solutions and generalized the problem, replacing the three straight lines by three circles. Plücker also considered this same generalization. But besides this Steiner studied the same problem for space: In connection with three given conics upon a surface of the second order to determine three others which shall each touch two of the given conics and two of the required. This general problem received an analytic solution from Schellbach and Cayley, and also from Clebsch with the aid of the addition theorem of elliptic functions, while the more simple problem in the plane was attacked in the greatest variety of ways by Gergonne, Lehmus, Crelle, Grunert, Scheffler, Schellbach (who gave a specially elegant trigonometric solution) and Zorer. The first perfectly satisfactory proof of Steiner's construction was given by Binder.*

After Steiner came von Staudt and Chasles who rendered excellent service in the development of pro-

* Programm Schönthal, 1868. 
jective geometry. In 1837 Michel Chasles published his Apercu historique sur l'origine et le developpement des méthodes en géométrie, a work in which both ancient and modern methods are employed in the derivation of many interesting results, of which several of the most important, among them the introduction of the cross-ratio (Chasles's "anharmonic ratio") and the reciprocal and collinear relation (Chasles's "duality" and "homography"), are to be assigned in part to Steiner and in part to Möbius.

Von Staudt's Geometrie der Lage appeared in 1847, his Beiträge zur Geometrie der Lage, 1856-1860. These works form a marked contrast to those of Steiner and Chasles who deal continually with metric relations and cross-ratios, while von Staudt seeks to solve the problem of "making the geometry of position an independent science not standing in need of measurement." Starting from relations of position purely, von Staudt develops all theorems that do not deal immediately with the magnitude of geometric forms, completely solving, for example, the problem of the introduction of the imaginary into geometry. The earlier works of Poncelet, Chasles, and others had, to be sure, made use of complex elements but had defined the same in a manner more or less vague and, for example, had not separated conjugate complex elements from each other. Von Staudt determined the complex elements as double elements of involution-relations. Each double element is characterized 
by the sense in which, by this relation, we pass from the one to the other. This suggestion of von Staudt's, however, did not become generally fruitful, and it was reserved for later works to make it more widely known by the extension of the originally narrow conception.

In the Beiträge von Staudt has also shown how the cross-ratios of any four elements of a prime form of the first class (von Staudt's Wïrfe) may be used to derive absolute numbers from pure geometry.*

With the projective geometry is most closely connected the modern descriptive geometry. The former in its development drew its first strength from the considerations of perspective, the latter enriches itself later with the fruits matured by the cultivation of projective geometry.

The perspective of the Renaissancef was developed especially by French mathematicians, first by Desargues who used co-ordinates in his pictorial representation of objects in such a way that two axes lay in the picture plane, while the third axis was normal to this plane. The results of Desargues were more important, however, for theory than for practice. More valuable results were secured by Taylor with a "linear perspective" (1715). In this a straight line is determined by its trace and vanishing point, a plane by its trace and vanishing line. This method was

* Stolz, O., Vorlesungen über allgemeine Arithmetik, 1885-1886.

+ Wiener. 
uscd by Lambert in an ingenious manner for different c snstructions, so that by the middle of the eighteenth century even space-forms in general position could be pictured in perspective.

Out of the perspective of the eighteenth century grew "descriptive geometry," first in a work of Frézier's, which besides practical methods contained a special theoretical section furnishing proofs for all cases of the graphic methods considered. Even in the "description," or representation, Frézier replaces the central projection by the perpendicular parallelprojection, "which may be illustrated by falling drops of ink."* The picture of the plane of projection is called the ground plane or elevation according as the picture plane is horizontal or vertical. With the aid of this "description" Frézier represents planes, polyhedra, surfaces of the second degree as well as intersections and developments.

Since the time of Monge descriptive geometry has taken rank as a distinct science. The Lecons de géométrie descriptive (1795) form the foundation-pillars of descriptive geometry, since they introduce horizontal and vertical planes with the ground-line and show how to represent points and straight lines by two projections, and planes by two traces. This is followed in the Lecons by the great number of problems of intersection, contact and penetration which arise from combinations of planes with polyhedra and surface: 
of the second order. Monge's successors, Lacroix, Hachette, Olivier, and J. de la Gournerie applied these methods to surfaces of the second order, ruled surfaces, and the relations of curvature of curves and surfaces.

Just at this time, when the development of descriptive geometry in France had borne its first remarkable results, the technical high schools came into existence. In the year 1794 was established in Paris the École Centrale des Travaux Publics from which in 1795 the École Polytechnique was an outgrowth. Further technical schools, which in course of time attained to university rank, were founded in Prague in 1806, in Vienna in 1815, in Berlin in 1820, in Karlsruhe in 1825, in Munich in 18: $\%$, in Dresden in 1828, in Hanover in 1831, in Stuttgart 1832, in Zürich in 1860, in Braunschweig in 1862, in Darmstadt in 1869, and in Aix-la-Chapelle in 18\%0. In these institutions the results of projective geometry were used to the greatest advantage in the advancement of descriptive geometry, and were set forth in the most logical manner by Fiedler, whose text-books and manuals, in part original and in part translations from the English, take a conspicuous place in the literature of the science.

With the technical significance of descriptive geometry there has been closely related for some years an artistic side, and it is this especially which has marked an advance in works on axonometry (Weisbach, 1844), relief-perspective, photogrammetry, and theory of lighting.

The second quarter of our century marks the time when developments in form-theory in connection with geometric constructions have led to the discovery of of new and important results. Stimulated on the one side by Jacobi, on the other by Poncelet and Steiner, 
Hesse (1837-1842) by an application of the transformation of homogeneous forms treated the theory of surfaces of the second order and constructed their principal axes.* By him the notions of "polar triangles" and "polar tetrahedra" and of "systems of conjugate points" were introduced as the geometric expression of analytic relations. To these were added the linear construction of the eighth intersection of three surfaces of the second degree, when seven of them are given, and also by the use of Steiner's theorems, the linear construction of a surface of the second degree from nine given points. Clebsch, following the English mathematicians, Sylvester, Cayley, and Salmon, went in his works essentially further than Hesse. His vast contributions to the theory of invariants, his introduction of the notion of the deficiency of a curve, his applications of the theory of elliptic and Abelian functions to geometry and to the study of rational and elliptic curves, secure for him a pre-eminent place among those who have advanced the science of extension. As an algebraic instrument Clebsch, like Hesse, had a fondness for the theorem upon the multiplication of determinants in its application to bordered determinants. His works $\nmid$ upon the general theory of algebraic curves and surfaces

* Nöther, "Otto Hesse," Schlömilch's Zeitschrift, Bd. 2o, Hl. A.

+"Clebsch, Versuch einer Darlegung und Würdigung seiner wissenschaftlichen Leistungen von einigen seiner Freunde" (Brill, Gordan, Klein, Lürotl, A. Mayer, Nöther, Von der Mühll) Math. Ann., Bd. 7. 
began with the determination of those points upon an algebraic surface at which a straight line has fourpoint contact, a problem also treated by Salmon but not so thoroughly. While now the theory of surfaces of the third order with their systems of twenty-seven straight lines was making headway on English soil, Clebsch undertook to render the notion of "deficiency" fruitful for geometry. This notion, whose analytic properties were not unknown to Abel, is found first in Riemann's Theorie der Abel'schen Funktionen (1857). Clebsch speaks also of the deficiency of an algebraic curve of the $n$th order with $d$ double points and $r$ points of inflexion, and determines the number $p=\frac{1}{2}(n-1)(n-2)-d-r$. To one class of plane or gauche curves characterized by a definite value of $p$ belong all those that can be made to pass over into one another by a rational transformation or which possess the property that any two have a one-to-one correspondence. Hence follows the theorem that only those curves that possess the same $3 p-3$ parameters (for curves of the third order, the same one parameter) can be rationally transformed into one another.

The difficult theory of gauche curves* owes its first general results to Cayley, who obtained formulae corresponding to Plücker's equations for plane curves. Works on gauche curves of the third and fourth orders had already been published by Möbius, Chasles, and Von Staudt. General observations on gauche curves

*Loria. 
in more recent times are found in theorems of Nöther and Halphen.

The foundations of enumerative geometry* are found in Chasles's method of characteristics (1864). Chasles determined for rational configurations of one dimension a correspondence-formula which in the simplest case may be stated as follows: If two ranges of points $R_{1}$ and $R_{2}$ lie upon a straight line so that to every point $x$ of $R_{1}$ there correspond in general a points $y$ in $R_{2}$, and again to every point $y$ of $R_{2}$ there always correspond $\beta$ points $x$ in $R_{1}$, the configuration formed from $R_{1}$ and $R_{2}$ has $(\alpha+\beta)$ coincidences or there are $(\alpha+\beta)$ times in which a point $x$ coincides with a corresponding point $y$. The Chasles correspondence-principle was extended inductively by Cayley in 1866 to point-systems of a curve of higher deficiency and this extension was proved by Brill. $\dagger$ Important extensions of these enumerative formulae (correspondence-formulae), relating to general algebraic curves, have been given by Brill, Zeuthen, and Hurwitz, and set forth in elegant form by the introduction of the notion of deficiency. An extended treatment of the fundamental problem of enumerative geometry, to determine how many geometric configurations of given definition satisfy a sufficient number of conditions, is contained in the Kalkül der abzählenden Geometrie by H. Schubert (1879).

The simplest cases of one-to-one correspondence 
or uniform representation, are furnished by two planes superimposed one upon the other. These are the similarity studied by Poncelet and the collineation treated by Möbius, Magnus, and Chasles.* In both cases to a point corresponds a point, to a straight line a straight line. From these linear transformations Poncelet, Plücker, Magnus, Steiner passed to the quadratic where they first investigated one-to-one correspondences between two separate planes. The "Steiner projection" (1832) employed two planes $E_{1}$ and $E_{2}$ together with two straight lines $g_{1}$ and $g_{2}$ not co-planar. If we draw through a point $P_{1}$ or $P_{2}$ of $E_{1}$ or $E_{2}$ the straight line $x_{1}$ or $x_{2}$ which cuts $g_{1}$ as well as $g_{2}$, and determines the intersection $X_{2}$ or $X_{1}$, with $E_{2}$ or $E_{1}$, then are $P_{1}$ and $X_{2}$, and $P_{2}$ and $X_{1}$ corresponding points. In this manner to every straight line of the one plane corresponds a conic section in the other. In 1847 Plücker had determined a point upon the hyperboloid of one sheet, like fixing a point in the plane, by the segments cut off upon the two generators passing through the point by two fixed generators. This was an example of a uniform representation of a surface of the second order upon the plane.

The one-to-one relation of an arbitrary surface of the second order to the plane was investigated by Chasles in 1863, and this work marks the beginning of the proper theory of surface representation which

* Loria. 
found its further development when Clebsch and Cremona independently succeeded in the representation of surfaces of the third order. Cremona's important results were extended by Cayley, Clebsch, Rosanes, and Nöther, to the last of whom we owe the important theorem that every Cremona transformation which as such is uniform forward and backward can be effected by the repetition of a number of quadratic transformations. In the plane only is the aggregate of all rational or Cremona transformations known; for the space of three dimensions, merely a beginning of the development of this theory has been made.*

A specially important case of one-to-one correspondence is that of a conformal representation of a surface upon the plane, because here similarity in the smallest parts exists between original and image. The simplest case, the stereographic projection, was known to Hipparchus and Ptolemy. The representation by reciprocal radii characterized by the fact that any two corresponding points $P_{1}$ and $P_{2}$ lie upon a ray through the fixed point $O$ so that $O P_{1} \cdot O P_{2}=$ constant, is also conformal. Here every sphere in space is in general transformed into a sphere. This transformation, studied by Bellavitis 1836 and Stubbs 1843, is especially useful in dealing with questions of mathematical physics. Sir Wm. Thomson calls it "the principle of electric images." The investigations upon representa-

* Klein, F., Vergleichende Betrachtungen über newre geometrische Forschungen, 1872 . 
tions, made by Lambert and Lagrange, but more especially those by Gauss, lead to the theory of curvature.

A further branch of geometry, the differential geometry (theory of curvature of surfaces), considers in general not first the surface in its totality but the properties of the same in the neighborhood of an ordinary point of the surface, and with the aid of the differential calculus seeks to characterize it by analytic formulae.

The first attempts to enter this domain were made by Lagrange (1761), Euler (1766), and Meusnier(1776). The former determined the differential equation of minimal surfaces; the two latter discovered certain theorems upon radii of curvature and surfaces of centers. But of fundamental importance for this rich domain have been the investigations of Monge, Dupin, and especially of Gauss. In the Application de l'analyse a la géometrie (1795), Monge discusses families of surfaces (cylindrical surfaces, conical surfaces, and surfaces of revolution,-envelopes with the new notions of characteristic and edge of regression) and determines the partial differential equations distinguishing each. In the year 1813 appeared the Développements de geometrie by Dupin. It introduced the indicatrix at a point of a surface, as well as extensions of the theory of lines of curvature (introduced by Monge) and of asymptotic curves.

Gauss devoted to differential geometry three trea- 
tises : the most celebrated, Disquisitiones generales circa superficies curvas, appeared in 1827, the other two Untersuchungen über Gegenstände der höheren Geodäsie were published in 1843 and 1846. In the Disquisitiones, to the preparation of which he was led by his own astronomical and geodetic investigations,* the spherical representation of a surface is introduced. The one-to-one correspondence between the surface and the sphere is established by regarding as corresponding points the feet of parallel normals, where obviously we must restrict ourselves to a portion of the given surface, if the correspondence is to be maintained. Thence follows the introduction of the curvilinear co-ordinates of a surface, and the definition of the measure of curvature as the reciprocal of the product of the two radii of principal curvature at the point under consideration. The measure of curvature is first determined in ordinary rectangular co-ordinates and afterwards also in curvilinear co-ordinates of the surface. Of the latter expression it is shown that it is not changed by any bending of the surface without stretching or folding (that it is an invariant of curvature). Here belong the consideration of geodetic lines, the definition and a fundamental theorem upon the total curvature (curvatura integra) of a triangle bounded by geodetic lines.

The broad views set forth in the Disquisitiones of 1827 sent out fruitful suggestions in the most vari-

* Brill, A., Antrittsrede in Tübingen, I884. 
ous directions. Jacobi determined the geodetic lines of the general ellipsoid. With the aid of elliptic coordinates (the parameters of three surfaces of a system of confocal surfaces of the second order passing through the point to be determined) he succeeded in integrating the partial differential equation so that the equation of the geodetic line appeared as a relation between two Abelian integrals. The properties of the geodetic lines of the ellipsoid are derived with especial ease from the elegant formulae given by Liouville. By Lamé the theory of curvilinear co-ordinates, of which he had investigated a special case in 1837, was developed in 1859 into a theory for space in his Leçons sur la théorie des coordonnées curvilignes.

The expression for the Gaussian measure of curvature as a function of curvilinear co-ordinates has given an impetus to the study of the so-called differential invariants or differential parameters. These are certain functions of the partial derivatives of the coeffcients in the expression for the square of the line-element which in the transformation of variables behave like the invariants of modern algebra. Here Saucé, Jacobi, C. Neumann, and Halphen laid the foundations, and a general theory has been developed by Beltrami.* This theory, as well as the contact-transformations of Lie, moves along the border line between geometry and the theory of differential equations. $\dagger$ 
With problems of the mathematical theory of light are connected certain investigations upon systems of rays and the properties of infinitely thin bundles of rays, as first carried on by $\mathrm{Du}$ pin, Malus, Ch. Sturm, Bertrand, Transon, and Hamilton. The celebrated works of Kummer (1857 and 1866) perfect Hamilton's results upon bundles of rays and consider the number of singularities of a system of rays and its focal surface. An interesting application to the investigation of the bundles of rays between the lens and the retina, founded on the study of the infinitely thin bundles of normals of the ellipsoid, was given by O. Böklen.*

Non-Euclidean Geometry. - Though the respect which century after century had paid to the Elements of Euclid was unbounded, yet mathematical acuteness had discovered a vulnerable point; and this point $\dagger$ forms the eleventh axiom (according to Hankel, reckoned by Euclid himself among the postulates) which affirms that two straight lines intersect on that side of a transversal on which the sum of the interior angles is less than two right angles. Toward the end of the last century Legendre had tried to do away with this axiom by making its proof depend upon the others, but his conclusions were invalid. This effort of Legendre's was an indication of the search now beginning after a geometry free from contradictions, a hyper-Euclidean geometry or pangeometry. Here also Gauss was among the first who recognized that this axiom could not be proved. Although from his correspondence with Wolfgang Bolyai and Schumacher it can easily

*Kronecker's Journal, Band 46. Fortschritte, 1884 .

+Loria. 
be seen that he had obtained some definite results in this field at an early period, he was unable to decide upon any further publication. The real pioneers in the Non-Euclidean geometry were Lobachevski and the two Bolyais. Reports of the investigations of Lobachevski first appeared in the Courier of Kasan, 1829-1830, then in the transactions of the University of Kasan, 1835-1839, and finally as Geometrische Untersuchungen über die Theorie der Parallellinien, 1840, in Berlin. By Wolfgang Bolyai was published (18321833*) a two-volume work, Tentamen Juventutem studiosam in elementa Mathescos purae, etc. Both works were for the mathematical world a long time as good as non-existent till first Riemann, and then (in 1866) R. Baltzer in his Elemente, referred to Bolyai. Almost at the same time there followed a sudden mighty advance toward the exploration of this "new world" by Riemann, Helmholtz, and Beltrami. It was recognized that of the twelve Euclidean axioms $\uparrow$ nine are of essentially arithmetic character and therefore hold for every kind of geometry; also to every geometry is applicable the tenth axiom upon the equality of all right angles. The twelfth axiom (two straight lines, or more generally two geodetic lines, include no space) does not hold for geometry on the sphere. The eleventh axiom (two straight lines, geodetic

* Schmidt, "Aus dem Leben zweier ungarischen Mathematiker," Grunert Arch., Bd. 48 .

† Brill, A., Ueber das elfte Axiom des Euclid, 1883. 
lines, intersect when the sum of the interior angles is less than two right angles) does not hold for geometry on a pseudo-sphere, but only for that in the plane.

Riemann, in his paper "Ueber die Hypothesen, welche der Geometrie zu Grunde liegen,"* seeks to penetrate the subject by forming the notion of a multiply extended manifoldness; and according to these investigations the essential characteristics of an $n$-ply extended manifoldness of constant measure of curvature are the following:

1. "Every point in it may be determined by $n$ variable magnitudes (co-ordinates).

2. "The length of a line is independent of position and direction, so that every line is measurable by every other.

3. "To investigate the measure-relations in such a manifoldness, we must for every point represent the line-elements proceeding from it by the corresponding differentials of the co-ordinates. This is done by virtue of the hypothesis that the length-element of the line is equal to the square root of a homogeneous function of the second degree of the differentials of the coordinates."

At the same time Helmholtz $\dagger$ published in the "Thatsachen, welche der Geometrie zu Grunde lie gen," the following postulates:

* Göttinger Abhandlungen, X1II., I868. Fortschritte, I868.

+Fortschritte, 1868. 
1. "A point of an $n$-tuple manifoldness is determined by $n$ co-ordinates.

2 . "Between the $2 n$ co-ordinates of a point-pair there exists an equation, independent of the movement of the latter, which is the same for all congruent point-pairs.

3. "Perfect mobility of rigid bodies is assumed.

4. "If a rigid body of $n$ dimensions revolves about $n-1$ fixed points, then revolution without reversal will bring it back to its original position."

Here spatial geometry has satisfactory foundations for a development free from contradictions, if it is further assumed that space has three dimensions and is of unlimited extent.

One of the most surprising results of modern geometric investigations was the proof of the applicability of the non-Euclidean geometry to pseudo-spheres or surfaces of constant negative curvature.* On a pseudo-sphere, for example, it is true that a geodetic line (corresponding to the straight line in the plane, the great circle on the sphere) has two separate points at infinity; that through a point $P$, to a given geodetic line $g$, there are two parallel geodetic lines, of which, however, only one branch beginning at $P$ cuts $g$ at infinity while the other branch does not meet $g$ at all; that the sum of the angles of a geodetic triangle is less than two right angles. Thus we have a geometry upon the pseudo-sphere which with the spherical ge-

* Cayley, Address to the British Association, etc., 1883 . 
ometry has a common limiting case in the ordinary or Euclidean geometry. These three geometries have this in common that they hold for surfaces of constant curvature. According as the constant value of the survature is positive, zero, or negative, we have to do with spherical, Euclidean, or pseudo-spherical geometry.

A new presentation of the same theory is due to F. Klein. After projective geometry had shown that in projection or linear transformation all descriptive properties and also some metric relations of the figures remain unaltered, the endeavor was made to find for the metric properties an expression which should remain invariant after a linear transformation. After a preparatory work of Laguerre which made the "notion of the angle projective," Cayley, in 1859, found the general solution of this problem by considering "every metric property of a plane figure as contained in a projective relation between it and a fixed conic." Starting from the Cayley theory, on the basis of the consideration of measurements in space, Klein succeeded in showing that from the projective geometry with special determination of measurements in the plane there could be derived an elliptic, parabolic, or hyperbolic geometry,* the same fundamentally as the spherical, Euclidean, or pseudo-spherical geometry respectively.

The need of the greatest possible generalization

* Fortschritte, 1871 . 
and the continued perfection of the analytic apparatus have led to the attempt to build up a geometry of $n$ dimensions; in this, however, only individual relations have been considered. Lagrange* observes that "mechanics may be regarded as a geometry of four dimensions." Plücker endeavored to clothe the notion of arbitrarily extended space in a form easily understood. He showed that for the point, the straight line or the sphere, the surface of the second order, as a space element, the space chosen must have three, four, or nine dimensions respectively. The first investigation, giving a different conception from Plücker's and "considering the element of the arbitrarily extended manifoldness as an analogue of the point of space," is found $\dagger$ in H. Grassmann's principal work, Die Wissenschaft der extensiven Grösse oder die lineale Ausdehnungslehre (1844), which remained almost wholly unnoticed, as did his Geometrische Analyse (1847). Then followed Riemann's studies in multiply extended manifoldnesses in his paper Ueber die Hypothesen, etc., and they again furnished the starting point for a series of modern works by Veronese, H. Schubert, F. Meyer, Segre, Castelnuovo, etc.

A Geometria situs in the broader sense was created by Gauss, at least in name; but of it we know scarcely more than certain experimental truths. The Analysis

* Loria.

†F. Klein, Vergleichende Betrachtungeu ïber neuere geometrische Fors hungen, I872.

$\doteqdot$ Brill, A., Antrittsrede in Tübingen, I884. 
situs, suggested by Riemann, seeks what remains fixed after transformations consisting of the combination of infinitesimal distortions.* This aids in the solution of problems in the theory of functions. The contacttransformations already considered by Jacobi have been developed by Lie. A contact-transformation is defined analytically by every substitution which expresses the values of the co-ordinates $x, y, z$, and the partial derivatives $\frac{d z}{d x}=p, \frac{d z}{d y}=q$, in terms of quantities of the same kind, $x^{\prime}, y^{\prime}, z^{\prime}, p^{\prime}, q^{\prime}$. In such a transformation contacts of two figures are replaced by similar contacts.

Also a "geometric theory of probability" has been created by Sylvester and Woolhouse; $\uparrow$ Crofton uses it for the theory of lines drawn at random in space.

In a history of elementary mathematics there possibly calls for attention a related field, which certainly cannot be regarded as a branch of science, but yet which to a certain extent reflects the development of geometric science, the history of geometric illustrative material. \$ Good diagrams or models of systems of space-elements assist in teaching and have frequently led to the rapid spread of new ideas. In fact in the geometric works of Euler, Newton, and Cramer are found numerous plates of figures. Interest in the

*F. Klein.

$\dagger$ Fortschritte, 1868.

$\ddagger$ Brill, A., Ueber die Modellsammlung des mathematischen Seminars der Universität Tübingen, 1886 . Mathematisch-naturaissenschaftliche Mittheilungen von O. Böklen. 1887 . 
construction of models seems to have been manifested first in France in consequence of the example and activity of Monge. In the year 1830 the Conservatoire des arts et métiers in Paris possessed a whole series of thread models of surfaces of the second degree, con. oids and screw surfaces. A further advance was made by Bardin (1855). He had plaster and thread models constructed for the explanation of stone-cutting, toothed gears and other matters. His collection was considerably enlarged by Muret. These works of French technologists met with little acceptance from the mathematicians of that country, but, on the contrary, in England Cayley and Henrici put on exhibition in London in 1876 independently constructed models together with other scientific apparatus of the universities of London and Cambridge.

In Germany the construction of models experienced an advance from the time when the methods of projective geometry were introduced into descriptive geometry. Plücker, who in his drawings of curves of the third order had in 1835 showed his interest in re lations of form, brought together in 1868 the first large collection of models. This consisted of models of complex surfaces of the fourth order and was considerably enlarged by Klein in the same field. A special surface of the fourth order, the wave-surface for optical bi-axial crystals was constructed in 1840 by Magnus in Berlin, and by Soleil in Paris. In the year 1868 appeared the first model of a surface of the 
third order with its twenty-seven straight lines, by Chr. Wiener. In the sixties, Kummer constructed models of surfaces of the fourth order and of certain focal surfaces. His pupil Schwarz likewise constructed a series of models, among them minimal surfaces and the surfaces of centers of the ellipsoid. At a meeting of mathematicians in Göttingen there was made a notable exhibition of models which stimulated further work in this direction.

In wider circles the works suggested by A. Brill, F. Klein, and W. Dyck in the mathematical seminar of the Munich polytechnic school have found recognition. There appeared from 1877 to 1890 over a hundred models of the most various kinds, of value not only in mathematical teaching but also in lectures on perspective, mechanics and mathematical physics.

In other directions also has illustrative material of this sort been multiplied, such as surfaces of the third order by Rodenberg, thread models of surfaces and gauche curves of the fourth order by Rohn, H. Wiener, and others.

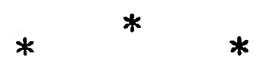

If one considers geometric science as a whole, it cannot be denied that in its field no essential difference between modern analytic and modern synthetic geometry any longer exists. The subject-matter and the methods of proof in both directions have gradually taken almost the same form. Not only does the synthetic method make use of space intuition; the 
analytic representations also are nothing less than a clear expression of space relations. And since metric properties of figures may be regarded as relations of the same to a fundamental form of the second order, to the great circle at infinity, and thus can be brought into the aggregate of projective properties, instead of analytic and synthetic geometry, we have only a projective geometry which takes the first place in the science of space.*

The last decades, especially of the development of German mathematics, have secured for the science a leading place. In general two groups of allied works may be recognized. $f$ In the treatises of the one tendency "after the fashion of a Gauss or a Dirichlet, the inquiry is concentrated upon the exactest possible limitation of the fundamental notions" in the theory of functions, theory of numbers, and mathematical physics. The investigations of the other tendency, as is to be seen in Jacobi and Clebsch, start "from a small circle of already recognized fundamental concepts and aim at the relations and consequences which spring from them," so as to serve modern algebra and geometry.

On the whole, then, we may say that $\ddagger$ "mathematics have steadily advanced from the time of the Greek geometers. The achievements of Euclid, Archimedes, and Apollonius are as admirable now as they

$$
\text { *F. Klein. †Clebsch. }
$$

$\ddagger$ Cayley, A., Address to the British Association, etc., 1883 . 
were in their own days. Descartes's method of coordinates is a possession forever. But mathematics have never been cultivated more zealously and diligently, or with greater success, than in this centuryin the last half of it, or at the present time: the advances made have been enormous, the actual field is boundless, the future is full of hope." 


\section{TRIGONOMETRY.}

\section{A. GENERAL SURVEY.}

TRIGONOMETRY was developed by the ancients 1 for purposes of astronomy. In the first period a number of fundamental formulae of trigonometry were established, though not in modern form, by the Greeks and Arabs, and employed in calculations. The second period, which extends from the time of the gradual rise of mathematical sciences in the earliest Middle Ages to the middle of the seventeenth century, establishes the science of calculation with angular functions and produces tables in which the sexagesimal division is replaced by decimal fractions, which marks a great advance for the purely numerical calculation. During the third period, plane and spherical trigonometry develop, especially polygonometry and polyhedrometry which are almost wholly new additions to the general whole. Further additions are the projective formulae which have furnished a series of interesting results in the closest relation to projective geometry. 


\section{B. FIRST PERIOD.}

FROM THE MOST ANCIENT TINES TO THE ARABS.

The Papyrus of Ahmes* speaks of a quotient called seqt. After observing that the great pyramids all possess approximately equal angles of inclination, the assumption is rendered probable that this seqt is identical with the cosine of the angle which the edge of the pyramid forms with the diagonal of the square base. This angle is usually $52^{\circ}$. In the Egyptian monuments which have steeper sides, the seqt appears to be equal to the trigonometric tangent of the angle of inclination of one of the faces to the base.

Trigonometric investigations proper appear first among the Greeks. Hypsicles gives the division of the circumference into three hundred sixty degrees, which, indeed, is of Babylonian origin but was first turned to advantage by the Greeks. After the introduction of this division of the circle, sexagesimal fractions were to be found in all the astronomical calculations of antiquity (with the single exception of Heron), till finally Peurbach and Regiomontanus prepared the way for the decimal reckoning. Hipparchus was the first to complete a table of chords, but of this we have left only the knowledge of its former exist-

*Cantor, I., p. 58. 
ence. In Heron are found actual trigonometric formulae with numerical ratios for the calculation of the areas of regular polygons and in fact all the values of $\cot \left(\frac{2 \pi}{n}\right)$ for $n=3,4, \ldots 11,12$ are actually computed.* Menelaus wrote six books on the calculation of chords, but these, like the tables of Hipparchus, are lost. On the contrary, three books of the Spherics of Menelaus are known in Arabic and Hebrew translations. These contain theorems on transversals and on the congruence of spherical as well as plane triangles, and for the spherical triangle the theorem that $a+b+c<4 R$, $\alpha+\beta+\gamma>2 R$.

The most important work of Ptolemy consists in the introduction of a formal spherical trigonometry for astronomical purposes. The thirteen books of the Great Collection which contain the Ptolemaic astronomy and trigonometry were translated into Arabic, then into Latin, and in the latter by a blending of the Arabic article $a l$ with a Greek word arose the word Almagest, now generally applied to the great work of Ptolemy. Like Hypsicles, Ptolemy also, after the ancient Babylonian fashion, divides the circumference into three hundred sixty degrees, but he, in addition to this, bisects every degree. As something new we find in Ptolemy the division of the diameter of the circle into one hundred twenty equal parts, from which were formed after the sexagesimal fashion

* Tannery in Mém. Bord., $188 \mathrm{r}$. 
two classes of subdivisions. In the later Latin translations these sixtieths of the first and second kind were called respectively partes minutae primae and partes minutae secundae. Hence came the later terms "minutes" and "seconds." Starting from his theorem upon the inscribed quadrilateral, Ptolemy calculates the chords of arcs at intervals of half a degree. But he develops also some theorems of plane and especially of spherical trigonometry, as for example theorems regarding the right angled spherical triangle.

A further not unimportant advance in trigonometry is to be noted in the works of the Hindus. The division of the circumference is the same as that of the Babylonians and Greeks; but beyond that there is an essential deviation. The radius is not divided sexagesimally after the Greek fashion, but the arc of the same length as the radius is expressed in minutes; thus for the Hindus $r=3438$ minutes. Instead of the whole chords (jiva), the half chords (ardhajya) are put into relation with the arc. In this relation of the half-chord to the arc we must recognize the most important advance of trigonometry among the Hindus. In accordance with this notion they were therefore familiar with what we now call the sine of an angle. Besides this they calculated the ratios corresponding to the versed sine and the cosine and gave them special names, calling the versed sine utkramajya, the cosine kotijy $a$. They also knew the formula $\sin ^{2} a$ 
$+\cos ^{2} a=1$. They did not, however, apply their trigonometric knowledge to the solution of plane triangles, but with them trigonometry was inseparably connected with astronomical calculations.

As in the rest of mathematical science, so in trigonometry, were the Arabs pupils of the Hindus, and still more of the Greeks, but not without important devices of their own. To Al Battani it was well known that the introduction of half chords instead of whole chords, as these latter appear in the Almagest, and therefore reckoning with the sine of an angle, is of essential advantage in the applications. In addition to the formulae found in the Almagest, Al Battani gives the relation, true for the spherical triangle, $\cos a=\cos b \cos c+\sin b \sin c \cos a$. In the consideration of right-angled triangles in connection with shadow-measuring, we find the quotients $\frac{\sin \alpha}{\cos \alpha}$ and $\frac{\cos \alpha}{\sin \alpha}$. These were reckoned for each degreee by $\mathrm{Al}$ Battani and arranged in a small table. Here we find the beginnings of calculation with tangents and cotangents. These names, however, were introduced much later. The origin of the term "sine" is due to Al Battani. His work upon the motion of the stars* was translated into Latin by Plato of Tivoli, and this translation contains the word sinus for half chord. In Hindu the half chord was called ardhajya or also jiva (which was used originally only for the whole

\footnotetext{
* Cantor, I., p. 693, where this account is considered somewhat doubtful.
} 
chord); the latter word the Arabs adopted, simply by reason of its sound, as jiba. The consonants of this word, which in Arabic has no meaning of its own, might be read jaib=bosom, or incision, and this pronunciation, which apparently was naturalized comparatively soon by the Arabs, Plato of Tivoli translated properly enough into sinus. Thus was introduced the first of the modern names of the trigonometric functions.

Of astronomical tables there was no lack at that time. Abul Wafa, by whom the ratio $\frac{\sin \alpha}{\cos \alpha}$ was called the "shadow" belonging to the angle $a$, calculated a table of sines at intervals of half a degree and also a table of tangents, which however was used only for determining the altitude of the sun. About the same time appeared the hakimitic table of sines which Ibn Yunus of Cairo was required to construct by direction of the Egyptian ruler Al Hakim.*

Among the Western Arabs the celebrated astronomer Jabir ibn Aflah, or Geber, wrote a complete trigonometry (principally spherical) after a method of his own, and this work, rigorous throughout in its proofs, was published in the Latin edition of his Astronomy by Gerhard of Cremona. This work contains a collection of formulae upon the right-angled spherical triangle. In the plane trigonometry he does not go 
beyond the Almagest, and hence he here deals only with whole chords, just as Ptolemy had taught.

\section{SECOND PERIOD.}

FROM THE MIDDLE AGES TO THE MIDDLE OF THE SEVENTEENTH CENTURY.

Of the mathematicians outside of Germany in this period, Vieta made a most important advance by his introduction of the reciprocal triangle of a spherical triangle. In Germany the science was advanced by Regiomontanus and in its elements was presented with such skill and thorough knowledge that the plan laid out by him has remained in great part up to the present day. Peurbach had already formed the plan of writing a trigonometry but was prevented by death. Regiomontanus was able to carry out Peurbach's idea by writing a complete plane and spherical trigonometry. After a brief geometric introduction Regiomontanus's trigonometry begins with the right-angled triangle, the formulae needed for its computation being derived in terms of the sine alone and illustrated by numerical examples. The theorems on the rightangled triangle are used for the calculation of the equilateral and isosceles triangles. Then follow the principal cases of the oblique-angled triangle of which the first ( $a$ from $a, b, c$ ) is treated with much detail. The second book contains the sine theorem and a 
series of problems relating to triangles. The third, fourth, and fifth books bring in spherical trigonometry with many resemblances to Menelaus; in particular the angles are found from the sides. The case of the plane triangle ( $\alpha$ from $a, b, c$ ), treated with consider able prolixity by Regiomontanus, received a shorter treatment from Rhaeticus, who established the formula $\cot \frac{1}{2} a=\frac{s-a}{\rho}$, where $\rho$ is the radius of the inscribed circle.

In this period were also published Napier's equations, or analogies. They express a relation between the sum or difference of two sides (angles) and the third side (angle) and the sum or difference of the two opposite angles (sides).

Of modern terms, as already stated, the word "sine" is the oldest. About the end of the sixteenth century, or the beginning of the seventeenth, the abbreviation cosine for complementi sinus was introduced by the Englishman Gunter (died 1626). The terms tangent and secant were first used by Thomas Finck (1583); the term versed sine was used still earlier.*

By some writers of the sixteenth century, e. g., by A pian, sinus rectus secundus was written instead of cosine. Rhaeticus and Vieta have perpendiculum and basis for sine and cosine. $\dagger$ The natural values of the cosine, whose logarithms were called by Kepler "anti-

* Baltzer, R., Die Elemente der Mathematik, 1885.

+ Pfleiderer, Trigonometrie, 1802. 
logarithms," are first found calculated in the trigonometry of Copernicus as published by Rhaeticus.*

The increasing skill in practical computation, and the need of more accurate values for astronomical purposes, led in the sixteenth century to a strife after the most complete trigonometric tables possible. The preparation of these tables, inasmuch as the calculations were made without logarithms, was very tedious. Rhaeticus alone had to employ for this purpose a number of computers for twelve years and spent thereby thousands of gulden. $\nmid$

The first table of sines of German origin is due to Peurbach. He put the radius equal to 600000 and computed at intervals of $10^{\prime}$ (in Ptolemy $r=60$, with some of the Arabs $r=150$ ). Regiomontanus computed two new tables of sines, one for $r=6000000$, the other, of which no remains are left, for $r=$ 10000000 . Besides these we have from Regiomontanus a table of tangents for every degree, $r=100000$. The last two tables evidently show a transition from the sexagesimal system to the decimal. A table of sines for every minute, with $r=100000$, was prepared by Apian.

In this field should also be mentioned the indefatigable perseverance of Joachim Rhaeticus. He did not associate the trigonometric functions with the arcs of circles, but started with the right-angled tri-

* M. Curtze, in Schlömilch's Zeitschrift, Bd. XX.

1 Gerhardt, Geschichte der Nathematik in Deutschland 1877. 
angle and used the terms perpendiculum for sine, basis for cosine. He calculated (partly himself and partly by the help of others) the first table of secants; later, tables of sines, tangents, and secants for every $10^{\prime \prime}$, for radius $=10000$ millions, and later still, for $r=$ $10^{15}$. After his death the whole work was published by Valentin Otho in the year 1596 in a volume of 1468 pages.*

To the calculation of natural trigonometric func tions Bartholomaeus Pitiscus also devoted himself. In the second book of his Trigonometry he sets forth his views on computations of this kind. His tables contain values of the sines, tangents, and secants on the left, and of the complements of the sines, tangents and secants (for so he designated the cosines, cotangents, and cosecants) on the right. There are added proportional parts for $1^{\prime}$, and even for $10^{\prime \prime}$. In the whole calculation $r$ is assumed equal to $10^{25}$. The work of Pitiscus appeared at the beginning of the seventeenth century.

The tables of the numerical values of the trigonometric functions had now attained a high degree of accuracy, but their real significance and usefulness were first shown by the introduction of logarithms.

Napier is usually regarded as the inventor of logarithms, although Cantor's review of the evidencet leaves no room for doubt that Bürgi was an independent discoverer. His Progress Tabulen, computed be-

$$
\text { * Gerhardt. † Cantor, II., pp. } 662 \text { et seq. }
$$


tween 1603 and 1611 but not published until 1620 is really a table of antilogarithms. Bürgi's more general point of view should also be mentioned. He desired to simplify all calculations by means of logarithms while Napier used only the logarithms of the trigonometric functions.

Bürgi was led to this method of procedure by comparison of the two series $0,1,2,3, \ldots$ and 1,2 , $4,8, \ldots$ or $2^{0}, 2^{1}, 2^{2}, 2^{3}, \ldots$ He observed that for purposes of calculation it was most convenient to select 10 as the base of the second series, and from this standpoint he computed the logarithms of ordinary numbers, though he first decided on publication when Napier's renown began to spread in Germany by reason of Kepler's favorable reports. Bürgi's Geometrische Progress Tabulen appeared at Prague in 1620,* and contained the logarithms of numbers from $10^{8}$ to $10^{9}$ by tens. Bürgi did not use the term logarithmus, but by reason of the way in which they were printed he called the logarithms "red numbers," the numbers corresponding, "black numbers."

Napier started with the observation that if in a circle with two perpendicular radii $O A_{0}$ and $O A_{1}$ $(r=1)$, the sine $S_{0} S_{1} \| O A_{1}$ moves from $O$ to $A_{0}$ at intervals forming an arithmetic progression, its value decreases in geometrical progression. The segment $O S_{0}$, Napier originally called numerus artificialis and later the direction number or logarithmus. The first

* Gerhardt. 
publication of this new method of calculation, in which $r=10^{7}, \log \sin 60^{\circ}=0, \log \sin 0^{0}=\infty$, so that the $\log$ arithms increased as the sines decreased, appeared in 1614 and produced a great sensation. Henry Briggs had studied Napier's work thoroughly and made the important observation that it would be more suitable for computation if the logarithms were allowed to increase with the numbers. He proposed to put $\log 1$ $=0, \log 10=1$, and Napier gave his assent. The tables of logarithms calculated by Briggs, on the basis of this proposed change, for the natural numbers from 1 to 20000 and from 90000 to 100000 were reckoned to 14 decimal places. The remaining gap was filled by the Dutch bookseller Adrian Vlacq. His tables which appeared in the year 1628 contained the logarithms of numbers from 1 to 100000 to 10 decimal places. In these tables, under the name of his friend De Decker, Vlacq introduced logarithms upon the continent. Assisted by Vlacq and Gellibrand, Briggs computed a table of sines to fourteen places and a table of tangents and secants to ten places, at intervals of $36^{\prime \prime}$. These tables appeared in 1633. Towards the close of the seventeenth century Claas Vooght published a table of sines, tangents, and secants with their logarithms, and, what was especially remarkable, they were engraved on copper.

Thus was produced a collection of tables for logarithmic computation valuable for all time. This was extended by the introduction of the addition and subtraction logarithms always named 
after Gauss, but whose inventor, according to Gauss's own testi mony, is Leonelli. The latter had proposed calculating a table with fourteen decimals; Gauss thought this impracticable, and calculated for his own use a table with five decimals.*

In the year 1875 there were in existence 553 logarithmic tables with decimal places ranging in number from 3 to 102 . Arranged according to frequency, the 7-place tables stand at the head, then follow those with 5-places, 6-places, 4-places, and 10-places. The only table with 102 places is found in a work by H. M. Parkhurst (Astronomical Tables, New York, 1871).

Investigations of the errors occurring in logarithmic tables have been made by J. W. L. Glaisher. $\dagger$ It was there shown that every complete table had been transcribed, directly or indirectly after a more or less careful revision, from the table published in 1628 which contains the results of Briggs's Arithmetica logarithmica of 1624 for numbers from 1 to 100000 to ten places. In the first seven places Glaisher found 171 errors of which 48 occur in the interval from 1 to 10000 . These errors, due to Vlacq, have gradually disappeared. Of the mistakes in Vlacq, 98 still appear in Newton (1658), 19 in Gardiner (1742), 5 in Vega (1797), 2 in Callet (1855), 2 in Sang (1871). Of the tables tested by Glaisher, four turned out to be free from error, viz., those of Bremiker (1857), Schrön (1860), Callet (1862), and Bruhns (1870). Contributions to the rapid calculation of common logarithms have been made by Koralek (1851) and R. Hoppe (1876); the work of the latter is based upon the theorem that every positive number may be transformed into an infinite product. $\neq$

* Gauss, Werke, III., p. 244. Porro in Bonc. Bull., XVIII.

+ Fortschritte, 1873 .

† Stolz, Vorlesungen über allgemeine Arithmetik, I885-1585. 


\section{THIRD PERIOD.}

FROM THE MIDDLE OF THE SEVENTEENTH CENTURY TO THE PRESENT.

After Regiomontanus had laid the foundations of plane and spherical trigonometry, and his successors had made easier the work of computation by the computation of the numerical values of the trigonometric functions and the creation of a serviceable system of logarithms, the inner structure of the science was ready to be improved in details during this third period. Important innovations are especially due to Euler, who derived the whole of spherical trigonometry from a few simple theorems. Euler defined the trigonometric functions as mere numbers, so as to be able to substitute them for series in whose terms appear arcs of circles from which the trigonometric functions proceed according to definite laws. From him we have a number of trigonometric formulae, in part entirely new, and in part perfected in expression. These were made especially clear when Euler denoted the elements of the triangle by $a, b, c, a, \beta, \gamma$. Then such expressions as $\sin \alpha, \tan \alpha$ could be introduced where formerly special letters had been used for the same purpose.* Lagrange and Gauss restricted themselves to a single theorem in the derivation of spherical trigonometry. The system of equations

* Baltzer, R., Die Eleme'nte der Mathematik, 1885. 


$$
\sin \frac{a}{2} \sin \frac{b+c}{2}=\sin \frac{a}{2} \cos \frac{\beta-\gamma}{2},
$$

with the corresponding relations, is ordinarily ascribed to Gauss, though the equations were first published by Delambre in 1807 (by Mollweide 1808, by Gauss 1809).* The case of the Pothenot problem is similar: it was discussed by Snellius 1614, by Pothenot 1692, by Lambert $1765 . \dagger$

The principal theorems of polygonometry and polyhedrometry were established in the eighteenth century. To Euler we owe the theorem on the area of the orthogonal projection of a plane figure upon another plane; to Lexell the theorem upon the projection of a polygonal line. Lagrange, Legendre, Carnot and others stated trigonometric theorems for polyhedra (especially the tetrahedra), Gauss for the spherical quadrilateral.

The nineteenth century has given to trigonometry a series of new formulae, the so-called projective formulae. Besides Poncelet, Steiner, and Gudermann, Möbius deserves special mention for having devised a generalization of spherical trigonometry, such that sides or angles of a triangle may exceed $180^{\circ}$. The important improvements which in modern times trigonometric developments have contributed to other mathematical sciences, may be indicated in this one sentence: their extended description would considerably encroach upon the province of other branches of science.

* Hammer, Lefrrbuch der ebenen und sphärischen Trigonometrie, 1897.

+ Baltzer, R., Die Elemente der Mathematik, 1885. 



\section{BIOGRAPHICAL NOTES.*}

Abel, Niels Henrik. Born at Findöe, Norway, August 5, 1802; died April 6, I829. Studied in Christiania, and for a short time in Berlin and Paris. Proved the impossibility of the algebraic solution of the quintic equation; elaborated the theory of elliptic functions; founded the theory of Abelian functions.

Abul Jud, Mohammed ibn al Lait al Shanni. Lived about I050. Devoted much attention to geometric problems not soluble with compasses and straight edge alone.

Abul Wafa al Buzjani. Born at Buzjan, Persia, June ro, 940; died at Bagdad, July I, 998. Arab astronomer. Translated works of several Greek mathematicians; improved trigonometry and computed some tables; interested in geometric constructions requiring a single opening of the compasses.

Adelard. About I I20. English monk who journeyed through Asia Minor, Spain, Egypt, and Arabia. Made the first translation of Euclid from Arabic into Latin. Translated part of Al Khowarazmi's works.

Al Battani (Albategnius). Mohammed ibn Jabir ibn Sinan Abu Abdallah al Battani. Born in Battan, Mesopotamia, c. 850; died in Damascus, 929. Arab prince, governor of Syria; great-

* The translators feel that these notes will be of greater value to the reader by being arranged alphabetically than, as in the original, by periods, especially as this latter arrangement is already given in the body of the work. They also feel that they will make the book more serviceable by changing the notes as set forth in the original, occasionally eliminating matter of little consequence, and frequently adding to the meagre information given. They have, for this purpose, freely used such standard works as Cantor, Hankel, Günther, Zeuthen, et al, and especially the valuable little Zeittafeln zur Geschichte der Mathematik, Physik und Astronomie bis zum Jahre I500, by Felix Müller, Leipzig, I892. Dates are A. D., except when prefixed by the negative sign. 
est Arab astronomer and mathematician. Improved trigonometry and computed the first table of cotangents.

Alberti, Leo Battista. I404-I472. Architect, painter, sculptor.

Albertus Magnus. Count Albrecht von Bollstädt. Born at Lauingen in Bavaria, II93 or I205; died at Cologne, Nov. I5, I280. Celebrated theologian, chemist, physicist, and mathematician.

$1 l$ Biruni, Abul Rihan Mohammed ibn Ahmed. From Birun, valley of the Indus; died I038. Arab, but lived and travelled in India and wrote on Hindu mathematics. Promoted spherical trigonometry.

Alcuin. Born at York, 736; died at Hersfeld, Hesse, May I9. 804. At first a teacher in the cloister school at York; then assisted Charlemagne in his efforts to establish schools in France.

thazen, Ibn al Haitam. Born at Bassora, 950; died at Cairo 1038. The most important Arab writer on optics.

Al Kalsadi, Abul Hasan Ali ibn Mohammed. Died 1486 or I477. From Andalusia or Granada. Arithmetician.

Al Karkhi, Abu Bekr Mohammed ibn al Hosain. Lived about Ioro. Arab mathematician at Bagdad. Wrote on arithmetic, algebra and geometry.

Al Khojandi, Abu Mohammed. From Khojand, in Khorassan; was living in 992. Arab astronomer.

Al Khowarazmi, Abu Jafar Mohammed ibn Musa. First part of ninth century. Native of Khwarazm (Khiva). Arab mathematician and astronomer. The title of his work gave the name to algebra. Translated certain Greek works.

Al Kindi, Jacob ibn Ishak, Abu Yusuf. Born c. 813; died 873. Arab philosopher, physician, astronomer and astrologer.

Al Kuhi, Vaijan ibn Rustam Abu Sahl. Lived about 975. Arab astronomer and geometrician at Bagdad.

Al Nasazi, Abul Hasan Ali ibn Ahmed. Lived about Iooo From Nasa in Khorassan. Arithmetician.

Al Sagani. Ahmed ibn Mohammed al Sagani Abu Hamid al Usturlabi. From Sagan, Khorassan; died 990. Bagdad astronomer 
Anaxagoras. Born at Clazomene, Ionia, -499; died at Lampsacus, -428 . Last and most famous philosopher of the Ionian school. Taught at Athens. Teacher of Euripides and Pericles.

Apianus (Apian), Petrus. Born at Leisnig, Saxony, I495; died in 1552. Wrote on arithmetic and trigonometry.

Apollonius of Perga, in Pamphylia. Taught at Alexandria between -250 and -200 , in the reign of Ptolemy Philopator. His eight books on conics gave him the name of "the great geometer." Wrote numerous other works. Solved the general quadratic with the help of conics.

Arbogast, Louis François Antoine. Born at Mutzig, 1759; died 1803. Writer on calculus of derivations, series, gamma function, differential equations.

Archimedes. Born at Syracuse, -287 (?); killed there by Roman soldiers in -2I2. Engineer, architect, geometer, physicist. Spent some time in Spain and Egypt. Friend of King Hiero. Greatly developed the knowledge of mensuration of geometric solids and of certain curvilinear areas. In physics he is known for his work in center of gravity, levers, pulley and screw, specific gravity, etc.

Archytas. Born at Tarentum -430; died -365 . Friend of Plato, a Pythagorean, a statesman and a general. Wrote on proportion, rational and irrational numbers, tore surfaces and sections, and mechanics.

Argand, Jean Robert. Born at Geneva, r768; died c. 1825. Private life unknown. One of the inventors of the present method of geometrically representing complex numbers (I806).

Aristotle. Born at Stageira, Macedonia, -384 ; died at Chalcis, Euboea, -322. Founder of the peripatetic school of philosophy; teacher of Alexander the Great. Represented unknown quantities by letters; distinguished between geometry and geodesy; wrote on physics; suggested the theory of combinations.

Aryabhatta. Born at Pataliputra on the Upper Ganges, 476. Hindu mathematician. Wrote chiefly on algebra, including quadratic equations, permutations, indeterminate equations, and magic squares. 
August, Ernst Ferdinand. Born at Prenzlau, I795; died 1870 as director of the Kölnisch Realgymnasium in Berlin.

Autolykus of Pitane, Asia Minor. Lived about -33o. Greek astronomer; author of the oldest work on spherics.

Avicenna. Abu Ali Hosain ibn Sina. Born at Charmatin, near Bokhara, 978; died at Hamadam, in Persia, ı036. Arab physician and naturalist. Edited several mathematical and physical works of Aristotle, Euclid, etc. Wrote on arithmetic and geometry.

Babbage, Charles. Born at Totnes, Dec. 26, I792; died at London, Oct. I8, 1871. Lucasian professor of mathematics at Cambridge. Popularly known for his calculating machine. Did much to raise the standard of mathematics in England.

Bachet. See Méziriac.

Bacon, Roger. Born at Ilchester, Somersetshire, I2 I4; died at Oxford, June II, I 294. Studied at Oxford and Paris; professor at Oxford; mathematician and physicist.

Balbus. Lived about roo. Roman surveyor.

Baldi, Bernardino. Born at Urbino, I553; died there, I6I7. Mathematician and general scholar. Contributed to the history of mathematics.

Baltzer, Heinrich Richard. Born at Meissen in 1818; died at Giessen in 1887 . Professor of mathematics at Giessen.

Barlaam, Bernard. Beginning of fourteenth century. A monk who wrote on astronomy and geometry.

Barozzi, Francesco. Italian mathematician. I537-1604.

Barroze, Isaac. Born at London, I630; died at Cambridge, May 4, I677. Professor of Greek and mathematics at Cambridge. Scholar, mathematician, scientist, preacher. Newton was his pupil and successor.

Beda, the Venerable. Born at Monkton, near Yarrow, Northumberland, in 672; died at Yarrow, May 26, 735. Wrote on chronology and arithmetic.

Bellavitis, Giusto. Born at Bassano, near Padua, Nov. 22, I803; died Nov. 6, 1880. Known for his work in projective geometry and his method of equipollences. 
Bernelinus. Lived about ro20. Pupil of Gerbert at Paris. Wrote on arithmetic.

Bernoulli. Famous mathematical family.

Facob (often called James, by the English), born at Basel, Dec.

27, 1654 ; died there Aug. 16,1705 . Among the first to recognize the value of the calculus. His De Arte Conjectandi is a classic on probabilities. Prominent in the study of curves, the logarithmic spiral being engraved on his monument at Basel. Fohn (Johann), his brother; born at Basel, Aug. 7, I667; died there Jan. I, 1748 . Made the first attempt to construct an integral and an exponential calculus. Also prominent as a physicist, but his abilities were chiefly as a teacher.

Nicholas (Nikolaus), his nephew; born at Basel, Oct. 10, 1687; died there Nov. 29, I759. Professor at St. Petersburg, Basel, and Padua. Contributed to the study of differential equations. Daniel, son of John; born at Gröningen, Feb. 9, I700; died at Basel in 1782 . Professor of mathematics at St. Petersburg. His chief work was on hydrodynamics.

John the younger, son of John. I7xo-r79o. Professor at Basel. Bézout, Étienne. Born at Nemours in 1730 ; died at Paris in 1783. Algebraist, prominent in the study of symmetric functions and determinants.

Bhaskara Acharya. Born in III4. Hindu mathematician and astronomer. Author of the Lilavati and the Vijaganita, containing the elements of arithmetic and algebra. One of the most prominent mathematicians of his time.

Biot, Jean Baptiste. Born at Paris, Apr. 2I, I774; died same place Feb. 3, x862. Professor of physics, mathematics, astronomy. Voluminous writer.

Boëthius, Anicius Manlius Torquatus Severinus. Born at Rome, 480; executed at Pavia, 524. Founder of medieval scholasti cism. Translated and revised many Greek writings on mathematics, mechanics, and physics. Wrote on arithmetic. While in prison he composed his Consolations of Philosophy.

Bolyai: Wolfgang Bolyai de Bolya. Born at Bolya, $\mathrm{x} 775$; died in 1856 . Friend of Gauss.

Johann Bolyai de Bolya, his son. Born at Klausenburg, I802 ; died at Maros-Vàsàrhely, I860. One of the discoverers (see Lobachevsky) of the so-called non-Euclidean geometry. 
Bolzano, Bernhard. I78I-1848. Contributed to the study of series.

Bombelli, Rafaele. Italian. Born c. I530. His algebra (I572) summarized all then known on the subject. Contributed to the study of the cubic.

Boncompagni, Baldassare. Wealthy Italian prince. Born at Rome. May ıо, I821; died at same place, April 12, I894. Publisher of Boncompagni's Bulletino.

Boole, George. Born at Lincoln, I8ז5; died at Cork, I864. Professor of mathematics in Queen's College, Cork. The theory of invariants and covariants may be said to start with his contributions (I $84 \mathrm{I}$ ).

Booth, James. I806-I878. Clergyman and writer on elliptic integrals.

Borchardt, Karl Wilhelm. Born in 1817 ; died at Berlin, 1880. Professor at Berlin.

Boschi, Pietro. Born at Rome, 1833: died in 1887. Professor at Bologna.

Bouquet, Jean Claude. Born at Morteau in 1819 ; died at Paris, 1885 .

Bour, Jacques Edmond Émile. Born in 1832 ; died at Paris, 1866. Professor in the École Polytechnique.

Bradwardine, Thomas de. Born at Hardfield, near Chichester, I290; died at Lambeth, Aug. 26, I349. Professor of theolog! at Oxford and later Archbishop of Canterbury. Wrote upoii arithmetic and geometry.

Brahmagupta. Born in 598. Hindu mathematician. Contrib uted to geometry and trigonometry.

Brasseur, Jean Baptiste. 1802-1868. Professor at Liège.

Bretschneider, Carl Anton. Born at Schneeberg, May 27, 1808, died at Gotha, November 6, I878.

Brianchon, Charles Julien. Born at Sèvres, 1785 ; died in 1864 . Celebrated for his reciprocal (I 806 ) to Pascal's mystic hexagram

Brigos, Henry. Born at Warley Wood, near Halifax, Yorkshire, Feb. I560-I; died at Oxford Jan. 26, I630-I. Savilian Pro- 
fessor of geometry at Oxford. Among the first to recognize the value of logarithms; those with decimal base bear his name.

Briot, Charles August Albert. Born at Sainte-Hippolyte, I8I7; died in I882. Professor at the Sorbonne, Paris.

Brouncker, William, Lord. Born in 1620 (?) ; died at Westminster, I684. First president of the Royal Society. Contributed to the theory of series.

Brunelleschi, Filippo. Born at Florence, 1379; died there April I6, I446. Noted Italian architect.

Biirgi, Joost (Jobst). Born at Lichtensteig, St. Gall, Switzerland, I552; died at Cassel in I632. One of the first to suggest a system of logarithms. The first to recognize the value of making the second member of an equation zero.

Caporali, Ettore. Born at Perugia, I855; died at Naples, I886.

Professor of mathematics and writer on geometry.

Cardan, Jerome (Hieronymus, Girolamo). Born at Pavia, I5OI; died at Rome, I576. Professor of mathematics at Bologna and Padua. Mathematician, physician, astrologer. Chief contributions to algebra and theory of epicycloids.

Carnot, Lazare Nicolas Marguerite. Born at Nolay, Côte d'Or, I753; died in exile at Magdeburg, I823. Contributed to modern geometry.

Cassini, Giovanni Domenico. Born at Perinaldo, near Nice, I625; died at Paris, I7r2. Professor of astronomy at Bologna, and first of the family which for four generations held the post of director of the observatory at Paris.

Castigliano, Carlo Alberto. I847-1884. Italian engineer.

Catalan, Eugène Charles. Born at Bruges, Belgium, May 30, I8I4; died Feb. I4, I894. Professor of mathematics at Paris and Liège.

ataldi, Pietro Antonio. Italian mathematician, born 1548; died at Bologna, I626. Professor of mathematics at Florence, Perugia and Bologna. Pioneer in the use of continued fractions.

(attaneo, Francesco. I8II-I875. Professor of physics and mechanics in the University of Pavia. 
Cauchy, Augustin Louis. Born at Paris, I789; died at Sceaux, 1857. Professor of mathematics at Paris. One of the most prominent mathematicians of his time. Contributed to the theory of functions, determinants, differential equations, theory of residues, elliptic functions, convergent series, etc.

Cavalieri, Bonaventura. Born at Milan, I598; died at Bologna, I647. Paved the way for the differential calculus by his method of indivisibles (I629).

Cayley, Arthur. Born at Richmond, Surrey, Aug. I6, I82 I died at Cambridge, Jan. 26, I895. Sadlerian professor of mathematics, University of Cambridge. Prolific writer on mathematics.

Ceva, Giovanni. I648-c. I737. Contributed to the theory of transversals.

Chasles. Michel. Born at Chartres, Nov. I5, I793; died at Paris, Dec. I2, I880. Contributed extensively to the theory of modern geometry.

Chetini, Domenico. Born I802; died Nov. I6, I878. Italian mathematician; contributed to analytic geometry and mechanics.

Chuquet, Nicolas. From Lyons; died about I500. Lived in Paris and contributed to algebra and arithmetic.

Clairaut, Alexis Claude. Born at Paris, I7I3; died there, I765. Physicist, astronomer, mathematician. Prominent in the study of curves.

Clausberg, Christlieb von. Born at Danzig, I689; died at Copenhagen, I75I.

Clebsch, Rudolf Friedrich Alfred. Born January I9, I833; died Nov, 7, 1872. Professor of mathematics at Carlsruhe, Giessen and Göttingen.

Condorcet, Marie Jean Antoine Nicolas. Born at Ribemont, near St. Quentin, Aisne, I743; died at Bourg-la Reine, I794. Secretary of the Académie des Sciences. Contributed to the theory of probabilities.

Cotes, Roger. Born at Burbage, near Leicester, July ıo, I682; died at Cambridge, June 5, I7I6. Professor of astronomy at Cambridge. His name attaches to a number of theorems in geometry, algebra and analysis. Newton remarked, "If Cotes had lived we should have learnt something." 
Cramer, Gabriel. Born at Geneva, I704; died at Bagnols, 1752. Added to the theory of equations and revived the study of determinants (begun by Leibnitz). Wrote a treatise on curves.

Crelle, August Leopold. Born at Eichwerder (Wriezen a. d. Oder), 1780 ; died in 1855 . Founder of the Journal fiir reine und angewandte Mathematik (1826).

D'Alembert, Jean le Rond. Born at Paris, I7I7; died there, I783. Physicist, mathematician. astronomer. Contributed to the theory of equations.

De Beaune, Florimond. I60I-1652. Commentator on Descartes's Geometry.

De la Gournerie, Jules Antoine René Maillard. Born in 1814; died at Paris, I833. Contributed to descriptive geometry.

Del Monte, Guidobaldo. I 545-IE07. Wrote on mechanics and perspective.

Democritus. Born at Abdera, Thrace, -46o; died c. - 37o. Studied in Egypt and Persia. Wrote on the theory of numbers and on geometry. Suggested the idea of the infinitesimal.

De Moivre, Abraham. Born at Vitry, Champagne, 1667 ; died at London, r754. Contributed to the theory of complex num. bers and of probabilities

De Morgan, Augustus. Born at Madura, Madras, June I806; died March 18, 187r. First professor of mathematics in University of London (1828). Celebrated teacher, but also contributed to algebra and the theory of probabilities.

Desargues, Gerard. Born at Lyons, I593; died in 1662 . One of the founders of modern geometry.

Descartes, René, du Perron. Born at La Haye, Touraine, I596; died at Stockholm, I650. Discoverer of analytic geometry. Contributed extensively to algebra.

Dinostratus. Lived about -335 . Greek geometer. Brother of Menaechmus. His name is connected with the quadratrix.

Diocles. Lived about -r8o. Greek geometer. Discovered the cissoid which he used in solving the Delian problem.

Diophantus of Alexandria. Lived about 275. Most prominent of Greek algebraists, contributing especially to indeterminate equations. 
Dirichlet, Peter Gustav Lejeune. Born at Düren, I805; died at Göttingen, I 859. Succeeded Gauss as professor at Göttingen. Prominent contributor to the theory of numbers.

Dodson, James. Died Nov. 23, I757. Great grandfather of De Morgan. Known chiefly for his extensive table of anti-logarithms ( 1742$)$.

Donatello, I386-I468. Italian sculptor.

Du Bois-Reymond, Paul David Gustav. Born at Berlin, Dec. 2, I83I; died at Freiburg, April 7, I889. Professor of mathematics in Heidelberg, Freiburg, and Tübingen.

Duhamel, Jean Marie Constant. Born at Saint-Malo, 1797; died at Paris, I872. One of the first to write upon method in mathematics.

Dupin, François Pierre Charles. Born at Varzy, I784; died at Paris, I 873 .

Dürer, Albrecht. Born at Nuremberg, I47I ; died there, I528.

Famous artist. One of the founders of the modern theory of curves.

Eisenstein, Ferdinand Gotthold Max. Born at Berlin, I823; died there, 1852 . One of the earliest workers in the field of invari ants and covariants.

Enneper, Alfred. I830-1885. Professor at Göttingen.

Epaphroditus. Lived about 200. Roman surveyor. Wrote on surveying, theory of numbers, and mensuration.

Eratosthenes. Born at Cyrene, Africa, -276 ; died at Alexandria, -i 94 . Prominent geographer. Known for his "sieve" for finding primes.

Euclid. Lived about -300 . Tanght at Alexandria in the reign of Ptolemy Soter. The author or compiler of the most famous text-book of Geometry ever written, the Elements, in thirteen books.

Eudoxus of Cnidus. - 408, - 355. Pupil of Archytas and Plato. Prominent geometer, contributing especially to the theories of proportion, similarity, and "the golden section."

Euler, Leonhard. Born at Basel, I707; died at St. Petersburg, I783. One of the greatest physicists, astronomers and mathematicians of the I8th century. "In his roluminous. 
writings will be found a perfect storehouse of investigations on every branch of algebraical and mechanical science."Kelland.

Eutocius. Born at Ascalon, 480. Geometer. Wrote commentaries on the works of Archimedes, Apollonius, and Ptolemy. Fagnano, Giulio Carlo, Count de. Born at Sinigaglia, I682; died in 1766 . Contributed to the study of curves. Euler credits him with the first work in elliptic functions.

Faulhaber, Johann. I580-I635. Contributed to the theory of series.

Fermat, Pierre de. Born at Beaumont-de-Lomagne, near Montauban, I60I; died at Castres, Jan. I2, I665. One of the most versatile mathematicians of his time; his work on the theory of numbers has never been equalled.

Ferrari, Ludovico. Born at Bologna, 1522 ; died in 1562 . Solved the biquadratic.

Ferro, Scipione del. Born at Bologna, c. I465; died between Oct. 29 and Nov. I6, I526. Professor of mathematics at Bologna. Investigated the geometry based on a single setting of the compasses, and was the first to solve the special cubic $x^{3}+p x=q$.

Feuerbach, Karl Wilhelm. Born at Jena, I80o; died in I834. Contributed to modern elementary geometry.

Fibonacci. See Leonardo of Pisa.

Fourier, Jean Baptiste Joseph, Baron. Born at Auxerre, I768; died at Paris, 1830. Physicist and mathematician. Contributed to the theories of equations and of series.

Frénicle. Bernard Frénicle de Bessy. I605-1675. Friend of Fermat.

Frézier, Amédée François. Born at Chambéry, I682; died at Brest, I773. One of the founders of descriptive geometry. Friedlein, Johann Gottfried. Born at Regensburg, I828; died in I875.

Frontinus, Sextus Julius. 40-103. Roman surveyor and engineer. Galois, Evariste. Born at Paris, I8II ; died there, I832. Founder of the theory of groups. 
Gauss, Karl Friedrich. Born at Brunswick, I777; died at Göttingen, I855. The greatest mathematician of modern times. Prominent as a physicist and astronomer. The theories of numbers, of functions, of equations, of determinants, of complex numbers, of hyperbolic geometry, are all largely indebted to his great genius.

Geber. Jabir ben Aflah. Lived about 1085. Astronomer at Seville; wrote on spherical trigonometry.

Gellibrand, Henry. I597-I637. Professor of astronomy at Gresham College.

Geminus. Born at Rhodes, -roo; died at Rome, -40. Wrote on astronomy and (probably) on the history of pre-Euclidean mathematics.

Gerbert, Pope Sylvester II. Born at Auvergne, 940; died at Rome, May I3, roo3. Celebrated teacher; elected pope in 999. Wrote upon arithmetic.

Gerhard of Cremona. From Cremona (or, according to others, Carmona in Andalusia). Born in III4; died at Toledo in I 87 . Physician, mathematician, and astrologer. Translated several works of the Greek and Arab mathematicians from Arabic into Latin.

Germain, Sophie. I776-1831. Wrote on elastic surfaces.

Girard, Albert. c. I590-I633. Contributed to the theory of equations, general polygons, and symbolism.

Göpel, Gustav Adolf. I8r2-r847. Known for his researches on hyperelliptic functions.

Grammateus, Henricus. (German name, Heinrich Schreiber.) Born at Erfurt, c. I476. Arithmetician.

Crrassmann, Hermann Günther. Born at Stettin, April 15, I809: died there Sept. 26, I877. Chiefly known for his Ausdehnungslehre (1844). Also wrote on arithmetic, trigonometry, and physics.

Grebe, Ernst Wilhelm. Born near Marbach, Oberhesse, Aug. 30, I804; died at Cassel, Jan. I4, I874. Contributed to modern elementary geometry.

Gregory, James. Born at Drumoak, Aberdeenshire, Nov. I638; died at Edinburgh, I675. Professor of mathematics at St. An- 
drews and Edinburgh. Proved the incommensurability of $\pi$; contributed to the theory of series.

Grunert, Johann August. Born at Halle a. S., I797; died in 1872 Professor at Greifswalde, and editor of Grunert's Archiv.

Gua. Jean Paul de Gua de Malves. Born at Carcassonne, r7r3; died at Paris, June 2, I785. Gave the first rigid proof of Descartes's rule of signs.

Gudermann, Christoph. Born at Winneburg, March 28, I798; died at Münster, Sept. 25, r852. To him is largely due the introduction of byperbolic functions into modern analysis.

Guldin, Habakkuk (Paul). Born at St. Gall, I577; died at Grätz, I643. Known chiefly for his theorem on a solid of revolution, pilfered from Pappus.

Hachette, Jean Nicolas Pierre. Born at Mézières, I769; died at Paris, I834. Algebraist and geometer.

Halley, Edmund. Born at Haggerston, near London, Nov. 8, 1656; died at Greenwich, Jan. 14, I742. Chiefly known for his valuable contributions to physics and astronomy.

Halphen, George Henri. Born at Rouen, Oct. 30, 1844; died at Versailles in 1889 . Professor in the École Polytechnique at Paris. Contributed to the theories of differential equations and of elliptic functions.

Hamilton, Sir William Rowan. Born at Dublin, Aug. 3-4, I805; died there, Sept. 2, I865. Professor of astronomy at Dublin. Contributed extensively to the theory of light and to dynamics, but known generally for his discovery of quaternions.

Hankel, Hermann. Born at Halle, Feb. I4, I839; died at Schramberg, Aug. 29, I873. Contributed chiefly to the theory of complex numbers and to the history of mathematics.

Harnack, Karl Gustav Axel. Born at Dorpat, I85I; died at Dresden in I888. Professor in the polytechnic school at Dresden.

Harriot, Thomas. Born at Oxford, 1560 ; died at Sion House, near Isleworth, July 2, r62r. The most celebrated English algebraist of his time.

IJeron of Alexandria. Lived about - Iro. Celebrated surveyor and mechanician. Contributed to mensuration. 
Hesse, Ludwig Otto. Born at Königsberg, April 22, I8I I ; died at Munich, Aug. 4, 1874. Contributed to the theories of curves and of determinants.

Hipparchus. Born at Nicaea, Bithynia, - I80; died at Rhodes, - I25. Celebrated astronomer. One of the earliest writers on spherical trigonometry.

Hippias of Elis. Born c. -460 . Mathematician, astronomer, natural scientist. Discovered the quadratrix.

Hippocrates of Chios. Lived about - 440. Wrote the first Greek elementary text-book on mathematics.

Horner, William George. Born in I786; died at Bath, Sept. 22, 1837. Chiefly known for his method of approximating the real roots of a numerical equation (1819).

Hrabanus Maurus. 788-856. Teacher of mathematics. Arch bishop of Mainz.

Hudde, Johann. Born at Amsterdam, I633; died there, I704. Contributed to the theories of equations and of series.

Honein ibn Ishak. Died in 873. Arab physician. Translated several Greek scientific works.

Huygens, Christiaan, van Zuylichem. Born at the Hague, I629; died there, I695. Famous physicist and astronomer. In mathematics he contributed to the study of curves.

Hyginus. Lived about ıoo. Roman surveyor.

Hypatia, daughter of Theon of Alexandria. 375-4I5. Composed several mathematical works. See Charles Kingsley's Hypatia.

Hypsicles of Alexandria. Lived about - Igo. Wrote on solid geometry and theory of numbers, and solved certain indeterminate equations.

Iamblichus. Lived about 325. From Chalcis. Wrote on various branches of mathematics.

Ibn al Banna. Abul Abbas Ahmed ibn Mohammed ibn Otman al Azdi al Marrakushi ibn al Banna Algarnati. Born 1252 or I 257 in Morocco. West Arab algebraist; prolific writer.

Jbn I'unus, Abul Hasan Ali ibn Abi Said Abderrahman. 960I008. Arab astronomer; prepared the Hakimitic Tables. 
Isidorus Hispalensis. Born at Carthagena, 570; died at Seville, 636. Bishop of Seville. His Origines contained dissertations on mathematics.

Ivory, James. Born at Dundee, I765; died at London, Sept. 21 , I842. Chiefly known as a physicist.

Jacobi, Karl Gustav Jacob. Born at Potsdam, Dec. 10, I804; died at Berlin, Feb. 18, 185I. Important contributor to the theory of elliptic and theta functions and to that of functional determinants.

Jamin, Jules Célestin. Born in 1818 ; died at Paris, 1886 . Professor of physics.

Joannes de Praga (Johannes Schindel). Born at Königgrätz, I 370 or 1375; died at Prag c. 1450. Astronomer and mathematician.

Johannes of Seville (Johannes von Luna, Johannes Hispalensis). Lived about II40. A Spanish Jew; wrote on arithmetic and algebra.

Johann von Gmünden. Born at Gmünden am Traunsee, between r 375 and 1385 ; died at Vienna, Feb. 23, I442. Professor of mathematics and astronomy at Vienna; the first full professor of mathematics in a Teutonic university.

Kästner, Abraham Gotthelf. Born at Leipzig, 1719; died at Göttingen, I80o. Wrote on the history of mathematics.

Kepler, Johann. Born in Würtemberg, near Stuttgart, 157I; died at Regensburg, I630. Astronomer (assistant of Tycho Brahe, as a young man); "may be said to have constructed the edifice of the universe,"-Proctor. Prominent in introducing the use of logarithms. Laid down the "principle of continuity" (I604); helped to lay the foundation of the infinitesimal calculus.

Khayyam, Omar. Died at Nishapur, 1123. Astronomer, geometer, algebraist. Popularly known for his famous collection of quatrains, the Rubaiyat.

Köbel, Jacob. Born at Heidelberg, I470; died at Oppenheim, in I533. Prominent writer on arithmetic (I5I4, I520).

Lacroix, Sylvestre François. Born at Paris, 1765 ; died there, May 25, I843. Author of an elaborate course of mathematics. 
Laguerre, Edmond Nicolas. Born at Bar-le-Duc, April 9, I834; died there Aug. I4, I886. Contributed to higher analysis.

Lagrange, Joseph Louis, Comte. Born at Turin, Jan. 25, I736; died at Paris, April Io, I8r3. One of the foremost mathematicians of his time. Contributed extensively to the calculus of variations, theory of numbers, determinants, differential equations, calculus of finite differences, theory of equations, and elliptic functions. Author of the Mécanique analytique. Also celebrated as an astronomer.

Lahire, Philippe de. Born at Paris, March I8, I640; died there April 2I, I7I8. Contributed to the study of curves and magic squares.

Laloubère, Antoine de. Born in Languedoc, I600; died at Toulouse, I664. Contributed to the study of curves.

Lambert, Johann Heinrich. Born at Mülhausen, Upper Alsace, I728; died at Berlin, I777. Founder of the hyperbolic trigonometry.

Lamé, Gabriel. Born at Tours, I795; died at Paris, I87o. Writer on elasticity, and orthogonal surfaces.

Landen, John. Born at Peakirk, near Peterborough, r7I9; died at Milton, I790. A theorem of his (I755) suggested to Euler and Lagrange their study of elliptic integrals.

Laplace, Pierre Simon, Marquis de. Born at Beaumont-en-Auge, Normandy, March 23, I749; died at Paris, March 5, I827. Celebrated astronomer, physicist, and mathematician. Added to the theories of least squares, determinants, equations, series, probabilities, and differential equations.

Legendre, Adrien Marie. Born at Toulouse, Sept. I8, I752; died at Paris, Jan. I0, I833. Celebrated mathematician, contributing especially to the theory of elliptic functions, theory of numbers, least squares, and geometry. Discovered the "lav of quadratic reciprocity, "- "the gem of arithmetic" (Gauss).

Leibnitz, Gottfried Wilhelm. Born at Leipzig, I646; died at Hanover in I7I6. One of the broadest scholars of modern times; equally eminent as a philosopher and mathematician. One of the discoverers of the infinitesimal calculus, and the inventor of its accepted symbolism. 
Leonardo of Pisa, Fibonacci (filius Bonacii, son of Bonacius). Born at Pisa, I180; died in I250. Travelled extensively and brought back to Italy a knowledge of the Hindu numerals and the general learning of the Arabs, which he set forth in his Liber Abaci, Practica geometriae, and Flos.

L'Hospital, Guillaume François Antoine de, Marquis de St. Mesme. Born at Paris, $166 \mathrm{r}$; died there 1704 . One of the first to recognise the value of the infinitesimal calculus.

Lhuilier, Simon Antoine Jean. Born at Geneva, I750; died in 1840. Geometer.

Libri, Carucci dalla Sommaja, Guglielmo Brutus Icilius Timoleon. Born at Florence, Jan. 2, 1803; died at Villa Fiesole, Sept. 28, I869. Wrote on the history of mathematics in Italy.

Lie, Marius Sophus. Born Dec. I2, I842; died Feb. 18, I899. Professor of mathematics in Christiania and Leipzig. Specially celebrated for his theory of continuous groups of transformations as applied to differential equations.

Liouville, Joseph. Born at St. Omer, I809; died in I882. Founder of the journal that bears his name.

Lobachevsky, Nicolai Ivanovich. Born at Makarief, I793; died at Kasan, Feb. I2-24, 1856. One of the founders of the socalled non-Euclidean geometry.

Ludolph van Ceulen. See Van Ceulen.

MacCullagh, James. Born near Strabane, I809; died at Dublin, I 846 . Professor of mathematics and physics in Trinity College, Dublin.

Maclaurin, Colin. Born at Kilmodan, Argyllshire, 1698; died at York, June I4, I746. Professor of mathematics at Edinburgh. Contributed to the study of conics and series

Malfatti, Giovanni Francesco Giuseppe. Born at Ala, Sept. 26, I73I; died at Ferrara, Oct. 9, I807. Known for the geometric problem which bears his name,

Malus, Êtienne Louis. Born at Paris, June 23, 1775; died there, Feb. 24, 1812. Physicist.

Miisrheroni, Lorenzo. Born at Castagneta, I750; died at Paris, 1800. First to elaborate the geometry of the compasses only (1795). 
Maurolico, Francesco. Born at Messina, Sept. 16, I494; died July 2I, 1575. The leading geometer of his time. Wrote also on trigonometry.

Maximus Planudes. Lived about I330. From Nicomedia. Greek mathematician at Constantinople. I rote a commentary on Diophantus; also on arithmetic.

Menaechmus. Lived about -350 . Pupil of Plato. Discoverer of the conic sections.

Menelaus of Alexandria. Lived about ıoo. Greek mathematician and astronomer. Wrote on geometry and trigonometry.

Mercator, Gerhard. Born at Rupelmonde, Flanders, I5I2: died at Duisburg, 1594. Geographer.

Mercator, Nicholas. (German name Kaufmann.) Born near Cismar, Holstein, c. I620; died at Paris, 1687. Discovered the series for $\log (1+x)$.

Metius, Adriaan. Born at Alkmaar, I57I ; died at Franeker, 1635.

Suggested an approximation for $\pi$, really due to his father.

Meusnier de la Place, Jean Baptiste Marie Charles. Born at Paris, I754; died at Cassel, I793. Contributed a theorem on the curvature of surfaces.

Méziriac, Claude Gaspard Bachet de. Born at Bourg-en-Bresse, I58I; died in 1638. Known for his Problemes plaisants, etc. (1624) and his translation of Diophantus.

Möbius, August Ferdinand. Born at Schulpforta, Nov. I7, I790 ; died at Leipzig, Sept. 26, I868. One of the leaders in modern geometry. Author of Der Barycentrische Calcül (1827).

Mohammed ibn Musa. See Al Khowarazmi.

Moivre. See DeMoivre.

Mollweide, Karl Brandan. Born at Wolfenbüttel, Feb. 3, I774; died at Leipzig, March Io, 1825. Wrote on astronomy and mathematics.

Monge, Gaspard, Comte de Péluse. Born at Beaune, 1746 ; died at Paris, I8I8. Discoverer of descriptive geometry; contributed to the study of curves and surfaces, and to differential equations. 
Montmort, Pierre Rémond de. Born at Paris, I678; died there, I7Ig. Contributed to the theory of probabilities and to the summation of series.

Moschopulus, Manuel. Lived about I300. Byzantine mathematician. Known for his work on magic squares.

Mydorge, Claude. Born at Paris, ${ }_{5} 8_{5}$; died there in 1647 . Author of the first French treatise on conics.

Napier, John. Born at Merchiston, then a suburb of Edinburgh, I550; died there in I6I7. Inventor of logarithms. Contributed to trigonometry.

Nezeton, Sir Isaac. Born at Woolsthorpe, Lincolnshire, Dec. 25, I642, O. S.; died at Kensington, March 20, I727. Succeeded Barrow as Lucasian professor of mathematics at Cambridge (I669). The world's greatest mathematical physicist. Invented fluxional calculus (c. I666). Contributed extensively to the theories of series, equations, curves, and, in general, to all branches of mathematics then known.

Nicole, François. Born at Paris, 1683; died there, 1758. First treatise on finite differences.

Nicomachus of Gerasa, Arabia. Lived roo. Wrote upon arithmetic.

Nicomedes of Gerasa. Lived - I80. Discovered the conchoid which bears his name.

Nicolaus von Cusa. Born at Cuss on the Mosel, I40I; died at Todi, Aug. II, I464. Theologian, physicist, astronomer, geometer.

Odo of Cluny. Born at Tours, 879; died at Cluny, 942 or 943. Wrote on arithmetic.

Oenopides of Chios. Lived -465. Studied in Egypt. Geometer.

Olivier, Théodore. Born at Lyons, Jan. 2I, I793; died in same place Aug. 5, 1853 . Writer on descriptive geometry.

Oresme, Nicole. Born in Normandy, c. I320; died at Lisieux, 1382. Wrote on arithmetic and geometry.

Oughtred, William. Born at Eton, I574; died at Albury, I660. Writer on arithmetic and trigonometry.

Pacioli, Luca. Fra Luca di Borgo di Santi Sepulchri. Born at Borgo San Sepolcro, Tuscany, c. I445; died at Florence, 
c. I509. Taught in several Italian cities. His Summa de Arithmetica, Geometria, etc., was the first great mathematical work published (I494).

Pappus of Alexandria. Lived about 30o. Compiled a work con taining the mathematical knowledge of his time.

Parent, Antoine. Born at Paris, I666; died there in I7I6. Fisst to refer a surface to three co-ordinate planes (I7OO).

Pascal, Blaise. Born at Clermont, I623; died at Paris, 1662 Physicist, philosopher, mathematician. Contributed to the theory of numbers, probabilities, and geometry.

Peirce, Charles S. Born at Cambridge, Mass., Sept. Io, I839. Writer on logic.

Pell, John. Born in Sussex, March I, I61o; died at London, Dec. Io, I685. Translated Rahn's algebra.

Perseus. Lived -r5o. Greek geometer; studied spiric lines.

Peuerbach, Georg von. Born at Peuerbach, Upper Austria, May 30, I423; died at Vienna, April 8, I46I. Prominent teacher and writer on arithmetic, trigonometry, and astronomy.

Pfaff, Johann Friedrich. Born at Stuttgart, I765; died at Halle in 1825 . Astronomer and mathematician.

Pitiscus, Bartholomaeus. Born Aug. 24, I56I; died at Heidelberg, July 2, I6 г3. Wrote on trigonometry, and first use the present decimal point (I6I2).

Plana, Giovanni Antonio Amedeo. Born at Voghera, Nov. 8, I78I; died at Turin, Jan. 2, I864. Mathematical astronomer and physicist.

Planudes. See Maximus Planudes.

Plateau, Joseph Antoine Ferdinand. Born at Brussels, Oct. I4, I80I ; died at Ghent, Sept. I5, I883. Professor of physics at Ghent.

Plato. Born at Athens, -429 ; died in -348 . Founder of the Academy. Contributed to the philosophy of mathematics.

Plato of Tivoli. Lived II20. Translated Al Battani's trigonometry and other works.

Plïcker, Johann. Born at Elberfeld, July I6, r8or ; died at Bonn, May 22, I868. Professor of mathematics at Bonn and Halle. One of the foremost geometers of the century. 
Poisson, Siméon Denis. Born at Pithiviers, Loiret, $178 \mathrm{I}$; died at Paris, 1840 . Chiefly known as a physicist. Contributed to the study of definite integrals and of series.

Poncelet, Jean Victor. Born at Metz, I788; died at Paris, I867. One of the founders of projective geometry.

I'othenot, Laurent. Died at Paris in 1732. Professor of mathematics in the Collège Royale de France.

Proclus. Born at Byzantium, 4I2; died in 485. Wrote a commentary on Euclid. Studied higher plane curves.

Ptolemy (Ptolemaeus Claudius). Born at Ptolemais, 87; died at Alexandria, 165. One of the greatest Greek astronomers.

Pythagoras. Born at Samos, -580 ; died at Megapontum, - 50 . Studied in Egypt and the East. Founded the Pythagorean school at Croton, Southern Italy. Beginning of the theory of numbers. Celebrated geometrician.

Quetelet, Lambert Adolph Jacques. Born at Ghent, Feb. 22, I796; died at Brussels, Feb. 7, I874. Director of the royal observatory of Belgium. Contributed to geometry, astronomy, and statistics.

Ramus, Peter (Pierre de la Ramée). Born at Cuth, Picardy, I5I5; murdered at the massacre of St. Bartholomew, Paris, August 24-25, I572. Philosopher, but also a prominent writer on mathematics.

Recorde, Robert. Born at Tenby, Wales, $\mathrm{I}_{5} \mathrm{Io}$; died in prison, at London, I558. Professor of mathematics and rhetoric at Oxford. Introduced the sign $=$ for equality.

Regiomontanus. Johannes Müller. Born near Königsberg, June 6, I436; died at Rome, July 6, I476. Mathematician, astronomer, geographer. Translator of Greek mathematics. Author of first text-book of trigonometry.

R'migius of Auxerre. Died about 908. Pupil of Alcuin's. Wrote on arithmetic.

lihaeticus, Georg Joachim. Born at Feldkirch, I5I4; died at Kaschau, I576. Professor of mathematics at Wittenberg; pupil of Copernicus and editor of his works. Contributed to trigonometry. 
Riccati, Count Jacopo Francesco. Born at Venice, $x 676$; died at Trèves, I754. Contributed to physics and differential equations.

Richelot, Friedrich Julius. Born at Königsberg, Nov. 6, I808; died March 3I, I875 in same place. Wrote on elliptic and Abelian functions.

Riemann, George Friedrich Bernhard. Born at Breselenz, Sept. I7, I826; died at Selasca, July 20, I866. Contributed to the theory of functions and to the study of surfaces.

Riese, Adam. Born at Staffelstein, near Lichtenfels, I492; died at Annaberg, 1559. Most influential teacher of and writer on arithmetic in the I6th century.

Roberval, Giles Persone de. Born at Roberval, I602; died at Paris, I675. Professor of mathematics at Paris. Geometry of tangents and the cycloid.

Rolle, Michel. Born at Ambert, April 22, 1652; died at Paris, Nov. 8, I7I9. Discovered the theorem which bears his name, in the theory of equations.

Rudolff, Christoff. Lived in first part of the sixteenth century. German algebraist.

Sacro-Bosco, Johannes de. Born at Holywood (Halifax), Yorkshire, I200(?); died at Paris, I256. Professor of mathematics and astronomy at Paris. Wrote on arithmetic and trigonometry.

Saint-Venant, Adhémar Jean Claude Barré de. Born in 1797 ; died in Vendôme, I886. Writer on elasticity and torsion.

Saint-Vincent, Gregoire de. Born at Bruges, 1584 ; died at Ghent, I667. Known for his vain attempts at circle squaring.

Saurin, Joseph. Born at Courtaison, I659; died at Paris, I737. Geometry of tangents.

Scheeffer, Ludwig. Born at Königsberg, I859; died at Munich, 1885. Writer on theory of functions.

Schindel, Johannes. See Joannes de Praga.

Schzuenter, Daniel. Born at Nuremberg, $\mathrm{I}_{5} 85$; died in 1636 . Professor of oriental languages and of mathematics at Altdorf.

Serenus of Antissa. Lived about 350. Geometer. 
Serret, Joseph Alfred. Born at Paris, Aug. 30, I8I9; died at Versailles, March 2, I885. Author of well-known text-books on algebra and the differential and integral calculus.

Sextus Julius Africanus. Lived about 220. Wrote on the history of mathematics.

Simpson, Thomas. Born at Bosworth, Aug. 20, r7io; died at Woolwich, May I4, I76r. Author of text-books on algebra, geometry, trigonometry, and fluxions.

Sluze, René François Walter de. Born at Visé on the Maas, I622; died at Liège in r685. Contributed to the notation of the calculus, and to geometry.

Smith, Henry John Stephen. Born at Dublin, I826; died at Oxford, Feb. 9, 1883 . Leading English writer on theory of numbers.

Sncll, Willebrord, van Roijen. Born at Leyden, $\mathrm{x} 59 \mathrm{I}$; died there, 1626. Physicist, astronomer, and contributor to trigonometry.

Stottiswoode, William. Born in London, Jan. II, I825; died there, June 27, 1883. President of the Royal Society. Writer on algebra and geometry.

Staudt, Karl Georg Christian von. Born at Rothenburg a. d. Tauber, Jan. 24, I798; died at Erlangen, June I, I867. Prominent contributor to modern geometry, Geometrie der Lage.

Steiner, Jacob. Born at Utzendorf, March I8, I796; died at Bern, April I, I863. Famous geometrician.

Stevin, Simon. Born at Bruges, I548; died at Leyden (or the Hague), r620. Physicist and arithmetician.

Stewart, Matthew. Born at Rothsay, Isle of Bute, I7I7; died at Edinburgh, I785. Succeeded Maclaurin as professor of mathematics at Edinburgh. Contributed to modern elementary geometry.

Stifel, Michael. Born at Esslingen, I 486 or I 487 ; died at Jena, 1567. Chiefly known for his Arithmetica integra (x544).

Sturm, Jacques Charles François. Born in Geneva, 1803; died in 1855. Professor in the École Polytechnique at Paris. "Sturm's theorem."

Sylvester, James Joseph. Born in London, Sept. 3, I8I4; died in same place, March 15, 1897. Savilian professor of pure 
geometry in the University of Oxford. Writer on algebra, especially the theory of invariants and covariants.

Tabit ibn Kurra. Born at Harran in Mesopotamia, 833; died at Bagdad, 902. Mathematician and astronomer. Translated works of the Greek mathematicians, and wrote on the theory of numbers.

Tartaglia, Nicolo. (Nicholas the Stammerer. Real name, Nicolo Fontana.) Born at Brescia, c. I500; died at Venice, $c$. 1557. Physicist and arithmetician; best known for his work on cubic equations.

Taylor, Brook. Born at Edmonton, 1685 ; died at London, I731. Physicist and mathematician. Known chiefly for his work in series.

Thales. Born at Miletus, -640 ; died at $A$ thens, -548 . One of the "seven wise men" of Greece; founded the Ionian School. Traveled in Egypt and there learned astronomy and geometry. First scientific geometry in Greece.

Theaetelus of Heraclea. Lived in -39o. Pupil of Socrates. Wrote on irrational numbers and on geometry.

Theodorus of Cyrene. Lived in -4 Io. Plato's mathematical teacher. Wrote on irrational numbers.

Theon of Alexandria. Lived in 370. Teacher at Alexandria. Edited works of Greek mathematicians.

Theon of Smyrna Lived in r30. Platonic philosopher. Wrote on arithmetic, geometry, mathematical history, and astronomy.

Thymaridas of Paros. Lived in -39o. Pythagorean; wrote on arithmetic and equations.

Torricelli, Evangelista. Born at Faënza, r608; died in I647. Famous physicist.

Tortolini, Barnaba. Born at Rome, Nov. I9, I808; died August 24, I874. Editor of the Annali which bear his name.

Trembley, Jean. Born at Geneva, 1749; died in I8II. Wrote on differential equations.

Tschirnhausen, Ehrenfried Walter, Graf von. Born at Kiesslingswalde, $\mathrm{I}_{5} \mathrm{I}$; died at Dresden, I708. Founded the theory of catacaustics. 
Ubaldi, Guido. See Del Monte.

Unger, Ephraim Solomon. Born at Coswig, I788; died in 1870.

Ursinus, Benjamin. I587-I633. Wrote on trigonometry and computed tables.

Van Ceulen, Ludolph. Born at Hildesheim, Jan. I8 (or 28), I540; died in Holland, Dec. 3I, I6ro. Known for his computations of $\pi$.

Vandermonde, Charles Auguste. Born at Paris, in I735; died there, I796. Director of the Conservatoire pour les arts et métiers.

Van Eyck, Jan. I385-1440. Dutch painter.

Van Schooten, Franciscus (the younger). Born in $16 \mathbf{r}_{5}$; died in I660. Editor of Descartes and Vieta.

Viette (Vieta), François, Seigneur de la Bigotière. Born at Fontenay-le-Comte, I540; died at Paris, I603. The foremost algebraist of his time. Also wrote on trigonometry and geometry.

Vincent. See Saint-Vincent.

Vitruvius. Marcus Vitruvius Pollio. Lived in - 15. Roman architect. Wrote upon applied mathematics.

Viviani, Vincenzo. Born at Florence, I622; died there, I703. Pupil of Galileo and Torricelli. Contributed to elementary geometry.

Wallace, William. Born in 1768 ; died in 1843 . Professor of mathematics at Edinburgh.

Wallis, John. Born at Ashford, I6r6; died at Oxford, I703. Savilian professor of geometry at Oxford. Published many mathematical works. Suggested (1685) the modern graphic interpretation of the imaginary.

Weierstrass, Karl Theodor Wilhelm. Born at Ostenfelde, Oct. 3I, I8I5; died at Berlin, Feb. I9, I897. One of the ablest mathematicians of the century.

Werner, Johann. Born at Nuremberg, $1_{4} 68$; died in 1528 . Wrote on mathematics, geography, and astronomy.

Widmann, Johann, von Eger. Lived in 1489 . Lectured on algebra at Leipzig. The originator of German algebra. Wrote also on arithmetic and geometry. 
Witt, Jan de. Born in 1625 , died in 1672 . Friend and helper of Descartes.

Wolf, Johann Christian von. Born at Breslau, I679; died at Halle, 1754. Professor of mathematics and physics at Halle, and Marburg. Text-book writer.

Woepcke, Franz. Born at Dessau, May 6, I826; died at Paris, March 25, 1864. Studied the history of the development of mathematical sciences among the Arabs.

Wren, Sir Christopher. Born at East Knoyle, I632; died at London, in I723. Professor of astronomy at Gresham College; Savilian professor at Oxford; president of the Royal Society. Known, however, entirely for his great work as an architect 


\section{INDEX.*}

Abacists, 39, $4 \mathrm{I}$.

Abacus, 15, 25, 26, 37 .

Abel, 62, 154, I55, 163, I81-188,

Abscissa, 229.

Abul Wafa, 225, 286.

Academies founded, I 16 .

Adelard (Ethelhard) of Bath, 74, 218. Africanus, S. Jul., 202.

A hmes, 19, 31, 32, 34, 77, 78, 192, 282.

Alcuin, 4I.

Al Banna, Ibn, 30, 76, 90 .

Al Battani, 285.

Alberti, 227.

Algebra, 61, 77, 96, 107; etymology,

88 ; first German work, I 10.

Algorism, 75 .

Al Kalsadi, 30, 31, 75, 76, 89, 90, 92.

Al Karkhi, 75, 93.

Al Khojandi, 76 .

Al Khowarazmi, 29, 33, 74, 75, 88, 89, 9I, 217.

Al Kuhi, 217.

Alligation, 34 .

Almagest, 283.

Al Nasawi, 30, 34 .

Al Sagani, 217.

Amicable numbers, 35 .

Anaxagoras, 195. 213.

Angle, trisection of, 196, 197, 207, 208, 217.

Annuities, 56, $1_{4} 8$.

Anton, r79n.

A pian, 108, 288, 289.

Apices, 15, 27. 37, 39 .

Apollonius, 80, 152, 190, 200-209, 228, 229, 23 I.

Approximations in square root, 70.
Arabs, 3, 15, 20, 35, 39, 53, 74, 76, 88, 89, I9I, 214, 285.

Arbitration of exchange, 55 .

Arcerianus, Codex, 214, 218.

Archimedes, 68-7I, 78, 8I-83, 190, 199, 204, 205, 208, 210, 212.

Archytas, 69, 82, 204, 207, 21 I.

Argand, 124, 125.

Aristophanes, 25.

Aristotle, 64, 70 .

Arithmetic, 18, 24, 36, 49, 5I, 64, 95 .

Arithmetic, foundations of, 189 ; required, 43.

Arithmetical triangle, II8.

Aronhold, $146,250$.

Aryabliatta, I2, 72, 74, 215, 216.

Aryans, 12.

Associative law, Irg.

Assurance, 56-60.

Astronomy, i8.

August, 246 .

Ausdehnungslehre, 127.

Austrian subtraction, 28, 48 .

Avicenna, 76 .

Axioms, 197.

Babylonians, 9, 10, 14, 19, 24, 25, 63,

64, 190, 192, 193.

Bachet, 106, 134, 137 .

Ball, W. W. R., I72n.

Baltzer, $167 n, 224 n$.

Bamberger arithmetic, 51 .

Banna. See Ibn al Banna.

Bardin, 277.

Barrow, I69, 238.

Bartl, 167.

Barycentrischer Calciil, I29, 250.

* The numbers refer to pages, the small italic $n$ 's to footnotes. 
Baumgart, $137 n$.

Beaune. See DeBeaune.

Bede, 36, 37, 40 .

Bellavitis, 250, 266.

Beltrami, 148, 269, 27r.

Beman, 124n., I25n., I29n.

Beman and Smith, $207 n$.

Benedictis, 225 .

Bernecker, rog.

Bernelinus, 37, 40.

Bernoulli family, 58 ; Jacob, 148 , I50, I52, I7I, 175, I78, 179, 238, 239; John, I52, I66, I13, I75, 178, 179, 238, 242, 243 ; Daniel, I66, I75.

Bertrand, I22, I55, 270.

Bessel, 237.

Betti, I65.

Beutel, 22.

Bézout, I43, I59, IC0, 167.

Bhaskara, 73, 74, 85, 86, 216.

Bianchi, I47.

Bianco, 237n.

Bierens de Haan, 222n.

Binder, 257.

Binomial coefficients, 103; binomial theorem, I 8 .

Biot, 242.

Boethius, 26, 27, 37, 215 .

Bois-Reymond, I55, 189 .

Böklen, I67n., 270.

Bolyai, 270, 271.

Bombelli, I01, I02, II2.

Boncompagni, 75 .

Bonnet, 155 .

Boole, I3I, I46.

Bouniakowsky, 139.

Bouvelles, 237.

Boys, 166.

Brachistochrone, $178,238$.

Brahmagupta, 52, 216.

Brianchon, 244.

Briggs, 292.

Brill, I42n., I75n., 180n., 189, 254, 264, $276 n$., 278 .

Bring, 165 .

Brioschi, I43, I44, I46.

Brocard, 245.

Brouncker, I34.

Brune, 59.

Brunelleschi, 227.

Burckhardt, I34, I4I, I47.
Bürgerschulen, 23.

Bürgi, 4, 50, 98, I15, I16, 290.

Busche, 139 .

Calculating machines, 48 .

Calculus, differential, 168, 170, 171, I78; directional, I27; integral, 174. I78; of logic, I3I; of variations, I79.

Cantor, G., 120, 123; Cantor, M., $7 n$. Capelli, I65.

Cardan, IOI-I03, IO9, II2, I13, 150, I55, 225.

Cardioid, $24 \mathbf{I}$.

Carnot, 174, 244, 246, 248.

Cassini's oval, 241 .

Castelnuovo, 275.

Cataldi, I31.

Catenary, 241.

Cattle problem of Archimedes, 83 .

Cauchy, 62, I19, 124, I25, I38, 139, I43 I53, I54, I64, 167, I68, I74, I8I, I88 I89.

Caustics, 238.

Cavalieri, $168,173,224,229,234,235$ 237.

Cayley, 126n., 129n., 131, 143, 146, 168 . $178,253,257,263,264,266,274,277$.

Ceulen, 222.

Ceva, 244 .

Chain rule, 52, 55 .

Chance. See Probabilities.

Chapple, 244.

Characteristics, Chasles's method of, 264.

Chasles, 290n., 246, 249, 256-258, 263265.

Chessboard problem, 135 .

Chinese, 8, I4, 19, 28, 74, 87, 214, 216.

Christoffel, 147 .

Chiquet, $47,95$.

Church schools, 3, 36, 37, 94.

Circle, division of, 24 ; squaring, I9 I97, 207, 215, 221.

Cissoid, $21 r$.

Cistern problems, 34 .

Clairaut, $117,242$.

Clausberg, 55.

Clavius, III.

Clebsch, 146; 147, 176, 177, 250, $251 \mathrm{~m}$. $257,262,266,279$. 
Cloister schools. See Church schools. Codex Arcerianus, 214.

Coefficients and roots, $115,156$.

Cohen, $172 n$.

Cole, I62n.

Combinations, 70, 74, 150, 151 .

Commercial arithmetic, 22, 5I, 60.

Commutative law, IIg.

Compasses, single opening, 225.

Complementary division, 38 .

Complex numbers, 73, I01, 123, 126, 182. Complex variable. See Functions, theory of.

Complexes, 254.

Compound interest, 52.

Computus, 37,39 .

Conchoid, 21 .

Condorcet, 149 .

Conics, 8I, 202, 204-208, 228, 230, 239, 256.

Congruences, theory of, $13 \mathrm{I}$.

Conon, 2ro.

Conrad, H., rog.

Conrad of Megenberg, 2rg.

Contact transformations, $178,269,276$.

Continued fractions, 131-133, 168.

Convergency, 152-155, I89. See Series.

Coördinates, Cartesian, 231 ; curvilinear, 268, 269; elliptic, 269.

Copernicus, 289.

Correspondence, one-to-one, 251, 264, $266,268$.

Cosine, 288.

Coss, 96-99, 107, 109, IIr.

Cotes, I74, 239, 241, 244.

Counting, 6 .

Cousin, 227 .

Covariants, 146 . See also Forms, Invariants.

Cramer, 132. 167, 240; parados, 240.

Crelle, I4I, 245, 257.

Cremona, 256, 266.

Crofton, 276 .

Cross ratio, 258, 259.

Cube, duplication of, $82,104,204,207$; multiplication of, 207, 21 I.

Culvasutras, 72.

Cuneiform inscriptions, 9 .

Cunynghame, 166 .

Curtze, 289n.
Curvature, measure of, 268.

Curves, classification of, 233, 239, 246; deficiency of, 262, 263; gauche (of double curvature), 243, 255, 263; with higher singularities, 253.

. Cusa, 237.

Cycloid, 178, 237, 238.

$d$, symbol of differentiation, $170-172$;

$\delta$, symbol of differentiation, 180 .

D'Alembert, 175, 180.

Dante, 94.

DeBeaune, 156 .

Decimal fractions, 50.

Decker, 292.

Dedekind, 120-122, 126, 127, 189.

Defective numbers, 35 .

Deficiency of curves, 262, 263.

Definite integrals, 174 .

Degrees (circle), 24.

De Lagny, 157.

De la Gournerie, $26 \mathrm{r}$.

Delambre, 295.

De l'Hospital, 173, 178, 179.

Delian problem, 82, I04, 204, 207.

Democritus, 213.

De Moivre, 124, 152, 160.

De Morgan, I43, 155 .

Desargues, 205, 237, 242, 259.

Descartes, 4, 108, 117, 119, 124, 136, 140, I56, 191, 228, 230-233, 238.

Descriptive geometry, $247,259,260$.

Determinants, $133,144,145,167,168$, 262.

DeWitt, $57,148$.

Dialytic method, I44, 145 .

Diametral numbers, ro5.

Differential calculus, I68, I $>0,17 \mathrm{I}, \mathrm{I} 78$; equations, $174-178,269$; geometry, 267.

Dimensions, $\boldsymbol{n}$., 275.

Dini, 155, 189 .

Dinostratus, 197, 210.

Diocles, 2Ir.

Diophantus, 65, 70, 77, 81, 84, 85, 90, $93,133,134$.

Dirichlet, 62, 125, 126, 133, 139, 140, 153, I74, I77, I8I, 189, 279.

Discount, 54 .

Discriminant, 145 .

Distributive law, I19, I30. 
Divani numerals, 15.

Divisibility tests, 35 .

Division, 38, 42, 44, 48, 49.

Dodson, 58.

Donatello, 227.

Duality, 249.

DuBois-Reymond, 155,189 .

Duhamel, I 55 .

Duodecimal fractions, 19.

Dupin, 267, 270.

Duplication of the cube, $82,104,204$, 207.

Dürer, 22I, 224-227.

Dyck, 278.

$e$, irrationality of, 133 .

Easter, 4I.

Ecole polytechnique, 261 .

Eccentricity, 22.4.

Egyptians, 8, 10, 18, 24, 31, 35, 63, 77, 190, 192, 282.

Eisenstein, I26, 127, I38.

Elimination, theory of, I42, I43.

Ellipse, 81, 205.

Ellipsoid, 242.

Elliptic functions. See Functions.

Elliptic integrals, classed, 183, 186, I87.

Ellis, I3I.

Enneper, I8I $n$.

Enumerative geometry, 264.

Envelopes, 242.

Equations, approximate roots, ${ }_{5} 6$, I66; A belian, I63; cubic, 81, 82, 92, 93 . III-II3, I55; cyclotomic, I60-I63, 207; differential, I74-I78; fundamental theorem, I63; higher, 92, I 5 , I55-I60, I64-I66; indeterminate, $83,84,86,93,135,137,139$; linear, $77,78,87,90$; limits of roots, 156 , I66; Diophantine, 93, I35, I37; quadratic, 79-8I, 85, 9I, I09, I55; quartic, III-II3; quintic, 165; mechanical solutions, I66; modular, 164 ; negative roots, 234 .

Equipolent, 96.

Eratosthenes, I4I, 190, 208.

Erchinger, I62.

Eschenbach, I5I.

Euclid, 35, 65-69, 79, 80, I00, II9, I33, I9o, 195, 197-199, 212, 213.
Eudoxus, 79, I99, 204, 210, 212, 223.

Euler, 58, 62, I18, 124, I32, 135 I36, I38, I40, I43, I52-I54, I58, I60, I73, 175, I79, 180-182, 240, 244, 247, 167, $29+, 295$.

Evolutes, 238, 242.

Excliange, 52, 55.

Exliaustions, 199, 225.

Exponents. See Symbols.

Eyck, 226.

Eycke, 222.

Fagnano, r8o, 18 r.

Farr, 59.

Faulhaber, 96 .

Felkel, if I.

Fermat, 57, 118, 134, 135, I37, I4n, : : I68, I73, 229, 234.

Ferrari, I12, I55, 225.

Ferro, ir2.

Fenerbach, 245.

Fibonacci. See Leonardo.

Finck, 288.

Finger reckoning, 25, 36, 43 .

Fischer, 59.

Fluxions, I71, 173.

Forms, theory of, I3I, I42-I47.

Fourier, I53.

Fourth dimension, 274.

Fractional exponents, I02.

Fractions, 3I, 40, 49; continued, I3I-

I33, I68; sexagesimal, 282-284; duodecinal, 19.

Français, 125.

Frenicle, Io6.

Frézier, 260.

Frobenius, 177, 178, 189 .

Finchs, I77, I78, I8I.

Functional determinants, 168 .

Functions, Abelian, I8o, I86, I88, i 89 ; elliptic, 165 , I80-182; periodicity of, I 84 ; symmetric, $I_{42}, I_{43}$; theory of, I77, I8o, I8I, I88; theta, I82, I88, 189 Fundamental laws of number, I 19 , I31, I89.

Galileo, 237, 24 I.

Galois, I64.

Gauss, 4, 124-128, 133, 135n., 136-140, I42, I43, I45, I49, I50, I $53, I_{54}, I_{56}$, 
I60-163, I67, I74, I81, 188, 207, 245, 267, 270, 275, 279, 294, 295.

Geber, 286.

Gellibrand, 292.

Geminus, 2 II.

Genocchi, 139.

Geometric means, 78, I03; models, 276.

Geometry, 66, I90, 214 ; analytic, I9I, 205, 230, 232, 246; descriptive, 247 , 259, 260; differential, 267; enumerative, 264; metrical, I90, 192, I93; projective, I9I, $246,247,258$; nonEuclidean, 270; of position, I90, 246 , 248,258 ; of space, 2 II, 242; three classes of, 274 .

Gerbert, 15, 37, 40, 61, 218.

Gergonne, 249, 257.

Gerhard of Cremona, 40, 286.

Gerhardt, $47 n$.

German algebra, 96, I07; universities, 95 .

Giesing, ro6n.

Girard, 124.

Girls' schools, 2 I.

Gizeh, 9.

Glaisher, I42.

Gmunden, 95.

Gnomon, 66, 92, 195, 215.

Goepel, I88.

Golden rule, 5 I.

Golden section, I95, 222, 223.

Gordan, I44, I46, I47.

Gournerie, $26 \mathrm{r}$.

Goursat, 178 .

Gow, $7 n$.

Grammateus, 45, 49, 98, 99, 108, 109.

Grassmann, 127-I29, I31, 256, 275

Graunt, 57.

Grebe point, 245.

Greek fractions, 32.

Greeks, 2, 8, I0, I4, I9, 20, 25, 64, 77, I90, I93, 282.

Gregory, I5I.

Groups, theory of, 164 , I77; point, 240 Grube, 23.

Grunert, :28, 257.

Gubar numerals, 15, 17, 31 .

Gudermann, 183.

Guilds, 56.

Guldin, 213, 224, 234
Gunter, 288.

Güther, I6n., 107n., 133, 168, 220n

Haan, 222n.

Hachette, 26r.

Hahn, 48.

Halley, 57, 58, 166, 203, 204.

Halphen, I47, 253, 256, 264, 269.

Hamilton, $127,270$.

Hammer, $295 n$.

Hankel, 6n., 124, $247 n$.

Harmonic means, 78,79 .

Harpedonaptae, 193, 194.

Harriot, I0I, II7, I56.

Hebrews, 10.

Heine, I20, I23, I33, I89.

Helix, 2I I, 243.

Helmholtz, 27I, 272.

Henrici, 277.

Heptagon, 226.

Hermite, 133, 146, 147, I65.

Herodotus, 24.

Herodianus, II.

Heron, 64, 70, 78, 8I, 84, 20I, 212, 283

Hess, 245.

Hesse, I43-145, 164, I68, I76, 244, 250. 262.

Hessel, 245.

Heteromecic numbers, 67.

Hexagram, mystic, 237, 244,

Heyn, 59.

Hieratic symbols, 9.

Hilbert, I47, I 48 .

Hindenburg, $132,150$.

Hindu algebra, 84 ; arithmetic, 34,71 . 72 ; fractions, 33; geometry, 214; mathematics, 2, I2 following.

Hipparchus, 213, 266. 282, 283.

Hippias, r96, 2 ro.

Hippocrates, 65, 82, 197, 204, 213.

Hölder, 189.

Homology, 249.

Hoppe, 167, 173n., 245.

Hospital, I73, 178, 179.

Horner, 166.

Hudde, I08, 148, 156 .

Hugel, I07.

Hurwitz, 264.

Huygens, I31; I $48,222,238,242$.

Hyperbola, 81205.

Hyperboloid, 242. 
Hyperdeterminants, ${ }_{4} 6$.

Hyperelliptic integrals, 187 .

Hypergeometric series, 153.

Hypsicles, 84, 200, 212.

\section{$i$ for $\sqrt{-\mathrm{I}}, \mathrm{I} 24$.}

Iamblichus, 136 .

Ibn al Banna, 30, 76, 90.

Ibn Kurra, 136, 217.

Icosahedron theory, I66.

Ideal numbers, 126.

Imaginaries. See Complex numbers.

Incommensurable quantities, 69 .

Indeterminate equations. See Equations.

Indivisibles, 234, 236.

Infinite, 173. See Series.

Infinitesimals, 169, 170, 173, 174.

Insertions, 208, $21 \mathrm{r}$.

Insurance, 56-58.

Integral calculus, 174, I 78 .

Interest, 54 .

Invariants, $145-148,262,27$.

Involutes, $238,24 \mathrm{I}$.

Involutions, 252.

Irrational numbers, 68, 69, 100, Ir9, $122,123,133,189$.

Irreducible case of cubics, II2.

Isidorus, 36 .

Isoperimetric problems, I79, 200.

Italian algebra, 90 .

Jacobi, 62, 138, 139, I43, 14, 165, I68,

I74-I77, I8I-I87, 269, 276, 279.

Johann von Gmunden, 95.

Jonquières, 256.

Jordan, 165 .

Kalsadi. See Al Kalsadi.

Karup, 56, 59 .

Kästner, 48 .

Kepler, 4, 50, 61, 169, 173, 191, 222-224, 245, 288.

Khayyam, 75, 89, 92, 93.

Khojandi, 76 .

Khowarazmi. See Al Khowarazmi.

Klein, I47, 165, 177, 178, 207n., 254, 274, $277,278$.

Knilling, 23.

Königsberger, 180 .

Kossak, I20n.
Krafft, 135.

Kronecker, 139, i65.

Kriiger, I4I.

Krumbiegel and Amthor, 83 .

Kummer, 126, 138, 139n., 155, 270, 278.

Kurra, Tabit ibn, 136, 217.

Lacroix, 242, 26r.

Lagny, De, 157 .

Lagrange, 62, 136, 138, $143,151,159$ 160, I66, 167, 173, 175, 176, I79, 180 . $182,239,267,294,295$.

Laguerre, 274.

Lahire, 106, 249.

Lalanne, 167.

Laloubc̀re, 158 .

Lambert, 124, 133, I4I, 260, 267, 295

Lamé, 240, 269.

Landen, $180,182,244$.

Lansberg, 249.

Laplace, 150, 151, 167, 175.

Latin schools, 2I, 43.

Least squares, 149 .

Lebesgne, 139.

Legendre, 133, I36, 138-140, I49, I60, $174,180-184,187,270,295$.

Lehmus, 257.

Leibnitz, 4, 48, 54, 58, 62, 117, 150-152. $156,167,170-173,178,229,239,242$.

Lemniscate, 2.4 .

Lenicker, 227.

Leonardo da Vinci, 225; of Pisa (Fibonacci), 40, 4I, 45, 95, I01, 107, IO III, 218.

Leseur, 158.

Lessing, 83 .

Letters used for quantities, 64 .

Lexell, 295.

L'Hospital, I73, 178, I79.

Lhuilier, 244.

Lie, $147,177,269,276$.

Lieber, $245 n$.

Light, theory of, 270.

Limaçon, 24 I.

Limits of roots, $156,160,166$.

Lindemann, 133, $189,207$.

Liouville, 139, 18r, 269.

Lipschitz, It7.

Lituus, 24 I.

Lobachevsky, 271.

L.oci, 209, 210, 232. 
Logarithmic series, I5I; curve, $24 \mathrm{I}$.

Logarithms, 290.

Logic, calculus of, r3r.

Logistic, 64 .

Loria, $240 n$.

Loxodrome, 243.

Luca Pacioli. See Pacioli.

Lunes of Hippocrates, 197.

Lüroth, I68n.

Maclaurin, I52, I56, I74, I80, 238, 239. Macrobius, 36 .

Magic squares, 54, 105-107.

Magnus, 265, 277.

Majer, 210n

Malfatti, I 59, 256.

Malus, 270.

Marie, $230 n$.

Marre, 96i.

Mathematica, 64 .

Matthiessen, $77 n$., $87 n$., I08n.

Maxima, 169, 179, 180, 203.

Mean-value theorems, isg.

Means, geometric and harmonic, 78 , 79.

Mehmke, I67,

Meister, 24!.

Menaechmus, 82, 204-207.

Menelaus, 283.

Nenher, IIr.

Mercator, I5I.

Merchants' rule, $5 x$.

Merriman, I $49 n$.

Method, 23.

Meusnier, 243, 267.

Mejer, F., 275; W. F., I47; -Hirsch, I43.

Méziriac, 106, 134, 137.

Middle Ages, 3, 20, 44, 5I, 56, 106, $15 \mathrm{I}$. Minima, I69, I79, I80, 203.

Minus. See Symbols.

Möbius, I28, 129, I33, 244, 249, 250-252, $253,263,265,295$.

Models, geometric, 276 .

Mohammedans, 3. See Arabs.

Moivre, 124, 152, I60.

Nollweide, ro5.

Mommsen, $\mathrm{II}$.

Monge, $176, I 78,247,248,267,277$.

Monks. See Church schools.

.Iontucla, $69 n$.
Morgan, 59.

Mortality tables, 57,148 .

Moschopulus, 106.

Muir, 167n.

Müller, $47 n$.

Multiplication, 45,46 .

Muret, 277.

Mystic hexagram, 237, 244.

Mysticism. See Numbers.

Nachreiner, 168.

Napier, 47, 172, 288, 290.

Nasawi, 30, 34 .

Negative numbers and roots, 70, 72 .

8o, 9I, Ior, rog, Irg.

Neo-Platonists, 68; -Pythagoreans, 68.

Netto, 162n.

Neumann, C., 269; K., 57.

Newton, 4, 62, II7-II9, I52, 156, I66. I70-175, I78, 234, 239.

New Zealanders, 7 .

Nicomachus, 78 .

Nicomedes, 2 ro.

Nines, casting out, $35,46,76$.

Noether, 144n., 165, 180n., 189, 253 , 256, 264. 266.

Non-Euclidean geometry, 270.

Normal schools, 23.

Numbers, amicable, 136; classes of, 67 ; concept of, II8, I20; ideal, I26 ; irrational, 68, 69, I00, II9, I22, I23, 133, 189; mysticism of, 37, 106; nature of, II8, I20; negative, 70 , ror, 109; perfect, 35, 68; polygonal, 7I ; prime, $67,68,136$, 141, I6r, 162; pyramidal, $7 \mathrm{I}$; plane and solid, 66 ; systems of, 6 ; theory of, 133-140.

Numerals, 6 .

Nunez, III, 2.3.

Nuremberg, 2I.

Oddo, 39 .

Oekinghaus, 167

Oenopides, I95.

Olivier, 26r.

Omar Khayyam, 75, 89, 92, 93.

One-to-one correspondence, 25x, 264, $266,268$.

Ordinate, 229 . 
Oresme, 95, 102, 229,

Osculations, 239.

Oughtred, II7, 156.

$\pi$, nature of, 133,207 ; values of, 192 , 193, 199, 201, 215-218, 222.

Pacioli, 42, 45-47, 52, 95, 96, Iоr.

Page numbers, 16.

Pappus, 65, 179, 202, 203, 208, 209, 212, 234.

Parabola, 8I ; area, 68; name, 205.

Paraboloid, 242.

Parallel postulate, 20r, 270.

Parameter, 205.

Parent, 242, 247.

Partition of perigon, I60-162.

Partnership, 34.

Pascal, 48, 57, I18, I48, 150, 169, I73, I74, 234, 236-238.

Pascal's triangle, II8, I50.

Pauker, 155, I6r.

Peirce, 13I.

Peletier, III.

Pencils, 242.

Pepin, I39.

Perfect numbers, 35. 68.

Periodicity of functions, 184 .

Permutations, $7+$.

Perspective, 226, 227, 259.

Pessl, 107.

Pestalozzi, 23.

Petersen, 139.

Petty, 57.

Peuerbach, 3, 42, 45, 103, 289.

Pfatf, 15I, 153, 175, I76.

Philolaus, 78 .

Phoenicians, 8, 10.

Piazzi, 149.

Pincherle, r8g.

Pitiscus, 50n., 290.

Pitot, 243.

Plane numbers, 66.

Plato, 67, 82, 197, 207; of Tivoli, 285.

Platonic bodies, 2 I2.

Pliny, 26.

Plücker, I44, 239, 249-252, 254, 256, 257, $265,275,277$.

Plücker's equations, 253.

Plus, See Symbols.

Puëtius, I4I.
Poincaré, 165, I77.

Poinsot, 245.

Point groups, 240.

Poisson, I43, I73.

Polar, 249, 256.

Pole, 249.

Political arithmetic, 56.

Polygons, star, 218, 219, 224.

Polytechnic schools, 26r.

Poncelet, 246, 248, 249, 252, 258, 265.

Position arithmetic, I7.

Pothenot, 295.

Power series, ro3.

Powers of binomial, I 8 .

Prime numbers, 67, 68, 136, 141, 161, I62.

Pringsheim, 154n., 155, 189.

Prismatoid, 246.

Probabilities, I48, 149, 276.

Proclus, 219.

Projection, 213, 214. See Geometry.

Proportion, 79, rog.

Ptolemy, 201, 214, 266, 283.

Puzzles, 54.

Pythagoras, 68, 179, 190, 194, 195, 214:

Pythagoreans, 35, 66, 67, 78, 136, 194, I95, 198.

Quadratic equations. See Equations. Quadratic reciprocity, 137,138 ; remainders, 76 .

Quadratrix, 196, 24 .

Quadrature of circle. See Circle.

Quadrivium, 94.

Quaternions, 127, r29.

Quetelet, 59.

Raabe, 155.

Radicals, roo.

Rahn, 96n.

Ramus, 98, III, 133.

Raphson, I66.

Realschulen, 23.

Reciprocity, quadratic, I37, I38; Her mite's law of, $\mathbf{1} 46$.

Reciprocal polars, 249.

Reckoning schools, 4.

Redundant numbers, 35 .

Rees, 55.

Regeldetri, 34, 5 . 
Regiomontanus, 3, 42, 107, 108, 219, 287, 289, 294.

Regulae, various, 34, 4I, 5I, 52, 54, 90, II5.

Regular polygcns, I6I, I62, 22I, 223, 225, 226, 237, 245; solids, 2 I2.

Reiff, $151 n ., 178 n$.

Reinand, 75.

Resolvents, 159 .

Resultant, I $+3-\mathbf{I} 45$.

Reuschle, I42, I67.

Reymers, 96, 98, 107, I08, $x$ I5.

Rhabda, 25.

Rhaeticus, 288.

Riccati, I75.

Riemann, 62, 153, I54n., I8x, I88, I89, $27 \mathrm{I}, 272,275,276$.

Riese, 97, 99, го6, гпо, ІІз, Iт4, I20.

Right angle, construction of, 219.

Roberval, I69, I73, 229, 234, 236, 238.

Rodenberg, $2 ; 8$.

Rohn, 278.

Rolle, I58.

Roman fractions, 33 ; numerals, II, 36, 37; mathematics, 2, 8, 19, 214.

Roots, and coefficients, II5, 156; cube, 73, 103; negative, 234; real and imaginary, I24, see also Numbers, complex; square, $69,70,73$, I03. See also Equations.

Rope stretchers, 193; stretching, 215. Roriczer, 220.

Rosanes, 266.

Rosenhain, I88.

Rösler, ז20n.

Roth, 96, ro6.

Rothe, 132, I5I.

Rudel, 245.

Rudio, $222 n$.

Rudolff, 4, 50, 53, 97-100, I09-III, II3II 5 .

Ruffini, I63.

Rule of three. 34 , 5r. See Regulae.

$\int$, symbol of integration, $x 70, x>2$.

Saint-Vincent, $15 \mathrm{r}$.

Salignac, III.

Salmon, $143,263$.

Sand-reckoner, 7 I.

Sanskrit, I2, 13.

Saucé, 269.
Saurin, 244.

Scalar, rzo.

Scheeffer, I89.

Scheffler, 59, 127, 130, 245, 257.

Schellbach, 257.

Schering, 139.

Scheubel, 98, InI.

Schlegel, r27n., 245.

Schlesinger, $17 \div n$.

Schooten, Van, 136, I4I, 156, 242.

Schottky, i8g.

Schröder, I3I.

Schubert, 246, 264, 275.

Schwarz, 178, 279 .

Schwenter, I3I, 226.

Scipione del Ferro, II2.

Scott, $240 n$.

Secant, $=88$.

Seelhotf, I36n., I40n.

Segre, 275.

Seidel, 154 .

Semitic, 9.

Seqt, 282.

Series, 34, 67, 71, 74, 76, 103, 15I-154, I89.

Serret, $165,246 n$.

Servois, 249.

Sexagesimal system, $24,25,34,64,70$,

282-284.

Sieve of Eratosthenes, 67 .

Signs. See Symbols.

Simpson, 166.

Sine, name, 285.

Skew determinants, 168.

Sinith, D. E., I $78 n$. See Beman and

Smith. H. J. S., 253.

Snellius, 222, 243, 295.

Soleil, 277.

Solid numbers, 66.

Sonnenburg, $223 n$.

Spain, 3.

Spirals, 24I of Archimedes, 2 IO.

Squares, least, I 49 .

Squaring circle. See Circle.

Stahl, I89.

Star polygons, 218, 219, 224.

Steiner, 225, 246, 249, 25I, 256-258, 265.

Stereographic projection, 266.

Stereometry, 2II, 224.

Stern, I33, I39.

Stevin, 50, 228. 
Stewart, 244 .

Stifel, 4, 49, 52, 53, 97, 99-105, IO9-III, Ir3, II, II 8, 220, 221, 224.

Stokes, I54.

Stoll, 246.

Stolz, izon.

Stringham, 245.

Stubbs, 266.

Sturm, 48, 270.

Substitutions, groups, I64, I65.

Sun tse, 87 .

Surfaces, families of, 267 ; models of, 277; of negative curvature, 273 ; second order, 213,262 ; third order, 263; skew, 255; Steiner, 256; ruled, 255.

Surveying, $18,7 x$.

Suter, $94 n$.

Swan pan, 28.

Sylow, r65.

Sylvester, I43-147, 276.

Sylvester II., Pope, 15.

Symbols, 47, 63, 65, 7I, 76, 88, 89, 9597, 99, 102, 108, I09, II7, I70, I7I, I83, 197.

Symmedians, 245.

Symmetric determinants, I68; functions, $\mathrm{I}_{42}, \mathrm{r}_{43}$.

Tabit ibn Kurra, 136, 217.

Tables, astronomical, 286 ; chords, 282 ; factor, $\mathrm{I}_{4} \mathrm{I}$; mortality, $\mathrm{I}_{4} 8$ : primes, I4I; symmetric functions, I43; sines, 286 ; theory of numbers. 142; trigonometric, 282, 286, 289, 290, 293.

Tacquet, 574 .

Tanck, 23 .

Tangent. 288.

Tannery, 33, 70, I20.

Tartaglia, 3, 49, 51, 52, II2, II5, I55, 225.

Tatstha, 29.

Taylor, B., I52, I66, 259; C., 224n.

Thales, I94.

Theaetetus, 212 .

Theodorus, 69 .

Theon of Alexandria, 34, 70 .

Thieme, 244.

Thirty years' war, 22.

Thome, I77.
Thompson, 107, 266.

Timaeus, 212.

Tonti, 56.

Tontines, 57.

Torricelli, 237.

Torus, 213.

Transformations of contact, 178,269 276.

Transon, 270.

Transversals, $144,248$.

Trenchant, 47.

Treutlein, 52n., 67, 96n., $97 n$.

Trigonometry, 28r.

Trisection. See Angle.

Trivium, 94.

Tschirnhausen, I57, I59, I65, x78, 238, $241,242$.

Tylor, $6 n$.

Ubaldi, 228.

Ulpian, 56.

Unger, $16 n$.

Universities, rise of, 94 .

Unverzagt, I29n., 130n.

Valentiner, 256.

Van Ceulen, 222.

Van der Eycke, 222.

Vandermonde, I18, I59, I67.

Van Eyck, 226.

Van Schooten, I36, I I , I56, 242.

Variations. See Calculus

Vector, I3o.

Vedas, 25.

Veronese, 275.

Versed sine, 288 .

Victorius, 27.

Vieta, 107, I08, II5, I17, I19, I34, 156 , I9I, 222, 229, 249, 287, 288.

Vincent, St., I5I.

Vitruvius, 215.

Vlacq, 292.

Voigt, I39.

Von Staudt, 162, 246, 249, 257-259, 26j

Vooght, 292.

Wafa, 225, 286.

Wallis, II7, 125, I31, 135, I54, 173, 23: 236, 237, 242.

Waring, I43, I59, 239. 
Weber, r89.

Weierstrass, 62, 120, 147, 179, I8I, IS9. Welsh counting, 8; practice, 53.

Wesse1, I25.

Widmann, 47, 5I, 220.

Wiener, 226n., 245, 278.

Witt, De, 57,148 .

Wittstein, 59, $256 n$.

Wolf, 47,48 .

Woodhouse, r7 $\$ n$.

Woolhouse, $276 x$.
Wordsworth, I2n.

Wren, $243,247$.

$x$, the symbol, 97 .

Year, length of, 24.

Zangemeister, Ir

Zeller, r39.

Zenodorus, 200.

Zero, I2, I6, 39, 40, 74 .

Zeuthen, 68n., 253, 264. 


$$
34
$$







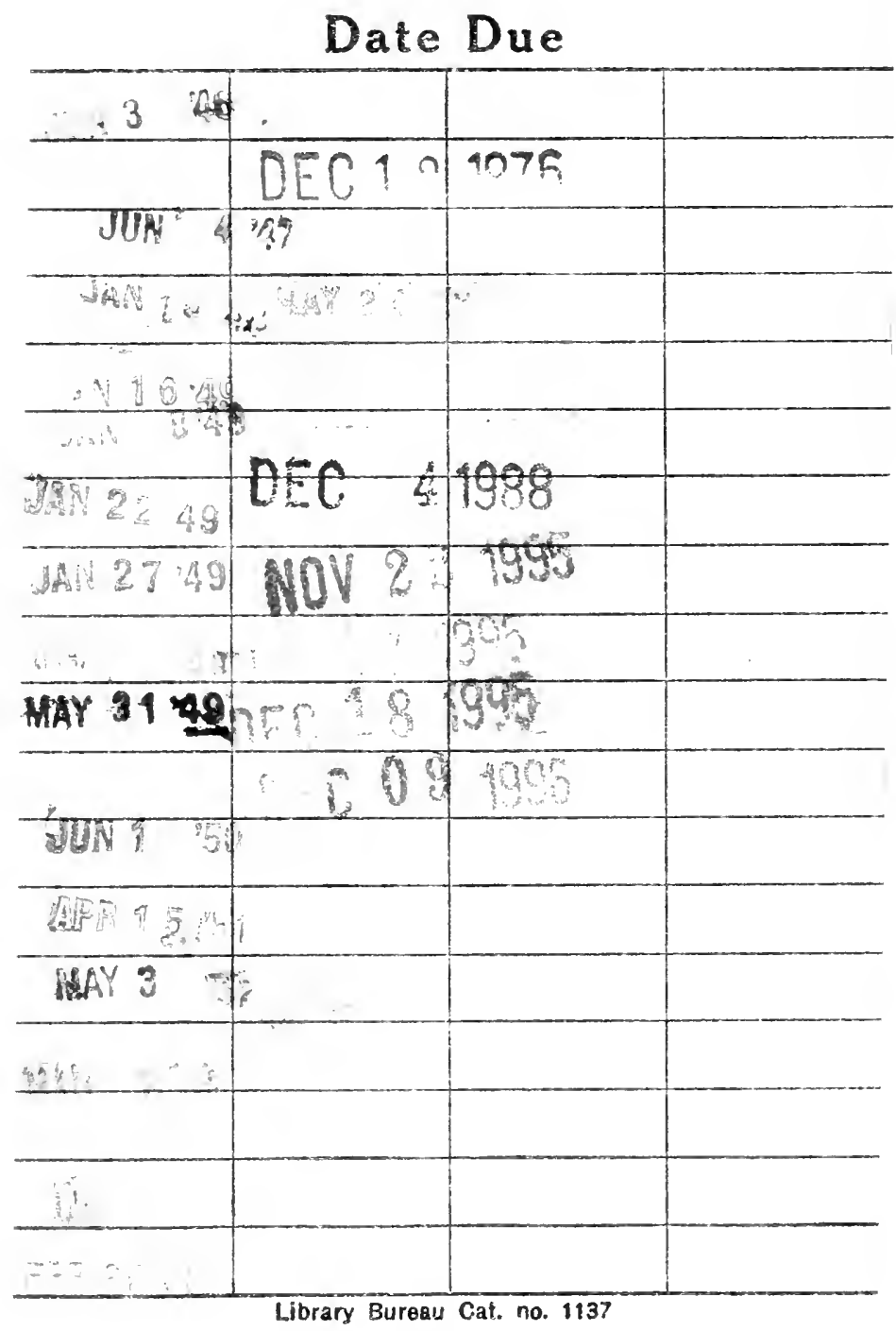




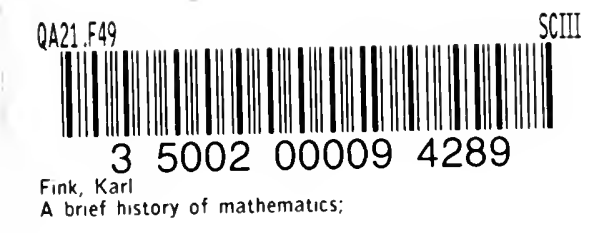

QA
21
F49

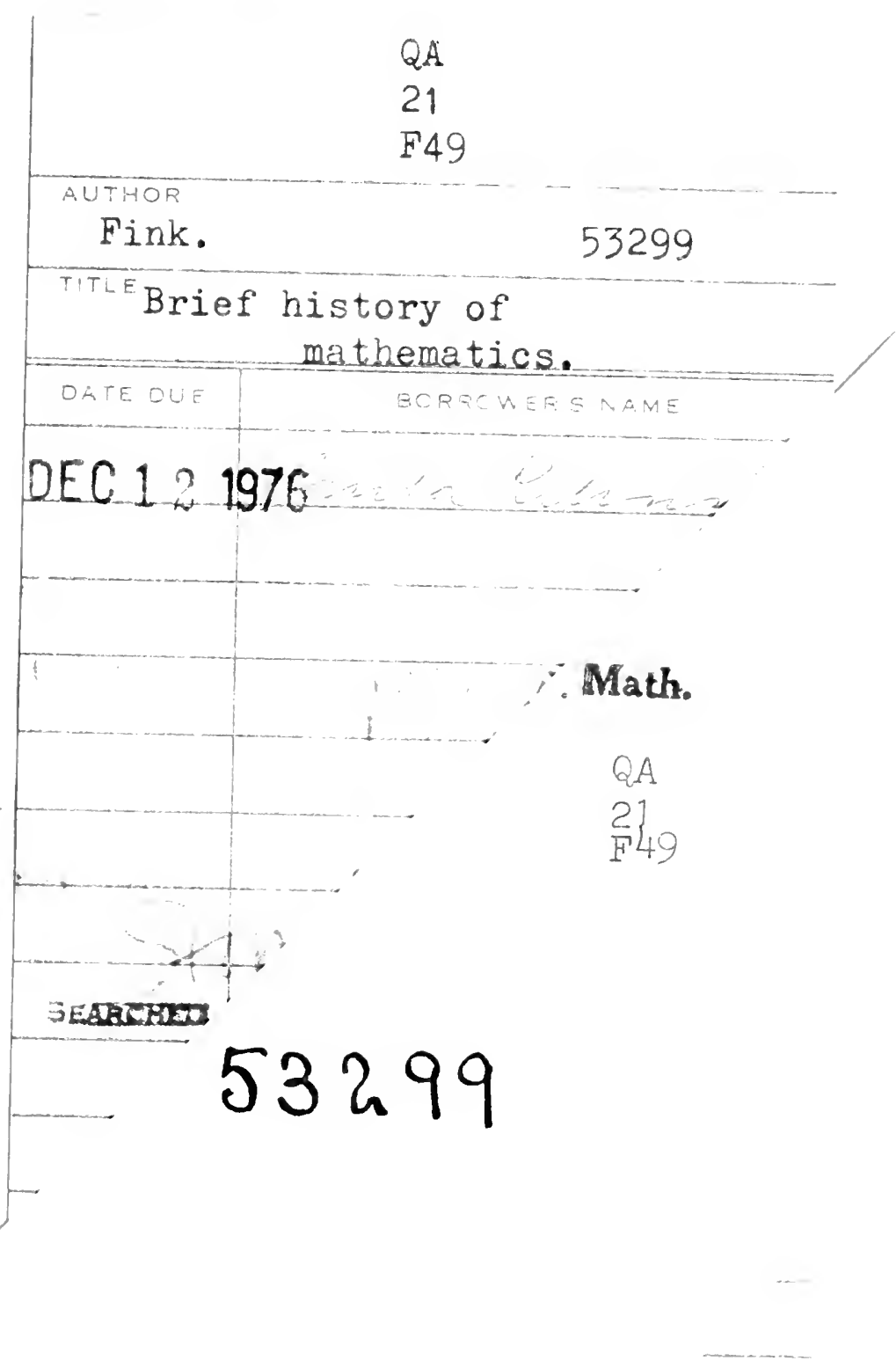


